\title{
Nutritional inflammatory modulation of pulmonary cachexia
}

Citation for published version (APA):

Broekhuizen, R. (2005). Nutritional inflammatory modulation of pulmonary cachexia. [Doctoral Thesis, Maastricht University]. https://doi.org/10.26481/dis.20050923rb

Document status and date:

Published: 01/01/2005

DOI:

10.26481/dis.20050923rb

Document Version:

Publisher's PDF, also known as Version of record

\section{Please check the document version of this publication:}

- A submitted manuscript is the version of the article upon submission and before peer-review. There can be important differences between the submitted version and the official published version of record.

People interested in the research are advised to contact the author for the final version of the publication, or visit the DOI to the publisher's website.

- The final author version and the galley proof are versions of the publication after peer review.

- The final published version features the final layout of the paper including the volume, issue and page numbers.

Link to publication

\footnotetext{
General rights rights.

- You may freely distribute the URL identifying the publication in the public portal. please follow below link for the End User Agreement:

www.umlib.nl/taverne-license

Take down policy

If you believe that this document breaches copyright please contact us at:

repository@maastrichtuniversity.nl

providing details and we will investigate your claim.
}

Copyright and moral rights for the publications made accessible in the public portal are retained by the authors and/or other copyright owners and it is a condition of accessing publications that users recognise and abide by the legal requirements associated with these

- Users may download and print one copy of any publication from the public portal for the purpose of private study or research.

- You may not further distribute the material or use it for any profit-making activity or commercial gain

If the publication is distributed under the terms of Article $25 \mathrm{fa}$ of the Dutch Copyright Act, indicated by the "Taverne" license above, 
Nutritional inflammatory modulation of pulmonary cachexia 
ISBN: $90-6464-252-4$

(C) 2005 Roelinka Broekhuizen

All rights reserved. No part of this book may be reproduced or transmitted, in any form or by any means without written permission from the author.

Cover design: Karen Broekhuizen

Cover photo: François Wauthelë

Lay-out: Karen en Roelinka Broekhuizen

Printed by: Grafisch bedrijf Ponsen en Looijen BV, Wageningen 


\section{Nutritional inflammatory modulation of pulmonary cachexia}

Proefschrift

ter verkrijging van de graad van doctor aan de Universiteit Maastricht, op gezag van de Rector Magnificus prof. Mr. G.P.M.F. Mols volgens het besluit van het College van Decanen in het openbaar

te verdedigen op vrijdag 23 september 2005 om 12.00 uur

door

Roelinka Broekhuizen 


\section{Promotores}

Prof. dr. Ir. A.M.W.J. Schols

Prof: dr. E.F.M. Wouters

\section{Beoordelingscommissie}

Prof. dr. Ir. R.P. Mensink (voorzitter)

Prof. dr. W.A. Buurman

Prof. dr. Ir. J.C. Seidell (VU Amsterdam)

Prof. dr. R. Stockbrügger

Prof. dr. J. Vestbo (North West Lung Center, Manchester; UK)

The publication of this thesis was financially supported by Numico Research BV, AstraZeneca BV, Boehringer-Ingelheim BV, GlaxoSmithKline, Stichting Hornerheide and Stichting Pulmonologie.

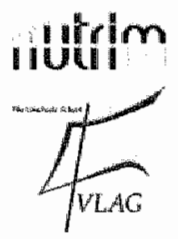

The studies presented in this thesis were conducted at Maastricht University, at the Department of Respiratory Medicine, Nutrition and Toxicology Research Institute Maastricht (NUTRIM), which participates in the Graduate School VLAG (Food Technology, Agrobiotechnology, Nutrition and Health Sciences), accredited by the Royal Netherlands Academy of Arts and Sciences (KNAW) and at Astmacentrum Hornerheide. 
Het leven is een feest, je moet alleen zelf de slingers ophangen

Mithi ipsi scripsi 



\section{Contents}

Chapter 1 General introduction 9

Chapter 2 Pulmonary cachexia, systemic inflammatory profile and 29

the $\operatorname{LL}-1 \beta-511$ single nucleotide polymorphism

Chapter 3 Body composition and mortality in chronic obstructive pulmonary disease

Chapter $4 \quad$ Elevated CRP levels mark metabolic and functional impairment in advanced COPD

Chapter 5 Leptin as local inflammatory marker in COPD

Chapter 6 Increased cellular protein breakdown is not reduced by pulmonary rehabilitation in COPD

Chapter $7 \quad$ Optimizing oral nutritional drink supplementation in patients with chronic obstructive pulmonary disease

Chapter 8 Polyunsaturated fatty acids improve exercise capacity in chronic obstructive pulmonary disease

Chapter 9 General discussion

Appendices Summary

Samenvatting

Abbreviations

Publications

Naschrift 



\section{General introduction}


Chapter y 


\section{Prevalence and risk factors of chronic obstructive pulmonary disease}

Chronic obstructive pulmonary disease (COPD) is a chronic, progressive, irreversible disease of the respiratory system. COPD represents a major problem for health care as it is one of the most common causes of morbidity and mortality. In the year 2000, the prevalence of COPD in the Netherlands was estimated at $2.4 \%$ for men and $1.4 \%$ for women (1). The prevalence of COPD increases with age, reaching $16 \%$ in men over 75 years (1). In addition, as much as $20 \%$ of the general adult population in the Netherlands are reported to have a decreased or rapid decline in lung function (2). Being the sixth largest cause of death worldwide in the year 1990, it has been estimated that, due to ageing and smoking, by the year 2020 COPD will be the third largest cause of death with an expected mortality of 4.7 million per year ( 3 ).

Smoking is the most important cause of COPD. It is estimated that up to $90 \%$ of all COPD patients have a smoking history (1). However, only $15 \%$ of cigarette smokers develop COPD. This suggests that genetic differences may influence the risk of COPD. Cessation of smoking has been shown to reduce the rate of decline in lung function but unfortunately the success rate of smoking cessation programs is very low $(4,5)$. Other risk factors of COPD are being male, being Caucasian, ambient air pollution, occupation and low socioeconomic status $(6,7)$. A well-known example is the genetic deficiency in the anti-protease atantitrypsin, which predisposes subjects to a very high risk of developing emphysema (8).

COPD represents a financial burden of $1.3 \%$ of the total health care costs in the Netherlands. It is estimated that, primarily due to an increase in the ageing population, these costs will rise by $60 \%$ by 2010 . Smoking cessation programs, however, are estimated to have a relatively small impact of only $4-14 \%$ on reducing cost (9). 


\section{Definitions and staging of COPD}

COPD can roughly be divided into two subtypes, often coexisting in one patient: chronic bronchitis and emphysema. Chronic bronchitis is defined according to clinical criteria as a cough with recurrent excessive sputum on most days of at least three months per year for at least two years in patients, with no other causes of cough (6). Emphysema is characterized by loss of elasticity of the lungs due to destruction of alveolar tissue distal of the terminal bronchioli, causing a loss of surface for gas exchange and an increase in dead space (6). The pathogenesis of both COPD subtypes involves pulmonary inflammation. It is difficult to clinically distinguish chronic bronchitis from emphysema, as both diseases have the same symptoms of dyspnea, cough and wheezing. High-resolution computed tomography (HRCT) gives an image of the presence, extent and severity of macroscopic emphysema, thereby enabling diagnosis of emphysema in vivo (10). Dominant symptoms of COPD are shortness of breath, first only during exercise, but in later stages also at rest (6), and impaired exercise performance (11). In advanced disease, patients may suffer from hypoxia during daily activities or even at rest. As the exercise capacity of patients with COPD worsens over the years, patients often become homebound avoiding dyspnea caused by everyday activities, leading patients into a vicious cycle of inactivity $(6,11)$. Although ventilatory capacity due to lung impairment is an important limiting factor for exercise capacity, respiratory and skeletal muscle weakness become more prominent determinants of exercise performance, particularly in advanced COPD (11).

Staging of severity of COPD is traditionally based on the severity of the airflow obstruction measured by the forced expiratory volume in one second (FEV $)$. Recently, the Global Initiative for Chronic Obstructive Lung Disease (GOLD) was founded as an initiative of the World Health Organization (WHO) in collaboration 
with the US National Heart, Lung and Blood Institute. The goals of GOLD are to increase awareness of COPD and decrease morbidity and mortality from the disease. A key component to realize these goals was a clear definition of staging, which was proposed in 2001 and adapted in $2003(12,13)$ :

Stage 0 , at risk: chronic cough and sputum production, lung function still normal;

Stage 1, mild COPD: mild airflow limitation ( $\mathrm{FEV}_{1} / \mathrm{FVC}<70 \%$ but $\mathrm{FEV}_{1} \geq 80 \%$ predicted) and usually, but not always, chronic cough and sputum production;

Stage II, moderate COPD: worsening airflow limitation $(50 \% \leq \mathrm{FEV} 1 \leq 80 \%$ predicted), and usually the progression of symptoms, with shortness of breath typically developing on exertion;

Stage III, severe COPD: Further worsening airflow limitation $\left(30 \% \leq \mathrm{FEV}_{1} \leq 50 \%\right.$ predicted), increased shortness of breath, and repeated exacerbations which have an impact on patients' quality of life;

Stage IV, very severe COPD: severe airflow limitation (FEV $1 \leq 30 \%$ predicted), or FEV $V_{1}<50 \%$ predicted plus chronic respiratory failure $(12,13)$.

In this thesis patients with stage II-IV are studied.

It is remarkable that this staging is still based on lung impairment alone, while COPD is increasingly emerging as a multi-organ systemic disease with decreased exercise capacity and dyspnea as dominant symptoms $(11,12)$. In addition, both exercise capacity and dyspnea are only weakly associated with the severity of the airflow obstruction $(14,15)$. Other systemic features that have been implicated in COPD are cachexia osteoporosis and altered metabolic and morphological status of respiratory and peripheral skeletal muscle (11). The notion that COPD is a systemic disease has been emphasized by the fact that mortality in COPD is not only predicted by lung function impairment, but also by low body mass index (BMI) and other systemic impairments, like exercise capacity and dyspnea (16-19). The impact of these systemic impairments is being increasingly recognized by lung disease researchers and professionals. This is illustrated by the fact that recently 
the American Thoracic Society (ATS) and the European Respiratory Society (ERS) proposed a new staging system, which includes FEV 1 , BMI fusing a cutoff of 21 $\mathrm{kg} / \mathrm{m}^{2}$ ) and functionall dyspnea (as assessed by the Medical Research Council dyspnea scale) (20).

\section{Low body weight and muscle atrophy}

Patients with COPD often suffer from weight loss, which may be associated with a disproportional loss of muscle mass. Prevalence rates of patients who are underweight range from $20 \%$ of stable out-patients to $49 \%$ of clinically stable patients eligible for pulmonary rehabilitation (21-24) and even to over $70 \%$ in patients with acute respiratory failure (25). Body weight consists of fat mass (FM) and fat-free mass (FFM), the latter reflecting the quantity of actively metabolizing and contracting tissue, also referred to as lean body mass. FFM-depletion is common amongst patients with COPD although it may be masked by normall body weight (21). However, longitudinal data on the course of weight and FFM loss during the progression of COPD are not yet available. There is no consensus yet on how weight loss and body compositional changes are defined, but they are often referred to as pulmonary cachexia.

Pulmonary cachexia is an important factor to consider from a therapeutic perspective. Regardless of disease severity, weight loss is related to increased morbidity in terms of increased risk of acute exacerbation (26), hospital readmission (27) and need for mechanical ventilation (28) and it is even related to increased mortality $(16,17)$. More specifically, loss of lean body mass has been shown to adversely affect respiratory and peripheral muscle function (29), exercise capacity $(21,30)$ and early onset of lactic acid production during exercise (30). In addition, low FFM is, independent of body weight, associated with impaired health status $(31,32)$ and increased mortality $(33)$. Previous research by our group has 
shown that these negative effects of weight loss and related muscle atrophy on functional capacity and even mortality can be reversed by dietary interventions in combination with either physiologic or pharmacologic anabolic stimuli (17).

Body composition is easily determined using bioelectrical impedance analysis (BIA). A prerequisite of the use of BIA is that the equations used to transform the measured resistance into FFM are adapted to the individual and have been tested for validity in the populations for which they are intended. In these conditions, BIA measurements are as accurate as other clinical techniques used to assess body composition (34). BIA has been extensively validated and evaluated in patients with $\operatorname{COPD}(35,36)$. The equations used in this thesis were validated against deuterium dilution as the reference method, while other studies showed good association with dual-energy x-ray absorptiometry (DEXA) $(36,37)$. In this thesis, we used a fat-free mass index (FFM/height ${ }^{2}$ : FFMI) cutoff of $16 \mathrm{~kg} / \mathrm{m}^{2}$ for men and $15 \mathrm{~kg} / \mathrm{m}^{2}$ for women, which is based on the linear association between FFM and body weight in normal to underweight COPD patients as has been described by Baarends et al. (30). In prior publications of our group, we have shown that these cutoffs are discriminative for exercise capacity (21) and health status (31). The cutoff for BMI used was $21 \mathrm{~kg} / \mathrm{m}^{2}$ as values below this are associated with increased risk of death $(16,17)$.

Cachexia, sarcopenia, muscle atrophy and semistarvation are all terms to indicate changes in body composition. In the available literature there is much confusion on the definition of the different patterns and contributing factors of tissue depletion. Available literature usually defines cachexia as being associated with inflammatory or neoplastic conditions, causing a marked decrease in FFMI (38). Sarcopenia, on the other hand, is related to ageing and characterized by low FFMI, usually in the absence of weight loss (39). This pattern is also seen in patients with muscle atrophy, which is related to inactivity ( 40$)$, but not necessarily with ageing. The loss of FM, caused by caloric deprivation, is called semistarvation (41). 
The underlying etiological processes of some of the above-mentioned body compositional changes may comprise of the same mechanistic pathways. The different patterns of tissue depletion are therefore not mutually exclusive and can co-exist in one patient.

\section{Energy metabolism}

Weight loss is a consequence of either decreased energy intake or increased energy expenditure, or a combination of both, resulting in a negative energy balance.

\section{Energy intake}

Clinically stable patients with COPD have a normal to elevated energy intake as compared to predicted energy requirements $(42,43)$. The subgroup of weightlosing patients, however, has a lower energy intake as compared to the weightstable patients, both in absolute terms and when expressed as percentage of measured resting energy expenditure (REE) (43). Patients who fail to gain weight after nutritional therapy, the so-called 'non-responders', have a lower habitual energy intake as compared to patients who do respond (44). Others reported that hypoxemic patients are at increased risk for a decreased dietary intake (43-45).

\section{Energy expenditure}

Energy expenditure, and in particular resting energy expenditure (REE), may be elevated in clinically stable COPD patients $(37,46,47)$. Elevated REE is shown to be associated with increased systemic inflammation (48).

Few studies have investigated total daily energy expenditure (TDEE) in patients with COPD (49-52). Hugli et al. (49) found no difference in TDEE in patients with COPD as measured in a metabolic chamber with limited room for 
activities. In addition, Hugli et al. reported lower activity in their patients than in healthy controls (49). This suggests that patients with COPD compensate their increased resting energy expenditure, by decreasing their activity patterns, resulting in equivalent TDEEs in patients and controls. Slinde et al. have studied underweight COPD patients living at home and found great variation in TDEE and physical activity level (PAL) (50). Baarends et al. (51) have previously reported a higher TDEE in patients with COPD compared to healthy subjects, using the doubly labeled water technique over a two-week period at a rehabilitation center in free-living conditions. They showed an increased TDEE compared to healthy controls, with equivalent or decreased activity levels. REE was similar between groups, suggesting that increased TDEE is due to the non-resting component of TDEE (51). A subsequent study of Baarends et al. reported no differences in TDEE between patients with normal or elevated REE. They also reported that REE and FFM did not significantly contribute to the variation in TDEE, suggesting that the underlying mechanisms for an increased REE are not involved in increasing TDEE in COPD (52). While increases in REE reflect increased levels of systemic inflammation (48), energy balance is reflected by TDEE in conjunction with energy intake. Because of adaptation in activity levels, differences in relative increased TDEE are difficult to assess without data on physical activity.

\section{Protein metabolism}

Loss of FFM is a more complex process involving imbalances in protein synthesis and breakdown, which may occur independently from energy balance. Not much is know about protein balance in COPD. At the whole-body level, weight stable COPD patients have been shown to have an increased protein synthesis and breakdown, without a net negative protein balance, indicating an increased protein turnover (53). Although it is unclear if protein breakdown is altered in muscle tissue of COPD patients with muscle atrophy, a reduced protein synthesis rate in underweight patients with emphysema has been reported (54). 
In general, the primary cause of loss of lean body mass is accelerated muscle proteolysis (55). Recent advances in the elucidation of the mechanisms responsible for accelerated muscle protein breakdown during muscle atrophy show a major role for the ubiquitin 26S-proteasome pathway (56). This is a multienzymatic energy-dependent process that degrades structural proteins into peptides, using the small protein cofactor ubiquitin (55). Several factors that may be present in COPD, have been shown to enhance the capacity of the ubiquitin 265-proteasome pathway, leading to muscle wasting. These factors include acidosis, fasting, inactivity and systemic inflammation (55). No studies are yet available that have measured markers of the ubiquitin 26S-proteasome pathway in skeletal muscle of patients with COPD.

\section{Systemic Inflammation}

COPD is characterized by a chronic inflammatory response throughout the lung. This local inflammatory reaction is thought to be initiated by the inhalation of noxious particles and gases such as in cigarette smoke (12). The chronic inflammatory response is characterized by cellular infiltrates, inflammatory mediators and reactive oxygen species and the extent of lung inflammation is shown to be associated with the severity of COPD (57-59).

In addition, COPD is also characterized by a chronic systemic inflammatory response (reviewed in 60). Several systemic inflammatory mediators, like tumor necrosis factor- $\alpha$ (TNFa), some interleukins (ILs), acute phase proteins (C-reactive protein (CRP), fibrinogen, lipopolysaccharide binding protein (LBP)) and leukocytes, are shown to be increased in COPD (60). The source of increased concentrations of systemic inflammatory markers has not yet been elucidated. It is possible that the systemic inflammation is a local-to-systemic spill-over, but no correlation has been found between sputum and plasma concentrations of 
inflammatory markers (61). Other factors, like smoking (62), hypoxia (63, 64), exercise (reviewed in 65,66 ) and evolutionary programming $(67)$ are also possible etiological factors (68).

Systemic inflammation is thought to negatively affect body composition. In particular TNFa has been associated with weight loss $(63,69,70)$. In addition, patients with impaired body composition, who do not respond to high-caloric nutritional therapy, have higher levels of soluble TNF receptors (sTNF-Rs) in peripheral blood than patients who do respond (44). Indeed, in animal models, several inflammatory cytokines can induce various features of cachexia. Exposure to lipopolysaccharide (LPS), IL-1 or TNFa induces acute muscle atrophy and anorexia in rats $(71,72)$. Chronic treatment of rats with TNFa results in depletion of body protein, anorexia, weight loss and tissue inflammation (73, 74). Moreover, high concentrations of TNFa increase amino acid release from mouse diaphragms (75). In humans, infusion of TNFa into weight stable cancer patients resulted in increased amino acid release and thus stimulated proteolysis $(76,77)$. It is hypothesized that the release of amino acids as a result of these catabolic effects on the muscle tissue contributes to the synthesis of acute phase proteins by the liver in inflammatory conditions (11).

Inflammation may cause muscle atrophy through the ubiquitin 26Sproteasome pathway (56). Nuclear factor-kappa $B,(N F-k B)$ is a pivotal regulator of inflammatory responses, as it mediates the transcription of several (inflammatory) genes and can be activated by various inflammatory signals, oxidative stress and tissure hypoxia (78). Recently, activation of NF-kB in skeletal muscle was shown to result in muscle atrophy through increased muscle protein degradation by the ubiquitin 26S-proteasome pathway (79). This mechanism may be involved in the muscle atrophy observed in COPD, as increased NF-KB activity has recently been shown in muscle biopsies of COPD patients with low body weight $(80)$. Unfortunately, these patients were not characterized for systemic inflammation. 
This study does, however, provide a first link between experimental findings and studies in patients (80).

Inflammatory cytokines have also been shown to increase circulating leptin $(81,82)$. Leptin is a hormone produced by adipose tissue that regulates energy homeostasis through a feedback mechanism by signaling the brain about the amount of fat stored in the body (83). Administration of leptin in animals results in a reduction of food intake (84) and an increase in energy expenditure (85). These effects seem to be mediated by a leptin-induced decrease of the hypothalamic biosynthesis and release of neuropeptide $Y$, a hormone that potently stimulates appetite and food intake and reduces energy expenditure (86-88). In patients with emphysema, leptin is positively correlated with the pro-inflammatory sTNF-R55, independently of FM. Moreover, sTNF-R55 has been shown to be related to both dietary intake as well as weight loss and REE $(89,90)$. In addition, TNFa or IL-1a infusion in cancer patients increases serum leptin concentration $(91,92)$. This suggests that the influence of leptin on energy balance might be under the controll of the systemic inflammatory response, while a higher level of systemic inflammation could cause involuntary weight loss (48).

Although leptin is thus a regulator of food intake and energy expenditure, it is increasingly emerging as a pleiotropic cytokine. Leptin is involved in a variety of physiological and pathological functions, influencing hematopoiesis, angiogenesis, wound healing, reproduction, hypothalamopituitary-adrenal axis, and the immune and inflammatory responses (reviewed in 93). The receptor for leptin has been demonstrated to be present throughout the body, including the lung (94), which may suggest a specific function of leptin in the lung. 


\section{Outline of this thesis}

In this thesis, we studied pulmonary cachexia and the potential role of systemic inflammation in the pathology of cachexia in patients with advanced COPD. In chapter 2 and chapter 3 , we characterize pulmonary cachexia, using body composition, biochemical and inflammatory markers. As described in chapter 2 , we found that patients, who were defined as cachectic on the basis of low FFMI, also had low fat mass index (FMI). Patients who were defined as non-cachectic also had a compromised body composition when compared with healthy age-matched controls, which was characterized by a lower FFMI and higher FMI. Although stratification by cachexia did not differentiate for the level of systemic inflammation, plasma leptin level was disproportionately decreased in patients with cachexia while pseudouridine, a marker for cellular protein breakdown, was increased compared to non-cachectic patients. Remarkably, patients with cachexia had a different distribution of IL1-511 polymorphism, which may indicate a genetic predisposition to the cachexia process. In chapter 3 , we studied the effect of pulmonary cachexia on survival. We found that low FFMl independently predicts mortality in patients with advanced COPD, irrespective of $F M$, as patients with cachexia and muscle atrophy had comparable survival. This study emphasizes the importance of body composition assessment as a systemic marker of disease severity in COPD staging and as a potential target for therapy.

The role of inflammation as a possible trigger of changes in body composition and metabolism in COPD is studied in chapter 4. Patients with elevated systemic CRP, as clinical marker of inflammation, were found to have impaired energy metabolism at rest and during exercise. In addition, patients with elevated CRP had lower exercise capacity and had more distress due to respiratory symptoms compared to patients with normal CRP. Using regression analysis, adjusting for $\mathrm{FEV}_{1}$, age and gender, CRP was also a significant predictor for BMI and FMI. 
As mentioned before, the link between local and systemic inflammation in COPD is still unclear. In chapter 5 we studied CRP and leptin concentrations in induced sputum, which is a surrogate marker of inflammation in the lung. The rationale for this study came from previous research, which has shown that the receptor for leptin is present throughout the body, including the lung (94), suggestive of a specific local function of leptin. We showed that leptin is present in the sputum of COPD patients and that sputum leptin was strongly correlated to sputum CRP and TNFa. These results indicate that leptin may play a role in the local innate immune system. Sputum leptin was inversely related to plasma leptin, which makes systemic-to-local spill-over unlikely. The question remains as to what the origin of sputum leptin is. Furthermore, this inverse relationship raises the question of what the relationship with pulmonary cachexia is, as we have shown in chapter 2 that cachectic patients have disproportionately low leptin levels.

The second part of this thesis evaluates targeted therapeutic approaches to modulate cachexia. Chapter 6 shows that an increased level of protein breakdown in COPD patients was associated with muscle dysfunction. Pulmonary rehabilitation was able to induce an anabolic shift in body composition and an improvement in muscle function, but did not change the catabolic markers of protein breakdown and systemic inflammation. Four weeks after the anabolic stimulus of pulmonary rehabilitation was stopped, patients were back in net catabolism, losing FFM and gaining FM. In chapter 7, we have compared two supplement drinks differing in portion size and energy content to explore the possibility of further optimization of the customary nutritional treatment of cachectic patients during pulmonary rehabilitation. In this study, we showed that simply decreasing the portion size of a nutritional supplement drink from 200 to $125 \mathrm{ml}$ is a useful strategy to increase the efficacy of supplemental nutrition in terms of weight gain in cachectic patients with COPD.

Previous research has shown that some cachectic COPD patients do not respond adequately to nutritional supplement drinks. This non-response, defined 
as weight gain $<2 \%$, has been shown to be associated with increased systemic inflammation (44). A possible option of modulation of systemic inflammation with nutrition is the use of polyunsaturated fatty acids (PUFA). Chapter 8 describes the results of a large randomized, placebo-controlled clinical trial exploring the effects of PUFA on systemic inflammatory markers, body composition, exercise capacity and metabolism in COPD patients participating in a pulmonary rehabilitation program. We did not find a systemic anti-inflammatory effect of PUFA. Nevertheless, we have found a greater increase in exercise capacity in patients receiving PUFA than in patients receiving placebo. This suggests that PUFA does have a beneficial effect in COPD.

In the general discussion (chapter 9), the most remarkable findings of this thesis are integrated in the context of treatment options for pulmonary cachexia and potential areas for future research. 


\section{References}

1. Feenstra TL, van Genugten ML, Hoogenveen AT, Wouters EF, Rutten-van Molken MP. The impact of aging and smoking on the future burden of chronic obstructive pulmonary disease: a model analysis in the Netherlands. Am J Respir Crit Care Med 2001;164:590-6.

2. van den Boom G, van Schayck CP, van Mollen MP, at al. Active detection of chronic obstructive pulmonary disease and asthma in the general population. Results and economic consequences of the DIMCA program. Am J Respir Crit Care Med 1998;158:1730-8.

3. Murray CJ, Lopez AD. Alternative projections of mortality and disability by cause 1990-2020: Global Burden of Diseasie Study. Lancet 1997;349:1498-504.

4. Camilli $A E$, Burrows $B$, Knudson RJ, Lyle SK, Lebowitz MD. Longitudinal changes in forced expiratory volume in one second in adults. Effects of smoking and smoking cessation. Am Rev Respir Dis 1987:135:794-9.

5. Anthonisen NR, Connett JE, Murray RP. Smoking and lung function of Lung Health Study participants after 11 years. Am J Respir Crit Care Med 2002;166:675-9.

6. ATS. Standairds for the diagnosis and care of patients with chronic obstructive pulmonary disease. American Thoracic Society. Am $\mathbb{U}$ Respir Crit Care Med 1995;152:S77-121.

7. Prescott E, Godtfredsen N, Vestbo J, Osler M. Sociall position and mortality from respiratory diseases in males and females. Eur Respir J 2003;21:821-6.

8. Snider GL. Pulmonary disease in alpha-1-antitrypsin deficiency. Ann Intern Med 1989;111:957-9.

9. Rutten-van Molken MP, Postma MJ, Joore MA, Van Genugten ML, Leidll $R$, Jager JC. Current and future medical costs of asthma and chronic obstructive pulmonary disease in The Netherlands. Respirir Med 1999;93:779-87.

10. Stern EJ, Frank MS. CT of the llung in patients with pulmonary emphysema: diagnosis, quantification, and correlation with pathologic and physiologic findings. AJP Am $\Downarrow$ Roentgenol $1994 ; 162: 791-8$.

11. Skeletal muscle dysfunction in chronic obstructive pulmonary disease. A statement of the American Thoracic Society and European Respiratory Society. Am J Respir Crit Carre Med 1999;159:S1-40.

12. Pauwels RA, Buist AS, Calverley PM, Jenkins CR, Hurd SS. Global strategy for the diagnosis, management, and prevention of chronic obstructive pulmonary disease. NHLBI/WHO Glabal Initiative for Chronic Obstructive Lung Disease (GOLD) Workshop summary. Am J Respir Crit Care Med 2001;163:1256-76.

13. Fabbri LM, Hurd SS. Glabal Strategy for the Diagnosis, Management and Prevention of COPD: 2003 update. Eur Respir J 2003;22:1-2.

14. Mahler DA, Weinberg DH, Wells CK, Feinstein AR. The measurement of dyspnea. Contents, interobserver agreement, and physiologic corrolates of two new clinical indexes. Chest 1984:85:751-8.

15. Cotes JE, Zejda $\mathrm{J}$, King B. Lung function impairment as a guide to exercise limitation in workrelated lung disorders. Am Rev Respir Dis 1988;137:1089-93.

16. Landbo $\mathrm{C}$, Prescott E, Lange P, Vestbo J, Almdal TP. Prognostic value of nutritional status in chronic obstructive pulmonary disease. Am J Respir Crit Care Med 1999;160:1856-61.

17. Schols AM, Slangen J, Volovics L, Wouters. EF. Weight loss is a reversible factor in the prognosis of chronic abstructive pulmonary disease. Am J Respir Crit Care Med 1998;157:1791-7. 
18. Gelli $\mathrm{BR}_{\mathrm{g}}$, Cote $\mathrm{CG}$, Marin $\mathrm{JM}_{3}$ et al. The body-mass index, ainflow obstruction, dyspnea, and exercise capacity index in chronic obstructive pumonary disease. $N$ Engl J Med 2004:350:1005-12.

19. Nishimura $K$, lzumi $T$, Tsukino M, Oga T. Dyspnea is a better predictor of 5 -year surviwal than airway obstruction in patients with COPD. Chest 2002;121:1434-40.

20. Celli BR, MacNee W. Standards for the diagnosis and treatment of patients with COPD: a summary of the ATS/ERS position paper. Eur Respir J 2004;23:932-46.

21. Schols AM, Soeters PB, Dingemans AM, Mostert R, Frantzen PJ, Wouters EF. Prevalence and characteristics of nutritional depletion in patients with stable COPD eligible for pulmonary rehabilitation. Am Rev Respir Dis 1993;147:1151-6.

22. Braun $S R$, Keim NL, Dixon $R M$, Clagnaz $P$, Anderegg $A$, Shrago ES. The prevalence and determinants of nutritional changes in chronic obstructive pulmonary disease. Chest 1984;86:55863.

23. Engelen MP, Schols AM, Lamers RJ, Wouters EF. Different patterns of chronic tissule wasting among patients with chronic obstructive pulmonary disease. Clin Nutr 1999;18:275-80.

24. Wilson DO, Rogers $\mathrm{RM}$, Wright $\mathrm{EC}_{\text {" }}$ Anthonisen NR. Body weight in chronic obstructive pulmonary disease. The National Institutes of Health Intermittent Positive-Pressure Breathing Trial. Am Rev Respir Dis 1989;139:1435-8.

25. Driver AG, McAlevy MT, Smith للL. Nutritional assessment of patients with chronic obstructive pulmonary disease and acute respiratory failure. Chest 1982;82:568-71.

26. Kessler $R$, Faller M, Fourgaut $G$, Mennecier B, Weitzenblum E. Predictive factors of hospitalization for acute exacerbation in a series of 64 patients with chronic obstructive pulmonary disease. Am J Respir Crit Care Med 1999; 159:158-64.

27. Pouw EM, Ten Velde GP, Croonen BH, Kester AD, Schols AM, Wouters EF. Early non-elective readmission for chronic obstructive pulmonary disease is associated with weight loss. Clin Nutr 2000;19:95-9.

28. Vitacca $M_{0}$ Clini $E$, Porta $R$, Foglio $K_{x}$ Ambrosino $N$. Acute exacerbations in patients with COPD: predictors of need for mechanicall ventilation. Eur Respir J 1996;9:1487-93.

29. Engelen MPKJ, Schols AMWJ, Baken WC, Wesseling GJ, Wouters EFM. Nutritional depletion in relation to respiratory and peripheral skeletal muscle function in out-patients with COPD. Eur Respir ل1994;7:1793-7.

30. Baarends EM, Schols AM, Mostert $R$, Wouters EF. Peak exercise response in relltition to tissue depletion in patients with chronic obstructive pulmonary disease. Eur Respir J 1997;10:2807-13.

31. Mostert $R_{n}$ Goris $A_{1}$ Weling-Scheepers $C$, Wouters EF, Schols AM. Tissue depletion and health related quality of life in patients with chronic obstructive pulmonary disease. Respir Med 2000;94:859-67.

32. Shoup $R$, Dalsky $G$, Warner $S$, et all. Body composition and health-related quality of life in patients with obstructive airways disease. Eur Respir J 1997;10:1575-80.

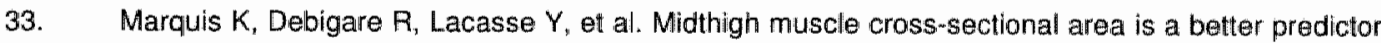
of mortality than body mass index in patients with chronic obstructive pulmonary disease. Am $\mathrm{J}$ Respir Crit Care Med 2002;166:809-13.

34. Kyle UG, Bosaeus I, De Lorenzo AD, et al. Bioelectrical impedance analysis--part I: review of principles and methods. Clin Nutr 2004;23:1226-43. 
35. Schols AM, Wouters EF, Soeters PB, Westerterp KR. Body composition by bioelectrical-impedance analysis compared with deuterium dilution and skinfold anthropometry in patients with chronic obstructive pulmonary disease. Am J Clin Nutr 1991;53:421-4.

36. Steiner MC, Barton RL, Singh SJ, Morgan MD. Bedside methods versus dual energy X-ray absorptiometry for body composition measurement in COPD. Eur Respir J 2002;19:626-31.

37. Schols AMWJ, Fredrix EW, Soeters PB, Westerterp KR, Wouters EFM. Resting energy expenditure in patients with chronic obstructive pulmonary disease. Am J Clin Nutr 1991;54:983-7.

38. Kotler DP. Cachexia. Ann Intern Med 2000;133:622-634.

39. Doherty TJ. Invited review: Aging and sarcopenia. J Appl Physiol 2003;95:1717-27.

40. Fitts $\mathrm{RH}$, Riley DR, Widrick Ju. Physiology of a microgravity environment invited review: microgravity and skeletal muscie. $₫$ Appl Physiol 2000;89:823-39.

41. Cahill GF, Jr. Starvation in man. N Engl J Med 1970;282:668-75.

42. Hunter AM, Carey MA, Larsh $H W$. The nutritional status of patients with chronic obstructive pulmonary disease. Am Rew Respir Dis 1981;124:376-81.

43. Schols AMWJ, Soeters PB, Mostert $R$, Saris WH, Wouters EFM. Energy balance in chronic obstructive pulmonary disease. Am Rev Respir Dis 1991;143:1248-52.

44. Creutzberg EC, Schols AM, Weling-Scheepers CA, Buurman WA, Wouters EF. Characterization of nonresponse to thigh caloric oral nutritional therapy in depleted patients with chironic abstructive pulmonary disease. Am J Respir Crit Care Med 2000;161:745-52.

45. Flaccadori $E$, Del Canale S, Coffrin $E$, et al. Hypercapnic-hypoxemic chronic obstructive pulmonary disease (COPD): influence of severity of COPD on nutritional status. Am J Clin Nutr 1988;48:680-5.

46. Goldstein $S$, Askanazi $J$, Weissman $C$, Thomashow $B$, Kinney JM. Energy expenditure in patients with chronic obstructive pulmonary disease. Chest 1987;91:222-4.

47. Creutzberg EC, Schols AM, Bothmer-Quaedvlieg FC, Wouters EF. Prevalence of an elevated resting energy expenditure in patients with chronic obstructive pulmonary disease in relation to body composition and lung function. Eur J Clin Nutr 1998;52:396-401.

48. Schols AM, Buurman WA, Staal wan den Brekel AJ, Dentener MA, Wouters EF. Evidence for a relation between metabolic derangements and increased levels of inflammatory mediators in a subgroup of patients with chronic obstructive pulmonary disease. Thorax 1996;51:819-24.

49. Hugli $O$, Schutz $Y$, Fitting JW. The daily energy expenditure in stable chronic obstructive pulmonary disease. Am J Respir Crit Care Med 1996;153;294-300.

50. Slinde $F$, Ellegard L. Gronberg AM, Larsson S, Rossander-Hulthen L. Total energy expenditure in underweight patients with severe chronic obstructive pulmonary disease living at home. Clin Nutr $2003 ; 22: 159-65$.

51. Baarends EM, Schols AMWJ, Pannemans DL, Westerterp KR, Wouters EFM. Total free living energy expenditure in patients with severe chronic abstructive pulmonary disease. Am J Respir Crit Care Med 1997;155:549-54.

52. Baarends EM, Schols AMWJ, Westerterp KR, Wouters EFM. Total daily energy expenditure relative to resting energy expenditure in clinically stable patients with GOPD. Thorax 1997;52 (9):780-785.

53. Engelen MP. Deutz NE, Wouters EF, Schols AM. Enhanced Levels of Whole-body Protein Turnover in Patients with Chronic Obstructive Pulmonary Disease. Am $J$ Respir Crit Care Med 2000;162:1488-1492.

54. Morrison WL, Gibson JN "Scrimgeour C, Rennie MJ. Muscle wasting in emphysema. Clin Sci $1988 ; 75: 415-20$. 
55. Mitch WE, Goldberg AL. Mechanisms of muscle wasting. The role of the ubiquitin-proteasome pathway. N Engl J Med 1996;335:1897-905.

56. Lecker SH, Solomon V, Mitch WE, Goldberg AL. Muscle protein breakdown and the critical role of the ubiquitin-proteasome pathway in normall and disease states. J Nutr 1999;129:227S-237S.

57. Finkelstein $R$, Fraser RS, Ghezzo $H$, Cosio MG. Alveolar inflammation and its relation to emphysema in smokers. Am J Respir Crit Care Med 1995;152:1666-72.

58. Saetta $M$, Di Stefano A, Turato $G$, et al. $C D 8+T$-lymphocytes in peripheral airways of smokers with chronic obstructive pulmonary disease. Am J Respir Crit Care Med 1998:157:822-6.

59. Peleman RA, Rytila PH, Kips JC, Joos GF. Pauwels RA. The cellular composition af induced sputum in chronic obstructive pulmonary disease. Eur Respir $\rfloor$ 1999;13:839-43.

60. Gan WQ, Man SF, Senthilselvan A, Sin DD. Association between chronic cbstructive pulmonary disease and systemic inflammation: a systematic review and a meta-analysis. Thorax 2004;59:57480 .

61. Vernooy $\mathrm{JH}$, Kucukaycan $M$, Jacobs $J A$, et al. Local and systemic inflammation in patients with chronic obstructive pulmonary disease: soluble tumor necrosis factor receptors are increased in sputum. Am J Respir Crit Care Med 2002;166:1218-24.

62. Frohlich $M$, Sund $M$, Lowel $H$, Imhof $A_{1}$ Hoffmeister $A$, Koenig $W$. Independent association of various smoking characteristics with markers of systemic inflammation in men. Results from a representative sample of the general population (MONICA Augsburg Survey 1994/95). Eur Heart J 2003:24:1365-72.

63. Takabatake $N$, Nakamura $H_{0}$ Abe $S$, et al. The relationship between chronic hypoxemia and activation of the tumor necrosis factor-aipha system in patients with chronic obstructive pulmonary disease. Am J Respir Crit Care Med 2000;161:1179-84.

64. Pitsiou G, Kyriazis G, Hatzizisi O, Argyropoulou P. Mavrofridis E, Patakas D. Tumor necrosis factoralpha serum levels, weight loss and tissue oxygenation in chronic obstructive pulmonary disease. Respir Med 2002;96:594-8.

65. Pedersen BK, Hoffman-Goetz L. Exercise and the immune system: regulation, integration, and adaptation. Physiol Rev 2000;80:1055-81.

66. Rabinovich $R A$, Figueras $M_{2}$ Ardite $E$, et al. Increased tumour necrosis factor-alpha plasma levels during moderate-intensity exercise in COPD patients. Eur Respir $\mathrm{J}$ 2003;21:789-94.

67. van den Biggelaar $\mathrm{AH}_{\text {, Huizinga } T W}$, de Craen $\mathrm{AJ}$, et al. Impaired innate immunity predicts Irailty in old age. The Leiden 85-plus study. Exp Gerontol 2004;39:1407-14.

68. Wouters EF, Creutzberg EC, Schols AM. Systemic Effects in COPD(*). Chest 2002;121:127S-30S.

69. Di Francia M, Barbier D, Mege JL, Orehek J. Tumor necrosis factor-alpha levels and weight loss in chronic obstructive pulmonary disease. Am J Respir Crit Care Med 1994;150:1453-5.

70. de Godoy I, Donahoe M, Calhoun WJ, Mancino J, Rogers RM. Elevated TNF-alpha production by peripheral blood monocytes of weight- losing COPD patients. Am I Respir Crit Care Med 1996;153:633-7.

71. Fong $Y$, Moldawer LL, Marano $M$, et al. Cachectin/TNF or IL-1 alpha induces cachexia with redistribution of body proteins. Am J Physiol 1989;256:R659-65.

72. Michie HR, Sherman ML, Spriggs DR, Rounds J, Christie M, Wilmare DW. Chronic TNF infusion causes anorexia but not accelerated nitrogen loss. Ann Surg 1989;209:19-24.

73. Tracey $\mathrm{KJ}$, Wei $\mathrm{H}_{2}$ Manogue KR, et al. Cachectin/tumor necrosis factor induces cachexia, anemia, and inflammation. J Exp Med 1988;167:1211-27. 
74. Pomposelli JJ, Flores EA, Bistrian BR. Role of biochemical mediators ün clinical nutrition and surgical metabolism. JPEN J Parenter Enteral Nutr $1988 ; 12: 212-8$.

75. Mahony SM, Beck SA, Tisdalle M. Comparison of weight loss induced by recombinant tumour necrosis factor with that produced by a ciachexia-inducing tumour. Br J Cancer 1988;57;385-9.

76. Warren RS, Starnes HF, Jr, Gabrilove JL, Oettgen HF, Brennan MF. The acute metabolic effects of tumor necrosis factor administration in humans. Arch Surg 1987;122:1396-400.

77. Starnes HF, Jr. Warren RS, Jeevanandam M, et al. Tumor necrosis factor and the aculte metabolic response to tissue injury in man. J Clin Invest 1988;82:1321-5.

78. Pahl HL. Activators and target genes of Rel/NF-kappaB transcription factors. Oncogene 1999;18:6853-66.

79. Cali D, Frantz JD, Tawa NE, ur., et al. IKKbeta/NF-kappaB activation causes severe muscle wasting in mice. Cell 2004;119:285-98.

80. Agusti $A$, Morla $M$, Sauleda $J_{\text {, Saus }} C$, Busquets $X$. NF-kappaB activation and iNOS upregulation in skeletal muscle of patients with COPD and low body weight. Thorax $2004 ; 59: 483-7$.

81. Grunfeld $\mathrm{C}$, Zhao $\mathrm{C}_{1}$ Fuller $\mathrm{J}$, et al. Endotoxin and cytokines induce expression of leptin, the ob gene product, in hamsters. J Clin Invesit 1996;97:2152-7.

82. Sarraf $P$, Frederich $\mathrm{RC}$, Turner $E M$, et al. Multiple cytokines and acute inflammation raise mouse leptin levels: potential role in inflammatory anorexia. J Exp Med 1997;185:171-5.

83. Campfield LA, Smith FJ, Burn P. The OB protein (leptin) pathway-a link between adipose tissue mass and central neural networks. Horm Metab Res 1996;28:619-32.

84. Seeley $\mathrm{Rl}$, van Dijk G, Camptield LA, et al. Intraventricular leptin reduces food intake and body weight of lean rats but not obese Zucker rats. Horm Metab Res 1996;28:664-8.

85. Hwa $\mathrm{N}$, Ghibaudi L, Compton D, Fawzi AB, Strader CD. Intracerebroventricular injection of leptin increases thermogenesis and mobilizes fat metabolism in ab/ob mice. Horm Metab Res $1996 ; 28: 659-63$.

86. Friedman JM. The alphabet of weight control. Nature 1997;385:119-20.

87. Dryden S, Frankish $\mathrm{H}$, Wang $\mathrm{Q}$. Williams $\mathrm{G}$. Neuropeptide $\mathrm{Y}$ and energy balance: one way ahead for the treatment of obesity? Eur J Clin Invest 1994;24:293-308.

88. Stephens TW, Basinski $M$, Bristow $P K_{1}$ et all. The role of neuropeptide $Y$ in the antiobesity action of the obese gene product. Nature $1995 ; 377: 530-2$.

89. Creutzberg EC, Wouters EF, Vanderhoven-Augustin IM, Dentener MA, Schols AM. Disturbances in leptin metabolism are related to energy imbalance during acute exacerbations of chronic obstructive pulmonary disease [In Process Cittation]. Am J Respir Crit Care Med 2000;162:1239-45,

90. Schols AM, Creutzberg EC, Buurman WA, Campfield LA, Saris WH, Wouters EF. Plasma leptin is related to prointlammatory status and dietary intake in patients with chronic obstructive pulmonary disease. Am J Respir Crit Care Med 1999;160:1220»6.

91. Zumbach MS, Boehme MW, Wahl P, Stremmel W, Ziegler R, Nawroth PP. Tumor necrosis factor Ancreases serum leptin levels in humans. J Clin Endocrinol Metab 1997;82:4080-2.

92. Janik JE, Curti $\mathrm{BD}_{\text {, Considine } \mathrm{RW}}$ et all. Interleukin 1 alpha increases serum leptin concentrations in humans. J Clin Endocrinol Metab 1997;82:3084-6.

93. Fantuzzi G, Faggioni R. Leptin in the regulation of immunity, inflammation, and hematopoiesis. J Leukoc Biol 2000;68:437-46.

94. Tsuchiya T, Shimizu H, Horie T, Mori M. Expression of leptin receptor in lung: leptin as a growth factor. Eur \& Pharmacol 1999;365:273-9 


\section{Pulmonary cachexia, systemic inflammatory profile and the IL- $1 \beta-511$ single nucleotide polymorphism}

Roelinka Broekhuizen Robert F. Grimble

W. Martin Howell

Dennis J. Shate

Eva C. Croutzberg

Emiel FM. Woilters

Annemie MW.J. Schols 


\section{Abstract}

\section{Background:}

Cachexia is common in COPD and thought to be linked to an enhanced systemic inflammatory response. The aim of this study was to investigate differences in systemic inflammatory profile and polymorphisms in related inflammatory genes in COPD patients stratified by cachexia.

\section{Mehods:}

A cross-sectional study was performed in 99 COPD patients (GOLD stage II-IV), stratified by cachexia based on fat-free mass index (FFMI $<16$ (men)/ 15 (women) $\left.\mathrm{kg} / \mathrm{m}^{2}\right)$, who were compared to healthy controls $(\mathrm{HC})$. Body composition was determined by bioelectrical impedance analysis. Plasma concentrations and gene polymorphisms of interleukin (IL) - $1 \beta(\mathrm{IL}-1 \beta-511), \quad \mathrm{L}-6$ (IL6 -174) and the TNFsystem (TNFa -308 and $L t \alpha+252$ ) were determined. C-reactive protein (CRP) and leptin were measured in plasma and pseudouridine (PSU) as a marker of cellular protein breakdown in urine.

Results:

Cachectic patients (CP: $n=35$ ) had a significant different fat mass (FM), leptin and PSU $(p<0.001)$ but similar systemic inflammatory cytokine profile compared with non-cachectic patients (NCP). NCP had a body compositional shift towards lower FFM and higher FM compared with HC. CP and NCP had a higher systemic inflammatory response $(p<0.05)$ than controls as reflected in CRP, sTNF-R75 and IL-6. The overall distribution of $\| \mathrm{L}-1 \beta-511$ polymorphism was significantly different between the 4 groups $(p<0.05)$.

\section{Conclusions:}

In COPD patients, characterized by an elevated systemic inflammatory response, cachexia is not discriminatory for the extent of increase in inflammatory status. The study, however, indicates a potential influence of genetic predisposition on the cachexia process. 


\section{Introduction}

Chronic obstructive pulmonary disease (COPD) is a lung disease characterized by irreversible chronic airflow limitation with or without alveolar wall destruction. Besides lung impairment, patients with COPD are progressively disabled by systemic impairment. Weight loss and particularly loss of fat-free mass (FFM), have been shown to adversely affect respiratory and peripheral muscle function (1) and exercise capacity (2). In addition, low FFM is associated with impaired health status $(3,4)$ and increased mortality (5).

The disproportionate loss of FFM in COPD is often referred to as pulmonary cachexia. Cachexia has been defined as disproportionate cytokine-driven loss of skeletal muscle (6), which is reflected in loss of FFM. However, in human studies, in COPD as well as in other chronic diseases, the association between cachexia and systemic inflammation is equivocal. While some studies report increased concentrations of inflammatory markers in cachectic COPD patients, other studies do not (7-9). This inconsistency is at least partly due to differences in the clinical definition of the cachexia syndrome used in studies varying from involuntary weight loss to a low body mass index (BMI) or a low FFM index (FFMI). In COPD, the precise relationship between cachexia and systemic inflammation therefore remains to be determined. Understanding this relationship is important for characterization and stratification of patients eligible for specific anabolic or antiinflammatory treatments and to monitor therapeutic outcome.

Cytokines play a key role in the inflammatory process. The production of a cytokine is influenced by single base changes (single nucleotide polymorphisms (SNPS)), usually in the promoter region of its gene (10). Therefore, individuals may have a genetically determined propensity for raised level of cytokine production. 
Both cachexia and systemic inflammation could be influenced by genetic polymorphisms. In recent literature, it has been hypothesized that differences in polymorphisms of inflammatory cytokines may influence the etiology of COPD (1114). Genetic predisposition could also explain the typical differences in COPD phenotypes that were traditionally characterized as the 'pink puffer' and the 'blue bloater and which showed striking differences in anthropometric features. However, no studies have been performed investigating whether there is a link between SNPs in inflammatory cytokine genes and cachexia and systemic inflammation in COPD.

The aim of the present study was to characterize the systemic inflammatory profile of cachectic relative to non-cachectic patients with COPD and to healthy controls and to study a possible modulatory role of SNPs in inflammatory cytokine genes.

\section{Subjects and methods}

\section{Patients}

One hundred and two stable COPD patients (GOLD stage II-IV $(15,16)$ ), free from exacerbation for at least eight weeks, were included from a Dutch Caucasian population for an intervention trial (17). Baseline measurements of this patient group were used and compared with two groups of healthy controls (see below). Patients were excluded if suffering from confounding diseases such as malignancies, gastrointestinal or kidney abnormalities, metabolic or endocrine diseases and inflammatory diseases. Because of technical reasons, it was not possible to measure genotype in three patients, who were therefore excluded from this study. The ethical review board of the University Hospital Maastricht approved the study and all patients gave their written informed consent. 


\section{Healthy controls}

1. Twenty healthy Dutch volunteers, gender- and age-matched, were recruited by an advertisement in a local newspaper for comparison of body composition, genotype and inflammatory parameters.

2. Genotypes of a larger healthy Caucasian population comprising of 213 renal and bone marrow donors (RBMD) from Southampton (male: female: 1:1) were also determined for comparison with the subjects' genotypes.

\section{Pulmonary function}

Forced expiratory volume in one second $\left(F E V_{1}\right)$ and forced vital capacity (FVC) were calculated from the flow volume curve using a spirometer (Masterlab, Jaeger, Würzburg, Germany). The highest value of at least three measurements was used. $\mathrm{FEV}_{1}$ was also calculated $15 \mathrm{~min}$ after inhalation of $\beta$-agonist via a metered-dose inhaler. Diffusing capacity for carbon monoxide ( $D L_{C o}$ ) was determined using the single breath method (Masterlab, Jaeger, Würzburg, Germany). Lung functional parameters were expressed as percentage of reference values (18). Blood was drawn from the brachial artery while the patients were breathing room air or using their oxygen therapy when indicated. Arterial oxygen tension $\left(\mathrm{PaO}_{2}\right)$ and carbon dioxide tension $\left(\mathrm{PaCO}_{2}\right)$ were analyzed with a blood gas analyzer (Radiometer, ABL 330, Copenhagen, Denmark).

\section{Body composition}

BMI was calculated as weight divided by height in squared meters $\left(\mathrm{kg} / \mathrm{m}^{2}\right)$. FFM (kg) was estimated using single frequency $(50 \mathrm{kHz})$ bioelectrical impedance analysis (BIA; Xitron Technologies, San Diego, CA, USA), with subjects in a supine position as described by Lukaski (19). FFM (kg) of patients was calculated using the disease-specific equation proposed by Schols (20) and FFM of controls was calculated using the equations of Lukaski (19). FFMI was calculated as FFM divided by height ${ }^{2}\left(\mathrm{~kg} / \mathrm{m}^{2}\right)$. Patients were classified as cachectic when their FFMI 
was lower than $16 \mathrm{~kg} / \mathrm{m}^{2}$ for men and lower than $15 \mathrm{~kg} / \mathrm{m}^{2}$ for women. Fat mass (FM; kg) was estimated as total body weight minus FFM.

\section{Blood variables}

For each subject, fasting blood was collected in evacuated blood collecting tubes containing EDTA (Becton Dickinson Vacutainer Systems, Plymouth, UK) in the early morning 108.00-09.00 hours). After centrifuging twice at $1000 \mathrm{~g}$ for $10 \mathrm{~min}$ at $4^{\circ} \mathrm{C}$ within 2 hours of collection, plasma for cytokines and peripheral blood mononuclear cells (PBMC) for DNA extraction, were subsequently stored at $-70^{\circ} \mathrm{C}$.

\section{Cytokines}

In plasma, IL-1 $\beta, I L-6$ and TNF $\alpha$ were determined in duplicate by Quantikine high sensitivity sandwich enzyme-linked immunosorbent assay (ELISA) kits (R\&D Systems, Minneapolis, USA). Soluble TNF-R55 and sTNF-R75 were measured in duplicate using the ELISA protocol as previously described by Leeuwenberg et al. (21). Leptin concentrations were measured in duplicate by an in-house double antibody sandwich ELISA assay using a monoclonal antibody specific for human leptin as described earlier (22). C-reactive protein (CRP) was assessed in duplicate by high-sensitivity particle-enhanced immunonephelometry (N Hs CRP, Dade Behring) (23). Albumin was determined using bichromatic digital endpoint methodollogy, with a Bromcresol purple reagent (Beckman Coulter Synchron LX20, Brea, Los Angeles, California, USA).

\section{Genotyping}

The PBMC were analyzed to determine single nucleotide polymorphisms (SNPS) for the TNFa-308 (TNF*1 and TNF*2), Lymphotoxin (Lt) $a+252$ (TNFB*1 and TNFB*2), interleukin $6-174$ (IL6*1 and IL6*2) and interleukin 1 (IL-1) $\beta-511$ (IL1*1 and $I L 1^{*}$ 2) genotypes. Genomic DNA was extracted by a salting out procedure (24). Each SNP was detected by using a two-reaction amplification refractory 
mutation system polymerase chain reaction (ARMS-PCR) approach based on previously published methods (25). Full details are described elsewhere $(26,27)$.

\section{Pseudouridine (PSU)}

A morning urine sample was collected in which pseudouridine (PSU), which is a stable urinary end product of RNA turnover and hence a marker of cellular protein breakdown, was measured by high-performance liquid chromatography (28). Values are reported as ratio to urinary creatinine and corrected for FFM.

\section{Statistical analysis}

Results are presented as mean ( \pm standard deviation (SD)) for all variables that were normally distributed. Differences between the groups were analyzed by the Student's $t$-test for independent samples. Differences in the distribution of the genotypes between groups were examined by using the $\chi^{2}$ test, or the Fisher's Exact test when appropriate. $\chi^{2}$ test was corrected for multiple comparisons when appropriate, showing both the uncorrected and the more conservative corrected $\mathrm{p}$ values. Differences in cytokine concentrations between the different genotypes were determined by one-factor analysis of variance (ANOVA). Genotype frequencies for each SNP were tested for agreement with Hardy-Weinberg equilibrium by comparing with expected values calculated from allele frequencies. Data were analyzed using SPSS (Statistical Package for the Social Sciences, version 11.0 for Windows, SPSS Inc., Chicago, IL, USA). P-values of less than 0.05 were considered significant. 


\section{Results}

Stratification of COPD patients by cachexia (table 1) revealed that cachectic patients (CP) had more compromised DLco than non-cachectic patients (NCP) $(p=0.024)$, but no significant difference in age, $F E V_{1}$, long-term oxygen therapy (LTOT), smoking history and resting $\mathrm{PaO}_{2}$. However, cachectic patients had higher $\mathrm{PaCO}_{2}$ than non-cachectic patients $(\mathrm{p}=0.030)$. Inflammatory markers were not significantly different between cachectic patients and non-cachectic patients. Cytokine analysis also showed that COPD patients had higher STNF-R75, CRP and IL-6 concentrations compared to controls $(p<0.001)$. Albumin was significantly lower in cachectic patients compared to non-cachectic patients $(p=0.032)$ (table 1). $\mathbb{L L}-1 \beta$ could not be detected.

Figure shows the body composition of patients stratified by cachexia and healthy gender-and age-matched controls ( $\mathrm{HC}$ ). By definition, cachectic patients had lower FFMI than non-cachectic patients and healthy controls [CP $\left(14.2 \pm 0.9 \mathrm{~kg} / \mathrm{m}^{2}\right), \mathrm{NCP}$ $\left(16.9 \pm 1.7 \mathrm{~kg} / \mathrm{m}^{2}\right), \mathrm{HC}\left(20.2 \pm 2.6 \mathrm{~kg} / \mathrm{m}^{2}\right)$, all: $\left.\mathrm{p}<0.001\right]$. Cachectic patients also had a lower BMI than non-cachectic patients and healthy controls [CP (19.0 2.2 $\left.\mathrm{kg} / \mathrm{m}^{2}\right)$ vs. NCP $\left(24.2 \pm 3.2 \mathrm{~kg} / \mathrm{m}^{2}\right), p<0.001 ; \mathrm{CP}$ vs. HC $\left(25.7 \pm 2.8 \mathrm{~kg} / \mathrm{m}^{2}\right)$, $p<0.001]$ and a lower FMI compared to non-cachectic patients but not compared to healthy controls [CP $\left(4.9 \pm 1.7 \mathrm{~kg} / \mathrm{m}^{2}\right)$ vs. NCP $\left(7.3 \pm 2.4 \mathrm{~kg} / \mathrm{m}^{2}\right), p<0.001 ; C P$ vs.

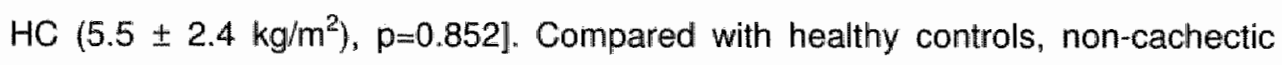
patients did not significantly differ in BMI $(p=0.137)$, but their FFMI was lower $(p<0.001)$ and their FMI was higher $(p=0.006)$. 
Table 1: Characteristics of cachectic patients, non-cachectic patients and heathy controls

\begin{tabular}{|c|c|c|c|c|}
\hline & & GP & NCP & HC \\
\hline n & & 35 & 64 & 20 \\
\hline $\mathrm{Age}^{2}$ & (yrs) & $62.2( \pm 9.2)$ & $63.0( \pm 9.4)$ & $607( \pm 3.5)$ \\
\hline Height? & (m) & $68( \pm 0.07)$ & $1.70( \pm 0.07)$ & $1.72(+0.07)$ \\
\hline \multicolumn{5}{|c|}{ Lung function'2 } \\
\hline FEV & (\%pred) & $32( \pm 13)^{a}$ & $37(114)^{2}$ & $105( \pm 16)^{\circ}$ \\
\hline FVC & $(\%$ pred) & $74( \pm 16)^{a}$ & $79( \pm 19)^{a}$ & $112( \pm 15)^{6}$ \\
\hline $\mathrm{DL} \mathrm{LCO}_{\mathrm{C}}$ & (\%pred) & $42( \pm 18)^{\mathrm{a}}$ & $54( \pm 20)^{6}$ & $110( \pm 23)$ \\
\hline $\mathrm{PaO}_{2}$ & $(k P a)$ & 9. $16( \pm 1,38)$ & $9.32( \pm 1.23)$ & NA \\
\hline $\mathrm{PaCO}_{2}$ & $(\mathrm{kPa})$ & $5.66( \pm 0.95)$ & $5.26( \pm 0.64)^{\circ}$ & $\mathrm{NA}$ \\
\hline $\mathrm{PaO}_{2}$ & (milg) & $68.7( \pm 10.4)$ & $69.9( \pm 8.5)$ & $\mathrm{NA}$ \\
\hline $\mathrm{PaCO}_{2}$ & $(\mathrm{nmm} / \mathrm{g})$ & $42.7 \pm 7.1)^{\mathrm{e}}$ & $39.4( \pm 7.8)^{6}$ & NA \\
\hline LTOT & $(n=)$ & 7 & 11 & 0 \\
\hline Smoking & $(p y)$ & $41( \pm 25)^{9}$ & $35( \pm 22)^{2}$ & $13( \pm 18)^{b}$ \\
\hline \multicolumn{5}{|c|}{ Inflammatory parameters } \\
\hline$T_{N F}{ }^{3}$ & $(\mathrm{pg} / \mathrm{m} /)$ & $1.35(0.64,3.19)$ & $122(0.431,3,42)$ & $1,23(0.74,2.70)$ \\
\hline STNFR5 $5^{3}$ & $(\mathrm{ng} / \mathrm{m} /)$ & $0.93(0.60,2.51)$ & $0.84(0.54,1.94)$ & $0.88(0.68,1.82)$ \\
\hline STNFP $75^{\circ}$ & $(\mathrm{gg} / \mathrm{ml})$ & $154(0.84,3.39)^{2}$ & $\left(32(0.81,3.33)^{2}\right.$ & $1,14(0.68,182)^{6}$ \\
\hline $1 L-1 \beta$ & & ND & ND & ND \\
\hline $1 L-6^{3}$ & (pg/mil) & $3,98(0.90,11.77)^{3}$ & $3.71(1,05,12.85)^{2}$ & $1.76(0.81,6.00)^{6}$ \\
\hline $\mathrm{CRP}^{3}$ & (mg/l) & $4.23(0,47,75.60)^{2}$ & $3.12(0.36,65.70)$ & $1.82(0.16,7.09)^{6}$ \\
\hline Albumin ${ }^{2}$ & $(g / l)$ & $40.4( \pm 5.9)^{a}$ & $43.1( \pm 5.0)^{\mathrm{b}}$ & NA \\
\hline
\end{tabular}

'CP: cachectic patients ( $n=35$ (24 men/ 11 women)): NCP: non-cachectic patients ( $n=64$ (45 men/19 women)); HC: healthy age- and gender-matched controls ( $n=20(15 \mathrm{men} / 5$ women)); FEV;: forced expiratory volume in 1 second; FVC: forced wital capacity; $D L_{\mathrm{CO}}$ : Diffusing capacity for carbon monoxide; PaO $\mathrm{O}_{2}$ arterial $\mathrm{O}_{2}$ pressure; $\mathrm{PaCO}_{2}$ : anterial $\mathrm{CO}_{2}$ pressure; LTOT: long term oxygen therapy" TNFa: tumor necrosis factor alpha; sTNF-R: soluble TNF-receptor; IL: interleukin; CAP: C-reactive protein; NA.: not available; ND: not detectable.

2 Values are mean ( $\pm S D$ ) and tested with One-factor analysis of variance (ANOVA) with Bonferront correction

${ }^{3}$ Values are median (range) and tested with the Mann-Whithey test with Bonferroni correction

a.b.c. Values not sharing a common superscript letter are significantly different at $p<0.05$ 


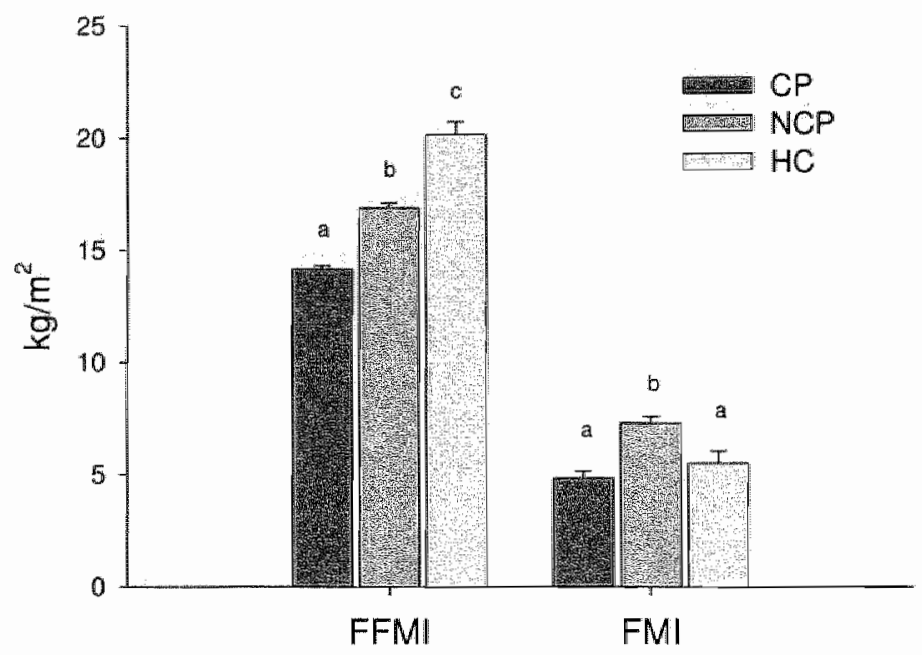

Figure 1: Mean ( \pm SEM) of fat-free mass index (FFM) and fat mass index (FMI) in cachectic patients (CP, $n=35)$, non $\cdot$ cachectic patients (NCP, $n=64$ ) and healthy controls ( $H C, n=20)$. Means not sharing a common lefter are significantly different at $0<0.01$ based on one-way ANOVA with Bonferroni correction.

Besides the observed difference in FM between patients stratified for cachexia, leptin was also significantly different, both absolutely [CP $(2.94 \pm 3.06 \mathrm{ng} / \mathrm{ml}) \mathrm{vs}$. $\operatorname{NCP}(9.99 \pm 11.40 \mathrm{ng} / \mathrm{ml}), p=0.002 ; \mathrm{CP}$ vs. HC $(9.94 \pm 11.26 \mathrm{ng} / \mathrm{ml}), p=1.000 ; \mathrm{NCP}$ vs. $\mathrm{HC} p=0.033]$ and corrected for FM [CP $(0.19 \pm 0.16 \mathrm{ng} / \mathrm{ml} / \mathrm{kg})$ vs. NCP $(0.42 \pm$ $0.40 \mathrm{ng} / \mathrm{ml} / \mathrm{kg}), p=0.024 ; \mathrm{CP}$ vs. HC $(0.58 \pm 0.66), p=0.003 ; \mathrm{NCP}$ vs. HC, $p=0.366]$ (figure 2). PSU, which is associated with active tissue breakdown, was highest in cachectic patients, intermediate in non-cachectic patients, and lowest in thealthy controls [CP $(50.6 \pm 11.8 \mu \mathrm{mol} / \mathrm{mmol})$ vs. NCP $(43.0 \pm 10.4 \mu \mathrm{mol} / \mathrm{mmol}), p=0.003$; CP vs. HC $(36.5 \pm 6.2 \mu \mathrm{mol} / \mathrm{mmol}), p<0.001)$; NCP vs. $H C, p=0.061]$. This difference was even more pronounced when PSU was corrected for FFM [CP (1.28 $\pm 0.37 \mu \mathrm{mol} / \mathrm{mmol} / \mathrm{kg})$ vs. NCP $(0.91 \pm 0.32 \mu \mathrm{mol} / \mathrm{mmol} / \mathrm{kg}), p<0.001 ; \mathrm{CP}$ vs. HC $(0.62 \pm 0.23 \mu \mathrm{mol} / \mathrm{mmal} / \mathrm{kg}$ ), $\mathrm{p}<0.001 ; \mathrm{NCP}$ vs. $\mathrm{HC}, \mathrm{p}=0.004$ ] (figure 2). 


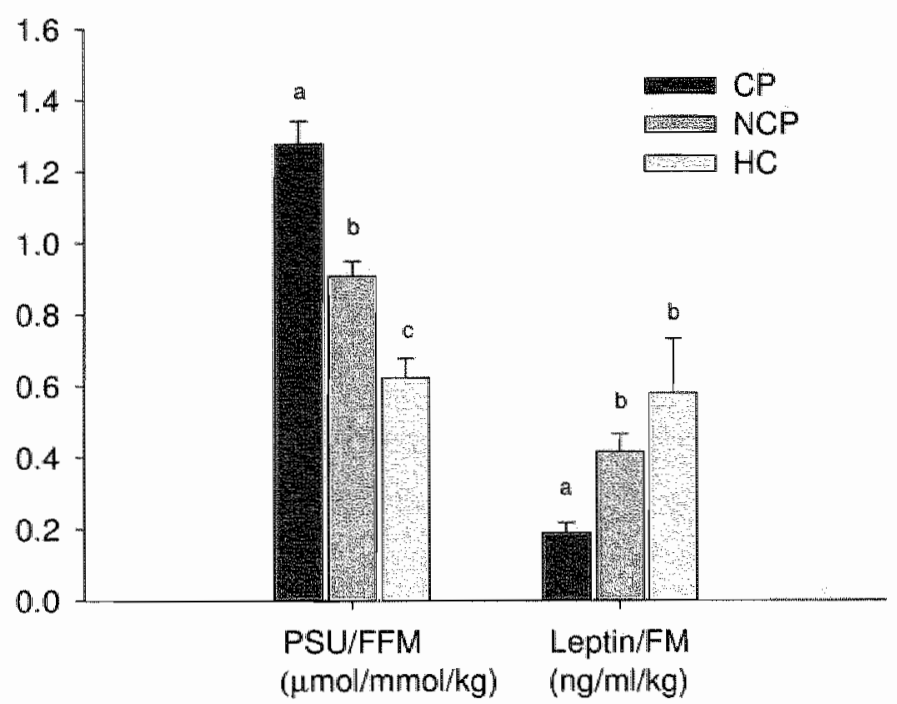

Figure 2. Mean ( \pm SEM) of pseudouridine corrected for fat-free mass (PSU/FFM; imnol/mmol/kg) and leptin corrected for fat mass ( $\mathrm{ng} / \mathrm{m} / \mathrm{kg}$ ) in cachectic patients $(\mathrm{CP}, \mathrm{n=35}$ ), non cachectic patients (NCP, n=64) and healthy controls $(H C, n=20)$. Means not sharing a common letter are significantly different at $p<0.05$ based' on one-way ANOVA with Bonferroni corraction.

The distribution of the genotypes among cachectic patients, non-cachectic patients, healthy controls and renal and bone marrow donors from Southampton (RBMD) is shown in table 2. A significant overall difference in distribution of the SNP at -511 in the IL-1 $\beta$ gene was seen $(p<0.01)$. This was due to a significant difference between cachectic patients and RBMD controls from Southampton $(p<0.006)$. However, due to the small sample size in some groups, differences among the other groups could not be pinpointed [CP vs. NCP, $p=0.174 ; C P$ vs. $H C$, $\mathrm{p}=0.096$ (using Bonferroni correction factor 6)]. The distribution of $\| \mathrm{L}-1 / \beta \quad-511$ genotypes fitted Hardy-Weinberg equilibrium in the non-cachectic patients, healthy age-matched controls and RBMD Southampton controls, but not in the cachectic patients. There were no significant differences in distribution of genotypes of the other inflammatory cytokine genes between COPD patients and controls. No significant differences were seen in polymorphism distribution between the healthy 
Dutch control group and the healthy control group from Southampton, although the distribution of the SNP at -308 of the TNFa and the SNP at +252 of the Lta genes in the Southampton controll group did not fit the Hardy-Weinberg equilibrium. There was no relation between plasma concentrations of pro-inflammatory cytokines and polymorphisms in the genes that code for these markers in patients or controls (data not shown).

Table 2: Distribution of genofype of cachectic patients, non-cachectic patients and controls $^{1}$

\begin{tabular}{|c|c|c|c|c|c|c|c|c|c|}
\hline & & & CP & & NCP & & HC & & RBMD \\
\hline & & $n=$ & $(\%)$ & $n=$ & $(\%)$ & $\mathrm{n}=$ & (\%) & $n=$ & $(\%)$ \\
\hline TNFa -308 & total & 35 & & 64 & & 20 & & 214 & \\
\hline & $\mathrm{GG}$ & 26 & $(74.3)$ & 38 & $(59.4)$ & 12 & (60) & 146 & $(68.2)$ \\
\hline & $A G$ & 9 & $(25.7)$ & 20 & $(31,3)$ & 8 & (40) & 56 & (26.2) \\
\hline & AA & 0 & (0) & 6 & $(9.4)$ & 0 & (0) & 12 & $(5,6)$ \\
\hline 4 ta +252 & total & 35 & & 64 & & 20 & & 214 & \\
\hline & $\mathrm{GG}$ & 6 & $(17.1)$ & 15 & $(23.4)$ & 3 & $(15.8)$ & 44 & $(20.6)$ \\
\hline & $\mathrm{AG}$ & 16 & $(45.7)$ & 24 & $(37.5)$ & 10 & $(52.6)$ & 80 & $(37.4)$ \\
\hline & $\mathrm{AA}$ & 13 & $(37.1)$ & 25 & $(39.1)$ & 6 & $(31.6)$ & 90 & $(421)$ \\
\hline 11.6 .174 & total & 34 & & 64 & & 20 & & 159 & \\
\hline & $\mathrm{CO}$ & 6 & $(17.6)$ & 5 & $(7.8)$ & 2 & (10) & 31 & (19.5) \\
\hline & CG & 10 & $(294)$ & 32 & $(50.0)$ & 11 & (55) & 65 & $(40.9)$ \\
\hline & $\mathrm{GG}$ & 18 & $(52.9)$ & 27 & $(42,2)$ & 7 & (35) & 63 & $(39.6)$ \\
\hline $1 L-1 \beta-511$ & total & 35 & & 63 & & 20 & a. & 159 & $b$ \\
\hline & $\mathrm{CC}$ & 25 & $(71.4)$ & 29 & (46) & 8 & (40) & 53 & $(33.3)$ \\
\hline & $\mathrm{CT}$ & 10 & $(28.6)$ & 29 & $(46)$ & 9 & (45) & 82 & (51.7) \\
\hline & TT & 0 & (0) & 5 & $(7.9)$ & 3 & (15) & 24 & $(14.9)$ \\
\hline
\end{tabular}

'CP: cachectic patients; NCP: non-cachectic patients; HC: healthy age- and gender-matched controis; RBMD: renal and bone marrow donors.

${ }^{a, b}$ : Values not sharing a common superscript letter are significantly different at $p<0.05$ using $\chi^{2}$ test. 


\section{Discussion}

In a group of patients with COPD characterized by systemic inflammation, the presence of cachexia did not relate to the severity of the systemic inflammatory response. However, a substantial difference was found in the distribution of the $\mathrm{LL}$ $1 \beta-511$ SNP between cachectic patients and controls.

The FFMI-based definition of cachexia used in this study not only discriminated for a low FFMI, but also for low FM on a group-level. In addition, cachexia discriminated for two different biochemical markers that are related to body composition. Pseudouridine (PSU), which is a stable urinary end product of RNA turnover and hence a marker of cellular protein breakdown, is related to muscle mass. In agreement with a previous study (29), PSU was higher in cachectic patients than in non-cachectic patients, even after correction for FFM. This could be a reflection of increased muscle breakdown in cachectic COPD patients. It is hypothesized that the increase in protein breakdown coincides with an increase in protein synthesis $(30)$, reflecting an inflammation-induced redirection of muscle protein in favor of synthesis of acute phase proteins (31). However further studies are needed to clarify this issue by measuring, for instance, acute phase protein turnover in COPD patients stratified according to the presence or absence of cachexia.

The second biochemical marker, leptin, which is a pleiotrophic cytokine produced by fat tissue, was disproportionatly lower in cachectic patients compared to noncachectic patients when corrected for the amount of FM. Excessively low leptin concentrations have also been found in chronic heart failure patients with cachexia (32). In that study, the authors hypothesized that low leptin concentration could be caused by an overactivation of the sympathetic nervous system found in cachectic heart failure patients. $\beta_{3}$ Adrenoceptor activation has indeed been shown to 
decrease leptin (33). In COPD, Takabatake et al. have linked the loss of circadian rhythm of circulating leptin, which is normally coupled to the activity of the autonomous nervous system, to pathophysiologic features in COPD (34). Given the fact that there are reports on abnormalities of hypothalamic-pituitary function in hypoxemic COPD patients (35), Takabatake et al. speculated that low leptin concentration and the blunted diurnal variation in leptin could cause an alteration in the negative feedback to the hypothalamic-pituitary axes (34). In the current study, the cachectic patients were not characterized by a lower resting $\mathrm{PaO}_{2}$, but had lower values for $D L_{c o}$ as hallmark of emphysema. Studies have shown that exercise-induced oxygen desaturation, indicative for the presence of intermittent hypoxia, is inversely related to the $\mathrm{DLco}(36)$.

The increased systemic inflammatory response observed in the patients of the present investigation, confirms other studies in comparable COPD populations (37, 38). In contrast to some studies, we did not find differences in inflammatory markers between patients with or without cachexia. Several studies relate inflammatory markers to FFM using different methods. COPD patients with low creatinine-height index $(\mathrm{CHI})$, a urinary marker of FFM, had higher concentrations of TNFa, IL-6 and their receptors than patients with normal $\mathrm{CHI}(8)$. However, $\mathrm{CHI}$ was determined using urinary creatinine nitrogen excretion, which is an indirect marker for skeletal muscle depletion. In addition, subjects did not receive standard meals and no correction was made for differences in nitrogen consumption of protein-rich products like meat (8). In contrast, using mid-thigh muscle crosssectional area as stratification, Debigaré et al. have reported no difference in IL-6 concentration (9).

Remarkably, the patients defined as non-cachectic also had a compromised body composition indicated by a lower FFM and higher FM than healthy controls. In nondiseased elderly subjects, sarcopenia, which is a decrease in muscle mass that 
does not necessarily coincide with weight loss, is related to increased systemic inflammation, especially to IL-6 $(39,40)$. These findings could imply that the noncachectic patients suffer from accelerated sarcopenia. This suggests a more gradual process in the etiology of pulmonary cachexia, first depleting FFM and in later stages also FM. Inflammation could be a trigger for the body compositional shift while in more advanced disease stages other factors could either enhance this process or specifically affect FM.

Differences in concentrations of inflammatory markers could be a consequence of differences in inflammatory gene polymorphisms. To explore this possibility, we studied the polymorphisms of the genes encoding for TNFa, $\| \mathrm{L}-1$ and IL-6. No significant differences were found between COPD patients and healthy controls in TNF-308, LTa+252 and IL6-174. This is in agreement with other studies in Caucasian subjects $(11,13,14,41,42)$ and some in Asian subjects (12). To our knowledge, this is the first study on IL6-174 distribution as well as on the possible relation between inflammatory cytokine gene polymorphisms and cachexia in COPD.

We found a significant difference in distribution of IL-1 $\beta-511$ polymorphisms between cachectic COPD patients and healthy renal and bone marrow donors. There are few studies investigating $\mathrm{IL}-1 \beta-511$ polymorphism in COPD. Ishii et al. have found no significant difference in $\mathrm{IL}-1 \beta-511$ polymorphism between Japanese COPD patients and controls $(12,43)$, neither did Joos et al. between smoking subjects with fast or normal lung function decline (44). However, Joos et al. did find a difference in the distribution of the ratio between IL-1 receptor agonist and IL-1 $\beta$ (IL1RN/IL1 $\beta$ ) haplotypes, which suggests that an imbalance in $\mathrm{IL}-\uparrow \beta$ and its receptor agonist may increase risk for COPD. Hegab et al. found that IL-1 $\beta-511$ tended to be different between COPD patients (not stratified for cachexia) and healthy controls in an Egyptian population (43). This, and the percentages of genotype distribution of $\mathrm{LL}-1 \beta-511$ found by Hegab, are in 
accordance with our study. Hegab et al. also found that the distributions of the haplotype $(1 \mathrm{~L}-1 \beta-31 \mathrm{~T} / \mathrm{C}: \| \mathrm{L}-1 \beta+3954 \mathrm{C} / \mathrm{T})$ were different between patients with COPD and controls (43). The functional significance of these differences is, however, not clear. Locally, $\|L-\| \beta$ plays a role in the chemotaxis of neutrophils into the lungs, inducing the release of neutrophil elastase (45). IL-1 $\beta$ furthermore induces proliferation of fibroblasts and synthesis of fibronectin and collagen (46). Systemically, IL-1 $\beta$ has been shown to play a role in cachexia through suppression of food intake by stimulating release of catecholamines and through influencing macronutrient metabolism (reviewed in 47). Unfortunately, we could not detect IL$1 \beta$ in this study. Looking at the available literature, no consensus has yet been reached on which allele is linked with a raised inflammatory status, which is partly due to the fact that this gene is in linkage equilibrium with genes encoding for $1 L-1 \alpha$ and $\mathrm{IL}-1$ receptor antagonist $(48-50)$. These findings need to be confirmed in larger populations and the possible consequences need to be studied.

In summary, in COPD patients, characterized by an increased systemic inflammatory response, cachexia was not discriminatory for the level of inflammation. This may be related to the fact that the non-cachectic patients also had an impaired body composition profile compared with healthy controls. Remarkably, cachectic patients had a significantly different genotype distribution of $\| \mathrm{L}-1 \beta-511$ polymorphism than healthy controls, requiring further investigation.

Supported by the British Lung Foundation, GlaxoSmithKline and Numico Research B.V. 


\section{References}

1. Engelen MPKJ, Schols AMWJ, Baken WC, Wesseling GJ, Wouters EFM. Nutritional depletion in relation to respiratory and peripheral skeletal muscle function in out-patients with COPD. Eur Respir ل1994;7:1793-7.

2. Schols AM, Soeters PB, Dingemans AM, Mostert R, Frantzen PJ, Wouters EF. Prevalence and characteristics of nutritional depletion in patients with stable COPD eligible for pulmonary rehabilitation. Am Rev Respir Dis 1993;147:1151-6.

3. Mostert R, Goris A, Weling-Scheepers C, Wouters EF, Schols AM. Tissue depletion and health related quality of life in patients with chronic obstructive pulmonary disease. Respir Med 2000;94:859-67.

4. Shoup R, Dalsky $\mathrm{G}$, Warner $\mathrm{S}$, et al. Body compasition and health-related quality of life in patients with obstructive airways disease. Eur Respir $\Downarrow 1997 ; 10: 1575-80$.

5. Marquis K, Debigare R, Lacasse $Y$, et al. Midthigh muscle cross-sectional area is a better predictor of mortality than body mass index in patients with chronic obstructive pulmonary disease. Am J Respir Crit Care Med 2002;166:809-13.

6. Kotler DP. Cachexia. Ann Intern Med 2000;133:622-634.

7. de Godoy I, Donahoe M, Calhoun WJ, Mancino J, Rogers RM. Elevated TNF-alpha production by peripheral blood monocytes of weight- losing COPD patients. Am J Respir Crit Care Med 1996;153:633-7.

8. Eid AA, lonescu AA, Nixon LS, et al. Inflammatory response and body composition in chronic obstructive pulmanary disease. Am J Respir Crit Care Med 2001;164:1414-8.

9. Debigare $\mathrm{R}$, Marquis $\mathrm{K}$, Cote $\mathrm{CH}_{\text {, }}$ et al. Catabolic/anabolic balance and muscle wasting in patients with COPD. Chest 2003;124:83-9.

10. Paoloni-Giacobino $A_{*}$ Grimble $\mathrm{R}$, Pichard $\mathrm{C}$. Genomic interactions with disease and nutrition. Clin Nutr 2003;22:507-14.

11. Keatings $V M$, Cave $S J$, Henry $M J$, et al. A polymorphism in the tumor necrosis factor-alpha gene promoter region may predispose to a poor prognosis in COPD. Chest 2000;118:971-5.

12. Ishii $T$, Matsuse $T$, Teramoto $S$, et al. Neither IL-1 beta, IL-1 receptor antagonist, nor TNF-alpha polymorphisms are associated with susceptibility to COPD. Respir Med 2000;94:847-51.

13. Patuzzo $C$, Gile LS, Zorzetto $M$, et al. Tumor necrosis factor gene complex in COPD and disseminated bronchiectasis. Chest 2000;117:1353-8.

14. Higham MA, Pride NB, Alikhan A, Morrell NW. Tumour necrosis factor-alpha gene promoter polymorphism in chronic obstructive pulmonary disease. Eur Respir $\mathrm{J}$ 2000;15:281-4.

15. Pauwels RA, Buist AS, Calverley PM, Jenkins CR, Hurd SS. Global strategy for the diagnosis, management, and prevention of chronic obstructive pulmonary disease. NHLBI/WHO Glabal Initiative for Chronic Obstructive Lung Disease (GOLD) Workshop summary. Am J Respir Crit Care Med 2001:163:1256-76.

16. Fabbri $\mathrm{LM}_{z}$ Hurd SS. Global Strategy for the Diagnosis, Management and Prevention of COPD: 2003 update. Eur Respir J 2003;22:1-2.

17. Broekhuizen R, Wouters EF, Creutzberg EC, Weling-Scheepers CA, Schols AM. Polyunsaturated fatty acids improve exercise capacity in chronic obstructive pulmonary disease. Thorax 2005;60:376-82. 
18. Quanjer PHe. Standardized lung function testing. Official statement of the European Respiratory Society [see comments]. Eur Respir i 1993;6 (suppl.16):1-100.

19. Lukaski HC, Johnison PE, Bolonichuk WW, Lykken Gi. Assessment of fat-free mass using bioelectrical impedance measurements of the human body. Am J Clin Nutr 1985,41:810-7.

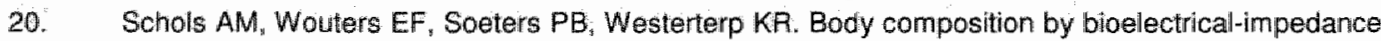
analysis compared with deuterium dilution and skinfold anthropometry in patients with chronic abstructive pulmonary disease. Am J Clin Nutr 1991;53:421-4.

21. Leeuwenberg JF, Jeunhomme TM, Buurman WA. Slow release of soluble TNF receptors by monocytes in vitro. J Immunoll 1994;52:4036-43.

22. van Dielen $F M$, wan " $t$ Veer $C$, Butuman WA, Greve JW. Leptin and soluble leptin receptor levels in obese and weight-losing individuals. J Clin Endocrinol Metab 2002;87:1708-16.

23. Rothkrantz-Kas S, Bekers O, Gubbels A, Drent M, Schmitz MP, vam Dieijen-Visser MP. Evaluation of two new high-sensitivity methods for C-reactive protein. Ann Clin Biochem 2003;40:398-405.

24. Miller SA, Dykes DD, Polesky HF. A simple salting out procedure for extracting DNA from human nucleated cells. Nucleic Acids Res 1988;16:1215.

25. Perrey C, Pravica $V$, Sinnott PJ, Hutchinsain IV. Genotyping for polymorphisms in interferongamma interleukin-10, transforming growth factor-beta 1 and tumour recrosis factor-alpha genes: $a$ technical report. Transpl Immunol 1998;6:193-7.

26. Howell WM, Tumer SJ, Theaker JM, Bateman AC. Cytokine gene single nucleotide polymorphisms

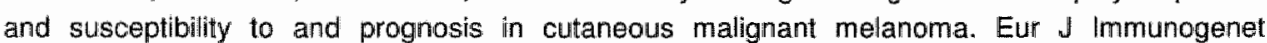
2003;30:409 14

27. Howell WM, Turner S., Collins A, Bateman AC, Theaker JM. Influence of TNFalpha and LTalpha single nucleotide polymorphisms on susceptibility to and prognosis in cutaneous malignant melanoma in the British population. Eur J Immunogenet 2002;29:17-23.

28. Li $Y$, Wang $S$, Zhong $N$. Simultaneous determination of pseudouridine and creatinine in urine of narmal children and patients with leukaemia by high pertormance liquid chromatography. Biomed Chromatogr 1992;6:191-3.

29. Bolton $C E$, lonescu $\mathrm{AA}_{\mathrm{y}}$ Shiels $\mathrm{KM}$, et al. Associated Loss of Fat Free Mass and Bone Mineral Density in Chronic Obstructive Pulmonary Disease. Am J Respir Crit Care Med 2004;170:12861293.

30. Engelen MP " Deutz NE, Wouters EF, Schols AM. Enhanced Levels of Whole-body Protein Turnover in Patients with Chronic Obstructive Pulmonary Disease. Am J Respir Crit Care Med $2000 ; 162: 1488 \cdot 1492$

31. Schols AM. Pullmonary cachexia. Int J Gardiol 2002;85:101-10.

32. Murdoch DR, Rooney E, Dargie $H J$, Shapiro D, Morton JJ, MclMurray JJ. Inappropriately low plasma leptin concentration in the cachexia associated with chronic heart failure. Heart $1999 ; 82: 352-6$

33. Trayhurn P, Duncan لJ, Rayner DV, Hardie LJ. Rapid inhibition of ob gene expression and circulating leptin levels in lean mice by the beta 3-adrenoceptor agonists BRL 35135A and ZD2079. Biochem Biophys Res Commun 1996;228:605-10.

34. Takabatake $N$, Nakamura $H$, Minamihaba $O$, et al. A Novell Pathophysiologic Phenomenon in Cachexic Patients with Chronic Obstructive Pumonary Disease. The relationship between the circadian ithythm of circulating leptin and the very low-frequency component of heart rate variability. Am J Respir Crit Care Med 2001;163:1314-9. 
35. Semple PD, Beastall GH, Watson WS, Hume R. Hypothalamic-pitultary dysfunction in respiratory hypoxia. Thorax 1981;36:605-9.

36. Owens GR, Rogers RM, Pennack BE, Levin D. The diffusing capacity as a predictor of arterial oxygen desaturation during exercise in patients with chronic obstructive pulmonary disease. $\mathrm{N}$ Engl J Med 1984;310:1218-21.

37. Gan WQ, Man SF, Senthilselvan A, Sin DD. Association between chronic obstructive pulmonary disease and systemic inflammation: a systematic review and a meta-analysis. Thorax 2004;59:57480.

38. Agusti $A G$, Noguera $A$, Saulleda $J$, Sala $E$, Pons $J_{\text {n }}$ Busquets $X$. Systemic effects of chronic obstructive pulmonary disease. Eur Respir $\mathrm{J} 2003 ; 21: 347-60$.

39. Doherty TJ. Invited review: Aging and sarcopenla. J Appl Physiol 2003;95:1717-27.

40. Bales CW, Ritchie CS. Sarcopenia, weight loss, and nutritional frailty in the elderly. Annu Rev Nutr 2002;22:309-23.

41. Sandford AJ, Chagani T, Weir TD, Connett JE, Anthonisen NR, Pare PD. Susceptibility genes for rapid decline of lung function in the lung health study. Am J Respir Crit Care Med 2001;163;469:73.

42. Kucukaycan M, Van Krugten M, Pennings HJ, et al. Tumor Necrosis Factor-alpha +489G/A gene polymorphism is associated with chronic obstructive pulmonary disease. Respir Res 2002;3:29.

43. Hegab AE, Sakamoto T, Saitoh W, et al. Polymorphisms of TNFalpha, IL1 beta, and IL1RN genes in chronic abstructive pulmonary disease. Biochem Biophys Res Commun 2005;329:1246-52.

44. Joos $L_{n}$ Mcintyre $L$, Ruan J, et al. Association of IL-1beta and IL-1 receptor antagonist haplotypes with rate of decline in lung function in smakers. Thorax 2001;56:863-6.

45. Brandolini $L$, Sergi $R$, Caselli $G$, et al. Interleukin- 1 beta primes interleukin-8-stimulated chemotaxis and elastase release in human neutrophils via its type I receptor. Eur Cytokine Netw 1997;8:173-8.

46. Chung KF. Cytokines in chronic obstructive pulmonary disease. Eur Respir J Suppl 2001;34:50s59 s.

47. Yeh SS, Schuster MW. Geriatric cachexia: the role of cytokines. Am J Clin Nutr 1999;70:183-97.

48. Santtila S, Savinainen $K$, Hurme M. Presence of the IL-1RA allele 2 (IL1RN*2) is associated with enhanced IL-1 beta production in witro. Scand J Immunal 1998;47:195-8.

49. Shimpuku $H$, Nosaka $Y$, Kawamura $T$, Tachi $Y$, Shinohara $M$, Ohura $K$. Genetic polymorphisms of the interleukin-1 gene and early marginal bone loss around endosseous dental implants. Clin Oral Implants Res 2003:14:423-9.

50. Nemetz A, Nosti-Escanilla MP, Molnar T, et al. IL1B gene polymorphisms influence the course and severity of inflammatory bowel disease. Immunogenetics 1999;49:527-31. 


\section{Body composition and mortality in chronic obstructive pulmonary disease}

Annemie M. W J Schols

Foelinka Broekhuizen

Clarie A.PM. Weling-Scheepers

Emiel F M, Wouters 


\section{Abstract}

\section{Background:}

Survival studies have consistently shown significantly greater mortality rates in underweight and normal-weight patients with chronic obstructive pulmonary disease (COPD) than in overweight and obese COPD patients. To compare the contributions of low fat-free mass and low fat mass to mortality, we assessed the association between body composition and mortality in COPD.

\section{Mathods:}

We studied 412 patients with moderate-to-severe COPD [Global Initiative for Chronic Obstructive Pulmonary Disease (GOLD) stages II-IV, forced expiratory volume in one second $\left(\mathrm{FEV}_{1}\right)$ of 36 (14) \%predicted; range: 19-70\%predicted]. Body composition was assessed by using single-frequency bioelectrical impedance. Body mass index (BMI), fat-free mass index (FFMI), fat mass index (FMI) and skeletal muscle index were calculated and related to recently developed reference values. COPD patients were stratified into defined categories of tissuedepletion pattern. Overall mortality was assessed at the end of follow-up.

Results:

Semistarvation and muscle atrophy were equally distributed among disease stages, but the highest prevalence of cachexia was seen in GOLD stage IV. Fortysix percent $(n=189)$ of the patients died during a maximum follow-up of five years. Cox regression models, with and without adjustment for disease severity, showed that FFMI (relative risk: $0.90 ; 95 \% \mathrm{Cl}: 0.84,0.96, p=0.003$ ) was an independent predictor of survival, but FMI was not. Kaplan-Meier and Cox regression plots for cachexia and muscle atrophy did not differ significantly.

\section{Conclusions:}

Fat-free mass is an independent predictor of mortality irrespective of fat mass. This study supports the inclusion of body composition assessment as a systemic marker of disease severity in COPD staging. 


\section{Introduction}

Survival studies in selected groups of patients with chronic obstructive pulmonary disease (COPD) and population-based studies have consistently shown higher COPD-related mortality rates in underweight and normal-weight patients than in overweight and even obese patients (1-3). This relation is different from the $U$ shaped survival curve that is commonly seen for body mass index (BMI) in large population studies (reviewed in 4). We hypothesized that this discrepancy might be explained by specific adverse effects of an excess loss of metabolically and functionally active fat-free mass (FFM) on mortality in chronic disease that are not seen with BMI. This increased mortality risk in COPD might be due to direct effects on lung function (5) or adverse effects of the loss of FFM on skeletal muscle strength (6), exercise capacity $(7,8)$, and health status (9) that may increase the frequency or severity of acute exacerbations of the disease. Furthermore, a recent study showed that a small midthigh cross-sectional area, as measured with computed tomography scan, was associated with increased mortality risk during a three-year follow-up (10). In the same study, midthigh cross-sectional area could not be estimated by using anthropometric measurements. Bioelectrical impedance analysis $(B \mid A)$ is an easy, safe, noninvasive and convenient method of measuring the lean and fat body compartments (11). In addition, it has been validated extensively in COPD and other chronic wasting conditions, which have shown high correlations between FFM measured by BIA and that measured by reference methods such as magnetic resonance imaging (12) or deuterium dilution (13). The objective of this study was to compare the effects of low FFM and low fat mass (FM) assessed by BIA on mortality in COPD patients. 


\section{Subjects and methods}

\section{Subjects}

Data were collected from 412 clinically stable COPD patients [Global Initiative for Chronic Obstructive Pulmonary Disease (GOLD) stages II-IV] who were screened for admission to a clinical pulmonary rehabilitation program between January 1 , 1988 and March 30, 1991. This group was selected because it was a homogeneous group of clinically stable patients from the southem part of the Netherlands and because none of the patients had undergone interventions that might modulate body composition, eg, nutritional intervention, intensive exercise training, or muscle strength training, before screening and during the total follow-up of five years. Such interventions currently are common in the Netherlands as part of an integrated COPD management approach. Patients with unstable disease or other confounding conditions such as type 1 diabetes, cardiovascular disease, thyroid disease or chronic inflammatory bowel disease were excluded. All baseline measurements were taken within one week of admission to the rehabilitation center.

\section{Lung function}

Lung function testing included spirometry and resting arterial blood gases. Forced expiratory volume in one second ( $\left.F E V_{1}\right)$ and inspiratory vital capacity (IVC) were measured with a wet spirometer using the highest value of at least three acceptable spirometric maneuvers. Prebronchodilation and postbronchodilation $\mathrm{FEV}_{1}$ and IVC were expressed as percentage of the reference values (14). Arterial blood gases were drawn by puncture of the at-rest brachial artery while the subjects breathed room air. Arterial oxygen tension $\left(\mathrm{PaO}_{2}\right)$ and arterial carbon dioxide tension $\left(\mathrm{PaCO}_{2}\right)$ were analyzed with the use of a blood gas analyzer ( $\mathrm{ABL}$ 330; Radiometer, Copenhagen, Denmark). 


\section{Body composition}

Body height was measured to the nearest $0.5 \mathrm{~cm}$ while the subjects were barefoot and standing (WM 715; Lameris, Breukelen, Netherlands). Body weight was measured on a calibrated beam scale (model 708; SECA, Hamburg, Germany). Body composition was assessed using single-frequency BIA $(50 \mathrm{~Hz}$; Xitron Technologies, San Diego, CA, USA). All measurements were performed by the same trained dietician at a standardized time after breakfast. FFM was calculated using disease-specific equations (13). FM was calculated as total body weight minus FFM. A prerequisite of the use of BIA is that the equations used to transform the measured resistance into FFM or total body water are adapted to the individuals measured and have been tested for validity in the populations for which they are intended. In these conditions, BIA measurements are accurate and comparable to other techniques to assess body composition. BIA has been extensively validated and evaluated in patients with COPD. The equations used were validated against deuterium dilution as the reference method, whereas other studies showed good association with dual-exposure X-ray absorptiometry (15, 16). The skeletal muscle index (SMI) was determined according to the equations used by Janssen et al. (12).

\section{Follow-up}

Mortality was assessed on January 31,1993 . Patients were followed for $2-5$ years or until death, whichever came first. Mortality was assessed as overall mortality due to all causes.

\section{Statistical analysis}

$B M I$, FFM index (FFMI), and FM index (FMI) were calculated by dividing body weight (in $\mathrm{kg}$ ), FFM, and FM, respectively, by height (in $\mathrm{m}$ ) squared to adjust for body surface area. Patients were stratified by body composition in four categories as follows. Patients in category 1 (cachexia) had $\mathrm{BMI}<21$ and FFMI $<16$ (men) or 
$<15$ (women); patients in category 2 (semistarvation) had $\mathrm{BMI}<21$ and FFMI $\geq 16$ (men) or 15 (women); patients in category 3 (muscle atrophy) had BMI $\geq 21$ and FFMI < 16 (men) or 15 (women); and patients in category 4 (no impairment) had $\mathrm{BMI} \geq 21$ and $F F M I \geq 16$ (men) $\geq 15$ (women).

The cutoff for FFMI is based on the linear association between FFM and body weight in normal-weight to underweight COPD patients as described by Baarends et al. (8). In earlier publications our group showed that these cutoffs are discriminative for exercise capacity (7) and health status (17). FFMI and FMI were compared with the gender-specific percentiles reported by Schutz et al. (18). As an additional characterization, the SMI was determined, as proposed by Janssen et al., for a comparison of the total study population as well as the subgroups with results from the third National Health and Nutrition Examination Survey (NHANES III), 1988-1994 (19). The percentage of patients theoretically at risk for physical disability was assessed using the cutoffs for physical disability risk set by Janssen et al: Subjects of NHANES III were classified as physically disabled (ie, having difficulty performing activities of daily living) if they answered "yes" to either or both of the following questions:

1) "Because of any impairment or health problem, do you need the help of other persons with personal care meeds, such as eating, bathing, dressing or getting around home?"

2) "Because of any impairment or health problem, do you need the help of other persons in handling routine needs, such as every day household chores, doing necessary business, shopping or getting around for other purposes?"

In the study by Janssen et al. (19), the cutoffs for severe physical disability risk were set at $\mathrm{SMI} \leq 5.75$ (women) or $\leq 8.50$ (men), and those for moderate physical disability risk were set at $\mathrm{SMI} \leq 6.75$ and $>5.75$ (women) or $\leq 10.75$ and $>8.50$ (men). 
Results are presented as mean ( \pm standard deviation (SD)) for all variables that were normally distributed. Univariate analysis was performed by using the KaplanMeier method. A log-rank $\chi^{2}$ test for comparing survival between groups was used to analyze the association between depletion pattern and survival. The Cox proportional hazards model was used to quantify the relation between mortality and body composition (ie, FFMI and FMI), age, gender ( $0=$ women, $1=$ men), disease severity $\left(\mathrm{PaO}_{2}, \mathrm{PaCO}_{2}\right.$ and $\mathrm{FEV}_{1}$ (\%predicted) as continuous variables), and GOLD classification (as categorized variable). Lung function criteria that defined the GOLD stages were normal lung function, GOLD 0 (at risk); $F E V_{1} / F V C<70 \%$ and $\mathrm{FEV}, \geq 80 \%$, GOLD I (mild); FEV $/$ FVC $<70 \%$ and $\mathrm{FEV}_{1}<80 \%$ and $\geq 50 \%$, GOLD II (moderate); FEV $/$ FVC $<70 \%$ and FEV $<50 \%$ and $\geq 30 \%$, GOLD III (severe); and $\mathrm{FEV}_{1} / \mathrm{FVC}<70 \%$ and $\mathrm{FEV}_{1}<30 \%$ or $\left(\mathrm{FEV}_{1}<50 \%\right.$ and $\mathrm{PaO}_{2}<8.0$ $\mathrm{kPa})$, GOLD IV (very severe).

The relative risk (RR) corresponding to a risk factor in this model is the exponential of the regression coefficient. The differences in distribution of body composition categories in GOLD stage II-IV were tested by using the $\chi^{2}$ test.

We performed all analyses with and without inclusion of the variable smoking $(0=$ no smoking ar former smoking, 1 = current smoking). However, the cumulative pack-year exposure was high in all patients, and status as a former smoker was not objectively verified (eg, by cotinine measurements in saliva). Therefore, smoking was not associated with mortality in these subjects, and we decided to report only the results without this variable in the model.

A two-sided value of $p<0.05$ was considered significant. Baseline comparisons between groups stratified by disease severity or body composition were performed by using an unpaired Student's t-test with Bonferroni correction for multiple comparisons. Data were analyzed using the SPSS for Windows Statistical software (version 11.0; SPSS Inc., Chicago, IL, USA). 


\section{Results}

Patient characteristics are shown in table 1 . The mean age of the study group was 64 ( \pm 9$)$ years, $77 \%$ were male, and mean $\mathrm{FEV}_{1}$ was $36( \pm 14) \%$ pred (range 19 70). Because there was a significant difference between men and women in BMI, FFMI and FMI (all: P<0.05), we stratified mean values for FFMI, FMI and SMI of the four body-composition groups by gender in table 2 and related them separately to

Table 1: Patient characteristics

\begin{tabular}{|c|c|c|}
\hline & & Mean (t SD) \\
\hline Gender & $(\mathrm{M} / \mathrm{F})$ & $318 \% 94$ \\
\hline Age & (y) & $64( \pm 9)$ \\
\hline FEV & & $x_{0}$ \\
\hline pre & (opred) & $36 .( \pm 14)$ \\
\hline post & (\%pred) & $39( \pm 15)$ \\
\hline We & (\%pred) & $72( \pm 18)$ \\
\hline $\mathrm{PaO}_{2}$ & $(K P a)$ & $8.8( \pm 1.6)$ \\
\hline $\mathrm{PaCO}_{2}$ & $(k P a)$ & $5.4( \pm 0.8)$ \\
\hline BMI & & (3) \\
\hline Men & $\left(\mathrm{kg} / \mathrm{m}^{2}\right)$ & $22.8( \pm 3.7)^{2}$ \\
\hline Women & $(\mathrm{kg} / \mathrm{m} / \mathrm{i})$ & $24.2( \pm 5.4)$ \\
\hline FFMII & & \\
\hline Men & $\left(\mathrm{kg} / \mathrm{m}^{2}\right)$ & $16.8( \pm 2.4)$ \\
\hline Women & $\left(\mathrm{kg} / \mathrm{m}^{2}\right)$ & $16.1( \pm 2.5)$ \\
\hline $\mathrm{FMI}$ & & \\
\hline Men & $\left(\mathrm{kg} / \mathrm{m}^{2}\right)$ & $6.0( \pm 2.1)^{2}$ \\
\hline Women & $\left(\mathrm{kg} / \mathrm{m}^{2}\right)$ & $8.0( \pm 3.4)$ \\
\hline
\end{tabular}

'All values are mean $( \pm S D)$. FEV pastbronchodilator; \%pred = percentage of predicted; $I V C=$ inspiratory vital capacity; $\mathrm{PaO}_{2}=$ resting arterial axygen tension; $\mathrm{PaCO}_{2}=$ resting arterial carbon dioxide tension; $\mathrm{BMI}=$ body mass index; $F F M I=$ fat-free mass index; $F M=$ fat mass index.

${ }^{2}$ Significanthy different from women, $p<0.001$ (Student's $t$-test). 


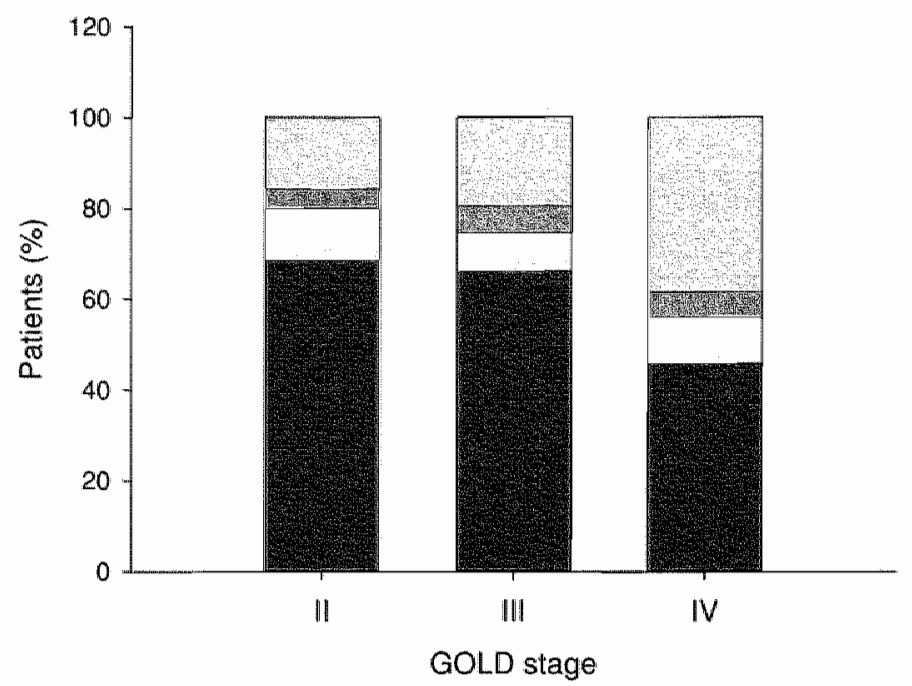

Figure 1: Body composition categories are linked to GOLD disease severity stage in a category comparison using the $\chi^{2}$ test. No impairment ( $n=232$; dark grey); muscle atrophy $(n=40$, white); semistarvation $(n=23$; grey); cachexia ( $n=117$; light grey). Cachexia was significantly $(p=0.001)$ more prevalent in GOLD stage $\mathrm{W}$ $(n=207)$ than in GOLD stages $\|(n=71)$ or $I I /(n=134)$.

the gender-specific reference values reported by Schutz et al. (18) and Janssen et al. (19). The proportions of men and women did not differ significantly between the four body-composition categories. In categories 1 and 3, mean FFMI was below the 10th or even the 5th percentile in both male and female patients. Mean FFMI in categories 2 and 4 was within median range ( $<50$ th percentile) except for male patients of category 2, whose values were below the 10th percentile. FMI did not differ significantly between cattegories 1 and 2 or between categories 3 and 4 in either men or women. Although female patients with a low BMI had an FMI below the 10th percentile, malle patients had an FMI within the median range. This indicates a gender-specific shift in body composition. When we applied the criteria for SMI and related physical disability that Janssen et al. (19) used, a high proportion of the total patient population was characterized as being at moderate $(51 \%)$ or high risk (31\%). In line with that study, male patients in the current study were at higher risk for physical disability than were female patients. On univariate 
Table 2: Characterization of COPD patienis by body composition and comparison with reference values ${ }^{1}$

\begin{tabular}{|c|c|c|c|c|c|}
\hline & & $\mathbf{N}$ & $\begin{array}{l}\text { Percentage } \\
\text { of pallents } \\
\text { \% }\end{array}$ & $\begin{array}{l}\mathrm{FFMI} \\
\mathrm{kg/m}\end{array}$ & Percentile? \\
\hline M & & & & & \\
\hline 1 & Cachexla & 92 & 29 & $14,3(4,2)^{5}$ & $<5$ th \\
\hline 2 & Semistarvation & 18 & 6 & $16.9(40,6)$ & $<10$ th \\
\hline 3 & Muscle alrophy & 31 & 10 & $14.9( \pm 1.0)$ & $<5 \mathrm{hh}$ \\
\hline 4 & Nol impaired & 177 & 56 & $184( \pm 1,7)$ & <501h \\
\hline & & & & & \\
\hline 1 & Cachexia & 25 & 27 & $13.5( \pm 0.9)$ & $<5 \mathrm{th}$ \\
\hline 2 & Semistarvation: & 5 & 5 & $159( \pm 0.5)$ & $<50$ th \\
\hline 3 & Muscle alliophy & 9 & 10 & $14.5( \pm 0.7)$ & <10th \\
\hline 4 & Not mimaired & 55 & 50 & $176(+22)$ & sooth \\
\hline
\end{tabular}

${ }^{\prime} F F M=$ fat-free mass index; FMI = fat mass index; $S M 1=$ skeletal muscle index. BMI was measured as $\mathrm{kg} / \mathrm{m}^{2}$. In men, cachexia is defined as a $B M l<21$ and an FFM $<16$; semistarvation is defined as a $B M 1<21$ and an FFMI $\geq 16$; muscle atrophy is defined as a $B M I \geq 21$ and an FFMI < 16; and no impairment is defined as a $B M I \geq 21$ and an FFMI $\geq 16$. In women, cachexia is defined as a $B M I<21$ and an FFMI $<15$; semistarvation is defined as a $B M I<21$ and an FFMI $\geq 15$; muscle atrophy is defined as a $B M I \geq 21$ and an FFMI $<15$; and no impairment is defined as a $B M I \geq 21$ and an $F F M I \geq 15$. Because there was a significant difference between men and women in BMI $(p<0.05)$. FFMI $(p<0.05)$ and FMI $(p<0.001)$, data for men and women are shown separately.

${ }^{2}$ Compared with percentiles reported by schutz et al. (18)

"In both men and women. FMl did not differ between categories 1 and 2 and between categories 3 and 4 (Student's t-test for independent samples)

"Compared with sMl and physical disability risk reported by Janssen et al.

The high (risk) column sthows the percentage of patients with $S M I \leq 8.50$ (men) and $\leq 5.75$ (women). The moderate (risk) columm shows the percentage of patients with $S M I \leq 10.75$ and $>8.50$ (men) and $\leq 6.75$ and $>5.75$ (women)(19).

5 mean ( $\pm S D$ ) (all such variables) 
Table 2: Continued

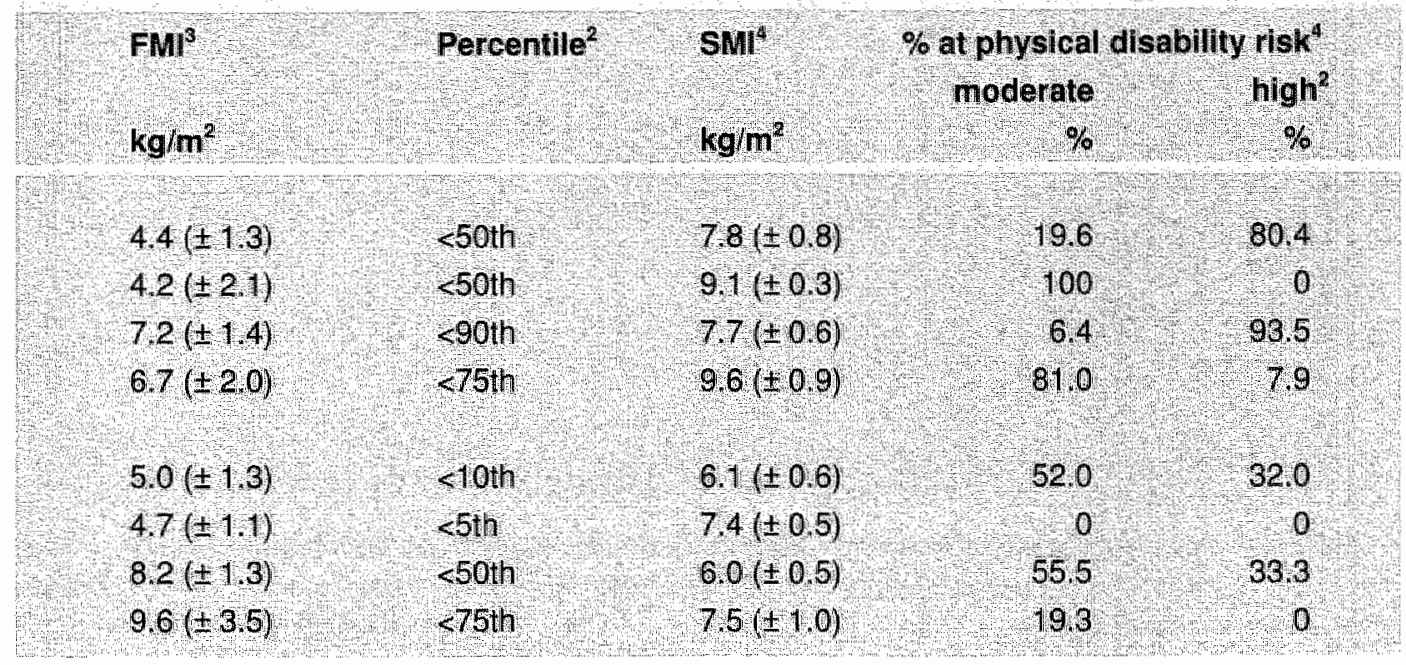

Cox regression analysis, however, the association between SMI and survival in the current study did not differ significantly between the men (RR: $0.75 ; 95 \% \mathrm{Cl}: 0.65$, 0.86 ) and the women (RR: $0.75 ; 95 \% \mathrm{Cl}: 0.51,0.99$ ). Furthermore, classification of the patients in the four categories clearly showed that, independent of gender, significantly $(p<0.001)$ more patients were at moderate to high disability risks in the cachexia and muscle atrophy categories (ie, 1 and 3 ) than in semistarvation and no-impairment categories (ie, 2 and 4) (table 2).

In figure 7 , body-composition categories are linked to GOLD stage of disease severity. Most of the patients had advanced COPD (GOLD II: $n=71$; GOLD II; $n=$ 134; and GOLD IV: $n=207$ ). Cachexia was silgnificantly $(p=0.001)$ more prevalent in GOLD stage IV than in GOLD stages II and III. 


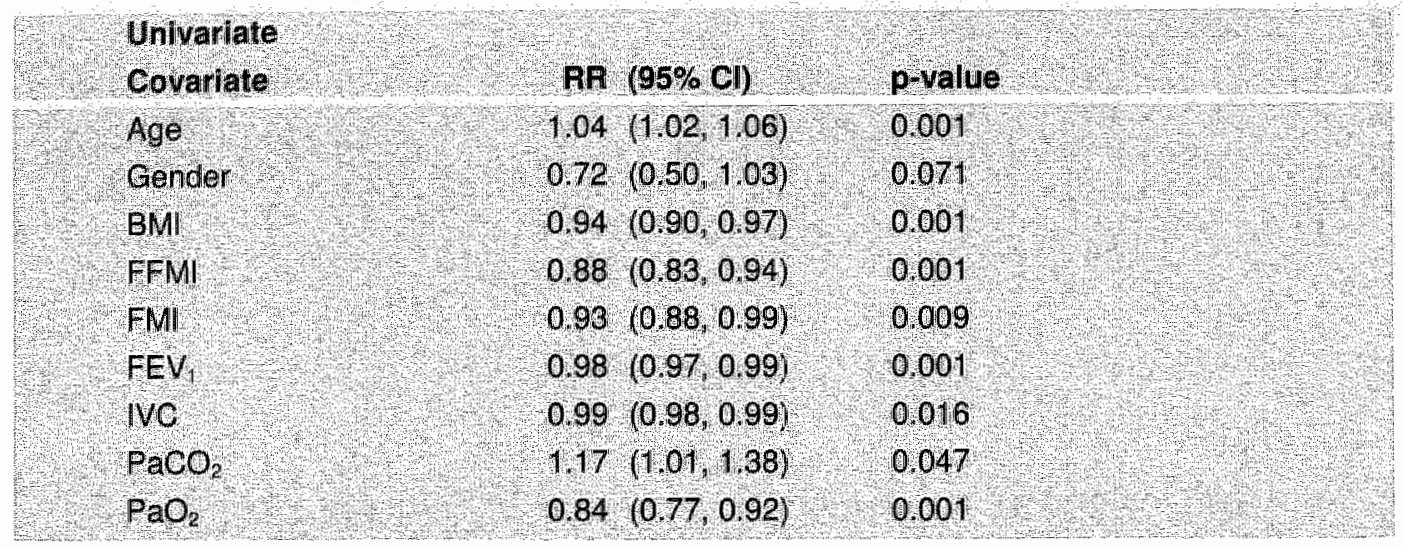

"AR, relative risk; BMI, body mass index; FFMI, fat-free mass index; FMI, fat mass index; FEV , forced expiratory volume in one second; $\mathrm{NC}_{1}$ inspiratory vital capacity; PaCO, arterial carbon dioxide tension; $\mathrm{PaO}_{2}$, arterial oxygen tension.

The mean duration of follow-up was $48( \pm 20)$ months, during which time $46 \%$ of the patients died. Univariate analysis showed that low BMI, FFMI and FMI were signiticantly associated with increased mortality risk (table 3a). In addition, Cox stepwise regression analysis showed that FFMI was selected when BMI was no longer significant (data not shown) when entered as either an absolute value or as dichotomized $\mathrm{BMI}(<$ or $\geq 21$ ). This indicates that FFMI is a stronger predictor for mortality than is BMI. After multivariate analysis, adjusted for age $(p=0.001)$ and gender ( $\mathrm{p=n} . \mathrm{s}$ ) (model 1) or also for $\mathrm{FEV}$ (either in vol/sec (data not shown) or as \%predicted $(p=0.037)$ ), IVC ( $\left.p=n . s_{\text {. }}\right)$, and resting arterial blood gases ( $\left.p=n . s.\right)$ (model 2), FFMI was an independent predictor of mortality $(p=0.001$ and 0.003 for model 1 and model 2 respectively), but FMI was not (table 3b). Although only a few patients were in the semistarvation category, the Kaplan-Meier plots for all the body composition categories are shown in figure 2. Survival was significantly ( $\mathrm{p}<0.001)$ less in patients with cachexia (median: 26 months; $95 \% \mathrm{Cl}: 21,31$ months) and muscle atrophy (median: 24 months; $95 \% \mathrm{Cl}: 15,33$ months) than in 
Table $3 \mathrm{~b}$ : Mutivariate analysis of predictors of mortality

\begin{tabular}{|c|c|c|c|c|c|c|}
\hline Multivariate & & Model ${ }^{2}$ & & & Model $2^{3}$ & \\
\hline Covariate & RR & $(95 \% \mathrm{cl})$ & p-value & RR & $(95 \% \mathrm{cl})$ & p-value \\
\hline Age & 1.04 & $(1.02,1.06)$ & 0.001 & 1.04 & $(1.02,1.06)$ & 0.001 \\
\hline Gender & 0.72 & $(0,49,1,06)$ & 0.100 & 0.84 & $(0.56,1.25)$ & 0,385 \\
\hline BMI & -4 & - & & 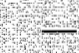 & -4 & \\
\hline FFMI & 0.88 & $(0.82,0.94)$ & 0.001 & 0.90 & $(0.84,0.96)$ & 0,003 \\
\hline FMI & 1.01 & $(0.94,1.08)$ & 0.843 & 1.02 & $(0.95,1.09)$ & 0.680 \\
\hline FEV, & $=$ & - & $=$ & 0.98 & $(0.97,0.99)$ & 0.037 \\
\hline IVC & $=$ & - & - & 1.00 & $(0.99,1.01)$ & 0.760 \\
\hline $\mathrm{PaCO}_{2}$ & $=$ & - & $=$ & 0.98 & $(0.81,1.20)$ & 0.860 \\
\hline $\mathrm{PaO}_{2}$ & - & - & - & 0.92 & $(0.82,1.02)$ & 0.120 \\
\hline
\end{tabular}

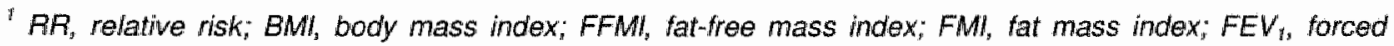
expiratory volume in one second; IVC, inspiratory vital capacity; $\mathrm{PaCO}_{2}$, arterial carbon dioxide tension; $\mathrm{PaO}_{2}$, anterial oxygen tension.

${ }^{2}$ FFM, FMl, age, gender ( $0=$ women, $\left.1=m e n\right)$

${ }^{3}$ FFMI, FMl, age, gender ( $0=$ women, $1=$ men) FEV $, I V C, \mathrm{PaO}_{2}$ and $\mathrm{PaCO}_{2}$

"variable not included in the model

patients with semistarvation (median: $36 ; 95 \% \mathrm{Cl}: 28,44$ months) or patients with no impairment (median: 47 months; $95 \% \mathrm{Cl}: 37,57$ months, $\mathrm{p}<0.001$ ). The survival plot for the semistarvation category did not differ significantly from that of the noimpairment category during the first three years (figure 2). In the last two years of the study, the survival curve of the semistarvation category diverged from that of no-impairment category to resemble the survival curves of the cachexia and muscle atrophy categories.

The Cox regression plots for the four categories, adjusted for age, gender, FMI, and disease severity markers, are shown in figure 3 . The RRs $(95 \% \mathrm{Cl})$ of patients in the three tissue-depletion categories compared with the RR of patients in the noimpairment were $1.91(1.37,2.67 ; p=0.006), 1.23(1.68,2.24 ; p=n . s),. 1.96(1.21$, $3.17 ; p<0.001$ ) for categories 1 (cachexia), 2 (semistarvation), and 3 (muscle 
atrophy) respectively. Therefore, patients in both categories with low FFMI have a greater mortality risk than do patients with no impairment, and, thus, low BMI does not increase mortality risk beyond the increase due to low FFMI.

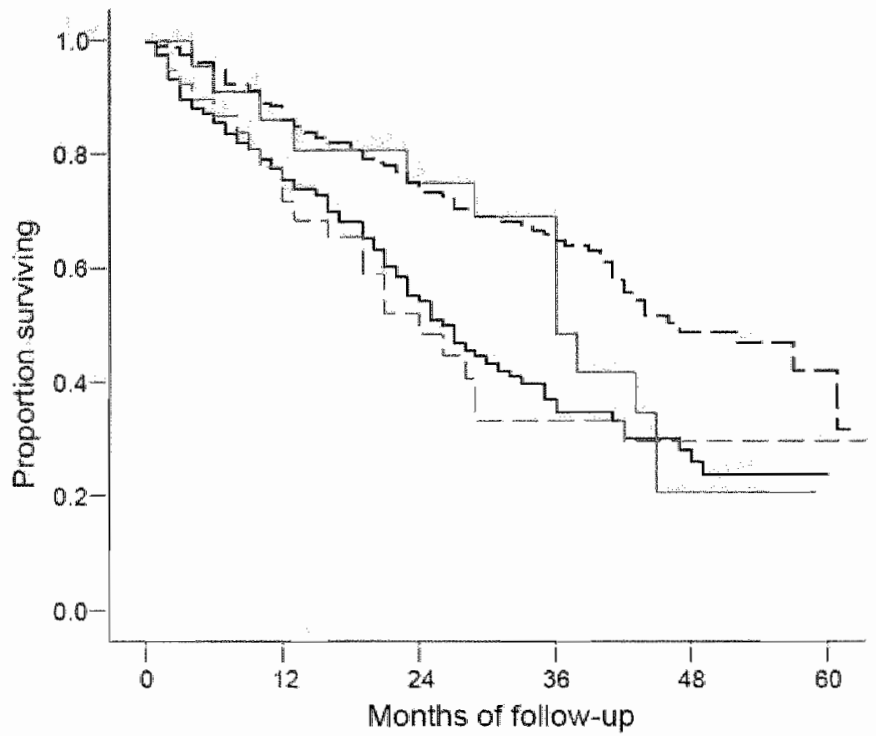

Figure 2: Kaplan Meier plot of survival in different body composition categories. Category 1 (cachexia: $n=117$ ), solid black line; category 2 (semistarvation; $n=23$ ), solid grey line; category 3 (muscle atrophy; $n=40$ ), dashed grey line; category 4 (no-impairment, $n=232$ ), dashed black line. Median (95\%Cl) survival was significantly $(p<0.001$ ) less in patients with cachexia (26 months; 21,31 months) and muscle atrophy (24 months; 15, 33 months) than in patients with semistarvation (36 months; 28,44 months) or no impairment ( 47 months: 37,57 months, $p<0.001$ ). The survival plot from the semistarvation category did not differ significantly from that of the no-impairment category during the first 3 years.

\section{Discussion}

This study shows that FFM is an independent predictor of mortality in COPD irrespective of FM and provides further support for the use of body composition assessment as systemic marker of disease severity in COPD staging. It also confirms a previous study of COPD that showed an independent association 
between lower-limb muscle cross-sectional area and mortality, particularly in patients with $\mathrm{FEV},<50 \%$ (10). In the current study, however, BIA was used, which is an easier method of estimating FFM in these patients without needing expensive apparatus or highly skilled technicians. Recently Janssen et al. (12) developed and cross-validated BIA equations against magnetic resonance imaging in a sample of 388 men and women who varied widely in age and BMI. In that study, the correlation between BIA- and magnetic resonance imaging-measured muscle mass was 0.86 . Gosker et al. (20) showed in patients with COPD that FFM assessed by BIA was significantly related to muscle fiber cross-sectional area taken from a biopsy of muscle tissue from the vastus lateralis, which indicated that whole-body FFM also reflects lower-limb muscle atrophy in chronic disease. FFM estimation via BIA was also used in a recent analysis of NHANES III that identified skeletal muscle cutoffs associated with a high likelihood of physical disability (19). With the use of these criteria, the current study group was characterized as being at moderate to high risk of physical disability. These studies all indicate that BIA may be a useful clinical screening instrument for characterization of the tissuedepletion pattern in chronic lung disease.

The findings of this study differ from those of population studies showing that an abundance of FM is particularly associated with increased cardiovascular disease.. related mortality risk in overweight to obese subjects (reviewed in 21). The current study indicates that, in COPD patients, the association between FFMI and survival is independent of the amount of FM and that FFMI provides information to assist prognosis beyond that provided by BMI. Strikingly similar physical disability and mortality risks were seen in the cachexia and muscle atrophy categories, which indicated that a critical loss of muscle mass, not reflected in BMI, may be responsible for physical disability and greater mortality risk. In previous studies, we also showed significant differences in functional impairment such as exercise capacity measured by a 12-minute walking test ( 7 ) or incremental cycle ergometry 
between patients in the cachexila and muscle atrophy categories relative to those in the semistarvation and no-impairment categories. Remarkably, the survival plot of the semistarvation category did not differ significantly from that of the noimpairment category during the first three years, whereas, thereafter, mortality was clearly higher in the semistarvation category. One could speculate that these patients initially have less mortality risk because of (relative) preservation of FFM but that, in due course, they are at greater risk of a critical loss of FFM. This hypothesis, however, should be confirmed in a longitudinal study using repeated measurements of body composition. The current study also showed remarkable gender-specific differences in body composition and disability risk from the reference values, and those differences warrant further investigation. As compared with the data from Schutz et al. (18), the shift in body composition toward less FFM

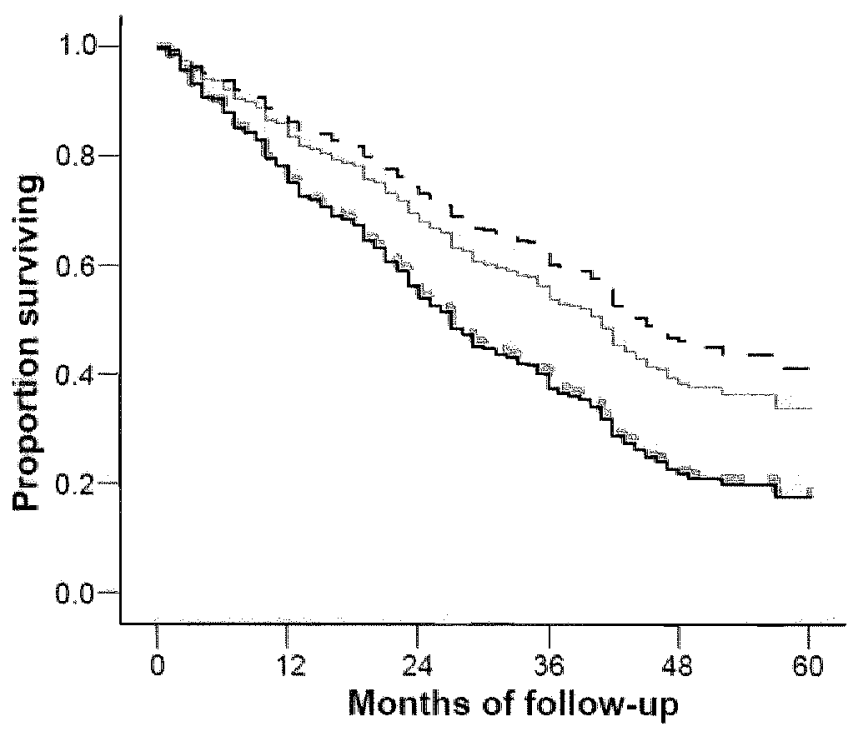

Figure 3: Cox regression plot for survival in different body-composition categories adjusted for age, gender, FMI, FEV, NC, PaOz and PaCO,. Patients with low FFMI [category 1 (cachexia; $n=117$ ), solid black line, and category 3 (muscilo atrophy; $n=40$, dashed grey line)] had a significantly greater risk of mortality risk than did patients with normal FFMI lcategory 2 (semistarvation; $n=23$ ), solid grey line, or category 4 (no impairment; $n=232$ ), dashed black linel. 
and more FM was more striking in men than in women. One could argue that the male patients in the semistarvation category were not truly starving according to the external standards of Schutz et al. (18). However, those patients clearly had lower FM than did patients in categories 3 and 4. Furthermore, in both the men and the women comparison with the reference values of Janssen et al. (19) showed that physical disability risk was clearly lower in categories 3 and 4 , which confirmed previous studies relating those tissue-depletion categories to objective measures of skeletal function and exercise capacity (6-8). As was also indicated by Janssen et al. (19), the SMI cutoffs were a significantly stronger predictor of physical disability in men than in women. This observation could indicate that SMI cutoffs should be adjusted. However, it might also be possible that the association between FFMI and physical disability risk, as judged by a questionnaire, really differs between men and women. This could reflect a different relation of body composition and functional capacity between men and women. It could also reflect a different coping strategy between men and women towards the functional limitations consequent to their chronic disease.

The relative preservation of $F M$ in COPD patients could result from inactivity as a consequence of the progressive disability due to the disease. It could also be a consequence of biological factors such as a derangement in (fat) oxidative metabolism, as indicated by an impaired $\beta$-adrenoceptor-mediated lipolysis, which reduces fat-mobilization (22). That, in turn, could lead to an increase in glucose turnover and protein utilization, as was reflected in an increased whole-body protein turnover (23). The abovementioned shift in body composition could therefore be an indication of either accelerated sarcopenia or an early phase of cachexia. Because cachexia was seen mostly in GOLD IV COPD patients (characterized not only by severe airflow obstruction but also by $\mathrm{PaO}_{2}<8.0 \mathrm{kPa}$ ), the loss of FM on top of FFM might be related to specific effects of hypoxia on energy balance. 
FFM was associated with mortality with and without adjustment for static lung volumes and resting arterial blood gases. These markers are traditionally used to define disease severity and are included in the recent GOLD stages, but that does not exclude the possibility that other lung function markers might affect FFMI or the relationship between FFMI and mortality. In particular, adjustment for the degree of emphysema would have been interesting, because previous studies have shown that FFMI correlated with the diffusing capacity for carbon monoxide as a hallmark of emphysema (6). Furthermore, weight loss and low FFMI were significantly more common in patients with emphysema, as assessed by high-resolution computed tomography, than in patients with chronic bronchitis (24). The process of emphysema might induce weight loss or loss of FFM, but weight loss or loss of FFM also may induce emphysema. Post-mortem studies of persons who died in the Warsaw Ghetto during World War II suggested that death due to starvation was associated with pulmonary emphysema (25). In line with this observation, but using advanced techniques to assess emphysema, an elegant study recently showed the presence of emphysema-like changes in the lungs of chronically malnourished anorexia nervosa patients (5).

On the basis of numerous reports showing an association between BMI and mortality risk in COPD, Celli et al. (26) recently proposed that clinical staging for COPD should be based not only on spirometry and resting arterial blood gases, eg, the recent GOLD criteria, but also on BMI, exercise capacity and dyspnea score. The results of the current study indicate that FFMI could be an even better independent predictor of systemic disease severity than is BMI.

The current study was limited by a skewed distribution of the study population towards more males and the more severe GOLD stages III and IV. In addition, categories 2 and 3 (semistarvation and muscle atrophy) were relatively small. Longitudinal studies with repeated assessments of body composition are needed 
to increase our knowledge of the sequence of body-composition changes so that we can better target therapeutic interventions. In advanced stages of disease, low FFM has already been clearly identified as a primary determinant of perceived disability, handicap, and healthcare costs, and is therefore currently considered as an important target for therapy $(7,17,19,27)$. Recently, several studies have specifically targeted therapeutic interventions at accretion of muscle mass in patients with advanced COPD in order to improve functional capacity (28-33). The current study indicates that therapeutic strategies should depend not on BMI but on body composition. Although studies $(28,29,31,34)$ indicate that current therapeutic modalities can increase FFM, the extent to which improvement in FFM per se is reflected in other relevant other outcome measures, including mortality, and the minimal clinically effective increase in FFM remain to be investigated. 


\section{References}

1. Landbo $\mathrm{C}$, Prescott $E$, Lange $P$, Vestbo $J_{3}$. Almdal TP. Prognostic value of nutritional status in chronic obstructive pulmonary disease. Am $J$ Respir Crit Care Med 1999;160:1856-61.

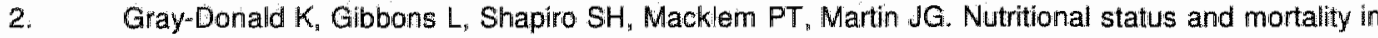
chronic obstructive pulmonary disease. Am J Respir Crit Care Med 1996;153:961-6.

3. Schols AM, Slangen J, Volovics $L$, Wouters EF. Weight loss is a reversible factor in the prognosis of chronic obstructive pulmonary disease. Am J Respir Crit Care Med 1998;157:1791-7.

4. Bray $G A$. Overweight is risking fate. Definition, classification, prevalence, and risks. Ann $\mathbb{N} Y$ Acad Sci $1987: 499: 14-28$.

5. Coxson $H O$, Chan $\mathbb{H}$, Mayo JR, Hlynsky J, Nakano $Y$, Birmingham $C L$. Early emphysema in patients with anorexia nervosa. Am J Respir Crit Care Med 2004;170:748-52.

6. Engelen MPKJ, Schols AMWJ, Baken WC, Wesseling GJ, Wouters EFM. Nutritional depletion in relation to respiratory and peripheral skeletal muscle function in out-patients with COPD. Eur Respir ل1994:7:1793-7.

7. Schols AM, Soeters PB, Dingemans AM, Mostert R, Frantzen PJ, Wouters EF. Prevalence and characteristics of nutritional depletion in patients with stable COPD elligible for pulmonary rehabilitation. Am Rev Respir Dis 1993;147:1151-6.

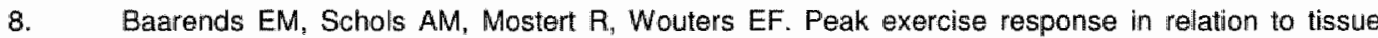
depletion in patients with chronic obstructive pulmonary disease. Eur Respir J 1997;10:28:07-13.

9. Shoup R, Dalsky G, Warner S, et al. Body composition and health-related quality of lite in patients with obstructive airways disease. Eur Respir J 1997;10:1575-80.

10. Marquis $K$, Debigare $R$, Lacasse $Y$, et al. Midthigh muscle cross-sectional area is a better predictor of mortality than bady mass index in patients with chronic obstructive pulmonary disease. Am J Respir Crit Care Med 2002;166:809-13.

11. Lukaski HC, Johnson PE, Bolonchuk WW, Lykken Gl. Assessment of tatmfree mass using bioelectrical impedance measurements of the human body. Am J Clin Nutr 1985;41:810-7.

12. Janssen I. Heymsfield SB, Baumgartner RN, Ross R. Estimation of skeletal muscle mass by bioelectrical impedance analysis. J Appl Physiol 2000;89:465-71.

13. Schols AM, Wouters EF. Soeters PB, Westerterp KR. Body composition by bioelectrical-impedance analysis compared with deuterium dilution and skinfold anthropometry in patients with chronic obstructive pulmonary disease. Am J Clin Nutr 1991;53:421-4.

14. Quanjer PHe. Standardized lung function testing. Official statement of the European Respiratory Society [see comments]. Eur Respir J 1993;6 (suppl.16):1-100.

15. Steiner MC, Barton $\mathrm{RL}$. Singh SJ, Morgan MD. Bedside methods versus dual energy $X$-ray absorptiometry for body composition measurement in COPD. Eur Respir J 2002;19:626-31.

16. Schols AMWd, Fredrix EW, Soeters PB, Westerterp KR, Wouters EFIM. Resting energy expenditure in patients with chronic obstructive pulmonary disease. Am J Clin Nutr 1991;54:983-7.

17. Mostert $R$, Goris $A$, Weling-Scheepers $C$, Wouters EF, Schols AM. Tussue depletion and health related quality of life in patients with chronic obstructive pulmoniary disease. Respir Med $2000 ; 94 ; 859-67$.

18. Sichutz $Y$, Kyle UU, Pichard $C$. Fat-free mass index and fat mass index percentiles in Caucasians aged 18-98 y. Int J Obes Relat Metab Disord 2002;26:953-60. 
19. Janssen I, Baumgartner RN, Ross $\mathrm{R}$, Rosenberg $\mathrm{H}_{3}$, Roubenoff $\mathrm{R}$. Skeletal muscle cutpoints associated with elevated physical disability risk in older men and women. Am $\lrcorner$ Epidemiol 2004;159:413-21.

20. Gasker HR, Engelen MP, van Mameren $H$, et al. Muscle fiber type IIX atrophy is involved in the loss of fat-free mass in chronic obstructive pulmonary disease. Am J Clin Nutr 2002:76:113-9.

21. Seidell JC, Hautvast JG, Deurenberg $P$. Overweight: fat distribution and health risks. Epidemiological observations. A review. Infusionstherapie 1989;16:276-81.

22. Schiffelers $S L$, Blaak EE, Baarends $E M$, et al. beta-Adrenoceptor-mediated thermogenesis and lipolysis in patients with chronic obstructiwe pulmonary disease. Am J Physiol Endocrinol Metab 2001;280:E357-64.

23. Engelen MP, Deutz NE, Wouters EF, Schols AM. Enhanced Levels af Whole-body Protein Turnover in Patients with Chronic Obstructive Pulmonary Disease. Am J Respir Crit Care Med 2000;162:1488-1492.

24. Engelen MP, Schols AM, Lamers RJ, Wouters EF. Different patterns of chronic tissue wasting among patients with chronic obstructive pulmonary disease. Clin Nutr 1999:18:275-80.

25. Stein J, Fenigstein H. Pathological anatomy of hunger disease. In: Winick M, ed. Hunger disease: studies by the Jewish physicians in the Warsaw Ghetto: current concepts in nutrition. New York: John Wiley \& Sons, 1979:207-229.

26. Celli BR, Cote $\mathrm{CG}_{3}$ Marin JM, et al. The body-mass index, airflow obstruction, dyspnea, and exercise capacity index in chronic obstructive pulmonary disease. N Engl J Med 2004;350:1005-12.

27. Bales CW, Ritchie CS. Sarcopenia, weight loss, and nutritional frailty in the elderly. Annu Rev Nutr 2002:22:309-23.

28. Creutzberg EC, Wouters EF, Mostert R, Pluymers RJ, Schols AM. A Role for Anabolic Steroilds in the Rehablitation of Patients With COPD?: A Double-Blind, Placebo-Controlled, Randomized Trial. Chest 2003;124:1733-42.

29. Franssen FM, Broekhuizen R, Janssen PP, Wouters EF, Schols AM. Effects of Whole-Body Exercise Training on Body Composition and Functional Capacity in Normal-Weight Patents With COPD. Chest 2004;125:2021-8.

30. Weisberg $\mathrm{J}$, Wanger $\mathrm{J}$, Olson $\mathrm{J}$, et al. Megestrol acetate stimulates weight gain and ventillation in underweight COPD patients. Chest 2002;121:1070-8

31. Burdet $L$, de Muralt $B$, Schutz $Y$, Pichard $C$, Fitting JW. Administration of growth thormone to underweight patients with chronic obstructive pulmonary disease. A prospective, randomized, controlled study. Am J Respir Crit Care Med 1997;156:1800-6.

32. Pape GS, Friedman M, Underwood LE, Clemmons DR. The effect of growth hormone on weight gain and pulmonary function in patients with chronic obstructive lung disease. Chest 1991;99:1495500.

33. Yeh SS, DeGuzman $\mathrm{B}$, Kramer $\mathrm{T}$. Reversall of COPD-associated weight loss using the anabolic agent oxandrolone. Chest 2002;122:421-8.

34. Schols AM, Soeters PB, Mostert A, Pluymers RJ, Wouters EF. Physiologic effects of nutritional support and anabolic steroids in patients with chronic obstructive pulmonary disease. A placebocontrolled randomized trial. Am \& Respir Crit Care Med 1995;152:1268-74. 


\section{Elevated CRP levels mark metabolic and functional impairment in advanced COPD}

Roelinka Broekhuizen

Emiel F.M. Wouters

Eva C. Creutzberg

Annemie M.W.J. Schols 


\section{Abstract}

\section{Background:}

C-reactive protein (CRP) is often used as clinical marker of acute systemic inflammation. Since low-grade inflammation is evident in chronic diseases like chronic obstructive pulmonary disease (COPD), new methods have been developed to enhance sensitivity of CRP assays in the lower range. We aimed to investigate the discriminative value of high sensitivity CRP in COPD with respect to markers of local and systemic impairment, disability and handicap.

Methods:

Plasma CRP (by high-sensitivity particle-enhanced immunonephelometry), interleukin-6 (IL-6) (by ELISA), body compasition (by bioelectrical impedance analysis), resting energy expenditure (REE: by ventilated hood), exercise capacity (6-minute walking distance, maximal and submaximal bicycle ergometry test), health status (by SGRQ) and lung function were determined in 102 clinically stable COPD patients (GOLD stage II-IV). The cutoff of normal vs. elevated CRP was $4.21 \mathrm{mg} / \mathrm{l}$.

\section{Results:}

CRP was elevated in 48 of 102 patients. In these patients, IL-6 $(p<0.001)$ and REE (adjusted for fat-free mass) ( $p=0.002)$ were higher, while maximal $(p=0.040)$ and submaximal exercise capacity $(\mathrm{p}=0.017)$ as well as 6-minute walking distance $(p=0.014)$ were lower. The symptom score of the SGRQ $(p=0.003)$ was lower in patients with elevated CRP as were postbronchodilator FEV $(p=0.031)$ and reversibility ( $p=0.001$ ). Regression analysis showed that, adjusted for $F E V_{1}$, age and gender, CRP was a significant predictor for body mass index ( $\mathrm{p}=0.044)$ and fat mass index $(p=0.016)$.

\section{Conclusions:}

High sensitivity CRP is a marker for impaired energy metabolism, functional capacity and distress due to respiratory symptoms in COPD. 


\section{Introduction}

Increasing evidence points towards chronic obstructive pulmonary disease (COPD) as a multi-organ systemic disease. Skeletall muscle weakness and wasting and impaired exercise performance have been well described as frequently occurring symptoms in advanced COPD. These features are poorly related to severity of the airflow limitation but appear to be linked to a systemic inflammatory response (1). As reviewed by Gan et al., several systemic inflammatory mediators, like tumor necrosis factor- $\alpha$ (TNFa), some interleukins (ILs), acute phase proteins (C-reactive protein (CRP), fibrinogen, lipopolysaccharide binding protein (LBP)) and leukocytes, are increased in COPD (2). One of the markers of systemic inflammation that is consistently shown to be slightly increased in COPD patients compared to healthy controls is CRP (reviewed in 2). The prevalence of increased CRP in COPD has been examined in the Third National Health and Nutrition Examination Survey (NHANES III), which showed that $41 \%$ of patients with moderate COPD (FEV $1 \geq 50 \%$ pred to $80 \%$ pred) had a CRP above $3 \mathrm{mg} / \mathrm{l}$ and $6 \%$ above $10 \mathrm{mg} /$, while as much as $52 \%$ of patients with severe COPD (FEV $<$ $50 \%$ pred) had CRP above $3 \mathrm{mg} / \mathrm{l}$ and $23 \%$ above $10 \mathrm{mg} / \mathrm{l}(3)$.

COPD patients with slightly elevated CRP levels have not yet been characterized nor have there been studies to explore a potential role of CRP as marker for local or systemic impairments. The aim of the present study was to investigate whether an increased concentration of high sensitivity (HS) CRP is related to the degree of lung function impairment, systemic inflammation, body composition, exercise capacity, energy metabolism and quality of life in patients with advanced COPD. 


\section{Subjects and methods}

\section{Subjects}

Patients with clinically stable COPD, consecutively admitted to an inpatient pulmonary rehabilitation center (Asthma Center Hornerheide, Horn, the Netherlands), were included if they met the criteria for COPD of the American Thoracic Society (ATS) (4). Patients were excluded if suffering from concurrent diseases such as malignancies "gastrointestinal or kidney abnormalities, metabolic or endocrine diseases and inflammatory diseases since elevated CRP levels have also been described in these conditions. Twenty age-matched healthy volunteers were recruited from an advertisement in a local newspaper for baseline cytokine measurement. Prior to inclusion, the healthy controls were fully physically examinated by a chest physician for lung impairment, cardiovascular disease, diabetes, or other diseases.

\section{Pulmonary function}

Forced expiratory volume in one second $\left(F E V_{1}\right)$, forced vital capacity (FVC) and inspiratory vital capacity (IVC) were calculated from the flow volume curve using a spirometer (Masterlab, Jaeger, Würzburg, Germany). The highest value of at least three measurements was used. $\mathrm{FEV}_{1}$ was also calculated $15 \mathrm{~min}$ after inhalation of a $\beta$-agonist via a metered-dose inhaler. Diffusing capacity for carbon monoxide (DLco) was determined using the single breath method (Masterlab, Jaeger, Würzburg, Germany). Lung functional parameters were expressed as percentage of reference values (5). For arterial blood gas analysis" blood was drawn from the brachial artery while the patients were breathing room air or using their oxygen therapy when indicated $(n=16)$. Arterial oxygen tension $\left(\mathrm{PaO}_{2}\right)$ and carbon dioxide tension $\left(\mathrm{PaCO}_{2}\right)$ were analyzed with a blood gas analyzer (Radiometer, $\mathrm{ABL} 330$, Copenhagen, Denmark). 


\section{Body compasition}

Body mass index (BMI) was calculated as weight divided by height ${ }^{2}\left(\mathrm{~kg} / \mathrm{m}^{2}\right)$. Fatfree mass ( $F F M_{;} \mathrm{kg}$ ) was estimated using single frequency $(50 \mathrm{kHz}$ ) bioelectrical impedance analysis (BIA; Xitron Technologies, San Diego, CA, USA), with subjects in supine position and calculated using the COPD-specific equation (6). FFM index (FFMI) was calculated as FFM divided by height ${ }^{2}\left(\mathrm{~kg} / \mathrm{m}^{2}\right)$. Fat mass ( $\mathrm{FM}^{*} \mathrm{~kg}$ ) was estimated as total body weight minus FFM. Percentage FM was calculated by dividing FM by total body weight * $100 \%$.

\section{Energy expendifure}

Resting energy expenditure (REE) was measured in the early morning 108.30 hours) by indirect calorimetry using a ventilated hood (Oxycon Beta; Jaeger, Würzburg, Germany) after at least 10 hours of fasting. When patients were on additional oxygen during rehabilitation, the oxygen was temporarily withdrawn 30 min before and during measurement of REE. REE was calculated from oxygen consumption $\left(\mathrm{VO}_{2}\right)$ and carbon dioxide production $\left(\mathrm{VCO}_{2}\right)$ using the abbreviated Weir formula (7). The ratio of REE and FFM was used for statistical analysis.

\section{Blood sampling}

Fasting EDTA blood was collected in the early morning (08.00-10.00 hours). Soluble tumor necrosis factor receptor 55 (STNF-R55) and STNF-A75 were measured in duplicate using the enzyme-linked immunosorbent assay (ELISA) protocol as previously described by Leeuwenberg et al. (8). Lower detection limits for the essays were $40 \mathrm{ng} / \mathrm{ml}$ for sTNF-R55, and $70 \mathrm{ng} / \mathrm{ml}$ for STNF-R75. IL-6 and TNFa were determined in duplicate with a Quantikine high sensitivity $E L I S A$ (R\&D Systems, Minneapolis, USA) with lower detection of $0.039 \mathrm{pg} / \mathrm{ml}$ for $\| \mathrm{L}-6$ and 0.5 $\mathrm{pg} / \mathrm{ml}$ for total TNFa. CRP was assessed in duplicate by high-sensitivity particleenhanced immunonephelometry ( $\mathrm{N} \mathrm{Hs}$ CRP, Dade Behring) with a lower detection limit of $0.159 \mathrm{mg} / \mathrm{l}$. 


\section{Exercise performance}

Incremental bicycle ergometry test

An incremental bicycle ergometry test was performed on an electromagnetic braked ergometer (Corival 400, Lode, Groningen, Netherlands). After $2 \mathrm{~min}$ of resting and 1 min unloaded cycling, power was increased every minute by $10 \mathrm{~W}$. None of the subjects knew the exercise load and all were encouraged to cycle at 60 revs/min untill exhaustion. Of the patients who did not desaturate $\left(\mathrm{PaO}_{2}<88 \%\right)$ during the exercise tests $(n=63)$, oxygen consumption $\left(\mathrm{VO}_{2}\right)$ and carbon dioxide $\left(\mathrm{VCO}_{2}\right)$ were measured and calculated from breath by breath analysis using a breathing mask (Oxycon Beta, Jaeger, Würzburg, Germany).

\section{Submaximal bicycle ergometry test}

The patients performed a submaximal bicycle test of $2 \mathrm{~min}$ unloaded cycling, 10 min at $50 \%$, followed by maximally $20 \mathrm{~min}$ at $70 \%$ of individually measured peak workload of the incremental bicycle ergometry test to assess total endurance time and net mechanical efficiency. Mechanical efficiency was calculated with the following equation:

Net mechanical efficiency $(9)=[$ load $(W)$ of exercise * $0.01433(\mathrm{kcal} / \mathrm{min}) /(\mathrm{energy}$ expenditure during exercise (at $50 \%$ of peak workload) -REE)(kcal/min)] ${ }^{*} 100 \%$

Energy expenditure during exercise mentioned in the equation was calculated using the steady state values of $\mathrm{VO}_{2}$ and $\dot{\mathrm{VCO}}_{2}$ and the abbreviated Weir formula (7). A good reproducibility of this method in COPD patients was described earlier $(10)$.

\section{6-minute walking distance}

Exercise performance was also measured using a 6-minute walk test according to a standardized protocol (11). 
Health related quality of life

Health related quality of life was measured by the St. George's Respiratory Questionnaire (SGRQ). The SGRQ consists of three subcategories: symptoms (distress due to respiratory symptoms), activity (disturbance of physical activity), impact (overall impact on daily life and well-being) that combine into the total score (mean of the three subcategories). Subscores ranged from 0-100, with a high score meaning greater impairment. A difference of four points in total score is considered clinically significant (12).

\section{Statistical analysis}

The median (range) CRP level of healthy age-matched controls was $1.82(0.16$, 7.09) $\mathrm{mg} / \mathrm{l}$. The cutoff of normal vs. elevated CRP level was determined at 4.21 $\mathrm{mg} / \mathrm{l}$, which was the 95th percentile of the GRP values of these healthy controls.

Results are presented as mean ( \pm standard deviation (SD)) for all variables that were normally distributed and as median (range) when not-normally distributed. Differences between the groups (normal vs. elevated CRP) were analyzed by the Student's $t$-test for independent samples and the Mann Whitney $U$ test when not-normally distributed. Regression analysis, adjusting for FFM (when appropriate), lung function (post-bronchodilatation (\%pred) and diffusion capacity (\%pred)), age and gender, was used to establish the variables that were influenced by (logtransformed, $\log _{10}$ ) CRP. Results are presented as regression coefficient ( $\beta$ ) $(95 \%$ confidence interval of $\beta)$ ). Stepwise regression was used to select the variables that influence $\left(\log _{10}\right)$ CRP. Correlations between parameters were calculated with either Pearson or Spearman's correllation test. Data were analyzed using SPSS (Statistical Package for the Social Sciences, version 11.0 for Windows, SPSS Inc., Chicago, IL, USA). Significance was assumed at a p-value of less than 0.05 


\section{Results}

One hundred and two ( $71 \mathrm{men} / 31$ women) COPD patients (mean age: $63( \pm 9)$ years) were included; of whom 22 had GOLD stage 11,37 GOLD stage III and 43 GOLD stage IV COPD. Patients were using the following pulmonary maintenance medication: $89 \% \mathrm{~B}_{2}$-sympaticomimetics, $37 \%$ theophylline, $76 \%$ ipratropium bromide, $30 \%$ oral corticosteroids, $58 \%$ inhalation corticosteroids and $58 \%$ oral $\mathrm{N}$ acetylcysteine.

Table 1: Lung function and body composition of patients with normal vs. elevated CRP'

\begin{tabular}{|c|c|c|c|c|c|c|}
\hline & & \multicolumn{2}{|c|}{ Normal } & \multicolumn{2}{|c|}{ Elevated } & \multirow{2}{*}{$\begin{array}{l}\text { p-value } \\
0.122\end{array}$} \\
\hline$n$ & $(M / F)$ & 54 & $(34 / 20)$ & 48 & $(37111)$ & \\
\hline $\mathrm{Age}^{2}$ & (vrs) & 61.3 & $( \pm 10.2)$ & 64.7 & $( \pm 8.0)$ & 0.062 \\
\hline Smoking history & (PY) & 30.0 & $(0,80)$ & 35.0 & $(0,125)$ & 0.777 \\
\hline \multicolumn{7}{|c|}{ Bady composition } \\
\hline BMI & $\left(\mathrm{kg} / \mathrm{m}^{2}\right)$ & 21.9 & $( \pm 4.1)$ & 228 & $( \pm 3.3)$ & 0.209 \\
\hline FFMI & $\left(\mathrm{kg} / \mathrm{m}^{2}\right)$ & 15.8 & $( \pm 2.1)$ & 16.1 & $( \pm 1.7)$ & 0.363 \\
\hline FM & $(\%)$ & 270 & $( \pm 7.8)$ & 28.9 & $( \pm 6.3)$ & 0.191 \\
\hline \multicolumn{7}{|l|}{ Lung function } \\
\hline$F E V,(p r e)$ & (\%pred) & 35.9 & $( \pm 14.3)$ & 33. 1 & $( \pm 12.4)$ & 0,294 \\
\hline FEV (post) & (\%pred) & 39.9 & $( \pm 15.3)$ & 33.8 & $( \pm 12.2)$ & 0.031 \\
\hline FVG & (\%pred) & 780 & $( \pm 17.9)$ & 75.3 & $( \pm 18.7)$ & 0.472 \\
\hline Reversibility & (\%opred) & 29 & $(-83,13.0)$ & 0.0 & $(7.2,8.7)$ & 0.001 \\
\hline FEV, FVO & $(1 \%)$ & 36 & $( \pm 9)$ & 35 & $( \pm 9)$ & 0.366 \\
\hline $\mathrm{DL}_{\mathrm{CO}}$ & $(\%$ pred) & 50.7 & $( \pm 19.7)$ & 47.4 & $( \pm 20.2)$ & 0.423 \\
\hline $\mathrm{PaO}_{2}$ & (kPa) & 9,34 & $( \pm 1,26)$ & 9.17 & $(4,1,15)$ & 0.460 \\
\hline $\mathrm{PaCO}_{2}$ & (kPa) & 5.49 & $( \pm 0.87)$ & 5.48 & $( \pm 0.87)$ & 0.538 \\
\hline
\end{tabular}


The median value (range) of CRP in COPD patients was $3.47(0.36,75.60) \mathrm{mg} /$. Twenty-six (25\%) patients had a CRP level higher than $10 \mathrm{mg} / \mathrm{l}$ (median (range): $21.25(11.5,75.6) \mathrm{mg} / \mathrm{l})$. Patients with GOLD stage III and IV had significantly higher CRP levels than patients with GOLD stage II [II: $1.92(0.36,16.00)$; III: 4.43 $(0.47,75.60)$; IV: $4.90(0.47,65.70)$; both $p<0.03]$.

CRP was elevated (higher than $4.21 \mathrm{mg} / \mathrm{l})$ in $47 \%$ of the 102 patients ( $37 \mathrm{men} / 11$ women), who had median CRP of 12.50 (range: $4.29,75.60$ ) $\mathrm{mg} / \mathrm{l}$. Patients with normal CRP (34 men/ 20 women) had median CRP of $1.49(0.36,4.07) \mathrm{mg} / \mathrm{l}$. Table 1 compares BMI, body composition and lung function of patients with normal vs. elevated CRP. Age, gender, smoking history and body composition were not significantly different between the two groups. $\mathrm{FEV}_{1}$ (post-bronchodilator) was more impaired in the patients with elevated CRP $(p=0.031)$. In addition, patients with elevated CRP had less reversible $\mathrm{FEV}_{1}$ than patients with normal CRP $(p=0.001)$,

CRP was moderately inversely correlated with FEV (post-bronchodilator) $(r=-0.22, p=0.026)$ and reversibility $(r=-0.35, p<0.001)$. No differences were found between patients with elevated and normal CRP in maintenance medication or long-term oxygen therapy $(n=16)$.

Table 2: Inflammatory markers in patients with normal and elevated CRP and in healihy controls

\begin{tabular}{|c|c|c|c|c|}
\hline & & COPI & & Controls \\
\hline & & Normal CRP & Elevated CAP & \\
\hline TNFa & $(\mathrm{pg} / \mathrm{ml})$ & $1.25(0.60,3.42)$ & $1.31(0.43,3.19)$ & $1.23(0.74,2.70)$ \\
\hline STNF-R55 & $(\mathrm{ng} / \mathrm{ml})$ & $0.87(0.54,2.51)^{2}$ & $1,00(0.591,2.20)^{b}$ & $0.88(0.59,1,46)^{0}$ \\
\hline STNF-R75 & $(\mathrm{ng} / \mathrm{ml})$ & $1.42(0.81,3.39)^{\mathrm{a}, \mathrm{b}}$ & $1.54(0.84,3.33)^{\mathrm{a}}$ & $1,14(0.68,1.82)^{b}$ \\
\hline$\| L-6$ & $(\mathrm{pg} / \mathrm{ml})$ & $2.60(1.00,11.45)^{\mathrm{a}}$ & $6.45(0.90,12.85)^{6}$ & $1.76(0.81,6.00)$ \\
\hline
\end{tabular}


Inflammatory markers are shown in table 2. IL-6 was increased in patients with elevated CRP $(p<0.001)$ and correlated with CRP $(r=0.59, p<0.001)$. In addition, sTNF-R55 was higher in patients with elevated CRP $(\mathrm{p}=0.024)$ and also correlated mildly with CRP $(r=0.25, p=0.012)$, whereas TNFa and receptor 75 were not significantly different between the CRP groups. COPD patients of both groups had increased IL-6 compared to healthy controls (both $p<0.005$ ). Soluble TNF-R75 was significantly increased in patients with elevated CRP ( $\mathrm{P}=0.003)$ and tended to be increased in patients with normal CRP $(p=0.056)$ compared to healthy controls.

Table 3: Exercise parameters in COPD patients with normal and elevated CRP

\begin{tabular}{|c|c|c|c|c|c|c|}
\hline & & \multicolumn{2}{|c|}{ Normal } & \multicolumn{2}{|c|}{ Elevated } & p-value \\
\hline \multicolumn{7}{|c|}{ Incremental ergometry } \\
\hline Workload? & $(\mathrm{W})$ & 63.0 & $( \pm 29.3)$ & 51.8 & $( \pm 24.0)$ & 0.040 \\
\hline Load/FFM & (W/kg) & 1.38 & $( \pm 0.59)$ & 1.11 & $( \pm 0,49)$ & 0.015 \\
\hline $\mathrm{VO}_{2}$ & $(\mathrm{~m} / \mathrm{min})$ & 996 & $( \pm 333)$ & 894 & $( \pm 268)$ & 0.116 \\
\hline $\mathrm{VCO}_{2}$ & $(\mathrm{~m} / \mathrm{min})$ & 989 & $( \pm 395)$ & 865 & $(+288)$ & 0.095 \\
\hline RER & & 0.98 & $( \pm 0.11)$ & 0.96 & $(+0.09)$ & 0.472 \\
\hline & $(V$ min $)$ & 38.6 & $( \pm 13.0)$ & 37.3 & $( \pm 10.3)$ & 0.629 \\
\hline $\mathrm{VE} / \mathrm{VO}_{2}$ & & 39.4 & $( \pm 7.1)$ & 42.9 & $( \pm 8.6)$ & 0.046 \\
\hline $\mathrm{VO}_{2} / \mathrm{load}$ & $(\mathrm{m} / \mathrm{w})$ & 149 & $(8,2,43,2)$ & 16.2 & $(10.1,27.9)$ & 0.056 \\
\hline $\mathrm{VCO}_{\mathrm{a} / \mathrm{lod}}$ & $(\mathrm{m} / \mathrm{w})$ & 14.7 & $(7.2 .35 .7)$ & 15.9 & $(10.6,279)$ & 0.133 \\
\hline \multicolumn{7}{|c|}{ Submaximal ergometry } \\
\hline Duration tim & $(\mathrm{min})$ & 13 & $(3,30)$ & 8 & $(2,30)$ & 0.017 \\
\hline Efficiency & $(\%)$ & 16.2 & $(5.5,25.5)$ & 14.2 & $(8,1,19,4)$ & 0,138 \\
\hline \multicolumn{7}{|c|}{ 6-min walking distance } \\
\hline Distance & (m) & 355 & $( \pm 120)$ & 301 & $( \pm 96)$ & 0.014 \\
\hline
\end{tabular}

'FFM: fat-free mass; $\mathrm{VO}_{2}$ : oxygen consumption; $\mathrm{V} \mathrm{O}_{2}$ : carbon dioxide production; RER: respiratory exchange ratio; VE: ventilation. All parameters of the incremental ergometry test are shown as peak values.

${ }^{2}$ Values are mean $( \pm S D)$.

${ }^{3}$ Values are median (range). 
Exercise capacity was assessed with three tests (table 3). In all three tests, exercise capacity was more impaired in the group of COPD patients with elevated CRP relative to patients with normal CRP $(p<0.04)$. Log 10 CRP was moderately inversely correlated with load/FFM $(r=-0.25, p=0.012), 6$-minute walking distance $(r=-0.27, p=0.007)$ and duration time $(r=-0.29, p=0.010)$.

Resting energy expenditure (REE) adjusted for FFM was increased in patients with elevated CRP levels (elevated CRP: $31.4( \pm 5.4) \mathrm{kcal} / \mathrm{kg}$, normal CRP: $28.0( \pm 4.8)$ $\mathrm{kcal} / \mathrm{kg} ; \mathrm{p}=0.002$ ) (figure 1). CRP was positively correlated with REE/FFM ( $r=0.31$, $p=0.002)$ and with REE $(r=0.41, p<0.001)$.

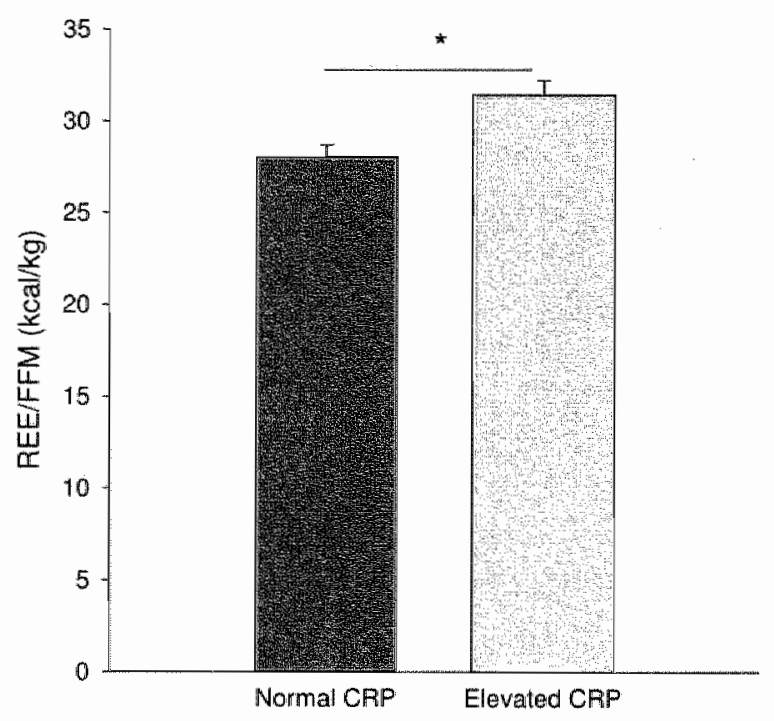

Figure 1: Resting energy expenditure (REE) adjusted for fat-free mass (FFM) is increased in patients with elevated CRP compared with patients with normal CRP. Data are presented as mean (SEM). ": p<0.002 
Figure 2 shows the scores on health status of both groups. Patients with elevated CRP tended to have higher total score on the SGRQ (elevated CRP: $51.5( \pm 13.9)$ points, normal CRP: 47.0 ( \pm 10.9 ) points; $p=0.095$; difference of 4.5 points) than patients with normal CRP. A difference of four points is considered climically significant (12). Patients with elevated CRP had a significant higher score on the symptom domain compared to patients with normal CRP (elevated CRP: 64.7 $( \pm 16.5)$ points, normal CRP: $54.2( \pm 17.1)$ points; $p=0.003)$.

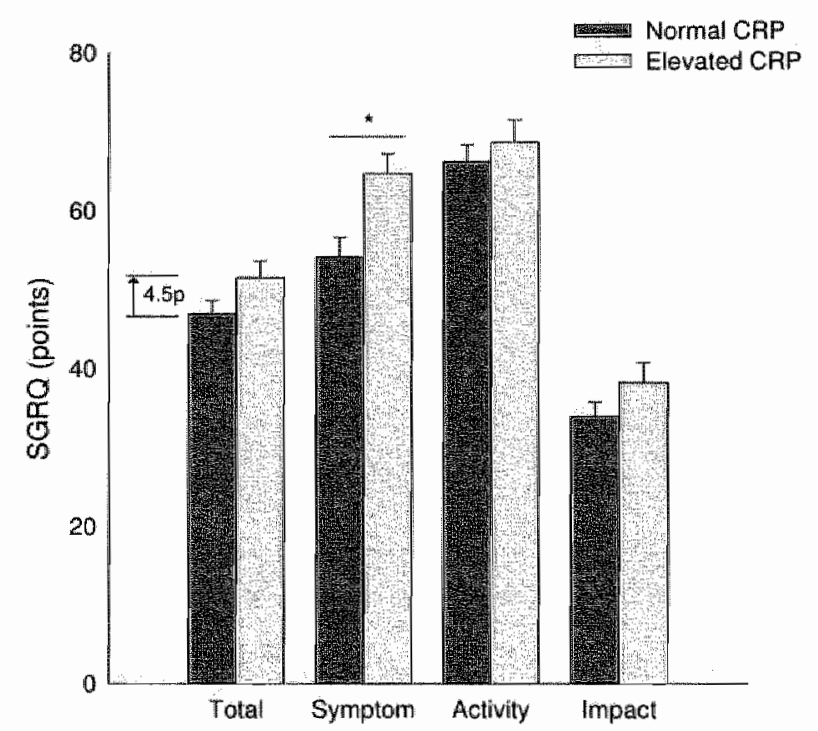

Figure 2: Patients with elevared CRP have impaired quality of life as measured with the St. George's Respiratory Questionnaire. The total score was 4.5 points higher in patients with elevated CRP. Data are presented as mean (SEM). : $p=0.003$

Regression analysis, adjusting for $\mathrm{FEV}_{1}$ (post-bronchodilation), $\mathrm{DL} \mathrm{L}_{\mathrm{C}}$, age, FFM and gender, revealed that $\log _{10} \mathrm{CRP}$ was a significant and independent predictor for time cycled during submaximal ergometry $(\beta=-3.105(95 \% \mathrm{Cl}:-5.986,-0.224)$, $p=0.035)$. $\log _{10}$ CRP also was a significant predictor for $R E E(\beta=164$ (95\% Cl: 91 , 236), $p<0.001)$, IL-6 $(\beta=3.409(95 \% \mathrm{Cl}: 2.308,4.504), p<0.001)$, postbroncho- 
dilation $\mathrm{FEV}_{1}(\beta=-5.48(95 \% \mathrm{Cl}:-10.30,-0.66), p<0.026)$ and reversibility $(\beta=-2.52$ $(95 \% \mathrm{Cl}:-4.38,-0.66), p=0.008)$. In addition, $\log _{10} \mathrm{CRP}$ seemed to be a significant predictor for the symptom score of the SGRQ $(\beta=8.28(95 \% \mathrm{Cl}: 1.35,15.22)$, $p=0.020$ ). Interestingly, $\log _{10}$ CRP also seemed to be a significant predictor of BMI $(\beta=1.38(95 \% \mathrm{Cl}: 0.04,2.71), P=0.044)$, which was a reflection of the relation of CRP with FMI ( $\beta=1.103(95 \% \mathrm{Cl}: 0.213,1.994)$, $p=0.016)$ but not of FFMI ( $\beta=0.27$ ( $95 \% \mathrm{Cl}:-0.37,0.91), p=0.400$ ). The observation that body composition did not differ between the groups (table 1) can be explained by the different distribution in men and women.

Stepwise regression showed that IL-6 $(\beta=0.075$ (95\% Cl: $0.041,0.109), p<0.001)$, REE $(\beta=0.0006(95 \% \mathrm{Cl}: 0.000,0.001), p=0.035)$ and 6 -minute walking distance $(\beta=-0.0012(95 \% \mathrm{Cl}:-0.002,0.000), p=0.020)$ were selected as predictors of $\log _{10}$ CRP.

\section{Discussion}

The aim of this study was to characterize COPD patients with elevated CRP with respect to lung function, systemic inflammation, body composition, exercise capacity, energy metabolism, and quality of life. The main findings were that, irrespective of $F E V_{1}$, COPD patients with elevated plasma CRP concentration had increased impairment in energy metabolism, increased disability as defined by impaired exercise capacity, and more distress due to respiratory symptoms than patients with normal CRP. In addition, patients with elevated CRP had lower postbronchodilator $F E V_{1}$ related to less reversibility in $F E V_{1}$ after inhalation of a $\beta$ agonist than patients with normal CRP.

Reports on the relation of CRP with lung function are not very consistent. Results from NHANES III excluding patients with COPD, showed an inverse relation 
between systemic CRP and $\mathrm{FEV}_{1}$ (13). This was also found in the Caerphilly Prospective Heart Disease Study, including only male patients with ischaemic heart disease (14). Although a smaller study did not find a correlation between CRP and lung function in patients with mild to severe COPD (15), CRP seems to increase with increasing severity of $\operatorname{COPD}(3,16)$. In this study, we also found a more impaired postbronchodilator $\mathrm{FEV}_{1}$ and reversibility in patients with elevated systemic CRP. Although the exact origin of systemic inflammation remains to be explored, lung biopsy examination clearly illustrates that local inflammation is more pronounced with worse lung function (17). The higher level of systemic inflammation in COPD patients with low reversibility suggests a more inflammationdriven airflow limitation although no direct data of local inflammation are obtained in our study. However, at least two other studies in the stable state have not demonstrated a direct relationship between the pulmonary and systemic compartment suggesting that pulmonary and systemic inflammation may be modulated separately (18). Interestingly, diffusing capacity was not different between both groups, suggesting that exercise-induced intermittent hypoxemia was not different between both groups. Differences in the presence of sputum potentially pathogenic micro-organisms could be hypothesized as another difference between both COPD groups as it has been demonstrated previously that the presence of sputum potentially pathogenic micro-organisms in stable COPD patients has been associated with greater systemic inflammation (19). Future studies are needed to explore the relationship between the systemic inflammatory response and the level of pulmonary inflammation.

The association between CRP and IL-6 is well established. Previously, IL-6 was identified as 'exercise factor', being produced by contracting muscle and subsequently released into the blood. Under normal circumstances, the IL-6 gene is rapidly activated during exercise. It has been shown that IL-6 gene transcription is mediated by glycogen content (20) and that increased IL-6 expression is 
associated with increased glucose uptake during exercise (21). Therefore, IL-6 is thought to act as an energy sensor in response to exercise. When contracting muscles are low in glycogen, $\mathrm{L}-6$ is released to increase glucose uptake and induce lipolysis and gene transcription in abdominal subcutaneous fat (21). However, it has also been shown that murine myotubes express IL-6 when exposed to oxidative stress (22) and that oral supplementation with antioxidants can attenuate exercise-induced plasma IL-6 in healthy humans (23). Fisher et al. have shown that supplementation of vitamin $C$ in combination with vitamin $E$ resulted in lower exercise-induced plasma IL-6 levels, while no differences were found in muscle IL-6 mRNA nor in skeletal muscle IL-6 protein expression. This suggests that the release of IL-6 from the muscle was inhibited by the antioxidants (23).

In COPD, several changes have been reported that can influence the above-mentioned process. First of all, in some COPD patients, decreases in oxidative enzymes involved in carbohydrate and fatty acid oxidation have been reported (24). Furthermore, it has been shown that some COPD patients have impaired muscle glycogen content due to inactivity (25) and hypoxia (26) and thave enhanced lactic acid production during cycling as compared to healthy control subjects (27). Systemically, COPD patients also have an imbalance between oxidants and antioxidants in rest, but also after exercise, suggestive of increased oxidative stress (28). Moreover, Rabinovich et al. have shown that COPD patients cannot adapt their muscle redox status to training as healthy controls do (29).

We hypothesize that these changes could disturb the normal exercise-inducted rise in IL-6 in COPD via an earlier and exacerbated induction of IL-6 at lower exercise load. IL-6 would thus be a marker for impairment of exercise metabolism. Imbalances between oxidants and antioxidants could independently of muscleintrinsic changes increase the IL-6 release. Because IL-6 is a strong inducer of acute phase proteins (30), the exacerbated increase in IL-6 production of muscle 
could induce CRP, as is illustrated by the strong correlation of CRP and IL-6 in this study. Such an increase in CRP after exercise has in fact been shown in healthy subjects (23). Other studies have also shown an inverse relation between CRP and exercise capacity in healthy elderly (31) as well as in COPD (28).

The increased demand for specific amino acid to generate CRP may increase muscle protein breakdown, increasing REE (32) and inducing a vicious cycle of intrinsic muscle changes leading to decreased exercise capacity leading to more muscle impairment. CRP may thus be a marker of repetitive supra-physiological increase in IL-6 production of muscle in a subgroup of COPD patients. Prior research has also shown an association between systemic inflammation as measured by markers of the TNF-system and weight loss (33). In this study, we showed an association between CRP and BMI (when adjusted for FEV (post: $^{\text {B }}$ bronchodilation), $\mathrm{DL}_{\mathrm{CO}}$, age and gender) that could be attributed to $\mathrm{FMl}$, but not to FFMI. The assaciation between CRP and extent of obesity has previously been found in studies with non-diabetic subjects (34). It has been proposed that inflammatory cytokines could be secreted by adipocytes and by inflammatory cells present in adipose tissue (35). Further research is needed to further elucidate the role of different cytokines on body composition and vice versa.

The cutoff used in this study is not the standard cutoff of $5 \mathrm{mg} /$, which is often used in clinical practice. Interestingly, our cutoff, determined as the 95th percentile of our own healthy age- and gender-matched controls, is very similar to the clinical cutoff. In addition, analysis using 3 or $5 \mathrm{mg} / \mathrm{l}$ as cutoff provided the same results (data not shown).

High sensitivity CRP analysis already has been recommended for clinical application in cardiovascular disease detection and prevention (36). Given the fact that cardiovascular disease is a major cause of mortality in COPD (37), combined 
with the facts that CRP is a predictor for acute exacerbations of COPD (38), for hospitalization and mortality in chronic respiratory failure (39), as well as the fact that CRP seems to be a marker for impairments in exercise capacity and distress due to respiratory symptoms as shown in this study, routine HS-CRP analysis could prove itself to be of major clinical importance in COPD. Future research is needed to assess the value of CRP as biomarker for measuring progress of the disease and for the effects of treatment of COPD. 


\section{References}

1. Skeletal muscle dysfunction in chronic obstructive pulmonary disease. A statement of the American Thoracic Society and European Respiratory Society. Am J Respir Crit Care Med 1999;159:S1-40.

2. Gan WQ, Man SF, Senthilselvan A, Sin DD. Association between chronic obstructive pulmonary disease and systemic inflammation: a systematic review and a meta-analysis. Thorax 2004;59:57480.

3. Mannino DM, Ford ES, Redd SC. Obstructive and restrictive lung disease and markers of inflammation: data from the Third National Health and Nutrition Examination. Am $\downarrow$ Med 2003;114:758-62.

4. ATS. Standards for the diagnosis and care af patients with chronic obstructive pulmonary disease. American Thoracic Society. Am J Respir Crit Care Med 1995;152:S77-121.

5. Quanjer PHe. Standardized lung function testing. Official statement of the European Respiratory Society [see comments]. Eur Respir J 1993;6 (suppl.16):1-100.

6. Steiner MC, Barton RL, Singh $5 J$, Morgan MD. Biedside methods versus dual energy $X$-ray absorptiometry for body composition measurement in COPD. Eur Fespir J 2002:19:626-31.

7. Weir JB. New methods for calculating metabolic rate with special reference to protein metabolism. 1949. Nutrition 1990;6:213-21.

8. Leeuwenberg JF, Jeunhomme TM, Buurman WA. Slow release of soluble TNF receptors by monocytes in vitro. J immunol 1994;152:4036-43.

9. Gaesser GA, Brooks GA. Muscular efficiency during steady-rate exercise: effects of speed and work rate. J Appl Physiol 1975;38:1132-9.

10. Baarends EM, Schols AM, Akkermans MA, Wouters EF. Decreased mechanical efficiency in clinically stable patients with COPD. Thorax 1997;52:981-6.

11. ATS statement: guidelines for the six-mimute walk test. Am J Respir Crit Care Med 2002;166:111-7.

12. Jones PW. Issues concerning health-related quality of life in COPD. Chest 1995;107:187S-193S.

13. Cirillo DJ, Agrawal Y, Cassano PA. Lipids and pulmonary function in the Third National Health and Nutrition Examination Survey. Am J Epidemiol 2002;155:842-8

14. Mendall MA, Strachan DP, Butland BK, et al. C-reactive protein. relation to total mortality, cardiovascular mortality and cardiovascular risk factors in men. Eur Heart $\mathrm{J}$ 2000;21:1584-90.

15. Dentener MA, Creutzberg EC, Schols AM, et al. Systemic anti-inflammatory mediators in COPD: increase in soluble interleukin I receptor II during treatment of exacerbations. Thorax $2001: 56: 721$. 6.

16. Sin DD, Man SF. Why are patients with chronic obstructive pulmonary disease at increased risk of cardiovascular diseases? The potential role of systemic inflammation in chronic obstructive pulmonary disease. Circulation 2003;107:1514-9.

17. Hogg JC, Chu F, Utokaparch $S$, et al. The nature of smallmairway obstruction in chronic obstructive pulmonary disease. N Engl J Med 2004;350:2645-53.

18. Vernooy $\mathrm{JH}$, Kucukaycan $\mathrm{M}$, Jacobs JA, et al. Local and systemic inflammation in patients with chronic obstructive pulmonary disease: soluble tumor necrosis factor receptors are increased in sputum. Am J Respir Crit Care Med 2002;166:1218-24.

19. Banerjee $D$, Khair $O A$, Honeybourne D. Impact of sputum bacteria on airway inflammation and health status in clinical stable COPD. Eur Respir J 2004;23:685-91. 
20. Keller $C$. Steensberg $A$, Pilegaard $H$, el al. Transcriptional activation of the L L- 6 gene in human contracting skeletal muscle: influence of muscle glycogen content. Faseb J 2001;15:2748-50.

21. Pedersen $B K$, Steensberg A, Fischer $C$, et al. The metabolic role of IL- 6 produced during exercise: is IL-6 an exercise factor? Proc Nutt Soc 2004;63:263-7.

22. Kosmidou 1, Vassilakopoulos T, Xagorari A, Zakynthinos S, Papapetropoulos A, Roussos C. Production of interleukin- 6 by skeletal myotubes: role of reactive oxygen species. Am $\downarrow$ Respir Cell Mol Biol 2002;26:587-93.

23. Fischer $C P$, Hiscock $N J$, Penkowa $M$, et al. Supplementation with vitamins $C$ and $E$ inhibits the release of interleukin-6 from contracting human skeletal muscle. J Physiol 2004;558:633-45.

24. Maltais $F$, LeBlanc $P$, Whitom $F$, et all. Oxidative enzyme activities of the wastus lateralis muscle and the functional status in patients with COPD. Thorax 2000;55:848-53.

25. Engelen MP, Schols AM, Does JD, Gosker HR, Deutz NE, Wouters EF. Exercise-induced lactate increase in relation to muscle substrates in patients with chronic obstructive pulmonary disease. Am $\downarrow$ Respir Crit Care Med 2000;162:1697-704.

26. Jakobsson $P$, Jorfeldt L, Brundin A. Skeletal muscle metabolites and fibre types in patients with advanced chronic obstructive pulmonary disease (COPD), with and without chronic respiratory failure. Eur Respir J 1990;3:192-6.

27. Maltais F, Simard AA, Simard C, Jobin J, Desgagnes $P$, LeBlane P. Oxidative capacity of the skelletal muscle and lactic acid kinetics during exercise in normal subjects and in patients with COPD. Am J Respir Crit Care Med 1996;153:288-93.

28. Koechlin $C$, Couillard A, Cristol JP, et al. Does systemic inflammation trigger local exercise-Induced oxidative stress in COPD? Eur Respir $ل$ 2004;23:538-44.

29. Rabinovich RA, Ardite E, Troosters T, et al. Reduced muscle redox capacity after endurance training in patients with chronic obstructive pulmonary disease. Am J Respir Crit Care Med 2001:164:1114-8.

30. Kishimoto T. The biology of interleukin-6. Blood 1989;74:1-10.

31. Geffken DF, Cushman $M_{n}$ Burke GL, Polak JF, Sakkinen PA, Tracy RP. Association between physical activity and markers of inflammation in a healthy elderly population. Am $\mathrm{J}$ Epidemiol $2001 ; 153: 242-50$.

32. Reeds PJ, Fjeld CR, Jahoor F. Do the differences betweer the amino acid compositions of acutephase and muscle proteins have a bearing on nitrogen loss in traumatic states? J Nutr $1994 ; 124: 906-10$.

33. Di Francia $M_{4}$ Barbier D, Mege JL, Orehek. J. Tumor necrosis factor-alpha levels and weight loss in chronic obstructive pulmonary disease. Am J Respir Crit Care Med 1994;150:1453-5.

34. Yudkin JS, Stehouwer CD, Emeis JJ, Coppack SW. C-reactive protein in healthy subjects: associations with obesity, insulin resistance, and endothelial dysfunction: a potential role for cytokines originating from adipose tissue? Arterioscler Thromb Vasc Biol 1999;19:972-8.

35. Weisberg SP, McCann D, Desai M, Rosenbaum M, Leibel RL, Ferrante AW, Jr. Obesity is associated with macrophage accumulation in adipose tissue. J Clin Invest, 2003:1796-808.

36. Ridker PM. Climical application of C-reactive protein for cardiovascular disease detection and prevention. Circulation 2003;107:363-9.

37. Hansell AL, Walk JA, Soriano JB. What do chronic obstructive pullmonary disease patients die from? A multiple cause coding analysis. Eur Respir $₫ 2003 ; 22: 809-14$. 
38. Dev D. Wallace $E$, Sankaran $R$, et al. Value of $C$ rreactive protein measurements in exacerbations of chronic obstructive pulmonary disease. Respir Med 1998:92:664-7.

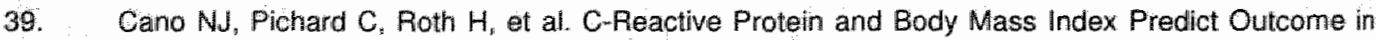
End-Stage Respiratory Failure. Chest 2004;126:540-546. 


\section{Leptin as local inflammatory marker in COPD}

Roelinka Broekhuizen Juanita H J. Vernooy Annemile M.W.J. Schols Mieke A. Dentener Emiel F.M. Wouters 


\section{Abstract}

\section{Background:}

Chronic inflammation of the lung is a characteristic finding in COPD. Leptin is a pleiotropic cytokine thought to play a role in host response to inflammation. As recent studies have shown that leptin receptors are present in the lung, this study aimed to determine if leptin is detectable in induced sputum of COPD patients and if there is a relationship between leptin and other inflammatory markers in sputum.

Methods:

Sputum was induced in 14 male patients with moderate COPD (FEV $: 58( \pm 11)$ \%pred). Leptin, total tumor necrosis factor- $\alpha$ (TNFa), and C-reactive protein (CRP) were analyzed in induced sputum supernatant by ELISA. Leptin was allso determined in EDTA plasma.

\section{Results:}

Leptin was detectable in induced sputum of to COPD patients. A significant relationship was found between sputum leptin and CRP $(r=0.943, p<0.001)$ and total TNFa $(r=0.690, p<0.01)$. Plasma leptin and sputum leptin were inverselly correlated $(r=-0.643, p<0.01)$.

\section{Conclusion:}

The present study demonstrated that leptin is detectable in induced sputum of patients with moderate COPD and is rellated to other inflammatory markers. The observed correlations between leptin and inflammatory markers in sputum may indicate that leptin is involved in the local inflammatory response in COPD. 


\section{Introduction}

Leptin, initially discovered as a regulator of food intake and energy expenditure, is increasingly emerging as a pleiotropic cytokine. It is involved in a variety of physiological and pathological functions, including the regulation of hematopoiesis, angiogenesis, wound healing, and the immune and inflammatory response (reviewed in 1). The receptor for leptin (leptin-R) has been demonstrated to be present throughout the body, including the lung (2), which may suggest a specific function of leptin in the lung.

Although the pathogenesis of chronic obstructive pulmonary disease (COPD) is not clear, patients with COPD have been shown to exhibit a chronic inflammatory response in the airways. Elevated numbers of alveolar macrophages and CD8+ T. cells have been found in the peripheral airways and lung parenchyma. In addition, an increased level of neutrophils has been demonstrated in sputum and bronchoalveolar lavage (BAL) fluid of COPD patients. Furthermore, increases in interleukin-8 (IL-8) and tumor necrosis factor- $\alpha$ (TNFa), which are assumed to act as chemo-attractants for neutrophils, have been reported in sputum of COPD patients (reviewed in 3 ).

In order to unravel the potential role of leptin in this process of chronic inflammation, we wondered if leptin is detectable in induced sputum of patients with COPD and, if so, whether leptin is related to other inflammatory markers in induced sputum of these patients. 


\section{Subjects and methods}

The study population consisted of normal weight male patients with clinically stable moderate to severe COPD (GOLD II-III). Exclusion criteria were regular use of inhaled steroids, a history of respiratory disease other than COPD and a recent exacerbation (four weeks prior to inclusion). Forced expiratory volume in one second $\left(F E V_{1}\right)$ was calculated from the flow volume curve using a spirometer (Masterlab, Jaeger, Würzburg, Germany) applied before and $15 \mathrm{~min}$ after inhalation of a $\beta_{2}$-agonist via a metered-dose inhaler. $F E V_{1}$ was expressed as a percentage of reference values (4). Body composition was estimated using single frequency $(50 \mathrm{kHz})$ bioelectrical impedance analysis (Xitron Technologies, San Diego, CA, USA). Fat-free mass (FFM) was calculated using the disease-specific equation proposed by Schols and described by Steiner et al. (5). Fat mass (FM) was calculated by subtracting FFM from weight. The ethical review board of the University Hospital Maastricht approved the study. All subjects gave written informed consent.

Table 1: Clinical characteristics of the study group"

\begin{tabular}{|c|c|c|c|}
\hline & & Mean & (t SD) \\
\hline Age & (yr) & 599 & $( \pm 8.3)$ \\
\hline Body mass index & $\left(\mathrm{kg} / \mathrm{m}^{2}\right)$ & 26.2 & $( \pm 3.6)$ \\
\hline Fat-free mass index & $(\mathrm{kg} / \mathrm{m})$ & 18.3 & $( \pm 1.5)$ \\
\hline Fat mass & $(\mathrm{kg})$ & 24.6 & $( \pm 8.2)$ \\
\hline$F E V_{1}$ & (\%pred) & 56 & $( \pm 15)$ \\
\hline FVo & (\%pred) & 78 & $( \pm 14)$ \\
\hline FEV, FV & & 57 & $( \pm 14)$ \\
\hline Smokerslex-smokers & & $10 / 4$ & 28 \\
\hline Smoking history & (PY) & 53 & $( \pm 28)$ \\
\hline
\end{tabular}


Sputum was induced through inhalation of $3 \%$ hypertonic saline and processed with $0.1 \%$ dithiothreitol (DTT; Sputolysin; Calbiochem, La Jolla, CA, USA) according to the procedure described by Keatings et al. (6). Blood was collected in evacuated blood collecting tubes containing EDTA (Sherwood Medical, St. Louis, MO, USA) in the morning before sputum induction (08.00-12.00 hours). Sputum and plasma samples were stored at $-80^{\circ} \mathrm{C}$ untill analysis.

Leptin was measured in induced sputum supernatant and plasma by sandwich enzyme-linked immunosorbent assay (ELISA) (7). C-reactive protein (CRP), total TNFa (ie, free TNFa and TNFa bound to soluble TNF-receptors) were determined in induced sputum supernatant by ELISA as described $(7,8)$. Lower detection limits were $120 \mathrm{pg} / \mathrm{ml}$ for leptin, $100 \mathrm{pg} / \mathrm{ml}$ for CRP and $20 \mathrm{pg} / \mathrm{ml}$ for total TNFa. Presence of DTT resulted in less than $10 \%$ inhibition of the detection of inflammatory mediators (data not shown).

Table 2: Inflammatory mediators in spulum and plasma

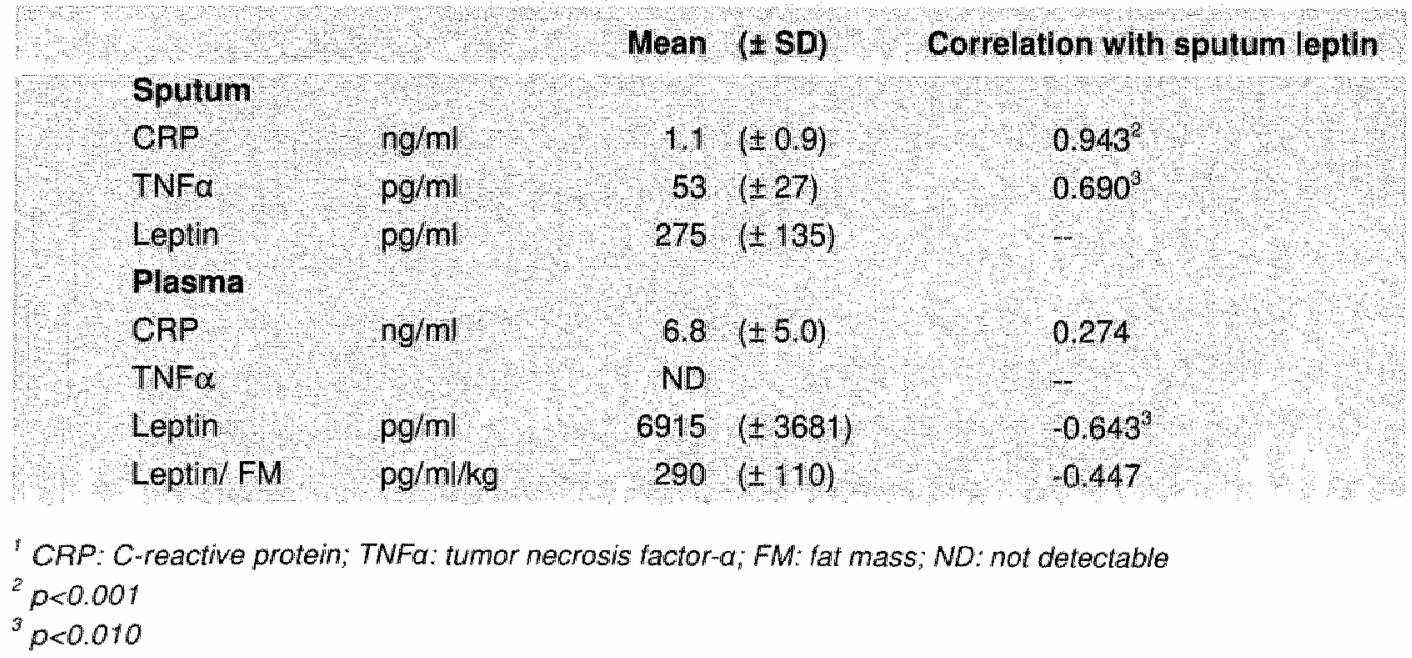


Results are presented as mean ( \pm standard deviation (SD)) for normally distributed variables. Plasma leptin levels were adjusted for fat mass when indicated. Differences between the groups with detectable and non-detectable leptin levels were analyzed using the Mann Whitney U-test. Correlations between parameters were calculated with Pearson's rank correlation analysis using SPSS (Statistical Package for the Social Sciences, version 10.1 for Windows, SPSS Inc., Chicago, IL, USA). Significance was assumed at a p-value of 0.05 .

\section{Results}

Fourteen weight-stable male patients with moderate to severe COPD (FEV $1: 56$ ( \pm 15 ) \%pred., range: $26-76 \%$ pred) were included in this study. Baseline characteristics are shown in table 1 . Mean smoking history of the study population was 53 (range: 25-125) pack years with four patients having quit smoking for at least one year and 10 patients still smoking. All patients tolerated the procedure of sputum induction well and produced an adequate specimen of sputum for analysis.

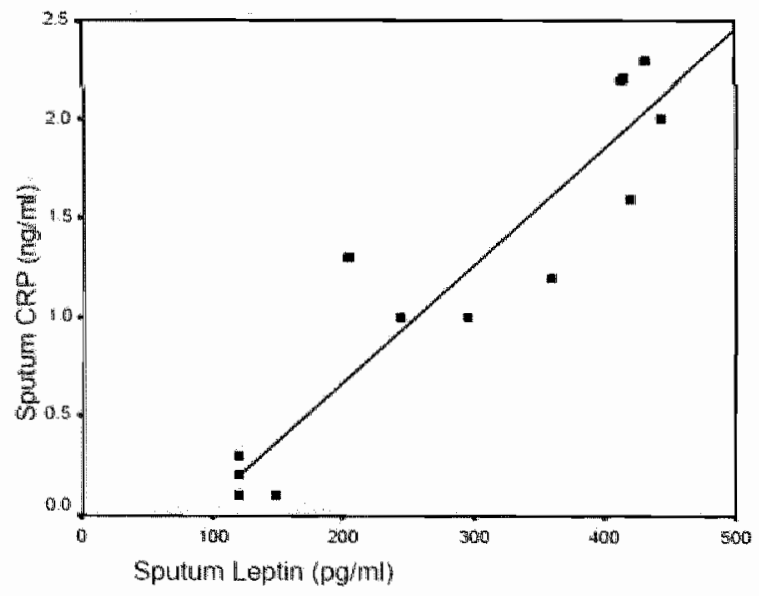

Figure 1: Correlation between leptin and CRP levels in induced sputum $(r=0.943, p<0.001)$ 
Table 3: Characteristics of patients with leptin level under detection limit compared to patients with detectable leptin levels in sputum

\begin{tabular}{|c|c|c|c|c|c|c|}
\hline \multicolumn{2}{|l|}{ Sputum leptin level } & \multicolumn{2}{|c|}{$\begin{array}{l}<120 \mathrm{pg} / \mathrm{ml} \\
\text { Mean }( \pm \mathrm{SD})\end{array}$} & \multicolumn{2}{|c|}{$\begin{array}{l}\geq 120 \mathrm{pg} / \mathrm{m} / \\
\text { Mean }( \pm \mathrm{SD})\end{array}$} & \multirow[t]{2}{*}{ p-value } \\
\hline n & & 4 & & 10 & & \\
\hline Age & $(y r)$ & 54.5 & $( \pm 11,6)$ & 62,1 & $( \pm 6.0)$ & n.s. \\
\hline Body mass index & $\left(\mathrm{kg} / \mathrm{m}^{2}\right)$ & 28.6 & $( \pm 3.5)$ & 25. & $( \pm 3.3)$ & n.s. \\
\hline Fat-free mass index & $\left(\mathrm{kg} / \mathrm{m}^{2}\right)$ & 18.2 & $( \pm 0,5)$ & 18.4 & $( \pm 1.9)$ & n.s. \\
\hline Fat mass index & $\left(\mathrm{kg} / \mathrm{m}^{2}\right)$ & 10.4 & $( \pm 3.0)$ & 7.1 & $( \pm 1.6)$ & 0.042 \\
\hline FEV & (\%pred) & 59 & $( \pm 10)$ & 55 & $( \pm 17)$ & 17.5. \\
\hline FVC & (\%pred) & 86 & $( \pm 6)$ & 75 & $( \pm 15)$ & ns. \\
\hline$F E V_{1} / F V C$ & & 54 & $( \pm 13)$ & 58 & $( \pm 16)$ & n.s: \\
\hline Smoking & (PY) & 41 & $( \pm 23)$ & 58 & $( \pm 30)$ & n.s. \\
\hline Sputum CRP & $(\mathrm{ng} / \mathrm{m})$ & 0.18 & $( \pm 0.10)$ & 1.49 & $( \pm 0.70)$ & 0.016 \\
\hline Sputum TNFa & $(\mathrm{pg} / \mathrm{m})$ & 30.4 & $( \pm 20.8)$ & 61.9 & $( \pm 24.2)$ & 0.074 \\
\hline Plasma Leptin & $(\mathrm{pg} / \mathrm{mi})$ & 10.8 & $( \pm 2,6)$ & 53 & $( \pm 2.8)$ & 0.016 \\
\hline Plasma Leptin/ FM & $(\mathrm{Pg} / \mathrm{mi} / \mathrm{kg})$ & 0.36 & $( \pm 0.10)$ & 0.26 & $( \pm 0.10)$ & ns \\
\hline
\end{tabular}

'FEV,: forced expiratory volume in one second; FVC: forced' wital capacity; CRP: C-reactive protein: TNFa: tumor necrosis factor-a; FM: fat mass; \%pred; percentage predicted; PY: pack years

Table 2 shows the levels of inflammatory markers with the correlations with sputum leptin. Leptin was detectable in the sputum samples of 10 of 14 patients, who did not differ from patients with non-detectable leptin in lung function, but did have a lower fat mass index (lable 3). The mean value of leptin in sputum was 275 ( \pm 135 ) $\mathrm{pg} / \mathrm{ml}$. In plasma, leptin was detectable in all samples, with a mean level of 6915 $( \pm 3681) \mathrm{pg} / \mathrm{ml}$. After adjustment for fat mass, which correlated positively with leptin $(r=0.719, p=0.008)$, mean plasma leptin level was $290( \pm 110) \mathrm{pg} / \mathrm{ml} / \mathrm{kg} \mathrm{FM}$. Leptin in plasma and in induced sputum were inversely correlated $(r=-0.643, p<0.001), a$ correlation that was no longer significant after plasma leptin had been adjusted for fat mass. In induced sputum, leptin level was strongly correllated with the acute 


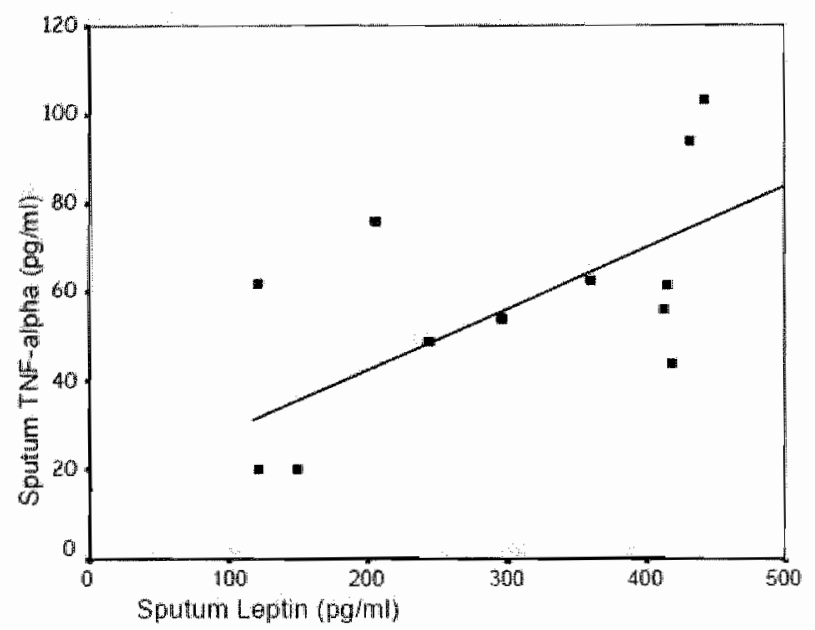

Figure 2: Correlation between leptin and TNFa levels in induced sputum $(r=0.690, p<0.010)$

phase protein CRP $(r=0.943, p<0.001)$ (figure 1) and with sputum TNFa levels $(\mathrm{r}=0.690, \mathrm{p}=0.006)$ (figure 2 ). No correlations were found between plasma CRP and sputum leptin $(r=0.274, p=n . s$.), plasma CRP and plasma leptin $(r=0.040$, $p=n$.s.) or between plasma CRP and sputum CRP $(r=0.410, p=n . s$. . TNFa was not detectable in plasma. In sputum, CRP and TNFa were positively correlated $(r=0.743, p=0.002)$. Sputum leptin, CRP and TNFa were not related to smoking history, smoking status or lung function (data not shown).

\section{Discussion}

The present study shows that leptin is detectable in induced sputum of COPD patients. Leptin was positively correlated with the inflammatory markers CRP and TNFa in sputum. In COPD, chronic airway inflammation is considered to be a hallmark, characterized by profound neutrophilia and increased sputum levels of $\mathrm{IL}-8$, TNFa and soluble TNF-receptors, correlating with the degree of airflow 
limitation $(6,8)$. The finding that sputum leptin was positively correlated with GRP and TNFa in these patients is an indication that leptin could be involved in the local inflammatory response in COPD.

To date, only few studies have addressed the presence of leptin in the lung. Its presence, together with the high concentrations of leptin receptor (2) suggests a specific local function of leptin. Leptin was demonstrated to stimulate cell proliferation in tracheal epithelial cells in vitro, suggesting that leptin may function as a growth factor helping to maintain the epithelial barrier (2). It could also play a role in the local immune response, as leptin receptors are found on neutrophils (9) and $T$-cells $(10)$.

Structurally, leptin and leptin receptor are part of the IL-6 super family $(11$, 12), which is an important inducer of acute phase proteins like CRP. Systemically, CRP is involved in first line of innate host defence, which includes activation of the classical complement cascade and mediating phagocytosis (13). TNF $\alpha$ is a proinflammatory cytokine with pleiotropic effects. TNFo expression in the lung has been described in several studies, being produced locally mainly by activated macrophages in response to inflammatory stimuli and functioning as a chemoattractant for inflammatory cells $(6,14)$.

Although we did not further investigate this, we hypothesize that the observed high correlation between leptin and CRP in induced sputum may indicate interplay between leptin and local inflammation on the level of innate immune response. CRP in sputum of chronic bronchitis patients has been shown to have antibactericidal activities in vitro (15). CRP is expressed in human respiratory epithelial cells and in stimulated human alveolar macrophages $(15,16)$ and mediates phagocytosis. On the other hand, leptin-deficient mice have been shown to have a reduced defence against bacteria, which was associated with in vitro defective alveolar phagocytosis. The addition of leptin has been found to restore this defect 
(17). This may suggest a co-dependence between leptin and CRP in activated macrophages. This hypothesis should be further investigated in future studies. The fact that TNFa in the lung is mainly produced by activated macrophages, can explain the observed correlations between the three markers.

The inverse correlation between sputum leptin and plasma leptin found in the present study makes it unlikely that the presence of leptin in sputum is attributable to microvascular leakage from the plasma leptin pool. As opposed to plasma leptin, which is produced by fat cells and therefore corrected for fat mass, leptin in sputum could be synthesized in the lung itself. Fetal rat lung fibroblasts, which are adipocyte-like cells, are reported to secrete leptin (18). In addition, preliminary observations by Bruno et al. suggested an increased expression of leptin in the submucosa of bronchial biopsies of patients with COPD compared to controls (10). Future research is needed to elucidate the origin of leptin in the lung.

Sputum induction with hypertonic saline may hypothetically stimulate synthesis of airway inflammatory mediators. However, induced sputum yielded the same cellular composition as spontaneous sputum in COPD patients (19). Moreover, soluble inflammatory markers in induced sputum correlated positively with those of lavage fluid (20). Therefore, it is unlikely that sputum induction itself stimulates airway inflammation.

Taken together, current data suggest that leptin may be involved in the innate immune system of the lungs in COPD. Future studies are clearly necessary to elucidate the role of leptin in airways of COPD patients.

The authors thank Prof. W.A. Buurman (General Surgery, Maastricht University, Maastricht, the Netherlands) for kindly providing the reagents for the ELISAs used in this study. The present work was supported by a research grant from GlaxoSmithkline, the Netherlands. 


\section{References}

1. Fantuzzi G, Faggioni R. Leptin in the regulation of immunity, inflammation, and hematopoiesis. $J$ Leukoc Bilol 2000;68:437-46.

2. Tsuchiya T, Shimizu H, Horie T, Mori M. Expression of leptin receptor in lung: leptin as a growth factor. Eur J Pharmacol 1999;365:273-9.

3. Barnes PJ. Chronic obstructive pulmonary disease. N Engl J Med 2000;343:269-80.

4. Quanjer PHe. Standardized lung function testing. Official statement of the European Respiratory Society [see comments]. Eur Respir J 1993;6 (suppl.16):1-100.

5. Steiner MC, Barton RL, Singh SJ, Morgan MD. Bedside methods versus dual energy $X$-ray absorptiometry for body composition measurement in COPD. Eur Respir J 2002;19:626*31.

6. Keatings VM, Collins PD, Scott DM, Bames PJ. Differences in interleukin-8 and tumor necrosis factor-alpha in induced sputum from patients with chronic obstructive pulmonary disease or asthma. Am J Respir Crit Care Med 1996;153:530-4.

7. van Dielen FM, van't Veer C, Schols AM, Soeters PB, Buurman WA, Greve JW. Increased leptin concentrations correlate with increased concentrations of inflammatory markers in morbidy obese individualls. Int $J$ Obes. Relat Metab Disord 2001;25:1759-66.

8. Vernooy $\mathrm{JH}$, Kucukaycan $\mathrm{M}$, Jacabs $\mathrm{JA}$, et al. Local and systemic inflammation in patients with chronic obstructive pulmonary disease: soluble tumor necrosis factor receptors are increased in sputum. Am J Respir Crit Care Med 2002; 166:1218-24.

9. Faggioni $R$, Feingold $K R_{\text {, }}$ Grunteld $C$. Leptin regulation of the immune response and the immunodeficiency of malnutrition. Faseb J 2001:15:2565-71.

10. Bruno $A$, Chiappara $G$, Chanez $P$, et al. Expression of leptin and leptin receptor in broncial biopsies of COPD and asthmatic subjects. Am J Respir Crit Care Med 2002;165:A559.

11. Baumann $H$, Morella KK, White DW, et al. The full-length leptin receptor has signaling capabilities of interleukin 6-type cyttokine receptors. Proc Natl Acad Sci U S A 1996:93:8374-8.

12. Zhang $F$, Basinski MB, Beals JM, et al. Crystal structure of the obese protein leptin-E100. Nature $1997 ; 387: 206-9$.

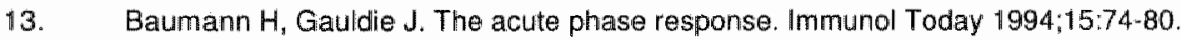

14. Churg $A_{1}$ Dai J, Tai $H$, Xie $C$, Wright JL. Tumor necrosis factor-alpha is centrai to acute cigarette smoke-induced inflammation and connective tissue breakdown. Am $₫$ Respir Crit Care Med $2002 ; 166: 849 \cdot 54$.

15. Gould JM, Weiser JN. Expression of C-reactive protein in the human respiratory tract. Infect Immun $2007 ; 69: 1747-54$.

16. Dong $Q$, Wright JR. Expression of C-reactive protein by alveolar macrophages. \lmmunol 1996;156:4815-20.

17. Mancuso P, Gottschalk. A, Phare SM, Peters-Golden M, Lukacs NW, Huffnagle GB. Leptin-deficient mice exhibit impaired host defense in Gram-negative pneumonia. J Immunol 2002;16:8:4018-24.

18. Torday $J S$, Sun $H$, Wang $L$, Torres $E$, Sunday ME, Rubin LP. Leptin mediates the parathyroid hormone-related protein paracrine stimulation of fetal lung maturation. Am J Physiol Lung Cell Mol Physiol 2002;282:L405-10. 
19. Bhowmik $A$, Seemungal TA, Sapstord RJ, Devalia $J L$, Wedzicha JA. Comparison of spontaneous and induced sputum for investigation of airway infiammation in chronic obstructive pulmonary disease. Thorax 1998;53:953-6.

20. Rutgers $S R$, Timens W, Kaufmann HF, wan der Mark TW, Koeter GH, Positma DS. Comparison of induced sputum with bronchial wash, bronchoalveolar lavagle and bronchial biopsies in COPD. Eur Respir J $2000,15: 109-15$. 


\section{Increased cellular protein breakdown is not reduced by pulmonary rehabilitation in COPD}

Charlotte E. Bolton*

Roelinka Brookhuizen*

Alina A. lonescu

Lisette S. Nixon

Emiel FM. Wouters

Dennis J. Shale

Annemie M.W.J. Schols

- These authors contributed equally to this work 


\section{Abstract}

\section{Background:}

Loss of fat free mass (FFM) and impaired skeletal muscle function occur in COPD. Pulmonary rehabilitation, which acts as an anabolic stimulus, can improve functional capacity, but has a variable effect on FFM. We hypothesized that pulmonary rehabilitation would not affect catabolic drives such as systemic inflammation and protein breakdown.

\section{Methods:}

Patients $(n=40)$ were studied at the commencement of an eight-week in-patient pulmonary rehabilitation program, at the end and four weeks later. FFM, functional capacity, pseudouridine (PSU) excretion (cellular protein breakdown) and inflammatory status were determined. Healthy subjects had a single baseline assessment $(n=18)$. Nutritional supplementation was given to those underweight, with a low FFM or actively losing weight.

Results:

PSU and inflammatory mediators were elevated in patients compared with healthy controls while FFM and functional capacity were reduced (all $p<0.01$ ). PSU was inversely related to both FFM and skeletal muscle function. FFM and functional parameters increased with rehabilitation, but PSU and inflammatory status were unaffected. The gain in FFM was lost four weeks after the completion of rehabilitation $(p<0.01)$.

\section{Conclusions:}

The anabolic effect of pulmonary rehabilitation improved FFM by offsetting the background catabolic state, but it did not reverse protein breakdown or systemic inflammation. Thus, on cessation of rehabilitation, the FFM gain of the pro-anabolic effect was lost due to a return to a predominantly catabolic intermediary metabolism. To enhance and maintain the improvements of rehabilitation anticatabolic measures need to be incorporated into rehabilitation regimens. 


\section{Introduction}

Altered body composition, in particular the loss of fat free mass (FFM) is associated with a worse prognosis with increased mortality "morbidity and a poorer quality of life in chronic obstructive pullmonary disease (COPD) (1-3). The reduction in FFM is due to a change in the balance between anabolic and catabolic processes in favor of the latter. The catabolic state is likely to be contributed to by a negative energy balance, secondary to increased energy expenditure for the energy intake, reduced physical activity and chronic systemic inflammation, the latter of which is associated with parallel catabolic intermediary metabolism (4-6).

This metabolic imbalance leads to increased whole body protein turnover in which breakdown predominates over synthesis $(7,8)$. This altered balance can be demonstrated and quantified using isotopically labeled amino acids, but this is a relatively invasive, expensive and difficult to apply to large study groups (7-9). Measurement of 5-ribosyl uracil (pseudouridine, PSU), a stable urinary metabolite of RNA, has been compared with isotopically labelled leucine turnover and found to be comparable (9). Pseudouridine excretion is unaffected by diet and is neither metabolized further nor reutilized by the body (10-12). Hence, it represents one limb of the turnover of RNA and can be used as an index of cell related protein breakdown. Increased PSU excretion occurs in patients with chronic inflammatory states associated with loss of normal body composition, such as in stable COPD, cystic fibrosis (CF) and HIV infection (3, 13-15).

The effect of the reduction in FFM is the loss of protein rich tissues, in particular skeletal muscle. Loss of skeletal muscle mass, in association with changes in the intrinsic properties of skeletal muscle, is considered to be a factor in the impaired peripheral muscle function reported in COPD (16-19). Additionally this appears to be a factor in the genesis of bone thinning, which is prevalent in the COPD population (3). Pulmonary rehabilitation, if it includes high intensity muscle 
reconditioning, improves skeletal muscle function while also improving morbidity and quality of life in COPD (20-25). In this format pulmonary rehabilitation is an anabolic stimulus, but has variable impact on body composition, even when a nutritional intervention is included in the protocol. However, weight gain can be achieved during pulmonary rehabilitation and is related to improved survival (2630).

We hypothesized that protein breakdown would be related to the loss of FFM and a reduction in skeletal muscle function. Additionally, we hypothesized that an eightweek pulmonary rehabilitation program would improve body composition due to its pro-anabolic effect, but was unlikely to reverse the increased breakdown of protein or systemic inflammation, and that any metabolic benefits would be short lived once the rehabilitation program ceased due to the unopposed background catabolic state.

\section{Subjects and methods}

\section{Subjects}

Forty patients with COPD (GOLD stage II-IV) (31, 32) were consecutively recruited at the commencement of an eight-week in-patient pulmonary rehabilitation program whilst clinically stable at the Asthma Center, Hornerheide, the Netherlands. Exclusion criteria included any malignancy, biochemical, malabsorptive, metabolic or endocrine diseases as well as systemic inflammatory disease. Eighteen healthy Dutch volunteers, gender- and age-matched, were recruited by an advertisement in a local newspaper for comparison of baseline parameters. The ethical review board of the University Hospital Maastricht approved the study and all subjects gave their written informed consent. 
The eight-week in-patient pulmonary rehabilitation program consisted of both physical and educational components of the disease and its management (28). Each day consisted of two activity sessions made up of 20 min of submaximal cycle ergometry, $20 \mathrm{~min}$ of treadmill exercise, $30 \mathrm{~min}$ of gymnastics and one session of unsupported arm exercise training (10 $\times 1$ min of exercise, interspersed with $1 \mathrm{~min}$ of rest). Exercise was based on the patients' functional impairment. During the rehabilitation program, patients received maintenance respiratory medication. Liquid nutritional supplementation (Respifor, Nutricia B.V., the Netherlands) was given thrice daily (total $564 \mathrm{kcal} /$ day) to patients who had either a low FFM index (FFMI), suffering from recent weight loss $>5 \%$ body weight in preceding three months or $>10 \%$ in six months) or with a low body mass index (BMI) $\left(<21 \mathrm{~kg} / \mathrm{m}^{2}\right)$.

The following parameters were determined at baseline and after eight weeks of rehabilitation.

\section{Lung function}

The forced expiratory volume in one second $\left(F E V_{1}\right)$, forced vital capacity (FVC) and their ratio ( $F E V_{1} / F V C$ ) were assessed using a spirometer (Masterlab, Jaeger, Würzburg, Germany) at baseline and in patients also 15 min after inhalation of $\beta$ agonists via a metered-dose inhaler. Patients were classified according to the GOLD criteria $(31,32)$.

\section{Urinary Sampling and PSU analysis}

A fasting spot urinary sample was collected in which urinary creatinine and PSU were analyzed by high performance liquid chromatography (33). PSU was standardized for creatinine concentration to allow for dilutional effect $(\mu \mathrm{mol} / \mathrm{mmol})$. To allow for the differences in the actively metabolizing FFM, PSU was expressed as a ratio to $\mathrm{FFM}(\mathrm{PSU} / \mathrm{FFM}(\mu \mathrm{mol} / \mathrm{mmol} / \mathrm{kg}))$. 


\section{Body composition}

Height and weight were measured to determine body mass index (BMl, $\mathrm{kg} / \mathrm{m}^{2}$ ). Fat-free mass (FFM, kg) was measured using single frequency $(50 \mathrm{kHz})$ bioelectrical impedance analysis (BIA, Xitron Technologies, San Diego, CA, USA), with subjects in a supine position. Using the COPD-specific equation (34), the FFM was determined and from this, a height squared fat-free mass index (FFMI) was calculated $\left(\mathrm{kg} / \mathrm{m}^{2}\right)$. Cachexia was classed as a FFM $<15 \mathrm{~kg} / \mathrm{m}^{2}$ (women) and $<16$ $\mathrm{kg} / \mathrm{m}^{2}$ (men) (16).

\section{Btood sampling}

Interleukin-6 (IL-6) and tumor necrosis factor-a (TNFa) (Quantikine, R\&D Systems, USA) were determined using enzyme-linked immunosorbent assay (ELISA) from a venous blood sample with a lower detection of $0.039 \mathrm{pg} / \mathrm{ml}$ for $\mathrm{IL}-6$ and $0.5 \mathrm{pg} / \mathrm{ml}$ for total TNFa. Soluble tumor necrosis factor receptor 55 (sTNF-R55) and STNFR75 were measured using ELISA, as previously described (35).

\section{Functional capacity}

\section{Bicycle ergometry test}

Using an electromagnetic braked ergometer (Corival 400, Lode, Groningen, the Netherlands), incremental ergometry was performed to investigate maximal leg exercise capacity. After 2 min of resting followed by 1 min unloaded cycling, the power was increased every minute by $10 \mathrm{~W}(36)$. Peak workload was determined (W).

\section{Skeletal muscle strength}

Isokinetic quadriceps strength $(\mathrm{Nm})$ of the dominant leg of the patients was measured using a Biodex dynamometer (Biodex Corporation, Shirley, USA) (29). The highest peak torque out of 15 sequential volitional maximal contractions at an angular velocity of $90 \%$ was recorded. Skeletal muscle function of the upper limb was assessed using the mean of three measurements $(\mathrm{kg})$ on the Harpenden 
handgrip dynamometer (Yamar, Preston, Jackson, MI, USA) (28). All of these parameters were performed after familiarization in order to prevent any learning effect.

Measurements of plasma cytokines, body composition, and urinary PSU were also repeated at 12 weeks (four weeks after the completion of rehabilitation).

\section{Statistics}

Data analysis was by Statistical Package for Social Science (SPSS) version 11.0 for Windows, SPSS Inc., Chicago, IL, USA. Results are the arithmetic or geometric (for non-normally distributed data such as PSU and the inflammatory mediators) mean and standard deviation ( \pm standard deviation (SD)). Analyses included the $\chi^{2}$ test, independent $t$-test, paired $t$-test, one-way ANOVA with a post-hoc Tukey's test and Pearson's correlation. Significance was assumed at a p-value of 0.05 .

\section{Results}

Comparisons between the whole patient group and healthy controls: functional and mutritional assessment

Of the 40 patients, 29 were male while 14 of 18 healthy controls were male (n.s.). The mean age $\left( \pm \mathrm{SD}\right.$ ) was 62.1 ( \pm 8.7) years and their $F E V_{1}$ was 36.7 ( \pm 15.6 ) \%pred. Ten patients had GOLD stage II, 11 had GOLD stage III and 19 patients had GOLD stage IV COPD. Twenty patients had a low FFMI. The healthy controls had an FEV ${ }_{\|}$of 106.3 ( \pm 16.4 ) \%pred.

Excretion of PSU was greater in patients ( $p<0.01$ ) (lable 1). BMI and FFM were greater in healthy controls than in patients (both $p<0.01$ ). $\log _{10} P S U$ and FFM were inversely related in the whole subject group $(r=-0.524, p<0.01)$ (fiqure 1). 
Table 1: Baseline body composinion, pseudouridine. functional siatus and inflammatory stabus of the subjects

\begin{tabular}{|c|c|c|c|c|c|}
\hline H. & & Health & controls & $\mathrm{Pe}$ & ents \\
\hline & & 18 & & 40 & \\
\hline $\mathrm{BM}$ & $(\mathrm{kg} / \mathrm{m} / \mathrm{l})$ & 25.8 & $( \pm 29)$ & 224 & $( \pm 3.8)^{*}$ \\
\hline $\mathrm{FFM}$ & $(\mathrm{kg})$ & 61.9 & $( \pm / 1.3)$ & 46.0 & $( \pm 77)^{*}$ \\
\hline FN & $(\mathrm{kg})$ & 16.1 & $( \pm 7.9)$ & 18.8 & $( \pm 71)$ \\
\hline PSU? & (inmolinmol) & 35.89 & $( \pm 1,19)$ & 44.48 & $(41,35)$ \\
\hline PSUTFFM? & (rmollmmolkg) & 177 & $( \pm 129)$ & 2.82 & $( \pm 1.5)^{\circ}$ \\
\hline Quadriceps Force & $(\mathrm{Nm})$ & 1213 & $( \pm 37,0)$ & 772 & $( \pm 36,3)^{\prime}$ \\
\hline Handgrip foree & $(\mathrm{kg})$ & 417 & $(+110)$ & 33.7 & $(19.6)^{t}$ \\
\hline Peak workload max & W) & 216.0 & $( \pm 57.5)$ & 613 & $( \pm 25.2)^{m}$ \\
\hline $1-6$ & $(00 / m)$ & 1,71 & $(t 1,70)$ & 403 & $(1+90)^{\prime}$ \\
\hline $\mathrm{NNF}^{2}$ & $(109 / 101)$ & 1.22 & $( \pm 1,37)$ & 128 & $(4,46)$ \\
\hline STNF $155^{2}$ & (109/m): & 1,14 & $( \pm+26)$ & 131 & $(t+4.4)$ \\
\hline STNF R75 & (ng/mi) & 1.14 & $( \pm 127)$ & 1.49 & $( \pm 1.39)^{*}$ \\
\hline
\end{tabular}

'The data are presented as mean ( \pm SD). BMI: body mass index; FFM: fat-free mass; FM: fat mass; PSU. pseudouridine; IL-6: interleukin-6. TNFa: tumor necrosis factor- $\alpha$; sTNF-R55/75: soluble TNF-receptor 55/75. PSU is corrected for creatinine: PSU/Cr ( $\mu$ mol/mmol)

"Q Geometric mean

$* 0<0.01$

There were no differences in the PSU or PSU/FFM between the subgroups of patients based on their GOLD stage and neither $\log _{10}$ PSU or $\log _{10}$ PSU/FFM were related to $\mathrm{FEV}_{1}$ (liter or \%predicted, data not shown).

Handgrip and quadriceps muscle force were reduced in the patients (both $p<0.01$ ) (table 1). Similarly, peak maximum workload was less in patients compared with healthy controls (both $p<0.01$ ). The $\log _{10}$ PSU/FFM was related to quadriceps strength $(r=-0.794, p<0.01)$ (figure 2), handgrip force $(r=-0.678, p<0.01$ ) and peak workload $(r=-0.636, p<0.01)$ in the subject group as a whole, with a similar pattern seen in the patients and healthy controls separately. 
IL-6 and STNF-R75 were greater in patients than healthy controls $(p<0.01)$, while TNFa and STNF-R55 were not different (table 1). None of the systemic inflammatory markers correlated with PSU in patients or controls.

The effect of pulmonary rehabilitation

After eight weeks rehabilitation, FFM increased by $1.1 \mathrm{~kg}$ from $46.0( \pm 7.7)$ to 47.1 $( \pm 7.4) \mathrm{kg}(p<0.01)$. This change occurred predominantly in the cachectic group from $41.0( \pm 5.0)$ to $42.6( \pm 5.4) \mathrm{kg}(p<0.01)$. In the non-cachectic group, the increase from $51.0( \pm 6.6)$ to $51.5( \pm 6.6) \mathrm{kg}$ was not significant. The excretion of PSU was unaffected by rehabilitation (start: $44.48( \pm 1.35) \mu \mathrm{mol} / \mathrm{mmol}$ creatinine, end: $43.35( \pm 1.28$ ), n.s.) as was the PSUIFFM (start: $2.82( \pm 1.45) \mu \mathrm{mol} / \mathrm{mmol} / \mathrm{kg}$, end: 2.68 ( \pm 1.35 ), n.s.) in the whole patient group (figure 3 ). No difference in PSU or PSU/FFM was seen between the cachectic and non-cachectic subgroups.

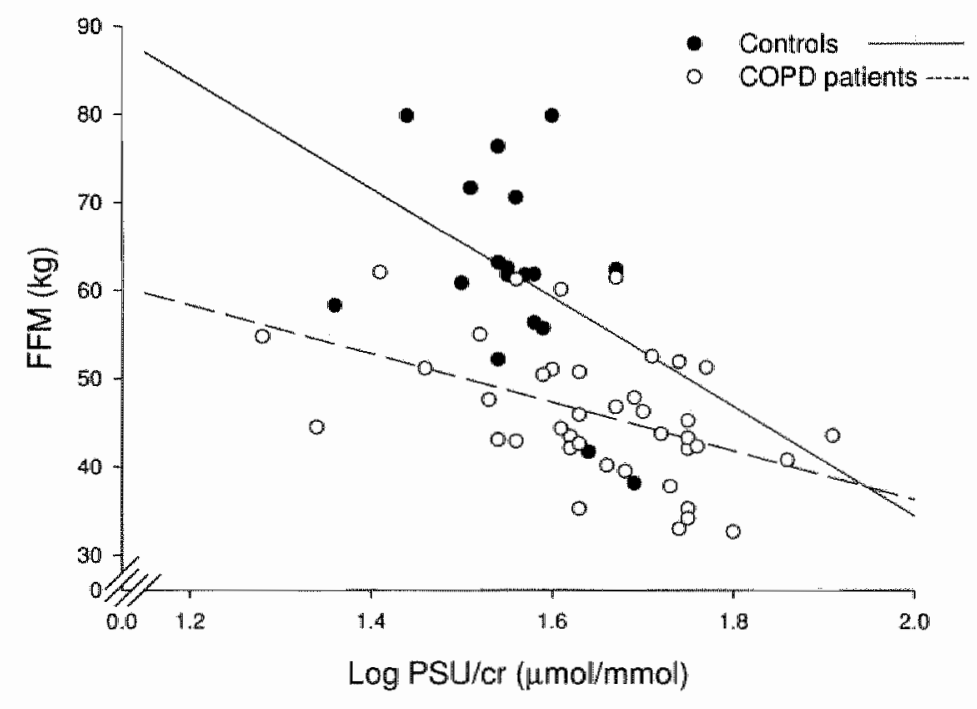

Figure 1: Relationship of fat free mass (FFM) to pseudouridine (PSU) in subjects at baseline. PSU is corrected for creatinine: PSU/Cr ( $\mu \mathrm{mol} / \mathrm{mm}$ ol) 
The gain in FFM at the end of pulmonary rehabilitation was lost four weeks later (end of rehab: $47.6( \pm 7.2) \mathrm{kg}$ to four weeks later: $46.7( \pm 7.1) \mathrm{kg}, \mathrm{p}<0.01(n=38)$ ). Both PSU and PSU/FFM did not significantly change between the end of rehabilitation and four weeks later (PSU: 41.98 ( \pm 1.27$) \mu \mathrm{mol} / \mathrm{mmol}$ creatinine at end of rehabilitation to 45.19 ( $₫ 1.36$ ), $p=0.249$ four weeks later; PSU/FFM: 2.62 ( $\sharp$ 1.33) $\mu \mathrm{mol} / \mathrm{mmol} / \mathrm{kg}$ end of rehabilitation to $2.83( \pm 1.44), p=0.133$ four weeks later). There was also no significant difference in FFM, PSU or PSU/FFM four weeks after rehabilitation compared with pre-rehabilitation values (figure 3). Two patients did not complete the four weeks postrehabilitation assessment as they declined further assessments.

FM increased significantly with rehabilitation from $18.8( \pm 7.1) \mathrm{kg}$ to $19.4( \pm 6.1) \mathrm{kg}$ $(p<0.05)$. There was a further significant increase in FM during the four weeks following rehabilitation to $20.3( \pm 6.1) \mathrm{kg}(p<0.01)$. BMI improved during rehabilitation to $23.1( \pm 3.2) \mathrm{kg} / \mathrm{m}^{2}(p<0.01)$ and was similar at four weeks post-rehabilitation, being $23.1( \pm 3.2) \mathrm{kg} / \mathrm{m}^{2}$.

Quadriceps strength were both improved with the rehabilitation program $(77.19$ $( \pm 36.27)$ to $88.91( \pm 32.51) \mathrm{Nm}, \mathrm{p}=0.018)$, peak workload $(61.3( \pm 25.21)$ to 71.25 $( \pm 32.79) W, p<0.01)$. Handgrip force tended to improve $(33.72( \pm 9.58)$ to 34.63 ( \pm 9.61$) \mathrm{kg}, \mathrm{p}=0.057$ ). The changes in markers of muscle function were not reflected by any change in PSU (Pearson's correlation, $p>0.05$ ).

There was no change in the levels of any of the circulating inflammatory mediators with the rehabilitation program- IL-6, TNFa, sTNF-R55 and -R75 (all p>0.05). 


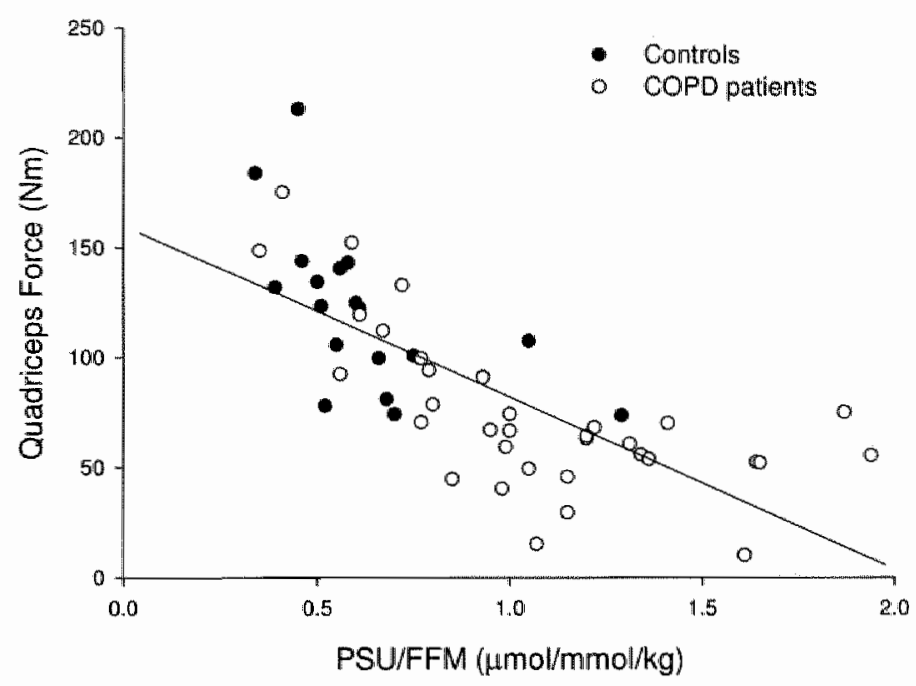

Figure 2: Relationship of quadriceps strength to PSUFFM at baseline in all subjects. PSU is corrected for creatinine: PSU/Cr (umolimmol)

\section{Discussion}

Increased cellular protein breakdown, as measured by PSU, was inversely related to FFM and impaired skeletal muscle function in the upper and lower limb and reduced exercise capacity in patients with COPD, independent of the severity of lung disease. Pulmonary rehabilitation resulted in improvements in skeletal muscle function and exercise capacity, and a short-term increase in FFM, but no reduction was seen in the increased cellular protein breakdown or systemic inflammation.

The relationships between PSU, FFM and skeletal muscle function suggest a mechanistic link between protein catabolism and loss of FFM, which together may explain some of the loss of skeletal muscle function. Supporting the relevance of such a link is the similar relationship between PSU and skeletal muscle function in 
the healthy controls, which suggests there is a physiological relationship between protein breakdown and skeletal muscle function in health.

Systemic inflammation has been repeatedly demonstrated in patients with stable COPD and was confirmed in this study $(3,6,37,38)$. Despite the view that inflammation is a factor in the catabolic drive in these patients, we did not find a relationship between the systemic inflammatory mediators and PSU. This could be due to a low power of this study to detect this relationship, the cascade nature of the cytokines and their synergistic interplay, or that cytokines produced in skeletal muscle are more closely related to muscle protein breakdown than circulating levels (39).

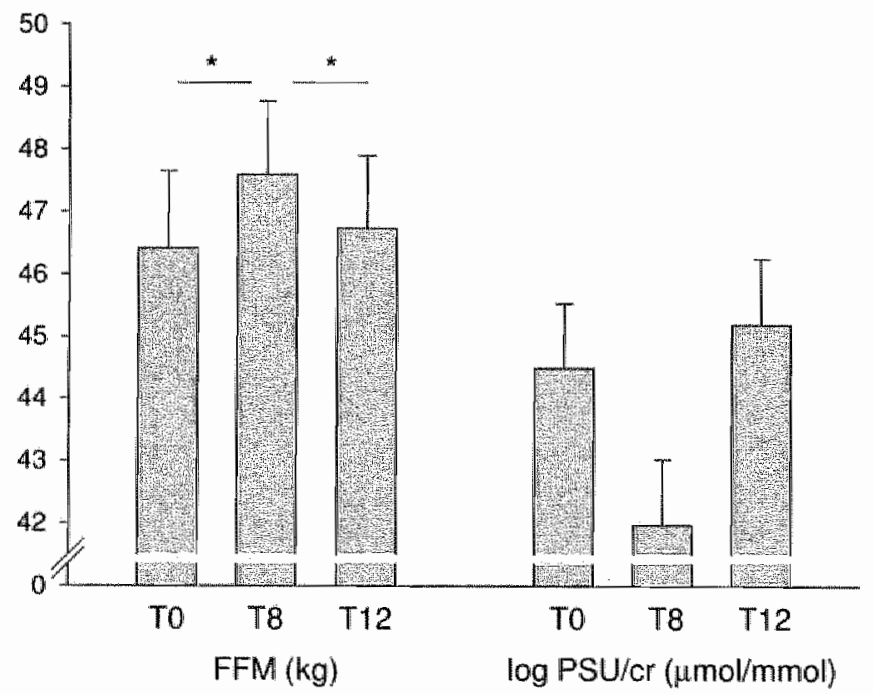

Figure 3: Fat-rree mass (FFM) and pseudouridine (FSU) in the 38 patients who completed the three visits. TO: baseline results, T8: end of rehabiltation. T12: four weeks after the completion of rehabilitation. PSU is corrected for creatinine: PSU/Cr (Hmal/mmol). Bar represents the mean, the error bar represents the SEM. * $0<0.05$ 
Depending on the components of the program, pullmonary rehabilitation may address the issues that reduce physical activity, nutritional depletion, the patients understanding of the disease process and their quality of life. The pulmonary rehabilitation program used here was of moderate to high intensity and incorporated both endurance and strength training, which acts as an anabolic stimulus and might be expected to reduce cellular protein breakdown if the catabolic state was purely due to physical deconditioning. However, in COPD the catabolic state is due to a range of factors including sustained systemic inflammation, which was not attenuated by pulmonary rehabilitation $(3,6,37,38)$. This may explain why the excretion of PSU was unaffected by the rehabilitation program. It may also explain the gain in FFM during rehabilitation when there was an anabolic stimulus, while on completion of the program this gain in FFM was lost due to the largely unopposed catabolic intermediary metabolism. This data indicate a continuous increased protein breakdown in COPD, which is similar to reports in CF, which could confound the effects of pulmonary rehabilitation (15).

The determination of body composition demonstrated both a gain in FFM during rehabilitation and a progressive gain in FM throughout the study period. The loss of FFM after the rehabilitation program ended was masked by the unchanged BMI which was maintained due to the further FM gain. Thus, in interventional studies a more precise assessment of nutritional status than BMI alone is required.

\section{Limitations of the study}

The use of PSU to assess protein breakdown could be criticized because it has not been validated directly against isotopic protein turnover assessment in COPD. However, it was closely related to amino acid turnover in other diseases (9). PSU has been shown to have a response to intervention that parallels clinical response in other disease groups such as rheumatoid arthritis and lung cancer $(13,40)$. Unlike other non-invasive measures, such as 3 -methylhistidine, it does not require 
dietary limitations that make it impractical for clinical studies where dietary restriction would be counter-productive or unethical

In summary, we demonstrated that an anabolic stimulus in the form of pulmonary rehabilitation increased the FFM but had no effect on the protein catabolic or systemic inflammatory state in our patients. The benefits of a high intensity pulmonary rehabilitation program on the FFM was short lived and emphasized the need to consider a tailored treatment program which includes nutritional supplementation, reconditioning physical exercise with anti-inflammatory or anticatabolic therapies. 


\section{References}

1. Schols AM, Soeters PB, Dingemans AM, Mostert R, Frantzen PJ, Wouters EF. Prevalence and characteristics of nutritional depletion in patients with stable COPD eligible for pulmonary rehabilitation. Am Rev Respir Dis 1993;147:1151-6.

2. Shoup R, Daisky $G$, Warner $S$, et al. Body composition and health-related quality of life in patients with obstructive airways disease. Eur Respir J1997; 10:1575-80.

3. Bolton $\mathrm{CE}$, lonescu $\mathrm{AA}$, Shiels $\mathrm{KM}$, et al. Associated Loss of Fat Free Mass and Bone Mineral Density in Chronic Obstructive Pulmonary Disease. Am \ Respir Crit Care Med 2004:170:12861293.

4. Donahoe $\mathrm{M}$, Rogers RM, Wilson DO, Pennock BE. Oxygen consumption of the respiraltary muscles in normal and in malnourished patients with chronic obstructive pulmonary disease. Am Rev Respir Dis $1989 ; 140: 385-91$.

5. Debigare $\mathrm{R}$, Marquis $\mathrm{K}, \mathrm{Cote} \mathrm{CH}$ et al. Catabolic/anabolic balance and muscle wasting in patients with COPD. Chest 2003;124:83-9.

6. Eid AA, Ionescu AA, Nixon LS, et al. Inflammatory response and body composition in chronic obstructive pulmonary disease. Am J Respir Crit Care Med 2001;164:1414-8.

7. Engelen MP, Deutz NE, Wouters EF, Schols AM. Enhanced Levels of Whole-body Protein Turnover in Patients with Chronic Obstructive Pulmonary Disease. Am J Respir Crit Care Med 2000;162:1488-1492.

8. Eingelen MP, Deutz NE, Mostent R. Wouters EF, Schols AM. Response of whole-body protein and urea turnover to exercise differs between patients with chronic obstructive pulmonary disease with and without emphysema. Am J Clin Nutr 2003;77:868-74.

9. Bohles $H$, Brendel $L$, Forster $H_{*}$, Trager $K$, Vogt $J$, Georgieff $M$. The effect of human growth hormone therapy on L-(methyl-2H3)-leucine turnover and urinary pseudouridine concentration in patients with Ullich-Turner syndrome. Eur J Pediatr 1996;155:275-80.

10. Gehrke CW, Kuo KC, Waalkes TP, Borek E. Patterns of urinary excretion of modified nucleosides. Cancer Res 1979;39:1150-3.

11. Itoh $K$, Aida $S_{i}$ Ishiwata $S$, Sasaki $S$, Ishida $N$, Mizugaki M. Urinary excretion patterns pf modilied nucleosides, pseudouridine and 1-methyladenosine, in healthy individuals. Clin Chim Acta $1993 ; 217: 221-3$

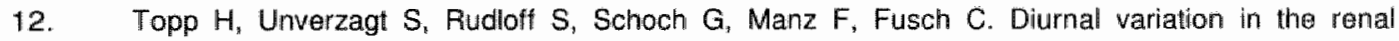
excretion of modified RNA catabolites in humans. Clin Sci (Lond) 2003;105:195-202.

13. Lu JY, Lail RS, Liang LL, Wang HC, Lin TI. Evaluation of urinary pseudouridine as a tumor marker in lung cancer. J Formos Med Assoc 1994;93:25-9.

14. Intrieri $M$, Calcagno $G$, Oriani $G$, et al. Pseudouridine and 1-ribosylpyridin-4-one-3-carboxamide (PCNR) serum concentrations in human immunodeficiency virus type 1 -infected patients are independent predictors for AIDS progression. $\$ Infect Dis 1996;174:199-203.

15. lonescu AA, Nixon LS, Luzio $S$, et al. Pulmonary function, body composition, and protein catabolism in adults with cystic fibrosis. Am J Respir Crit Care Med 2002;165:495-500.

16. Baarends EM, Schols AM, Mostert $R$, Wouters EF. Peak exercise response in relation to tissue depletion in patients with chronic obstructive pulmonary disease. Eur Respir $\sqrt{ }$ 1997;10:2807-13. 
17. Engelen MPKu, Schols AMWJ, Baken WC, Wesseling Gd, Wouters EFM. Nutritional depletion in relation to respiratory and peripheral skeletal muscle function in out-patients with COPD. Eur Respir $\checkmark 1994,7: 1793-7$.

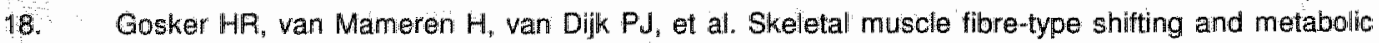
profile in patients with chironic abstructive putmonary disease. Eur Respir J 2002;19:617-25.

19. Agusti $A G$, Sauleda J, Miralles $C$, al. Skeletal muscle apoptosis and weight loss in chronic obstructive pulmonary disease. Am J Respir Crit Care Med 2002;166:485-9.

20. Chronic obstructive pulmonary disease. National clinical guideline on management of chronic obstructive pulmonary disease in adults in primary and secondary care. Thorax 2004;59 Suppl 1:1. 232.

21. Cell BR, MacNee W. Standards for the diagnosis and treatment of patients with COPD: a summary of the ATSJERS position paper. Eur Respir J 2004;23:932-46.

22. Lacasse $Y$, Wong $E$, Guyatt GH, King D, Cook DJ, Goldstein RS. Meta-analysis of respiratory rehabilitation in chronic obstructive pulmonary disease. Lancet 1996;348:1115-9.

23. Bendstrup KE, Ingemann Jensen J, Holm S, Bengtsson B. Out-patient rehabilitation improves activities of daily living, quality of life and exercise tolerance in chranic abstructive pulmonary disease. Eur Respir J 1997;10:2801-6.

24. Bernard $S$, Whittom $F$, Leblanc $P$, et al. Aerobic and strength training in patients with chronic obstructiwe pulmonary disease. Am $\mathbb{U}$ Respir Crit Care Med 1999;159:896-901.

25. Griffiths $T L$, Burr $M L$, Campbell $I A_{\text {, }}$ et al. Results at 1 year of outpatient multidisciplinary pulmonary rehabilitation: a randomised controlled trial. Lancet 2000;355:362-8.

26. Schols AM, Soeters PB, Mostert $R_{t}$ Pluymers RJ, Wouters EF. Physiologic effects of nutritionall support and anabolic steroids in patients with chronic obstructive pulmonary disease. A placebocontrolled randomized trial. Am J Respir Crit Care Med 1995;152:1268-74.

27. Steiner MC, Barton RL, Singh SJ, Morgan MD. Nutritional enhancement of exercise performance in chronic obstructive pulmonary disease: a randomised controlled trial. Thorax 2003;58:745-51.

28. Creutzberg EC, Wouters EF, Mostert R, Weling-Scheepers CA, Schols AM. Efficacy of nutritional supplementation therapy in depleted patients with chronic obstructive pulmonary disease. Niutrition $2003 ; 19: 120-7$.

29. Fianssen FM, Broekhuizen $R$, Janssen PP, Wouters EF, Schols AM. Effects of Wholle-Body Exercise Training on Body Composition and Functional Capacity in Normal-Weight Patients With COPD. Chest 2004;125:2021-8.

30. Schols $A M$, Slangen $J_{n}$ Volovics $L_{n}$, Wouteirs EF. Weight loss is a reversible factor in the prognosis of chronic obstructive pulmonary disease. Am J Respir Crit Care Med 1998;157:1791-7.

31. Pauwels RA, Buist AS, Calverley PM, Jenkins CR, Hurd SS. Global strategy for the diagnosis, management, and prevention of chronic obstructive pulmonary disease. NHLBINHO Global Initiative for Chronic Obstructive Lung Disease (GOLD) Workshop summary. Am J Respir Crit Care Med $2001 ; 163: 1256-76$

32. Fabbri LM, Hurd SS. Global Strategy for the Diagnosis, Management and Prevention of COPD: 2003 update. Eur Respir J 2003;22:1-2.

33. LI $Y$, Wang $S$, Zhong $N$. Simultaneous determination of pseudouridine and creatinime in urine of normal children and patients with leukaemia by high performance liquid chromatography. Biomed Chromatogr 1992;6:191-3. 
34. Steiner MG, Barton RL, Singh $S J$, Morgan MD. Bedside methods versus dual energy $X$-ray absorptiometry for body composition measurement in COPD. Eur Respir J 2002; $19: 626-31$.

35. Leeuwenberg JF, Dentener MA, Buurman WA. Lipopolysaccharide LPS.mediated soluble TNF receptor release and TNF receptor expression by monocytes, Role of CD14 LPS binding protein, and bactericidal/permeability-increasing protein. J Immunol 1994; $152: 5070-6$.

36. Gosker $H R_{\text {. }}$ Schrauwen $P$, Hesselink $M K_{*}$ et al. Uncoupling protein-3 content is decreased in peripheral skeletal muscle of patients with COPD. Eur Respir $₫ 2003 ; 22: 88-93$.

37. Di Francia $M$, Barbier D, Mege JL, Orehek J. Tumor necrosis factor-alpha levels and weight loss in chronic obstructive pulmonary disease. Am J Respir Crit Care Med 1994;150:1453-5.

38. Schols AM, Buurman WA, Staal van den Brekel Ad, Dentener MA, Wouters EF. Evidence for a relation between metabolic derangements and increased levels of inflammatory mediators in a subgroup of patients with chronic obstructive pumonary disease. Thorax 1996:51:819-24.

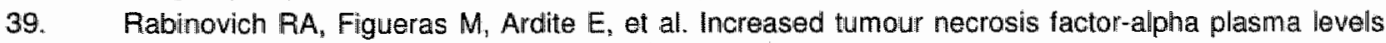

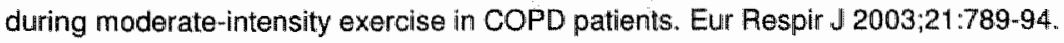

40. Tebib JG, Reynaud $\mathrm{C}_{\text {, }}$ Cedoz JP, Letroublon MC, Niveleau A. Relationship between urinary excretion of modified nucleosides and rheumatoid arthritis process. Br J Rheumatoll 1997;36:990-5. 


\section{Optimizing oral nutritional drink supplementation in patients with chronic obstructive pulmonary disease}

Roelinka Broekhuizen

Eva C. Creutzberg

Clarie A.P.M. Weling-Scheepers

Emiel F.M. Wouters

Annemie M.W.J. Sonols 


\section{Abstract}

\section{Background:}

Nutritional support is indicated in some patients with chronic obstructive pulmonary disease (COPD) to restore nutritional status and improve functional capacity. However, the efficacy of nutritional supplements is sometimes disappointing, partly owing to a compensatory drop in habitual food intake. We retrospectively studied the effect of nutritional drink supplements, differing in portion size and energy content, on weight gain and body composition.

\section{Methods:}

Thirty-nine patients with stable COPD, participating in an eight-week pulmonary rehabilitation program and eligible for nutritional support, were studied. Group $A$ $(n=19)$ received three portions of $125 \mathrm{mll}(2380 \mathrm{~kJ})$, whereas group $B(n=20)$ received three portions of $200 \mathrm{ml}(3350 \mathrm{~kJ})$ daily. The macronutrient composition of the regimens was similar (20 en\% protein, 60 en $\%$ carbohydrates and 20 en $\%$ fat). Lung function, body weight, body composition (by bioelectrical impedance analysis), habitual dietary intake (by dietary history) and resting energy expenditure (REE: by ventilated hood) were determined. Weight gain was compared with expected weight as predicted by a computer simulation model.

Results:

Although patients of both groups significantly increased in weight, this increase was higher in group $A\left(A: 3.3 \pm 1.9 \mathrm{~kg}_{i} B: 2.0 \pm 1.2 \mathrm{~kg}: p=0.019\right)$, while receiving less energy. Observed weight gain in group A was similar to expected, but in group $B$ it was lower than expected $(p<0.001)$. In both groups, fat-free mass and fat mass were gained in a ratio of $2: 1$, fat-free mass increasing primarily during the first four weeks.

\section{Conclusion:}

This study illustrates that there might be an optimum for the portion size of nutritional drink supplements in COPD and that more is not always better. 


\section{Introduction}

Weight loss and muscle wasting frequently occur in patients with chronic obstructive pulmonary disease (COPD), negatively influencing respiratory and peripheral muscle function (1), exercise capacity $(2,3)$, health status (4) and mortality (5).

As weight gain has been associated with decreased mortality (5), it is of great importance to maintain weight in COPD patients. Weight loss results from an imbalance in dietary intake and energy expenditure. In contrast to an adaptive decreased energy metabolism during (semi) starvation, increased total daily energy expenditure has been measured in ambulatory COPD patients $(6,7)$. The cause of this COPD-related increase in energy expenditure is not yet clear, although increased oxygen cost of breathing and possibly also a decreased mechanical and metabolic efficiency have been suggested to play a role (8).

Although the dietary intake of stable COPD patients has been shown to be adequate according to the recommended daily allowances $(9,10)$, patients can still lose weight owing to an insufficient adaptation of dietary intake to increased energy expenditure. Additional nutritional support is therefore indicated for these patients. Several studies have explored possibilities for reversing weight loss and improving body composition in patients with COPD. Although a Cochrane meta-analysis (11) previously concluded that nutritional supplementation did not have a significant effect on anthropometric measures, this issue is still under debate because of the limited available number of randomized controlled intervention studies.

In order to improve functional capacity and not only gain fat mass, nutritional support is best combined with an anabolic stimulus. One way to accomplish this is to integrate nutritional supplementation in a pulmonary rehabilitation program. This approach has been shown to increase weight and fatfree mass significantly $(12,13)$ and to improve respiratory and peripheral muscle function, exercise capacity and health status $(13,14)$. 
However, in the latter circumstances as well, the efficacy of nutritional supplements is sometimes disappointing, at least partly because of a compensatory drop in habitual food intake $(13,15,16)$. Voluntary food intake has been shown to be limited by the volume, frequency and energy density of the food portion, influencing symptoms like early satiety and bloating $(17,18)$. This suggests that there is an optimum in caloric load and/ or portion size in nutritional drink supplements. Nutritional drink supplements are commonly provided in $200 \mathrm{ml}$ packages. We hypothesized that smaller portions of energy-dense nutritional drink supplements administered between regular meals would improve the response to dietary management in COPD patients.

\section{Subjects and methods}

\section{Patients}

Patients with clinically stable COPD, consecutively admitted to an eight-week inpatient pulmonary rehabilitation center (Asthma Center Hornerheide, Horn, the Netherlands) during the periods 1995 - 1997 and 2000 - 2002, were included if they were considered eligible for nutritional support and if they met the criteria for COPD of the American Thoracic Society (ATS)(19) (see the section on lung function). Patients who met at least one of the following criteria were considered eligible for nutritional support and included in the study:

- Body mass index $(B M I) \leq 21 \mathrm{~kg} / \mathrm{m}^{2}$,

- Fat-free mass index (FFMl) $\leq 16$ (men) $/ 15$ (women) $\mathrm{kg} / \mathrm{m}^{2}$;

- $\mathrm{BMl} \leq 25 \mathrm{~kg} / \mathrm{m}^{2}$ and weight loss $\geq 5 \%$ in 1 month or $\geq 10 \%$ in 6 months prior to admission to the pulmonary rehabilitation center.

Patients were excluded if they were prescribed less than three cartons of nutritional supplements per day or if patients received pharmacological interventions to enhance body composition. Patients were also excluded if they suffered from 
concurrent diseases such as malignancies, gastrointestinall or kidney abnormalities, metabolic or endocrine diseases and inflammatory diseases.

\section{Research design}

To evaluate two different nutritional supplement regimes, we compared 19 COPD patients (group A, admitted to the rehabilitation center in $2000-2002$ ) receiving three $125 \mathrm{ml}$ cartons daily with a historical group of 20 patients (group $\mathrm{B}_{\text {, admitted }}$ to the rehabilitation center in 1995 - 1997) taken from the nutritionall intervention study of Creutzberg et al. (13) (figure 1). The historical group was matched with group A in terms of age, gender and oral corticosteroid use and received three 200 $\mathrm{ml}$ cartons per day.

Group A $(n=19)$ received three $125 \mathrm{ml}$ cartons of Respifor $(2380 \mathrm{~kJ}=6.35$ $\mathrm{kJ} / \mathrm{ml} ; 20$ en $\%$ from protein, 60 en\% from carbohydrate, 20 en $\%$ from fat, Nutricia B. V., Zoetermeer, the Netherlands), whereas group B $(n=20)$ received three $200 \mathrm{ml}$ cartons (one Ensini, one Fortimel, one Nutridrink $=3350 \mathrm{~kJ}=4.19 \mathrm{~kJ} / \mathrm{ml}: 22.3 \mathrm{en} \%$ from protein, 59.7 en\% from carbohydrate, 18 en\% from fat, Nutricia B.V.) daily for eilght weeks. The supplements were labelled with the name of each individual patient and handed out between regular standardized meals three times a day at standardized times in order to have control on their intake. Except for the nutritional supplement regimes, all circumstances were the same for both groups during the rehabilitation. In addition, during the first two weeks after admission and before the eight weeks of rehabilitation, patients received only regular meals from the rehabilitation center in order to create a standardized starting-point for both groups.

Nutritional intervention was embedded in an eight-week, standardized in-patient rehabilitation program, consisting of a combination of endurance and strength exercise training. The daily program comprised of $2 \times 20$ min submaximal cycle ergometry, $1 \times 20$ min treadmill exercise, $1 \times 30$ min gymnastics and one session of unsupported arm exercise training (consisting of $10 \times 1 \mathrm{~min}$ exercise, each minute 


\section{Body composition}

Body height was determined to the nearest $0.5 \mathrm{~cm}$ (WM 715; Lamaris, Breukelen, the Netherlands) with subjects standing barefoot. Bodly weight was measured with a beam scale to the nearest $0.1 \mathrm{~kg}$ (model 708, Seca, Hamburg, Germany) with subjects wearing light clothing and no shoes. Body mass index (BMI) was calculated as weight divided by height ${ }^{2}\left(\mathrm{~kg} / \mathrm{m}^{2}\right)$. Fat-free mass (FFM; $\mathrm{kg}$ ) was estimated using single frequency $(50 \mathrm{kHz})$ bioelectrical impedance analysis (BIA; Xitron Technologies, San Diego, CA, USA), with the subjects lying supime. FFM was calculated using the disease-specific equation proposed by Schols and described by Steiner (20). FFM index (FFMI) was calculated as FFM divided by height ${ }^{2}\left(\mathrm{~kg} / \mathrm{m}^{2}\right)$. Fat mass (FM) was calculated as total body weight minus FFM. Body weight, FFM and FM were measured at baseline and after two, four, six and eight weeks of intervention. Treatment non-response was defined as a body weight gain $<2 \%(21)$.

\section{Lung function}

COPD was defined according to the criteria for COPD of the ATS (19), as an FEV below $70 \%$ of the predicted value with reversibility after inhalation of a bronchodilator of less than $200 \mathrm{ml}$ or $10 \%$ of the reference value. FEV 1 was assessed from the flow-volume curve using a spirometer (Masterlab, Jaeger, Würzburg, Germany). The highest value of at least three measurements was used. $\mathrm{FEV}_{1}$ was also assessed $15 \mathrm{~min}$ after inhalation of a bronchodilator ( $\beta$-agonist) via a metered-dose inhaler to determine reversibility. $D L_{C O}$, which is an indirect measure of emphysema, was determined using the single-breath method (Masterlab, Jaeger). Instruments were calibrated twice daily. Lung functional parameters were expressed as a percentage of reference values (22). FEV 1 was determined at baseline and after eight weeks of intervention, and $D L_{C O}$ was determined at baseline. 


\section{Energy balance}

REE was measured in the early morning (08.30 hours) at baseline and after eight weeks of intervention by indirect calorimetry using a ventilated hood (Oxycon Beta, Jaeger). The system was calibrated daily at the start of the experiment, accuracy being regularly assessed using a methanol combustion test. Patients were in a fasting state for at least 10 hours and had a period of at least $30 \mathrm{~min}$ bed rest prior to the measurement. When patients were receiving additional oxygen during hospitalization, the oxygen was temporarily withdrawn $30 \mathrm{~min}$ before and during the measurement of REE. The patients lay comfortably on a bed in the supine position. REE was calculated from $\mathrm{O}_{2}$ consumption and $\mathrm{CO}_{2}$ production using the abbreviated Weir formula (23). The ratio of REE and FFM was used for analysis.

Habitual dietary intake was assessed at baseline using the dietary history method with cross-checking. All interviews were performed by the same trained dietitian. Computer nutrient analysis was performed with a program based on food tables (Becel Nutrition Program 96; Nederlandse Unilever Bedrijven B.V. Rotterdam, the Netherlands).

\section{Exercise capacity}

An incremental bicycle ergometry test was performed at baseline and after eight weeks on an electromagnetic braked ergometer (Corival 400, Lode, Groningen, the Netherlands) under supervision of a chest physician to investigate maximal leg exercise capacity. After 2 min of rest and 1 min unloaded cycling, the power was increased every minute by $10 \mathrm{~W}$ until exhaustion. Peak workload was used in the analysis.

\section{Health status}

At baseline and after eight weeks of intervention, disease-specific health status was measured by the St. George's Respiratory Questionnaire (SGRQ) (24). The patients completed the 50 items themselves, after which subscores were 
calculated for the categories of symptoms (distress owing to respiratory symptoms), activity (disturbance of physical activity), impact (overall impact on daily life and well-being), as well as the total score (the weighted mean of the three scores). Subscores ranged from 0 to 100 , a high score denoting greater impairment. A change of four or more points in total score is considered clinically significant, decreases being beneficial (25).

\section{Data handing and statistical analysis}

Results are presented as mean ( \pm standard deviation $(S D)$ ) for normally distributed variables. Differences between baseline characteristics of separate groups were tested using Student's $t$-test for independent samples when normally distributed. Changes within the groups between baseline and eight weeks were tested using the Student's paired $t$-test. The changes in body composition were compared between groups using linear regression with baseline value, age, gender and assigned intervention group as predictors. The percentage of non-responders between the groups was compared with the $\chi^{2}$ test. Data were analyzed using SPSS (Statistical Packagle for the Social Sciences, version 11 for Windows, SPSS Inc., Chicago, IL, USA). Significance was assumed at a $p$-value of 0.05 .

A computer model taking into account the patient's gender, age, height, body composition and dietary intake (26) was used for estimating the predicted weight gain on the basis of a net rise in dietary intake after nutritional supplementation. Changes in body composition were performed separately for men and women, and the weighed mean was taken for analysis. 


\section{Results}

At baseline, patients in group A and B did not differ significantly in age, gender, lung function and body composition. Energy balance at baseline, as determined by resting energy expenditure and dietary intake, was also not significantly different between the two groups, the same being true for baseline peak work load. Patients in group $B$ had a worse score on the impact dimension of the SGRQ $(p=0.030)$. The other three dimensions, however, were not significantly different (table 1).

Table 1: Baseline characteristics of graups $A$ and group $B^{1}$

\begin{tabular}{|c|c|c|c|c|c|c|}
\hline & & \multicolumn{2}{|c|}{ Croup A } & \multicolumn{2}{|c|}{ Group B } & \multirow[t]{2}{*}{ p-value } \\
\hline & & mean & $( \pm$ SD) & mean & ( \pm SD) & \\
\hline n & $(\mathrm{M} / \mathrm{F})$ & 19 & $(14 / 5)$ & 20 & $(16 / 4)$ & n.s. \\
\hline Age & (yrs) & 62.0 & $(f 11,1)$ & 63.5 & $( \pm 8.0)$ & nis. \\
\hline$F E V$ & (\%pred) & 35.7 & $( \pm 15.2)$ & 35.0 & $( \pm 7.3)$ & ns. \\
\hline $\mathrm{DL}_{60}$ & (\% pred) & 44.1 & $( \pm 16,5)$ & 47.4 & $( \pm 20.2)$ & n.s. \\
\hline Weight & $(\mathrm{kg})$ & 57.5 & $( \pm 7.7)$ & 56.8 & $( \pm 5.2)$ & m.s. \\
\hline BMI & $\left(\mathrm{kg} / \mathrm{m}^{2}\right)$ & 201 & $( \pm 1.9)$ & 197 & $( \pm 1.8)$ & ns. \\
\hline FFMI & $\left(\mathrm{kg} / \mathrm{m}^{2}\right)$ & 15.3 & $( \pm 1.0)$ & 15.1 & $( \pm 1.3)$ & n.s. \\
\hline $\mathrm{FM}$ & $(\%)$ & 23.6 & $( \pm 5: 2)$ & 23.0 & $( \pm 8.0)$ & nis: \\
\hline REE/FFM & $(\mathrm{kJ} / \mathrm{kg})$ & 128 & $( \pm 16)$ & 140 & $( \pm 31)$ & n.s. \\
\hline Dietary intake & $(\mathrm{kJ})$ & 8193 & $( \pm 2379)$ & 7886 & $(+2934)$ & ns. \\
\hline Intake/ REE & & 1.49 & $( \pm 0.49)$ & 1.33 & $( \pm 0.32)$ & n.s. \\
\hline Poak Load & (W) & 57 & $( \pm 31)$ & 52 & $( \pm 15)$ & n.s. \\
\hline SGRQ Symptom & (points) & 58 & $( \pm 16)$ & 54 & $( \pm 22)$ & n.s. \\
\hline SGRQ Activity & (points) & 59 & $( \pm 22)$ & 59 & $( \pm 23)$ & n.s. \\
\hline SGRQ/mpact & (points) & 31 & $( \pm 11)$ & 35 & $( \pm 16)$ & 0,030 \\
\hline SGRQ Total & (points) & 44 & $( \pm 12)$ & 45 & $( \pm 16)$ & n.s. \\
\hline
\end{tabular}


After eight weeks of nutritional intervention combined with pulmonary rehabilitation, both groups showed a significant gain in weight (both groups: $p<0.001$ ) and FFM (group $A: p<0.001$, group $B: p=0.004$ ) (table 2). FM was significantly increased in group $A(p=0.002)$, but not in group $B(n . s$.$) . The patients of group A$, however, gained more weight than patients of group $B(p=0.019)$ (figure 2 and table 2$)$. The proportional increases in FFM and FM were similar in both groups (group A: 66\% FFM, 34\% FM; group B: 70\% FFM, 30\% FM, p=n.s.). Figure 3 shows the change in FFM and FM after four and eight weeks of rehabilitation. It is remarkable that almost all the gain in FFM was obtained during the first four weeks of rehabilitation (group A: $2.1( \pm 1.9) \mathrm{kg}, p<0.001$ vs. group $B: 1.2( \pm 2.4) \mathrm{kg}, p=0.035$, between groups: $p=n . s$.$) . FM was primarily gained during the second half of the$ rehabilitation (group $A: 1.1( \pm 1.0) \mathrm{kg}, p<0.001$ vs. group $B: 0.8( \pm 1.8) \mathrm{kg}, p=n . s$., between groups: $p=n . s$.). Figure 4 shows the observed increase in body weight compared to the expected increase in body weight, as predicted by the Westerterp (26) model. In group $A$, the observed rise in body weight was similar to the expected rise $(3.3( \pm 1.9) \mathrm{kg}$ vs. $3.4 \mathrm{~kg}, \mathrm{p}=\mathrm{n} . \mathrm{s}$.). In group $\mathrm{B}$, however, the finally achieved rise in body weight was lower than the expected value $(2.0( \pm 1.2) \mathrm{kg}$ vs. $4.8 \mathrm{~kg}, \mathrm{p}<0.001)$.

Table 2: Change in body weight. FFM and FM and percentage of mon-response of the palients during eight weeks of intervention and rehabilitation'

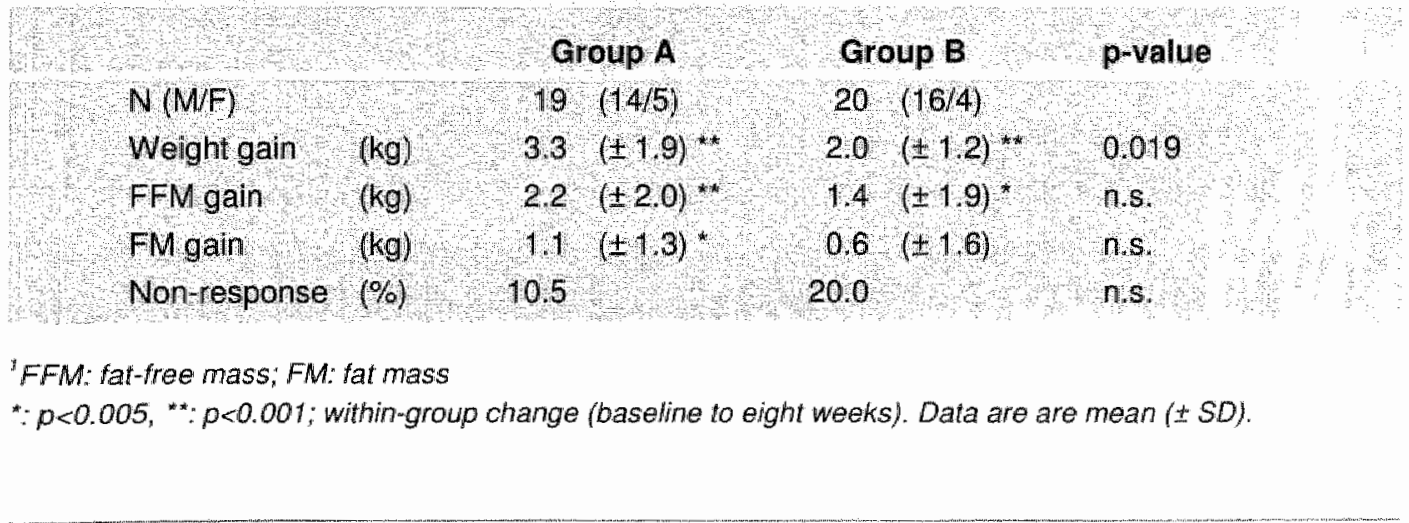




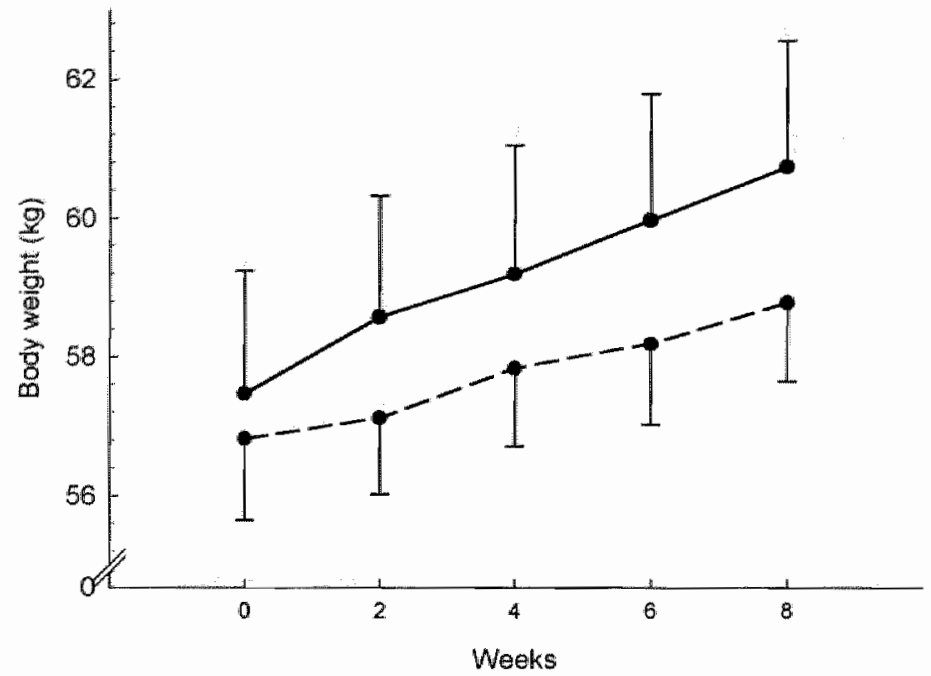

Figure 2: Course of body weight per two weeks during eight weeks of nutritional therapy. The change in body weight of group A (solid line: $3.3( \pm 1.9) \mathrm{kg}$ ) was significantly higher than that of group $B$ (dashed line: 2.0 (1.1.2) $\mathrm{kg} ; p=0.019)$.

Changes in health status during the intervention are shown in table 3. No significant differences in change in health status were found. However, only in group A did the total score decrease more than four points, which is considered a clinically significant improvement.

There were no differences in functional response between the two groups. Peak workload during the incremental bicycle ergometry test increased similarly in both groups (group A: $8.3( \pm 17.1) \mathrm{W}$, within-group change: $p=0.062$; group $B: 9.0( \pm$ 9.4) W, within-group change: $p=0.002$; between-group: $p=n . s$.). FEV $V_{f}$ did not change significantly (group A: 0.7 ( \pm 8.4 ) \%pred, within-group change: $p=n . s$.; group B: -2.3 ( 15.5 ) \% pred, within-group change: $p=n . s_{\text {.; }}$ between group change: $p=n . s_{\text {. }}$ ), nor did REE/FFM (group A: -0.7 ( \pm 5.6 ) $\mathrm{kcal} / \mathrm{kg}$, within-group change: $p=n . s_{\text {; }}$ group $B:-3.1( \pm 6.0) \mathrm{kcal} / \mathrm{kg}$, within-group change: $p=0.048$; between group change: $p=n . s$.$) .$ 


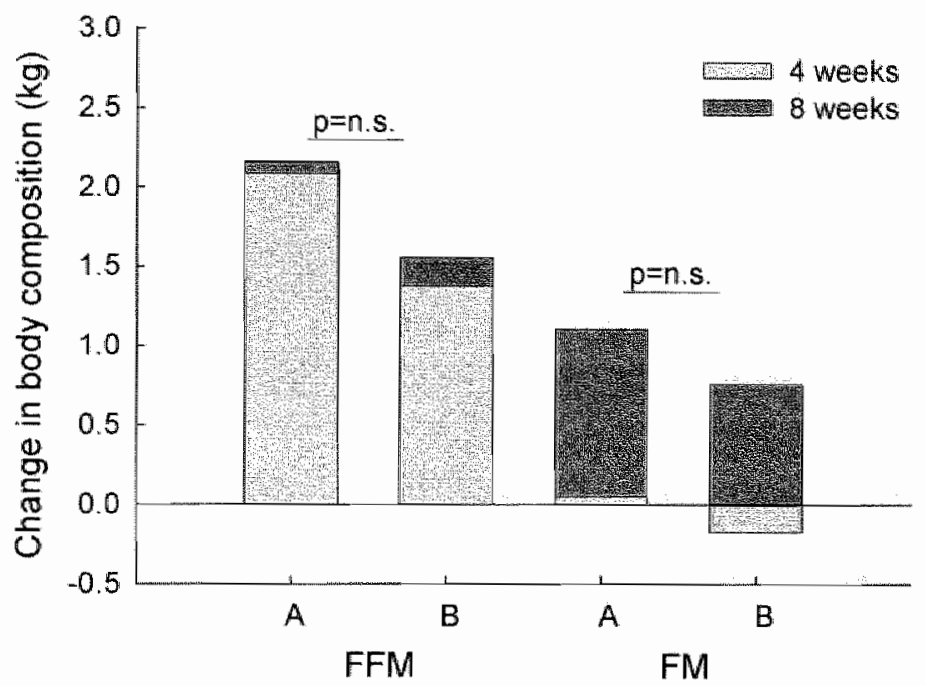

Figure 3: Change in FFM and FM after four and eight weeks of rehabilitation in groups $A$ and $B$. Patients in group $A$ gained more weight than patients in group $B(p=0.019$, see also table 2). Almost all FFM was gained during the first fourweeks of rehabilitation (light grey shading). FM was primarily gained during the second half of the rehabilitation (dark grey shading).

Table 3: Change in health status during eight weeks of nutritional intervention as part of pulmonary rehabilitation

\begin{tabular}{|c|c|c|c|c|}
\hline Change in & & Group A & Group B & p-value \\
\hline SGRO-Symptom & (points) & $9.9( \pm 16.9)^{\circ}$ & $-15.8( \pm 12.9)^{*}$ & ns: \\
\hline SGRQ-Activity & (points) & $7.0( \pm 15.2)^{\wedge}$ & $4.1 \quad( \pm 20.8)$ & ns. \\
\hline SGRQ-Impact & (points) & $-27( \pm 13.4)$ & $-0.0 .( \pm 13.9)$ & n.s. \\
\hline SGRQ-Total & (points) & $-5.4( \pm 10.7)^{\wedge}$ & $-1.4(+130)$ & nis. \\
\hline
\end{tabular}

'SGRQ: Saint George's Respiratory Questionnaire

$*: 0<0.05 ; \wedge: 0<0.08$ (within-group change (baseline to eight weeks). Data are are mean ( \pm SO). 


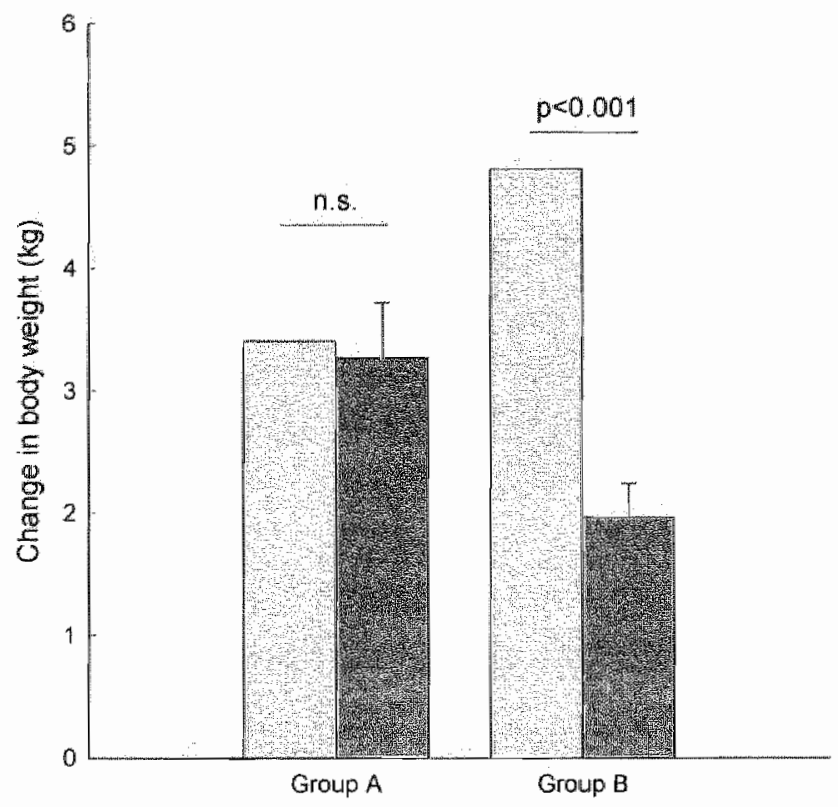

Figure 4: Observed weight gain (dark grey bars) compared to expected weight gain (tight grey bars) after eight weeks of nutritional supplementation. The observed body weight gain (3.3 (SEM 0.45) $\mathrm{kg}$ ) of group A was similar to the expected weight gain $(3.4 \mathrm{~kg}$; $p=n . \mathrm{s}$.). In group $B$, the observed body weight gain $(2.0$ (SEM 0.28) kg) was significantly less than the expected weight gain (4.8 $\mathrm{kg} ; p_{<0.001)}$. Data are presented as mean (SEM).

\section{Discussion}

This study shows a remarkable difference in response to two different nutritionall supplement regimes. Although patients in group A received less energy, they gained more weight than did the patients receiving commonly used $200 \mathrm{ml}$ portions. Since both nutritional support regimes were incorporated in a pulmonary rehabilitation program, the proportional gain of FFM was higher than the gain of FM and similar in both groups. FFM was primarily gained during the first four weeks of rehabilitation. 
The most likely explanation for the difference in weight response between the different portion sizes is a load-related drop in habitual dietary intake. Previous nutritional intervention studies in COPD have shown that patients tend to eat less of their regular meals during nutritional support consisting of liquid supplements $(13,15,16)$. Unfortunately, it is virtually impossible to measure changes in dietary intake accurately (27) especially during a prolonged intervention period and in conditions such as COPD (28) that are characterized not only by clinically stable periods, but also by acute exacerbations that may cause a temporary drop in dietary intake (29). Therefore, we did not measure the change in daily dietary intake in this study. However, as patients of group A increased in weight as predicted by the model from Westerterp et al. (26), it is not likely that these patients compensated in terms of their habitual intake. On the other hand, the increase in weight in patients of group B was significantly smaller than the predicted value. This may point towards a compensatory adaptation of the regular meals in the patients receiving the $200 \mathrm{ml}$ packages.

Compensation in habitual food intake can result from increased or prolonged satiety after the ingestion of the drink supplements in COPD patients, who already suffer from increased feeling of bloating and early satiety because of hyperinflation, a flattened diaphragm and a reduction in abdominal volume (30). Vermeeren et al. showed that postprandial satiety sensation is indeed adversely affected by the caloric load of nutritional supplements in COPD patients (31). In elderly hospitalized patients, it has been shown that volume rather than energy density limits the voluntary energy intake of food (17), which could largely be overcome by reducing portion size and increasing meal frequency (32). A similar observation has also been made in a study in adult patients with cystic fibrosis, which reported that reducing the volume and increasing the frequency of oral nutritional supplements relieved symptoms like fullness, nausea and bloating (18). 
One of the reasons that smaller portions lead to less satiety may be related to gastric emptying, as more volume in the stomach leads to a prolonged gastric emptying time. Another factor influencing gastric emptying is the fat content of food ingested, as high-fat meals have been shown to delay gastric emptying in COPD patients (33). In the present study, although the macronutrient content was simillar in both supplementary regimes, patients in group $B$ received more fat in absolute terms owing to the larger portion size. In addition, the extra volume of the $200 \mathrm{ml}$ supplements could theoretically have had a significant influence on the time needed to empty the stomach and therefore on prolonged feelings of satiety, leading to a drop in intake of regular meals.

The proportion of non-responders defined as patients with body weight gain less than $2 \%$ (21) was not significantly different in both groups. The in-patient setting of the rehabilitation center provided the same control over the adherence to the nutritional therapy and over the standardization of the exercise training for both groups. Creutzberg et al. previously characterized non-responders by a higher age, an enhanced systemic inflammatory response and a decreased spontaneous dietary intake (21). In the present study, group A and B did not differ in the parameters of age, lung function, baseline habitual dietary intake, basal metabolic rate, relative anorexia and systemic corticosteroid use. Unfortunately, no markers of systemic inflammation were included in this study.

Groups $A$ and $B$ gained FFM and FM in the same ratio, which is indicative of a similar anabolic stimulus. Another indication for this is a similar outcome of the rehabilitation program, as is reflected by comparable improvement in peak workload during incremental cycle ergometry. Improvements in exercise capacity are, however, not necessarily reflected in increases in FFM, as was observed in the present study $(34,35)$. To measure improvements in skeletal muscle function related to increases in FFM, sensitive tests of the lower limb function, such as 
isokinetic strength testing or magnetic simulation, should be used $(36,37)$.

This difference in gain in FFM between the two food regimens was most pronounced in the first four weeks of rehabilitation. A higher increase in FFM in the first four weeks has also been reported in a prior publication of our group (12). During the second four weeks, a gain predominantly in FM was seen in both studies. This indicates that timing and harmonization of training to nutritional intervention, for example by switching the intensity or type of exercise, may be of importance to further optimize the efficacy of nutritional support.

As weight loss is a predictor of mortality in COPD and weight gain has been associated with increased survival $(5,38)$, the weight gain of nutritionally depleted patients is of the utmost clinical importance. In this study, we show that simply decreasing the portion size of nutritional drink supplements from 200 to $125 \mathrm{ml}$ is a useful strategy to increase the efficacy of supplemental nutrition in terms of weight gain in depleted patients with COPD.

Nutritional supplements were kindly provided by Numico Research B.V. Numico Research B.V. did not play any role during collection, analysis or interpretation of the data, in writing the reports or deciding to submit the results. 


\section{References}

1. Engelen MPKJ, Schois AMWJ, Baken WC, et al. Nutritional depletion in relation to respiratory and peripheral skeletal muscle function in out-patients with COPD. Eur Respir $\$ 1994 ; 7: 1793-7$.

2. Schols AM, Soeters PB, Dingemans AM, Mostert R, Frantzen PJ, Wouters EF. Prevalence and characteristics of nutritional depletion in patients with stable COPD eligible for pulmonary rehabilitation. Am Rev Respir Dis 1993;147:1151-6.

3. Baarends EM, Schols AM, Mostert R, Wouters EF. Peak exercise response in relation to tissue depletion in patients with chronic abstructive pulmonary disease. Eur Respir $\mathrm{J}$ 1997; 10:2807-13.

4. Shoup $R$, Dalsky $G$, Warmer $S$, et al. Body composition and health-related quality of life in patients with obstructive airways disease. Eur Respir $\mathrm{J} 11997 ; 10: 1575-80$.

5. Schols AM, Slangen J, Volovics L, Wouters EF. Weight loss is a reversible factor in the prognosis of chronic obstructive pulmonary disease. Am J Respir Crit Care Med 1998;157:1791-7.

6. Baarends EM, Schols AMWJ, Pannemans DL, Westerterp KR, Wouters EFM. Total free living energy expenditure in patients with severe chronic obstructive pulmonary disease. Am J Respir Crit Care Med 1997;155:549-54.

7. Slinde $F$, Ellegard $L$, Granberg $A M$, et al. Total energy expenditure in underweight patients with severe chronic obstructive pulmonary disease tiving at home. Clin Nutr 2003:22:159-65.

8. Baarends EM, Schols AM, Akkermans MA, Wouters EF. Decreased mechanical efficiency in clinically stable patients with COPD. Thorax $1997 ; 52: 981-6$.

9. Hunter AM, Carey MA, Larsh HW. The nutritional status of patients with chronic obstructive pulmonary disease. Am Rev Respir Dis 1981;124:376-81.

10. Braun SR, Keim NL, Dixon RM, Clagnaz $P_{3}$ Anderegg $A_{y}$ Shrago ES. The prevalence and determinants of nutritional changes in chronic obstructive puimonary disease. Chest 1984,86:558-63.

11. Ferreira $I M$, Brooks D, Lacasse $Y$, Goldstein RS, White J. Nutritional supplementation for stable chronic obstructive pulmonary disease. Cochrane Database Syst Rev 2002:CD000998.

12. Schols AM, Soeters PB, Mostert R, Pluymers RJ, Wouters EF. Physiologic effects of nutritional support and anabolic steroids in patients with chronic obstructive pulmanary disease. A placebocontrolled randomized trial. Am J Respir Crit Care Med 1995;152:1268-74.

13. Creutzberg EC. Wouters EF, Mostert R, et al. Efficacy of nutritional supplementation therapy in depleted patients with chronic obstructive pulmonary disease. Nutrition 2003;19:120-7.

14. Rogers RM; Donahoe $M$, Costantino J. Physiologic effects of oral supplemental feeding in malnourished patients with chronic obstructive pulmonary disease. A randomized control study. Am Rev Respir Dis 1992;146:1511-7.

15. Knowles JB, Fairbarn MS, Wiggs Bd, Chan-Yan C. Pardy RL. Dietary supplementation and respiratory muscle pertormance in patients with COPD. Chest 198:8;93:977-83.

16. Lewis MII, Belman MJ, Dorr-Uyemura L. Nutritional supplementation in ambulatory patients with chronic abstructive pulmonary disease. Am Rev Respir Dis 1987;135:1062.8.

17. Olin AO, Osterberg P. Hadell K, Armyr I, Jerstrom S, Ljungqvist O. Energy-enriched haspital food to improve energy intake in elderly patients. JPEN J Parenter Enteral Nutr 1996;20:93-7.

18. Rettammel AL, Marcus MS, Farrell PM. Sondel SA, Koscilk RE, Mischler EH. Oral supplementation with a high-fat, high-energy product improves nutritional status and alters serum lipids in patients with cystic fibrosis. J Am Diet Assoc 1995;95:454-9. 
19. ATS. Standards for the diagnosis and care of patients with chronic obstruclive pulmonary disease. American Thoracic Society. Am J Respir Crit Care Med 1995:152:S77-121.

20. Steiner MC, Barton RiL, Singh SJ, Morgan MD. Bedside methods versus dual energy $X$-ray absorptiometry for body composition measurement in COPD. Eur Respir J 2002:19:626-31.

21. Creutzberg EC, Schols AM, Weling-Scheepers CA, Buurman WA, Wouters EF. Characterization of nonresponse to high calloric oral nutritional therapy in depleted patients with chronic obstructive puimonary disease. Am J Respir Crit Care Med 2000;161:745-52.

22. Quanjer PHe. Standardized lung function testing. Official statement of the European Respiratory Society [see comments]. Eur Respir J 1993;6 (suppl. 16):1-100.

23. Weir sB. New methods for calculating metabolic rate with special reference to protein metabolism. 1949. Nutrition 1990;6:213-21.

24. Jones PW, Quirk FH, Baveystock CM. The St George's Respiratory Questionnaire. Respir Med $1991 ; 85$ Suppl B:25-31; discussion 33-7.

25. Jones PW. Issues concerning health-related quality of life in COPD. Chest 1995; 107:1875-1935.

26. Westerterp KR, Donkers $\mathrm{JH}_{\text {}}$ Fredrix EW, Boekhoud P. Energy intake, physical activity and body weight: a simulation model. Br J Nutr 1995;73:337-47.

27. Schoeller DA. How accurate is self-reported dietary energy intake? Nutr Rev 1990;48:373-9.

28. Goris AH, Meijer EP, Westerterp KR. Repeated measurement of habitual food intake increases under-reporting and induces selective under-reporting. Br J Nutr 2001;85:629-34.

29. Vermeeren MA, Schols AM, Wouters EF. Effects of an acute exacerbation on nutritional and metabolic profile of patients with COPD. Eur Respir J 1997;10:2264-9.

30. Donahoe M, Rogers RM. Nutritional assessment and support in chronic obstructive pullmonary disease. Clin Chest Med 1990;11:487-504.

31. Vermeeren MA, Wouters EF, Nelissen LH, van Lier AA, Hofman Z, Schols AM. Acute effects of different nutritional supplements on symptoms and functional capacity in patients with chronic obstructive pulmonary disease. Am J Clin Nutr 2001;73:295-301.

32. Barton $A D$, Beigg $C L$, Macdonald IA, Allison SP. A recipe for improving food intakes in elderly hospitalized patients. Clin Nutr 2000;19:451-4.

33. Akrabawi SS, Mobarhan $S$, Stoltz RR, Ferguson PW. Gastric emptying, pulmanary function, gas exchange and respiratory quotient after feeding a moderate wersus high fat enteral formula meal in chronic obstructive pulmonary disease patients. Nutrition 1996;12:260-5.

34. Young $A$, Stokes $M$, Round JM, Edwards RH. The effect of high-resistance training on the strength and cross-sectional area of the human quadriceps. Eur J Clin Invest 1983;13:411-7.

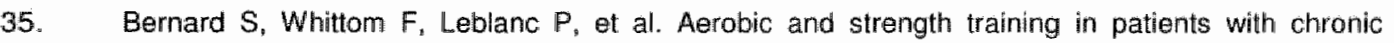
obstructive pulmonary disease. Am J Respir Crit Care Med 1999;159:896-901.

36. Gosker HR, Lencer NH, Franssen FM, van der Vusse Ga, Wouters EF, Schols AM. Striking similarities in systemic factors contributing to decreased exercise capacity in patients with severe chromic heart failure or COPD. Chest 2003;123:1416-24.

37. Polkey MI. Muscle Metabolism and Exercise Tolerance in COPD("). Chest 2002;121:131S 55 .

38. Prescott $E$, Almdal T, Mikkelsen KL, Tolteng $\mathrm{CL}$, Vestbo J, Lange P. Prognostic value of weight change in chronic obstructive pulmonary disease: results from the Copenhagen City Heart Study. Eur Respir J 2002;20:539-44. 


\section{Polyunsaturated fatty acids improve exercise capacity in chronic obstructive pulmonary \\ disease}

Roelinka Broekhuizen

Emiel F.M. Wouters

Eva C. Creutzberg

Clarie A P M Weling-Scheepers

Annemie M.W.J. Schols 


\section{Abstract}

\section{Background:}

Muscle wasting and decreased muscle oxidative capacity commonly occur in patients with chronic obstructive puimonary disease (COPD). Polyunsaturated fatty acids (PUFA) have been shown to mediate several inflammatory and metabolic pathways, which may be involved in the pathogenesis of muscle impairment in COPD. The aim of this study was to investigate the effect of PUFA modulation on systemic inflammation, reversal of muscle wasting and functional status in COPD.

Methods:

Eighty patients wit COPD (57 men) with forced expiratory volume in one second $\left(F E V_{1}\right) 37.3$ ( \pm 13.8 ) \%predicted received 9 g PUIFA or placebo daily in a doubleblind randomized fashion during an eight-week rehabilitation program. Body composition (bioelectrical impedance), functional capacity (lung function, incremental cycle ergometry test, submaximal cycle test, isokinetic quadriceps strength) and inflammatory markers (C-reactive protein (CRP), interleukin (IL)-6 and tumor necrosis factor-a (TNFa) were assessed at baseline and after 8 weeks.

\section{Results:}

Both groups had similar increases in weight, fat-free mass (FFM) and muscle strength. The peak load of the incremental exercise test increased more in the PUFA group than in the placebo group (difference in increase: $9.7 \mathrm{~W}(95 \% \mathrm{Cl}: 2.5$, 17.0), $\mathrm{p}=0.009$ ) even after adjustment for FFM. The duration of the constant work rate test also increased more in the patients receiving PUFA (difference in increase: $4.3 \mathrm{~min}(95 \% \mathrm{Cl}: 0.6,7.9), \mathrm{p}=0.023)$. The positive effects of PUFA could not be attributed to a decrease in systemic levels of CRP, IL-6 and TNFa.

\section{Conclusions:}

This is the first study to show beneficial effects of PUFA on exercise capacity in patients with COPD. 


\section{Introduction}

At present, the treatment of chronic obstructive pulmonary disease (COPD) is predominantly focused on primary organ dysfunction. However "COPD is increasingly emerging as a multiorgan systemic disease. Skeletal muscle weakness has been shown independently to aggravate important symptoms such as dyspnea and impaired exercise performance (1).

Skeletal muscle performance is characterized by strength and endurance. Muscle wasting, which has been linked to enhanced systemic inflammation (2), is common in patients with COPD, adversely affecting muscle strength and exercise capacity (3). Independent of muscle wasting, intrinsic abnormalities in peripheral skeletal muscle morphology and metabolism have been described in COPD patients, pointing towards a decreased oxidative capacity. These abnormalities include muscle fiber type shifts from the oxidative type | fibers towards the glycolytic type IIx fibers (4) and a decrease in oxidative enzymes involved in carbohydrate and fatty acid oxidation (5). These metabolic adaptations have clinical consequence as illustrated by a decreased mechanical efficiency (6) and enhanced lactic acid production during cycling compared with healthy control subjects (7). In addition, nuclear magnetic resonance (NMR) studies using single limb exercise models showed a rapid decline and impaired recovery of phosphocreatine stores ( 8 ).

Positive effects of pulmonary rehabilitation, particularly of endurance exercise training, illustrate that decreased muscle oxidative capacity in COPD is at least partially reversible (8). The available studies show that it is difficult to enhance this improvement by modulating exercise type and intensity only (9). It is therefore tempting to explore the potential of nutritional modulation on muscle substrate metabolism to enhance improvement of exercise capacity in COPD. Previous research in optimizing rehabilitation with nutrition has led toward a combination of 
training with a protein and energy-dense supplementation in cachectic COPD patients, increasing their fat-free mass (FFM) and muscle function (10). However some patients, characterized by an increased systemic inflammatory response, did not respond sufficiently to this combination in treatment and, as a consequence, did not gain weight or FFM (11).

Previous experimental research and clinical studies in other conditions indicate that the response to rehabilitation might be improved by polyunsaturated fatty acids (PUFA) $(12,13)$. PUFA can modulate nuclear factor kappa B (NF-kB) (14), subsequently influencing local and systemic cytokine biology. NF-kB is a transcription factor that is activated in response to inflammatory cytokines in many cell types, including skeletal myocytes. A recent study provided evidence for NF-KB activation in muscle biopsies of severely underweight COPD patients (15), making it a potential interesting target for modulation by PUFA. In addition, PUFA have been shown to upregulate (fat) oxidative gene expression by activation of peroxisome proliferators activated receptors (PPARs) (16). The latter mechanism could explain the results of a recent study in cachectic patients with pancreas cancer which found that PUFA supplementation increased physical activity level assessed by doubly labeled water (13).

The aim of the present study was to investigate the effect of PUFA supplementation on the outcome of pulmonary rehabilitation of COPD patients, firstly determined by functional performance and exercise capacity and, secondly, as determined by a reversal of muscle wasting in relation to chronic low-grade inflammation. 


\section{Subjects and methods}

\section{Subjects}

The study population consisted of Dutch patients with clinically stable GOLD stage II-IV COPD consecutively admitted to an in-patient pulmonary rehabilitation center (Asthma Center Hornerheide, Horn, the Netherlands) during the years 2000 - 2002. Patients were excluded if suffering from concurrent diseases such as malignancies, gastrointestinal or kidney abnormalities, metabolic or endocrine diseases and inflammatory diseases. During rehabilitation patients received maintenance respiratory medication that in general consisted of inhaled bronchodilators, inhaled corticosteroids, and, when indicated, theophyllines.

\section{Intervention}

The study design was placebo-controlled, randomized and double-blind. During an eight-week training program all patients received nine capsules daily, each capsule containing $1 \mathrm{~g}$ of either a blend of PUFA or placebo. The daily dosage of PUFA consisted of $3.4 \mathrm{~g}$ active fatty acids, a blend of $400 \mathrm{mg}$ stearidonic acid (STA, 18:4n-3), $760 \mathrm{mg}$ gamma-linoleinic acid (GLA, 18:3n-6), $1200 \mathrm{mg}$ alpha-linolenic acid (ALA, 18:3n-3), $700 \mathrm{mg}$ eicosapentanoic acid (EPA, 20:5n-3) and $340 \mathrm{mg}$ docosahexanoic acid (DHA, 22:6n-3). The placebo capsules contained $80 \%$ palm oil and $20 \%$ sunflower oil and had the same caloric content ( $9 \mathrm{kcal} / \mathrm{capsule}$ ) as the PUFA capsules. All capsules were enriched with $3.5 \mathrm{mg} / \mathrm{g}$ vitamin $E$ to stabilize the oil and to serve as an antioxidant. The patients who were depleted or suffering from recent weight loss ( $n=48,24$ in PUFA group and 24 in placebo group) also received three times daily liquid nutritional supplements (Respifor: $375 \mathrm{ml}$ total, containing $3.4 \mathrm{~g}$ PUFA (2.85 g linoleic acid (LA: 18:2n-6) and $0.6 \mathrm{~g}$ a-linolenic acid (ALA: 18:3n-3)). Depletion was defined as a body mass index (BMI: body weight/height ${ }^{2}$ ) $\leq 21 \mathrm{~kg} / \mathrm{m}^{2}$ and $/$ or tat-free mass index (FFMl: fat-free mass $/$ height $^{2}$ ) $\leq 16 \mathrm{~kg} / \mathrm{m}^{2}$ for men and $\leq 15 \mathrm{~kg} / \mathrm{m}^{2}$ for women. Capsules and drink supplements 
were given in between the regular meals under supervision of the staff of the inpatient rehabilitation center. The physical exercise training program, which was also blinded for PUFA intervention, consisted of a combination of supervised endurance and strength exercise training as described elsewhere (17).

The ethical review board of the University Hospital Maastricht approved the study and all patients gave their written informed consent.

\section{Measurements}

\section{Pulmonary function}

Forced expiratory volume in one second $\left(\mathrm{FEV}_{1}\right)$ and forced vital capacity (FVC) were assessed from the flow-volume curve using a spirometer (Masterlab, Jaeger, Würzburg, Germany) at baseline. $\mathrm{FEV}_{1}$ was also assessed 15 min after inhalation of $\beta$-agonists via a metered dose inhaller. Diffusing capacity for carbon monoxide ( $\left.D L_{c o}\right)$ was determined using the single breath method (Masterlab). Lung functional parameters were expressed as percentage of reference values (18). Blood was drawn from the brachial artery to analyze arterial oxygen tension $\left(\mathrm{PaO}_{2}\right)$ and carbon dioxide tension $\left(\mathrm{PaCO}_{2}\right)$ with a blood gas analyzer (Radiometer, $\mathrm{ABL}$ 330, Copenhagen, Denmark).

\section{Body composition}

At baseline and after eight weeks, BMI was calculated as weight divided by height ${ }^{2}$ $\left(\mathrm{kg} / \mathrm{m}^{2}\right)$. Fat-free mass (FFM; $\mathrm{kg}$ ) was measured using single frequency $(50 \mathrm{kHz})$ bioelectrical impedance analysis (BIA; Xitron Technologies, San Diego, CA, USA), with subjects in supine position. FFM of patients was calculated using the diseasespecific equation proposed by Schols and described by Steiner et al. (19). Fat-free mass index (FFMI) was calculated as FFM divided by height ${ }^{2}\left(\mathrm{~kg} / \mathrm{m}^{2}\right)$. 


\section{Blood sampling}

Fasting blood was collected in evacuated blood collecting tubes containing EDTA (Becton Dickinson Vacutainer Systems, Plymouth, UK) in the early morning (08.0010.00 hours.) at baseline and after eight weeks. After centrifuging twice at $1000 \mathrm{~g}$ for 10 min at $4^{\circ} \mathrm{C}$ within 2 hours of collection, plasma samples were stored at $70^{\circ} \mathrm{C}$ until analysis. Interleukin (L)-6 and tumor necrosis factor- $\alpha$ (TNF $\alpha$ ) were determined with the Quantikine high sensitivity ELISA (R\&D Systems, Minneapolis, USA) with lower detection of $0.039 \mathrm{pg} / \mathrm{ml}$ for $\mathrm{IL}-6$ and $0.5 \mathrm{pg} / \mathrm{ml}$ for total TNF $\alpha$. Creactive protein (CRP) was assessed by high-sensitivity particle-enhanced immuno-nephelometry (N Hs CRP, Dade Behring). The lower detection limit was $0.159 \mathrm{mg} / \mathrm{l}$. A CRP concentration that is higher than the cutoff of $5 \mathrm{mg} / \mathrm{l}$, as used by many clinical laboratories, was regarded as raised.

\section{Exercise capacity}

Incremental bicycle ergometry test

An incremental bicycle ergometry test was performed on an electromagnetic braked ergometer (Corival 400, Lode, Groningen, the Netherlands) under supervision of a chest physician to investigate maximal leg exercise capacity. After 2 min of resting and 1 min unloaded cycling, power was increased every minute by $10 \mathrm{~W}$. In a subgroup of patients not suffering from chronic hypoxia (PUFA $n=32$; placebo $n=33 ; \mathrm{PaO}_{2} \geq 7.3 \mathrm{kPa}$ ), peak oxygen consumption $\left(\mathrm{VO}_{2}\right)$, peak carbon dioxide production $\left(\mathrm{VCO}_{2}\right)$ and peak ventilation (VE) were also measured and calculated from breath by breath analysis using a breathing mask (Oxycon Beta, Jaeger, Würzburg, Germany). The respiratory exchange ratio (RER) was calculated as $\mathrm{VCO}_{2} / \mathrm{NO}_{2}$. Baseline peak workload used in the analysis was expressed as percentage of reference values (20). 


\section{Submaximal bicycle ergometry test}

The patients performed a submaximal bicycle test of 2 min unloaded cycling, 10 min at $50 \%$, followed by a maximum of $20 \mathrm{~min}$ at $70 \%$ of individually measured peak workload of the incremental bicycle ergometry test, performed on an electromagnetic braked ergometer (Corival 400 ). Endurance time, defined as the time of cycling, was measured.

\section{Skeletal muscle strength}

Isokinetic quadriceps strength of the dominant leg of the patients was measured using a Biodex dynamometer (Biodex Corporation, Shirley, USA), following the protocol described by Gosker et al. (21). In order to avoid learning effects, all subjects practiced on the dynamometer under supervision of a physiotherapist the day before the actual test.

Skeletal muscle function of the upper extremities was assessed with use of a Harpenden handgrip dynamometer (Yamar, Preston, Jackson, MI, USA). The mean of the highest of three attempts per hand was used in the analysis.

\section{Respiratory muscle tunction}

Respiratory muscle function was assessed by measuring maximal inspiratory mouth pressure (Pi-max) according to the method of Black and Hyatt (22). The best of three attempts was taken for analysis. Pi-max values were noted as positive values.

\section{Data handing and statistical analysis}

Results are presented as mean ( $95 \%$ confidence interval) for all variables that were normally distributed. Differences between the groups at baseline were analyzed by the Student's t-test for independent samples. The outcome of the variables after eight weeks of intervention were compared between groups by linear regression with baseline value of the parameter $r_{*}$ intervention with PUFA and 
intervention with drink supplements as predictors. There was no interaction between PUFA intervention and intervention with drink supplements. Normally distributed parameters within groups were compared with the paired Student's $t$ test. Data were analyzed using Statistical Package for the Social Sciences (SPSS) version 10.1 for Windows (SPSS Inc., Chicago, IL, USA). Statistical significance was assumed at a $p$-value of 0.05 .

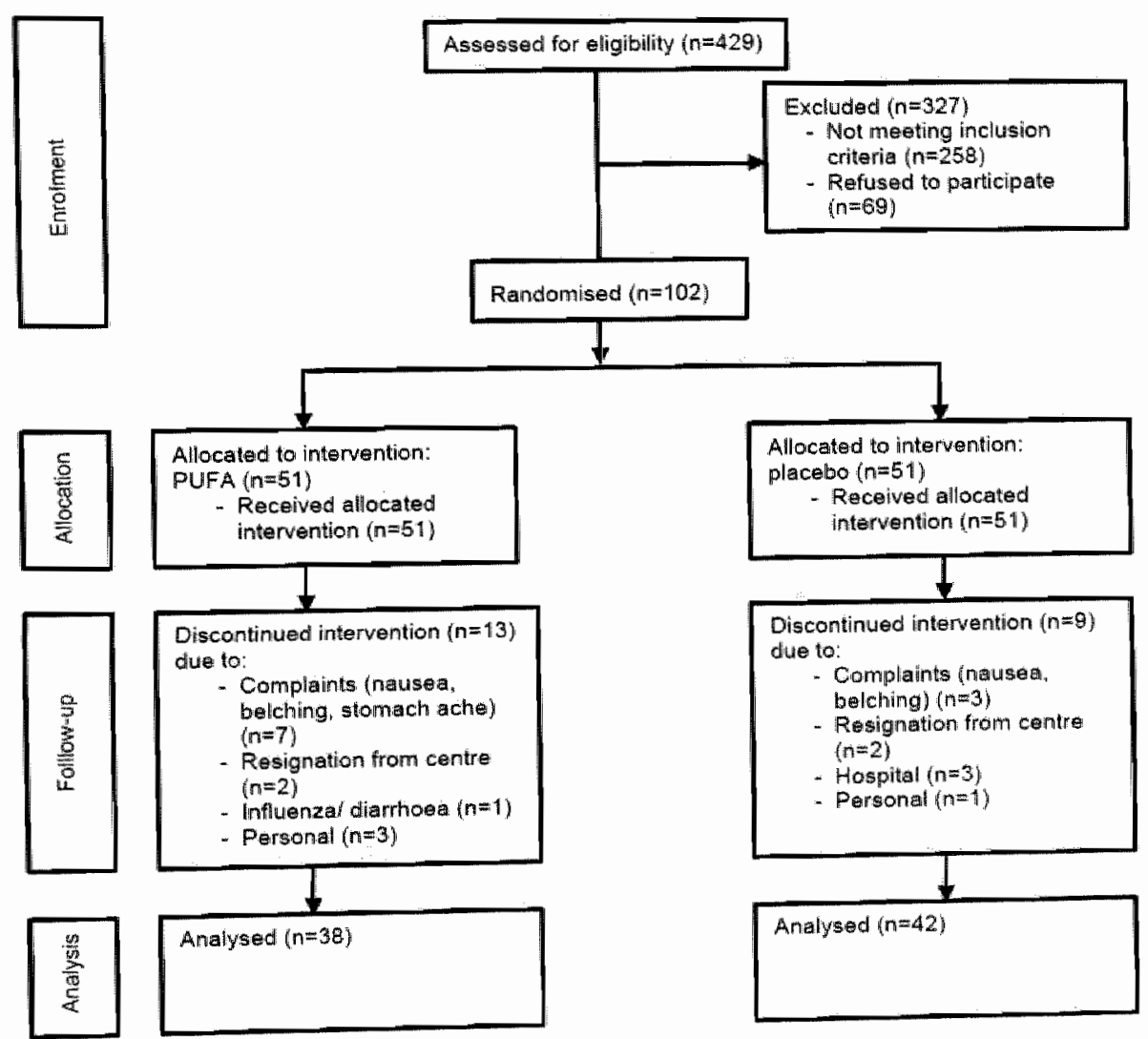

Figure 1: Patient flow diagram 


\section{Results}

\section{Participants}

Four hundred and twenty nine patients were admitted to the rehabilitation center during the study period which lasted from July 2000 until October 2002; 258 did not meet the inclusion criteria and 69 patients did not want to participate. The intent-

Table 1: Mean ( 1 SD) baselne characteristics of the intent-10-treat group

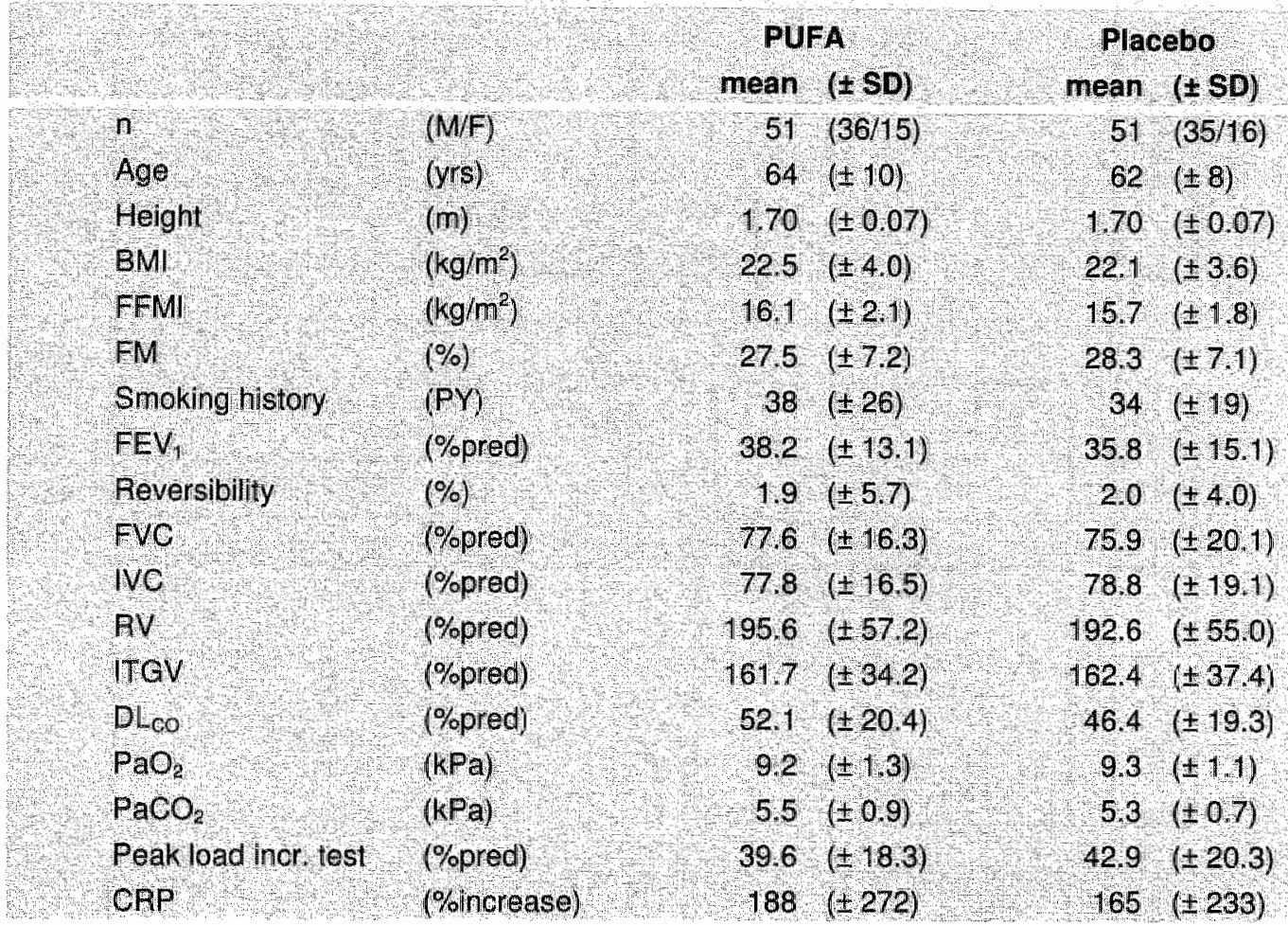

'BMI: body mass index; FFM: fat-free mass index; FM: fat mass; FEV second; FVC: forced vital capacity; IVC: inspiratory wital capacity; RV: residual volume, ITGV: intrathoracic gas volume; $D L_{C O}$ : diffusing capacity for carbon monoxide; $\mathrm{PaO}_{2}$ : arterial oxygen pressure; $\mathrm{PaCO}_{2}$; arterial carbon dioxide pressure; incr.: incremental: CRP: C-reactive protein. Variables were compared between groups by the Student's t-test for independent samples. There were no significant differences between groups $(p>0.05)$. 
to-treat group therefore consisted of 102 patients ( 71 men and 31 women; 51 PUFA and 51 placebo). Three patients in the placebo group had to discontinue the study because of admittance to hospital due to exacerbation $(n=2)$ or pneumothorax $(n=1)$. One patient in the PUFA group discontinued the intervention due to enteric fever. Four patients (PUFA: $n=2$, placebo: $n=2$ ) resigned from the rehabilitation center because of personal problems and four patients (PUFA: $n=3$, placebo: $n=1$ ) were not willing to cooperate further with the study. In the placebo group, three patients discontinued because of an increase in complaints such as belching and nausea, while in the PUFA group seven patients discontinued the study due to belching, nausea, vomiting, fishy taste in the mouth, and stomach ache. In total, nine patients of the placebo group and 13 patients of the PUFA group discontinued the intervention, leaving 80 patients to complete the study (PUFA: $n=38$, placebo: $n=42$ ) (figure 1 ). There was no significant difference either in number of patients dropping out of the study or in those with complaints due to the intervention between the PUFA and the placebo groups.

\section{Baseline characteristics}

The baseline characteristics of both groups in the intent-to-treat group of patients are shown in table 1. The patients were characterized by low BMI and low FFMI. In addition, these patients were compromised in exercise capacity as their peak load was $41.2( \pm 19.3) \%$ of predicted. CRP, as a marker of systemic inflammation, was increased $(176.1( \pm 252.3) \%$ of $5 \mathrm{mg} / \mathrm{l})$. No significant differences were found between baseline characteristics of the PUFA group and the placebo group. The patients who discontinued the study did not differ from the per-protocol group on all parameters, except for having a shorter duration time on the submaximal cycle ergometry test (drop out group: $7.2 \mathrm{~min}( \pm 4.4$ ); per-protocol group: $13.0 \mathrm{~min}$ $( \pm 7.7), p=0.01)$. 
Table 2: Difference in functional and ventilatory parameters of the maximal bicycle ergometry lest betore and after PUFA or placebo intervention duning an eightweel rehabiltation program

\begin{tabular}{|c|c|c|c|c|c|}
\hline & & $\begin{array}{l}\text { PUFA }^{2} \\
\text { mean }\end{array}$ & $\begin{array}{l}(n=37) \\
( \pm S D)\end{array}$ & $\begin{array}{l}\text { Placebo } \\
\text { mean }\end{array}$ & $\begin{array}{l}(n=38) \\
( \pm S D)\end{array}$ \\
\hline Peak load & $(w)$ & 19.7 & $( \pm 20.2)^{\circ}$ & 10.0 & $( \pm 13.6)^{\circ}$ \\
\hline Load/ffm & (W/kg) & 0.368 & $( \pm 0.383)^{*}$ & 0.163 & $( \pm 0.292)^{*}$ \\
\hline Peak VO, & (milmin) & 119 & $( \pm 219)^{\pi}$ & 146 & $( \pm 179)^{\circ}$ \\
\hline Peak $\mathrm{VCO}_{2}$ & $(\mathrm{~m} / / \mathrm{min})$ & 172 & $( \pm 277)^{*}$ & 128 & $( \pm 207)^{\star}$ \\
\hline REA & & 0.033 & $( \pm 0.096)^{*}$ & 0,009 & $( \pm 0.081)$ \\
\hline Peak VE & (Umin) & 5.5 & $( \pm 7.4)$ & 3.4 & $( \pm 7.7)$ \\
\hline $\mathrm{VE} / \mathrm{VO}_{2}$ & & 0.276 & $(+6.004)$ & 1733 & $( \pm 3.924)^{7}$ \\
\hline $\mathrm{VO}_{2} \mathrm{lload}$ & & $-1,396$ & $( \pm 3.444)^{t}$ & 0.571 & $( \pm 5.253)$ \\
\hline
\end{tabular}

'FFM: fat-free mass; $\mathrm{VO}_{2}$ : peak oxygen production; $\mathrm{VCO}_{2}$ : peak carbon dioxide production; RER: respiratory exchange ratio; VE: peak ventilation.

"Variables bofore and after intervention were compared within groups by the paired Student's t-test *: $p<0.05$

${ }^{3}$ The change in outcome of the variables after eight weeks of intervention were compared between groups by linear regression with baseline value of the parameter, intervention with PUFA, and intervention with drink supplements as predictors $(p<0.05)$. Values represent adjusted means with $95 \%$ confidence interval.

\section{PUFA intervention}

\section{Evercise capacity}

Figure 2 shows the results of the PUFA intervention on exercise capacity. The maximum load increased during the incremental maximal bicycle ergometry test in both the intervention and placebo groups. In the PUFA group, however, maximum load increased significantly more after eight weeks of intervention (difference in change in maximum load: $9.7 \mathrm{~W}(95 \% \mathrm{Cl}: 2.5,17.0), \mathrm{p}=0.009)$ (figure 2a), even when corrected for FFM (difference in change in maximum load corrected for FFM: $0.209 \mathrm{~W} / \mathrm{kg}(95 \% \mathrm{Cl}: 0.054,0.364), \mathrm{p}=0.009)$. In a subgroup of patients not using long-term oxygen therapy (LTOT: $n=31$ in the PUFA group and $n=32$ in the placebo group), ventilatory and metabolic data were obtained during the maximal bicycle test (table 2). In both intervention groups $\mathrm{VO}_{2}$ and $\mathrm{VCO}_{2}$ were similarly increased 
Table 2: Continued

\begin{tabular}{|c|c|c|}
\hline \multicolumn{3}{|c|}{ Pufa vs placebo ${ }^{3}$} \\
\hline mean & $(95 \% \mathrm{Cl})$ & p-value \\
\hline 97 & $(25,17.0)$ & 0.009 \\
\hline 0.209 & $(0.06,0.37)$ & 0.006 \\
\hline 23 & $(-122,77)$ & 0.648 \\
\hline 35 & $(-89,158)$ & 0.578 \\
\hline 0.039 & $(-0.001,0.078)$ & 0.054 \\
\hline 21 & $(-1.8,5.9)$ & 0.290 \\
\hline 2.1 & $(-0.451,4.586)$ & 0.106 \\
\hline 1.028 & $(2.808,0.752)$ & 0.252 \\
\hline
\end{tabular}
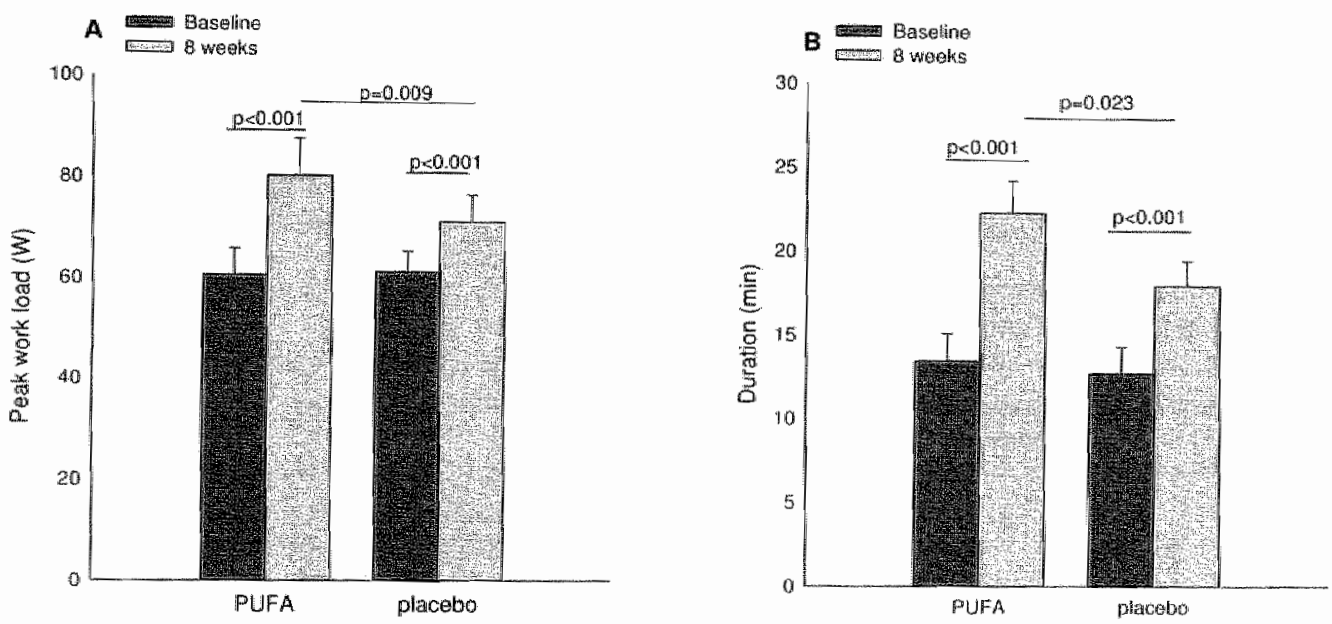

Figure 2 (A): Peak workload. The increase in peak workload during the incremental bicycle ergometry test was higher in patients receiving PUFA than in patients receiving placebo during an eight-week rehabilitation program (mean difference: $9.7 \mathrm{~W}(95 \% \mathrm{Cl}: 2.5,17.0), p=0.009)$. (B): Duration. The increase in duration of the submaximal bicycle ergometry test was higher in patients receiving PUFA than in patients receiving placebo during an eight-week rehabilifation program (mean difference: $4.3 \mathrm{~min}$ (95\% Cl: 0.6, 7.9); $p=0.023$ ). Data are presented as mean (SEM). Within group changes were tested with the paired t-lest, between groups by linear regression $(p<0.05)$. 
at eight weeks compared with baseline. However, RER tended to be increased by PUFA (mean difference: $0.039(95 \% \mathrm{Cl}:-0.001,0.078), \mathrm{p}=0.054)$. In addition, $\mathrm{V}_{2}$ per load was significantly decreased, while in the placebo group neither variables changed.

Besides an improvement in maximal exercise capacity, the duration of the submaximal bicycle ergometry test improved in both intervention groups but, again, a greater increase was seen in the PUFA group (difference in change in duration: $4.3 \min (95 \% \mathrm{Cl}: 0.6,7.9) ; \mathrm{p}=0.023$ ) (figure $2 b)$.

Table 3. Difference in body composition and peripheral muscle function before and after PUFA or placebo intervention during an eight-week rehabilitation program ${ }^{1}$

\begin{tabular}{|c|c|c|c|c|c|c|c|c|}
\hline & & \multicolumn{2}{|c|}{ PUFA $^{2}(n=38)$} & \multicolumn{2}{|c|}{ Placebo $^{2}(n=42)$} & \multicolumn{2}{|c|}{ PUFA vs, placebo } & \multirow[b]{2}{*}{ p-value } \\
\hline & & mean & $( \pm$ SD) & mean & $( \pm$ SD $)$ & mean & $(95 \% \mathrm{Cl})$ & \\
\hline Weight & (kg) & 2.0 & $( \pm 2,3)^{\pi}$ & 1.6 & $( \pm 27)^{*}$ & 0.4 & $(-0.6,1.4)$ & 0.414 \\
\hline FFM & $(\mathrm{kg})$ & 1,2 & $( \pm 2.2)^{x}$ & 11 & $( \pm 21)^{*}$ & 0.1 & $(-0.8,1,1)$ & 0.821 \\
\hline FM & $(\mathrm{kg})$ & 0.8 & $( \pm 1.9)^{*}$ & 0.5 & $( \pm 18)$ & 0.2 & $(-0.5,0.9)$ & 0.573 \\
\hline Strength & $(\mathrm{Nm})$ & 9 & $( \pm 21)^{*}$ & 12 & $( \pm 24)^{*}$ & -4 & $(-15,7)$ & 0.510 \\
\hline
\end{tabular}

'FFM: fat-free mass; FM: fat mass; Strength: quadriceps strength

${ }^{2}$ Variables were compared within groups by the paired Student's t-test (": $p<0.05$ ).

3 The outcome of the variables after eight weeks of intervention were compared between groups by linear regression with baseline value of the parameter, intervention with PUFA and intervention with drink supplements as predictors $(0<0.05)$.

\section{Body composition and peripheral muscle strength}

Body weight and FFM increased during the eight-week rehabilitation program in both the PUFA and the placebo groups, while FM only increased significantly in the PUFA group (table 3). Changes in weight and body composition were similar in both groups, however. In addition, within the group of depleted patients ( $n=36$ : 23M/13F; 19 PUFA 17 placebo), who were receiving nutritional supplementation, no differences in change of body composition or response were seen between 
those receiving PUFA or placebo (data not shown). No complementary effect of PUFA on FFM was therefore seen in addition to protein energy supplementation.

In line with the changes in FFM, quadriceps muscle strength increased similarly in both intervention groups. No effect of the PUFA intervention was seen in strength parameters in addition to rehabilitation.

\section{Systemic inflammation}

CRP, IL-6 and TNFa did not change after rehabilitation or after PUFA intervention (figure 3).

\section{Lung function}

PUFA intervention had no effect on $\mathrm{FEV}_{1}$ and inspiratory muscle strength (data not shown).

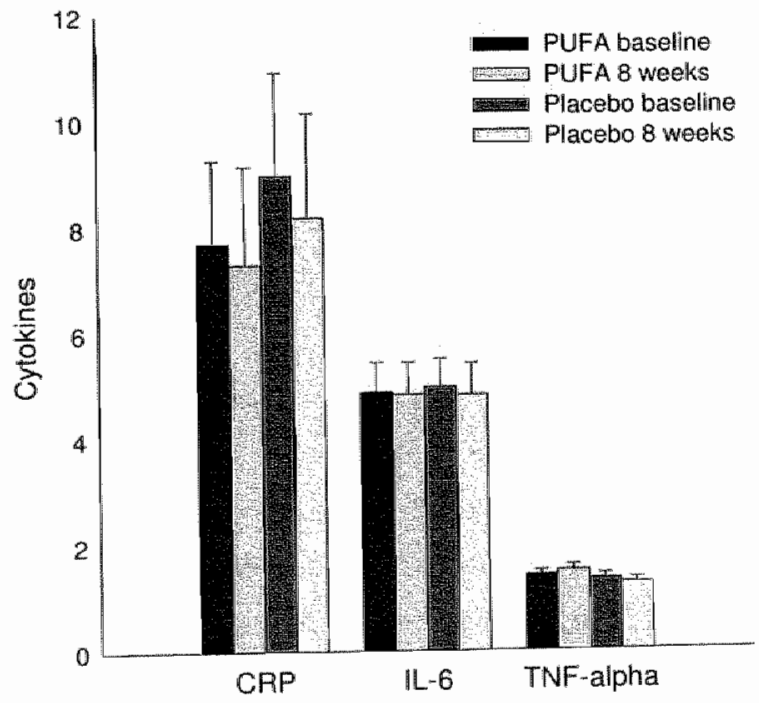

Figure 3: Inflammatory markers. No changes were seen in C-reactive protein (CRP), interleukin-6 (L-6) or wumor necrosis factor-a (TNFa) after eight weeks of either PUFA or placebo in combination with rehabilitation. Data are presented as mean (SEM) change. Within group changes were tested with the paired t-test, between groups by linear regression $(p<0.05)$. 


\section{Discussion}

This is the first study to show beneficial effects of PUFA on the response to exercise training in patients with COPD. The major new finding of this study was that, in addition to the beneficial effects of pulmonary rehabilitation, functional capacity in patients with COPD was increased after eight weeks of PUFA supplementation compared with placebo as shown by improvements in peak exercise capacity and submaximal endurance time.

Previous epidemiological research has shown that PUFA intake has a protective effect on the development of COPD, decreasing risk dose-dependently and increasing lung function in smokers (23). In this intervention study, which included patients with moderate to severe COPD, we did not find an increase in lung function after PUFA treatment. Health gain in these patients suffering from irreversible airflow obstruction is, however, more likely to be found in improvements of skeletal muscle function and exercise capacity. Peak work load and endurance time during submaximal cycle ergometry increased significantly more in the PUFA group than in the placebo group. This improvement could not be explained by an increase in muscle mass as peak load corrected for FFM increased more in the PUFA group than in the control group. However, PUFA supplementation increased RER which indicates that these patients could go deeper into anaerobic metabolism after rehabilitation than patients receiving placebo. Furthermore, mechanical efficiency (as measured by the difference in ratio of $\mathrm{VO}_{2}$ to peak work load) was improved in the PUFA group but remained unchanged in the placebo group. This may suggest improved muscle oxidative metabolism after PUFA intervention. Interestingly, and in line with this hypothesis, Moses et al. (13) showed that PUFA-enriched food supplements increased the physical activity level and total daily energy expenditure in cachectic patients with pancreatic cancer. Barber et al. (24) have also shown an improvement in performance status (using 
the Karnofsky score) after PUFA supplementation in patients with pancreatic cancer. These changes could reflect modulatory effects of PUFA on muscle metabolism. Further studies are indicated using nuclear magnetic resonance spectroscopy and metabolic markers in muscle biopsies to test this hypothesis.

PUFA are known PPAR activators (25). The PPARs have been shown to promote the uptake of circulating fatty acids by cells through upregulation of the lipoprotein lipase gene (26). In addition, PPARs control mitochondrial fatty acid import and $\beta$ oxidation (27). It is possible that the increase in exercise capacity induced by PUFA seen in this study could be attributed to a PUFA-induced activation of PPAR, increasing fatty acid availlability and oxidation. This possible increase in oxidative capacity might be related to changes in fiber types. Indeed, research has consistently shown a shift from the oxidative type I and type Ila fibers to the glycolytic type Ilx fibers in COPD patients compared with controls (4). An increase in oxidative capacity could increase muscle endurance by sparing glycogen and delaying lactic acid production and lactic acid threshold. In patients with COPD muscle glycogen is decreased compared with healthy controls (28), although this could be partly a reflection of inactivity (29). In addition, early lactic acidosis in response to exercise is common in COPD (29) which can, at least partially, be reversed by training $(30)$.

Another possible PPAR-mediated mechanism involves the chronic inflammation in the lungs of patients with COPD. Recent research has shown that locally, PPAR expressed by alveolar macrophages may play an anti-inflammatory role through inhibition of cytokine production and enhancement of phagocytosis (31). The antiinflammatory response of PPAR was shown to be increased by PPAR activators. Although in the present study FEV 1 did not seem to improve, a PUFA-induced decrease in local inflammation cannot be excluded. Further research is needed to elucidate the mechanism behind the improved exercise capacity after PUFA 
untervention, using more invasive techniques to assess local inflammatory and modulatory markers such as NF- kB in the lungs (for example, induced sputum or bronchial biopsies) and muscle (muscle biopsies).

The second aim of this study was to investigate the effects of PUFA on body composition in relation to low-grade systemic inflammation. The rationale for this hypothesis comes from previous positive results of PUFA modulation in other chronic inflammatory conditions such as rheumatoid arthritis and cancer cachexia. In patients with pancreatic cancer, preliminary uncontrolled studies have suggested that supplementation with fish oil or eicosapentanoic acid (EPA) reverses weight loss and decreases the acute-phase response (32). However, these results were not confirmed in a recent multicenter double-blind trial in which a higher dose of EPA supplementation was used (33). The interaction of PUFA and cytokine biology is, however, complex since it has been shown that the ability of healthy volunteers to downregulate TNFa production after PUFA intervention was associated with baseline TNFa production and with TNFa -308 and lymphotoxin-a +252 polymorphisms (34).

In this study, patients in the PUFA and the placebo groups showed a similar increase in body weight and FFM. These improvements in body composition are therefore the result of the rehabilitation program including protein-energy supplementation if indicated. It is probably not related to a decreased systemic inflammatory response as we did not find an effect of PUFA on the specific markers CRP, IL-6 and TNFa. Surprisingly, in this study only a few patients $(n=5)$ gained less than $2 \%$ of weight, which is used as an indication of non-response as defined by Creutzberg et al. (11). This could be due to the use of smaller portions of drink supplements, attemuating the fall in habitual food intake (35). Interestingly, the patients who did not respond adequately had a higher TNFa level than those who did gain sufficient weight (data not shown). This is in agreement with the 
observations of Creutzberg et al. who associated an increased systemic inflammation with non-response to nutritional therapy.

The fact that we did see a PUFA-induced increase in exercise capacity suggests that the PUFA blend used was sufficient in dosage and composition. In addition, it indicates that the intervention was long enough to cause an effect. Further research is needed to study dose-dependent mechanisms and the effects of other PUFA blends with different fatty acid compositions or other ratios of fatty acids. In addition, it remains to be investigated whether PUFA supplementation alone, without exercise training, will have a similar effect on exercise capacity in patients with COPD.

Although the nutritional supplementation with Respifor also contained PUFA, a possible synergistic effect has been separated from the PUFA effect as nutritional supplementation was also included in the statistical analysis as a predictor. In addition, there was no interaction between PUFA and the use of Respifor and the same number of depleted patients in the PUFA and the placebo group were included.

In conclusion, we have shown that PUFA modulation in combination with rehabilitation enhances the increase in exercise capacity in COPD which cannot be ascribed to changes in systemic inflammatory response. 


\section{References}

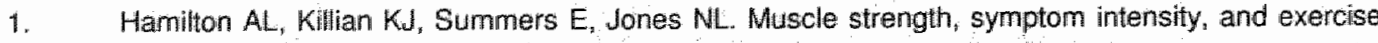
capacity in patients with cardiorespiratory disorders. Am J Respir Crit Care Med 1995;152:2021-31.

2. Di Francia M, Barbier $\mathrm{D}$, Mege $\mathrm{JL}$, Orehek J. Tumor necrosis factor-alpha levels and weight loss in chronic obstructive pulmonary disease. Am $J$ Respir Crit Care Med 1994;150:1453-5.

3. Baarends EM, Schols AM, Mostert $R$, Wouters EF. Peak exercise response in relation to tissue depletion in patients with chronic obstructive pulmonary disease. Eur Respir J 1997;10:2807-13.

4. Gosker HR, van Mameren H, van Dijk PJ, et al. Skeletal muscle fibre-type sinifting and metabolic profile in patients with chronic obstruictive pulmonary disease. Eur Respir J 2002;19:617-25.

5. Maltais $F$, LeBlanc $P$, Whittom $F$, et al. Oxidative enzyme actiwities of the vastus lateralis muscle and the functional status in patients with COPD. Thorax 2000;55:848-53.

6. Baarends EM, Schols AM, Akkermans MA, Wouters EF. Decreased mechanical efficiency in clinically stable patients with COPD. Thorax 1997;52:981-6.

7. Maltais $F$, Simard $A A_{n}$, Simard $C$, Jobin $J$, Desgagnes $P$, LeBlanc $P$. Oxidative capacity of the skeletal muscle and lactic acid kinetics during exercise in normal subjects and in patients with COPD. Am IJ Respir Crit Care Med 1996;153:288-93.

8. Sala E, Rocia J, Marrades RM, et al. Effects of endurance training on skeletal muscle bioenergetics in chronic obstructive pulmonary disease. Am J Respir Crit Care Med 1999;159:1726:34.

9. Ortega $F$, Toral $J$. Cejuda $P$, et al. Comparison of effects of strength and endurance training in patients with chronic obstructive pulmonary disease. Am J Respir Crit Care Med 2002;166:669-74.

10. Sohols AM, Soeters PB, Mostent $R$, Pluymers RJ, Wouters EF. Physiologic effects of nutritional support and anabolic steroids in patients with chronic obstruetive pulmonary disease. A placebocontralled randomized trial. Am il Respir Crit Care Med 1995,152:1268-74.

11. Creutzberg EC, Schols AM, Weling-Scheepers CA, Buurman WA, Wouters EF. Characterization of nonresponse to high caloric oral nutritional therapy in depleted patients with chronic obstructive pullmonary disease. Am I Respir Crit Care Med 2000;161:745-52.

12. Aguilaniu B, Flore P, Perrault H, Page JE, Payan E, Lacour JR. Exercise-induced hypoxaemia in master athletes: effects of a polyunsaturated fatty acid diet. Eur J Appl Physiol Occup Physiol $1995 ; 72: 44-50$.

13. Moses AW, Slater $C_{6}$ Preston T, Barber MD, Fearon KC. Reduced total energy expenditure and physical activity in cachectic patients with pancreatic cancer can be modulated by an energy and protein dense oral supplement enriched with n-3 fatty acids. Br J Cancer 2004;90:996-1002.

14. Komatsu W, Ishihara K, Murata M, Saito $H$, Shinohara K. Docosahexaenoic acid suppresses nitric oxide production and inducible nitric oxide synthase expression in interferon-gamma plus lipopolysaccharide-stimulated murine macrophages by inhibiting the oxidative stress. Free Radic Biol Med 2003:34:1006-16.

15. Agusti $A$, Morla M. Sauleda J, Saus $G$, Busquets X. NF-kappaB activation and iNOS upregulation in skeletal muscle of patients with COPD and low body weight. Thorax 2004;59:483-7.

16. Schoonjans $K$. Staels B, Auwerx J. The peroxisome proliferator activated receptors (PPARS) and their effects on lipid metabolism and adipocyte differentiation. Biochim Biophys Acta 1996;1302:93109. 
17. Creutzberg EC, Wouters EF, Mostert R, Weling-Scheepers CA, Schols AM. Efficacy of nutritional supplementation therapy in depleted patients with chronic obstructive pulmonary disease. Nutrition 2003;19:120-7.

18. Quanjer PHe. Standardized lung function testing. Official statement of the European Respiratory Society [see comments]. Eur Respir J 1993;6 (suppl.16):1-100.

19. Steiner MC, Barton RL, Singh SJ, Morgan MD. Bedside methods versus dual energy $X$-ray absorptiometry for body composition measurement in COPD. Eur Respir $\mathrm{J} 2002 ; 19: 626-31$.

20. Jones NL, Summers E, Killian KJ. Influence of age and stature on exercise capacity during incremental cycle ergometry in men and women. Am Rev Respir Dis 1989;140:1373-80.

21. Gosker HR, Lencer NH, Franssen FM, van der Vusse GJ, Wouters EF, Schols AM. Striking similarities in systemic factors contributing to decreased exercise capacity in patients with severe chronic heart fallure or COPD. Chest 2003;123:1416-24.

22. Black LF, Hyatt RE. Maximal respiratory pressures: normal values and relationship to age and sex. Am Rev Respir Dis 1969;99:696-702.

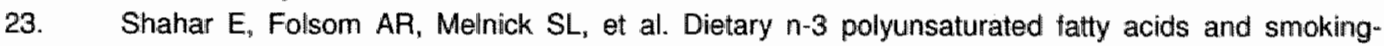
related chronic obstructive pulmonary disease. Atherosclerosis Risk in Communities Study Investigators. N Engl ل Med 1994;331:228-33.

24. Barber MD, Ross JA, Voss AC, Tisdale MJ, Fearon KC. The effect of an aral nutritional supplement enriched with fish oil on weight-loss in patients with pancreatic cancer. Br $\checkmark$ Cancer 1999;81:80-6.

25. Keller $H_{4}$ Dreyer $C_{\text {, Medin }} \downarrow$, Mahfoudi A, Ozato K, Wahli W. Fatty acids and retinoids control lipid metabolism through activation of peroxisome proliferator-activated receptor-retinoid $X$ receptor heterodimers. Proc Natl Acad Sci U S A 1993;90:2160-4.

26. Schoonjans $K_{s}$ Peinado-Onsurbe $J_{y}$ Lefebvre AM, et al. PPARalpha and PPARgamma activators direct a distinct tissue-specific transcriptional response via a PPRE in the lipoprotein lipase gene. Embo J 1996;15:5336-48.

27. Gulick T, Cresci S, Caira T, Moore DD, Kelly DP. The peroxisome proliferator-activated receptor regulates mitochondrial fatty acid oxidative enzyme gene expression. Proc Natl Acad Sci U S A 1994:91:11012-6.

28. Jakobsson $P$, Jorfeldt L. Long-term axygen therapy may improve skeletal muscle metabolism in advanced chronic obstructive pulmonary disease patients with chronic hypoxaemia. Respir Med $1995 ; 89: 471 \% 6$

29. Engelen MP, Schols AM, Does JD, Gosker HR, Deutz NE, Wouters EF. Exercise-induced lactate increase in relation to muscle substrates in patients with chronic obstructive pulmonary disease. Am $J$ Respir Crit Care Med 2000;162:1697-704.

30. Maltais $F$, LeBlanc $P$, Simard $C$, et al. Skeletal muscle adaptation to endurance training in patients with chronic obstructive pulmonary disease. Am J Respir Crit Care Med 1996;154:442-7.

31. Asada K, Sasaki S, Suda T, Chida K, Nakamura H. Antiinflammatory rotes of peroxisome proliferator-activated receptor gamma in human alveolar macrophages. Am J Respir Crit Care Med 2004;169:195-200.

32. Wigmore SJ, Fearon KC, Maingay JP, Ross JA. Down-regulation of the acute-phase response in patients with pancreatic cancer cachexia receiving orall eicosapentaenoic acid is mediated wia suppression of interleukin-6. Clin Sci (Colch) 1997:92:2:15-21. 
33. Fearon $\mathrm{KC}$, Von Meyenfeldt MF, Moses $\mathrm{AG}$, el al. Effect of a protein and energy dense $\mathbb{N}-3$ tatty acid enriched oral supplement on loss of weight and lean tissue in cancer cachexia: a randomised double blind trial. Gut 2003;52:1479-86.

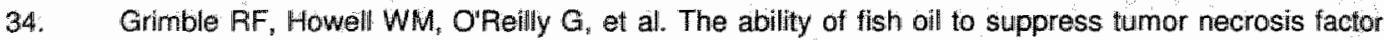
alpha production by peripheral blood mononuclear cells in healthy men is associated with polymorphisms in genes that influence tumor necrosis factor alpha production. Am J Clin Nutr $2002: 76: 454-9$.

35. Broekhuizen R, Creutzberg EC, Weling-Scheepers CA, Wouters EF, Schols AMI. Portion size rather than energy content of nutritional supplements enhances body weight gain in depleted COPD patients. Eur Respir ل 2003;22:551s-552s. 


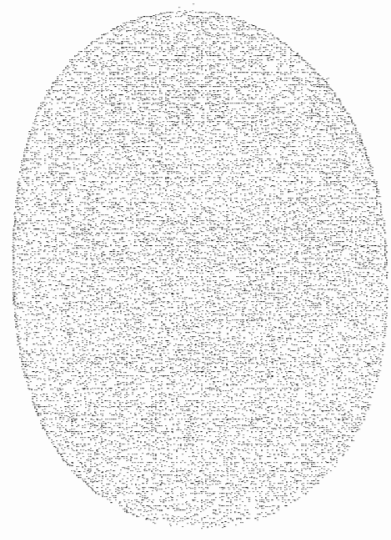

General discussion 
Chapter 9 


\section{Introduction}

This general discussion will integrate the most important findings of this thesis regarding pulmonary cachexia and subsequently discuss potential areas for future research.

\section{Cachexia: imbalance between anabolism and catabolism}

Prior research thas shown that loss of fat-free mass (FFM), which is a reflection of muscle mass, is an independent predictor of mortality in patients with chronic obstructive pulmonary disease (COPD) (chapter 3) (1). In addition, lass of FFM adversely affects respiratory and peripheral muscle function (2) and exercise capacity (3). Low FFM is also associated with impaired health status $(4,5)$ and it appears to be a factor in the genesis of bone thinning which is prevalent in the COPD population (6). Prevention and reversal of the loss of FFM are therefore important therapeutic targets in COPD.

Muscle homeostasis is a dynamic process between anabolism and catabolism, influencing either protein synthesis, protein breakdown or a combination of both. A disruption of this balance can ultimately lead to cachexia. There are several factors that may influence the anabolic/ catabolic balance. In some COPD patients, decreased levels of anabolic hormones like testosterone have been reported (7). In addition, a reduced level of the adrenal steroid dehydroepiandrosterone sulfate (DHEAS) was found in COPD patients with muscle wasting (8). Low food and protein intake may also lead to a decreased anabolic response (9). Other factors in COPD, like systemic inflammation, hypoxemia, inactivity, reactive oxygen species and the use of medication, have been implicated in accelerated protein breakdown by activation of the ubiquitin 26S-proteasome pathway (10-12). In chapter 2 and chapter 4 of this thesis, some factors were 
studied that may be involved in the disruption of the anabolic/catabolic balance in COPD. Using a cross-sectional study design, these chapters show that there was no difference in systemic inflammatory cytokine profile. However, there was a significant difference in the pro-inflammatory $\mathrm{L}-1 \beta-511$ polymorphism between cachectic patients and controls, which may suggest a role of $\mathrm{IL}-1 \beta$ in pulmonary cachexia. Chapter 2 also shows that cellular protein breakdown was indeed increased in patients with cachexia compared to non-cachectic COPD patients. Pulmonary cachexia may thus be a result of chronic low-grade disequilibrium between anabolism and catabolism. Therapeutic managements should therefore be targeted at restoring protein balance by specific modulation of anabolic and catabolic responses.

\section{Anabolic interventions}

\section{Pulmonary rehabilitation}

It is generally acknowledged that pulmonary rehabilitation is an evidence-based intervention to improve exercise capacity and health status in COPD. Most rehabilitation programs comprise of a combination of endurance and strength exercise training and if indicated, nutritional intervention. Chapter 6 of this thesis shows that pulmonary rehabilitation has beneficial effects on body composition of COPD patients by increasing FFM. In a recently published study from our group, it was shown that in non-cachectic patients, receiving no additional nutritional supplementation, a beneficial shift in body composition of increased FFM and decreased FM occurred after eight weeks of rehabilitation (13). This is in agreement with an earlier study that showed enhanced bilateral midthigh muscle cross-sectional area after 12 weeks of training, without an increase in bodly mass index (BMI) (14). These studies illustrate that intensive supervised exercise training is able to induce an anabolic response in patients with COPD not suffering from 
pulmonary cachexia. The mechanism of exercise-induced anabolism may involve the stimulation of the expression of a protein growth factor known als insulin-like growth factor (IGF)-1 within the muscle (15). IGF-1 is a known blocking agent of the proteasome pathway, which is an important proteolytic pathway that causes muscle wasting (11).

The imbalance between anabolism and catabolism is also illustrated by chapter 6. This chapter describes that pseudouridine (PSU), a marker of cellular protein breakdown and thus a marker of catabolism, was increased in patients with COPD. Pulmonary rehabilitation did not modulate this marker, but nevertheless did increase FFM and muscle function. This may indicate that the anabolic stimulus provided by exercise training does not affect catabolism, but that exercise training temporarily shifts the balance between anabolism and catabolism in favor of anabolism. This was also suggested by the fact that four weeks after rehabilitation body compositional changes were reversed: although BMI did not change significantly after removal of the anabolic stimulus, FFM decreased to prerehabilitation level. So, although it is possible to get an anabolic response in COPD patients, the ongoing catabolic process is not targeted by rehabilitation alone. Therefore, after discontinuation of rehabilitation, the balance between anabolism and catabolism will shift back toward net catabolism.

\section{Nutrition}

In patients who are losing weight, are underweight, or have low FFM, nutritional support, containing additional energy and protein, is indicated in order to gain weight and FFM. The efficacy of nutritional intervention alone is, however, not supported by a recent meta-analysis (16). The poor treatment response in the studies used in this meta-analysis could be related to too short an intervention period, insufficient supplementation of energy intake or because of a compensatory decrease in normal dietary intake due to early satiety and/ or bloating (17-19). From a functional point of view, it seems logical to combine nutritional support with 
an anabolic stimulus to enhance muscle mass, rather than just accumulating fat mass.

As described above, pulmonary rehabilitation can elicit an anabolic response. Indeed, the effects of nutritional supplementation combined with pulmonary rehabilitation resulted in significant weight gain in several studies $(17,20)$. The combined treatment of nutritional support and exercise not only increased body weight but also resulted in significant improvement in FFM and respiratory muscle strength (20). In the same study, it was shown that pulmonary rehabilitation without nutritional supplementation did not result in increased body weight, increased FFM, or functional improvements in cachectic patients with COPD (20). Therefore, to elicit an anabolic change in body composition in COPD patients that are cachectic, the combination of exercise training with nutritional supplementation appears to be necessary. Further optimization of this combination is possible by simply decreasing the portion size of energy-dense nutritional supplement drinks as illustrated in chapter 7 . In addition, there are indications that increased availability of amino acids enhances the exercise-induced stimulation of protein synthesis (21). Moreover, leucine, one of the branched chain amino acids, has been shown to upregulate protein synthesis in skeletal muscle through activation of signaling pathways that enhance activity and synthesis of proteins involve in messenger ribonucleic acid (RNA) translocation (22). These observations may further enhance efficacy of nutritional supplementation during rehabilitation to increase weight and muscle mass gain.

Another possible option to optimize nutritional supplementation for COPD patients might be the addition of specific nutrients known to stimulate IGF-1 release and therefore promote anabolism. Besides energy and protein intake, which have been shown to affect IGF-1 concentration, there are some indications from literature that certain minerals, including potassium, zinc, magnesium, calcium and phosphorus, 
increase plasma IGF-1 in well-nourished middle-aged to elderly men (23). Moreover, the age-related decline in plasma IGF-1 may be exacerbated by low intakes of protein and minerals (23).

The combination of nutrition and rehabilitation has also been studied in a group of non-cachectic COPD patients. In these patients, Steiner et al. have shown that supplementation with additional carbohydrate-rich drinks can further increase exercise capacity (24). In contrast to a study from our group with no additional nutritional supplementation (13), they did not find an increase in FFM, but only in FM. This could be due to a difference in training program, as they used a lowintensity endurance program while our training program consisted of high endurance training in combination with strength training, which has more impact on muscle mass and oxidative capacity. However, these studies illustrate that significant health gain can be achieved even in non-cachectic COPD patients, given a combination of exercise training and optimal nutrition.

Therefore, previous research aimed at optimizing rehabilitation with nutrition has tended towards a combination of training along with a protein- and energy-dense supplement drink in cachectic COPD patients, resulting in increased FFM and improved muscle function $(17,20)$. In this way, rehabilitation has been shown to be a potent anabolic stimulator. However, some patients do not respond sufficiently to this combination of therapies and, as a consequence, do not gain weight or FFM. These patients are characterized by an elevated systemic inflammatory response (25). This increased systemic inflammation could possibly be modulated to achieve further optimization of nutritional treatment (see section on 'Anti-catabolic interventions") 


\section{Phamaceutical anabolic agents}

Some pharmaceutical drugs are also anabolic stimuli for muscle mass gain. Several studies in COPD have shown that anabolic steroids specifically induce muscle mass gain $(20,26-29)$. Four months of treatment with oral doses of the anabolic steroid oxandrolone without additional dietary or exercise regimens led to significant increases in body weight and lean body mass in patients with involuntary weight loss and moderate to severe COPD. These gains, however, were not associated with improved 6-minute walking distance in approximately half of the study objects (29). Four injections of intra-muscular nandrolone decanoate in 8 weeks in combination with nutritional supplements implemented in a pulmonary rehabilitation program resulted in a greater increase in the percentage of FFM than nutrition alone in depleted and non-depleted patients (20). This was also found in a similar study, where intra-muscular injections of nandrolone decanoate resulted in increases in body weight and FFM, but without further improvement in muscle function or exercise capacity relative to rehabilitation alone (27).

Similarly, 27 weeks of oral treatment with the anabolic steroid stanozolol (a synthetic substance derived from testosterone) in addition to inspiratory muscle and cycle ergometer exercise training led to an increased body weight and lean body mass in 10 nutritionally depleted patients with COPD but the weight gain did not result in improved 6-minute walking distance or maximal exercise capacity (26).

Casaburi et al. studied the effect of 10 weeks of intramuscularly injected testosterone in combination with resistance training in male COPD patients with low testosterone levels. They showed that administering replacement testosterone increased lean body mass and leg muscle strength, while resistance training showed similar improvements and the combination tended to be additionally beneficial (28). Although circulating IGF-1 concentrations were not significantly different between the intervention groups of this study, it has been shown in a 
study of elderly men that testosterone supplementation upregulates intramuscular IGF-1 gene expression, which was accompanied by increases in muscle mass (30).

The study of Creutzberg et al. (27) also showed that, although there was no significant effect of anabolic steroids on function in the whole group, nandrolone decanoate increased respiratory muscle strength and peak workload in a subgroup of COPD patients also receiving oral glucocorticosteroids. Glucocorticosteroids have known catabolic effects (27). Animal studies have also shown an antagonizing effect of nandrolone decanoate on the loss of diaphragm function induced by long-term low-dose methylprednisolone administration $(31,32)$. This could be caused by competitive binding of anabolic steroids on the glucocorticosteroid receptor, thereby neutralizing the deleterious effect of glucocorticosteroids (33).

Other pharmaceuticals, like growth hormone, may also act pro-anabolically, possibly through the systemic induction of IGF-1. In COPD only one randomized controlled trial with growth hormone has been performed. In that study, three weeks of growth hormone administration increased lean body mass with an absolute decrease in fat mass in cachectic patients during a puimonary rehabilitation program (34), but did not improve muscle strength, 6-minute walking distance or maximal exercise capacity. In that study, a marked increase of IGF-1 was seen in the patients receiving growth hormone (34). However, the administration of recombinant human growth hormone can induce salt and water retention, which could also lead to a false measurement of improvements in body weight and/ or lean body mass when body composition is measured by dualenergy X-ray absorptiometry (DEXA).

Overall, clinical outcomes of anabolic hormone supplementation did not improve exercise capacity, but did improve body composition. Given the limited 
effects on exercise capacity and the high risk for adverse side effects of most pharmaceuticals, particularly when used in high doses or for a prolonged time, nutritional modulation might be a more attractive alternative.

\section{Anti-catabolic interventions}

Besides modulation of anabolism, catabolism could also be a target for therapeutic intervention. One factor contributing to catabolism is systemic inflammation. In COPD, several proinflammatory cytokines are increased (reviewed in 12). The source of the increased systemic inflammatory response in COPD has not yet been elucidated. It is possible that the systemic inflammation is a local-to-systemic spill-over, but no correllation was found between sputum and plasma concentrations of inflammatory markers (35) (chapter 5). Other factors, like smoking (36), hypoxia $(37,38)$ and evolutionary programming (39) are also possible etiological factors $(40)$. In addition, it is possible that the increased inflammatory response originates from exacerbated exercise-induced increases in muscle-derived inflammatory mediators like IL-6 (reviewed in 41, 42) (see also chapter 4 for hypothesis). Although more research is needed to elucidate the source of the increased systemic inflammation in COPD, treatments have already been suggested.

\section{PUFA}

Previous research has suggested a beneficial effect of polyunsaturated fatty acids (PUFA) and particularly of $n-3$ fatty acids on cancer cachexia by modulating systemic inflammation (43-46). The anti-inflammatory effects of $n-3$ fatty acids may be mediated by the incorporation of $n-3$ fatty acids in the cell membrane. Human inflammatory cells contain high proportions of the n-6 PUFA arachidonic acid and low proportion of n-3 PUFA. Arachidonic acid is the precursor of the 2-series 
prostanoids and 4-series leukotrienes, which are highly active mediators of inflammation. Replacing membrane phospholipids derived from arachidonic acid with polyunsaturated $n-3$ derived phospholipids will lead to the synthesis of less potent lipid-derived mediators such as 5-series leukotrienes and 3-series prostanoids. These eicosanoids have lower inflammatory properties, thereby reducing the production of proinflammatory cytokines $(47,48) . N-3$ fatty acids also decrease binding of nuclear factor-KB (NF-KB), a transcriptional regulatory element, to the nucleus. This results in less NF-KB binding to the promoter region of proinflammatory cytokine genes, thereby decreasing transcription of these mediators (47).

Anticachectic benefits of $n-3$ fatty acids were first observed in experimental animal studies. Feeding rodents fish oil showed a significant reduction in the rate of weight loss (49), which was attributable to the $n-3$ fish oil component eicosapentanoic acid (EPA: 20:5n-3) (50). It was shown that EPA reduced protein degradation without an effect on protein synthesis in mice at doses equivalent to $6.4-12.8 \mathrm{~g} /$ day in humans (50). In addition, the anticachectic effect of EPA correlated with the in vitro inhibition of a lipid-mobilizing factor, which is thought to be responsible for cachexia (51).

Uncontrolled human studies in patients with pancreatic cancer and cachexia showed that a median dose of $12 \mathrm{~g}$ fish oil/day containing approximately $2 \mathrm{~g}$ of EPA in 18 patients with pancreatic cancer caused a reversal of weight loss which persisted for three months (46). In addition, EPA-enriched nutritional supplements containing $600 \mathrm{kcal}$ and 2 gram EPA per day increased weight with a median of 2 $\mathrm{kg}$ in seven weeks in 20 patients with pancreatic cancer (44). Weight gain was also associated with a temporary decrease in C-reactive protein $(45,46)$.

However, a recent eight-week multicenter, double-blind trial carried out by Fearon et al. supplementing an average dose of $1.5 \mathrm{~g}$ of EPA per day could not 
confirm these results (52). This is in agreement with our study (chapter 8 ), in which no additional beneficial effect on rehabilitation was found of an eight-week placebo controlled, double-blind intervention with a PUFA blend containing $0.7 \mathrm{~g}$ EPA per day on weight or FFM gain or on systemic inflammatory markers. This could be due to low EPA dose, which may be insufficient to have anti-inflammatory effects. In addition, we used a specific PUFA blend, containing not only EPA, but also other PUFA like stearidonic acid (STA, 18:4n-3), gamma-linoleinic acid (GLA, 18:3n-6), alpha-linolenic acid (ALA, 18:3n-3) and docosahexanoic acid (DHA, 22:6n-3). These components could have less effective anti-cachectic and anti-inflammatory effects than EPA. However, more importantly, the placebo-controlled study of Fearon et al. also did not show a different change in body composition between cancer patients receiving EPA or placebo (52), as both groups showed weight stabilization. The above-mentioned study of Barber et al. was performed by the same research group using the same intervention (44), but without a placebo group. The weight stabilization in this study is therefore also probably mainly due to the nutritional supplementation.

The interaction of PUFA and cytokine biology is, however, complex since it has been shown that the ability of healthy volunteers to downregulate TNF $\alpha$ production after PUFA intervention was associated with baseline TNF-production and with TNFa -308 and lymphotoxin-a +252 polymorphisms 153 ). However, we have explored this possibility by determining the polymorphisms of TNFa -308 and lymphotoxin- $\alpha+252$ as well as $\mathrm{LL}-1 \beta-511$ and $\mathrm{LL} 6-174$. Analyses correcting for polymorphism did not show a difference in response (data not shown).

\section{AnIT-TNE}

Aside from potential nutritional modulation, pharmacological inhibition of TNF $\alpha$ with antibodies or soluble receptors may have beneficial effects both in terms of controlling disease activity and reversing effects on protein degradation. In animal 
models, TNFa can induce various features of cachexia. Exposure to TNFa induces acute muscle atrophy and anorexia in rats $(54,55)$. Chronic treatment of rats with TNFa results in depletion of body protein, anorexia, weight loss and tissue inflammation $(56,57)$. Moreover, high concentration of TNF $\alpha$ increases amino acid release from mouse diaphragms (58). In humans, infusion of TNFa into weight stable cancer patients resulted in increased amino acid release and thus stimulated proteolysis $(59,60)$. In COPD, there are some studies suggesting a potential role of TNFa in pulmonary cachexia $(37,61,62)$. Chapter 2 of this thesis does not show a difference in circulating TNFa or its receptors between patients with or without cachexia, but increased systemic inflammation can still be a trigger in the etiology of cachexia.

Potential drugs that may inhibit TNFo are infliximab, an anti-TNFa monoclonal antibody, and etanercept, a soluble TNFa receptor fusion protein. In a mouse transgenic model expressing $T N F a$, administration of infliximab resulted in weight gain and increased survival (63). Treatment of patients with myelofibrosis with myeloid metaplasia using etanercept showed that two of the seven patients with unintentional weight loss stopped losing weight and the other five gained weight (64). These data suggest a therapeutic potential for anti-TNFa treatment in pulmonary cachexia. However, anti-TNFa treatment with pharmaceuticals like infliximab may have some serious side effects like increasing the risk for respiratory infections, tuberculosis and heart failure (65).

As opposed to the systemic anti-inflammatory treatment using anti-TNFa pharmaceuticals, another possible option of anti-inflammatory treatment could be sought locally in the target tissue: skeletal muscle. During recent years, considerable progress has been made in the elucidation of accelerated muscle proteolysis. Modulation of the more downstream atrophy/ hypertrophy pathway in muscle cells is therefore becoming a more feasible option $(11,66)$. 


\section{Metabolic and pulmonary effects of PUFA}

During the PUFA trial (chapter 8), a remarkable increase in exercise capacity was found. These results are in line with recent findings from the group of Fearon, who showed that PUFA-enriched food supplements in cachectic patients with pancreatic cancer increased physical activity level and total daily energy expenditure and improved performance status $(44,67)$. PUFA are known activators of peroxisome proliferator-activated receptors (PPAR) (68). In general, PPARs are transcription factors that, once activated, lead to changes in expression of genes involved in the regulation of lipoprotein and lipid metabolism, glucose homeostasis, inflammation and cellular differentiation. Three different PPAR isoforms are described in humans: $a, \beta / \delta$ and $\gamma$, each with its own specific characteristics and effects. PPAR-a is predominantly expressed in tissues with a high metabolic rate, such as liver and to a lesser extent heart, kidney ad muscle. In these tissues, PPAR- $a$ has a crucial role in controlling fatty acid oxidation and acts as a major regulator of energy homeostasis (69). In addition, PPAR- $\alpha$ attenuates the inflammatory response and regulates amino acid metabolism (70). PPAR-y is predominantly expressed in adipose tissue, large intestine and hematopoietic cells (71). PPAR- $\gamma$ controls energy, lipid and glucose homeostasis. Like PPAR- $a$, PPAR-y is also involved in attenuating the inflammatory response (70). PPAR- $\delta$ is a powerful regulator of fatty acid catabolism and energy homeostasis in several tissues as skeletal muscle, heart and adipose tissue (72). Thus, while PPAR-y is a regulator of fat storage, PPAR-ס regulates fat oxidation.

One could speculate that the increase in exercise capacity induced by PUFA in this study could be attributed to a PUFA-induced activation of PPAR, increasing fatty acid availability and oxidation. An increase in oxidative capacity could increase muscle endurance, by sparing glycogen and delaying lactic acid production and the lactic acid threshold. In COPD patients, muscle glycogen is shown to be decreased 
as compared to healthy controls (73), although this could be partly a reflection of inactivity (74). In addition, early lactic acidosis in response to exercise is common in COPD (74), which can, at least partially, be reversed by training (75).

Locally, induction of PPAR expressed by alveolar macrophages could have an anti-inflammatory effect by inhibiting cytokine production and enhancing phagocytosis (76). Although the effect of PUFA on the lungs was not studied in chapter 8 , recent studies in patients with acute respiratory distress syndrome (ARDS) have shown a remarkably beneficial effect of PUFA on pulmonary inflammation, oxygenation and clinical outcome $(77,78)$. Pacht et al. have also found an inverse relation between neutrophil count in bronchoalveolar lavage fluid (BALF) and gas exchange, suggesting that when pulmonary inflammation was lowered, oxygenation was increased (78). In addition, PUFA have been shown to promote vasodilatation and oxygen delivery (79). This provides an interesting new explanation for the results of the PUIFA trial and warrants further investigation. PUFA could decrease alveolar inflammation, induce vasodilatation and increase oxygenation, with a possible result that patients with COPD can reach higher levels of exercise performance.

\section{Conclusion}

In summary, in this thesis specific modulation of cachexia with nutrition was studied. Although the hypothesis at first was the modulation of cachexia using PUFA, it turned out that this specific nutritional intervention had beneficial effects on exercise capacity in cachectic and non-cachectic COPD patients. Hypothetically, this might ultimately lead to improvements in quality of life, but this is still to be investigated with longitudinal studies. In addition, more research is needed to elucidate the factors that play a role in the etiology of pulmonary 
cachexia in order to more effectively target anti-cachectic interventions. The nutritional modulation of pulmonary inflammation and the relation between pulmonary and systemic inflammation are outside of the scope of this thesis, but are nonetheless important issues needing to be addressed in the near future. Nutritional modulation thus seems a feasible option in the treatment of at least some impairments of COPD patients with relatively few side effects, and therefore it warrants more research in this field in the future. 


\section{References}

1. Marquis $K$, Debigare $R$, Lacasse $Y$, et al. Midthigh muscle cross-sectional area is a better predictor of mortality than body mass index in patients with chronic obstructive pulmonary disease. Am J Respir Crit Care Med 2002;166:809-13.

2. Engelen MPKu, Schols AMWJ, Baken WC, Wesseling GJ, Wouters EFM. Nutritional depletion in relation to respiratory and peripheral skeletal muscle function in out-patients with COPD. Eur Respir J 1994;7:1793-7.

3. Schols AM, Soeters PB, Dingemans AM, Mostert $R_{3}$ Frantzen PJ, Wouters EF. Prevalence and characteristics of nutritional depletion in patients with stable COPD eligible for pulmonary rehabilitation. Am Rev Respir Dis 1993;147:1151-6.

4. Mostert $\mathbb{R}$, Goris $A$, Welling-Scheepers $C$, Wouters EF, Schols AM. Tissue depletion and health related quality of life in patients with chronic obstructive pulmonary disease. Respir Med 2000;94:859-67.

5. Shoup $R$, Dalsky G, Warner $S$, et al. Body composition and health-related quality of life in patients with obstructive airways disease. Eur Respir J 1997;10:1575-80.

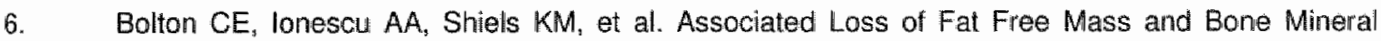
Density in Chronic Obstructive Pulmonary Disease. Am J Respir Crit Care Med 2004;170:12861293.

7. Kamischke A, Kemper DE, Castel MA, et al. Testosterone levels in men with chronic obstructive pulmonary disease with or without glucocorticoid therapy. Eur Respir J 1998;11:41-5.

8. Debigare $\mathrm{R}$, Marquis $\mathrm{K}$, Cote $\mathrm{CH}_{\text {, }}$ et al. Catabolic/anabolic balance and muscle wasting in pattients with COPD. Chest 2003;124:83-9.

9. Volpi E, Mittendorfer B, Wolf SE, Wolfe RR. Oral amino acids stimulate muscle protein anabolism in the elderly despite higher first-pass splanchnic extraction. Am J Physiol 1999;277:E513-20.

10. Lecker SH, Solomon V, Mitch WE, Goldberg AL. Muscle protein breakdown and the critical role of the ubiquitin-proteasome pathway in normal and disease states. J Nutr 1999;129:227S-2375.

11. Mitch WE, Goldberg AL. Mechanisms of muscle wasting. The role of the ubiquitin-proteasome pathway. N Engi J Med 1996;335:1897-905.

12. Gan WQ, Man SF, Senthilselvan A, Sin DD. Association between chronic obstructive pulmonary disease and systemic inflammation: a systematic review and a meta-analysis. Thorax 2004:59:57480.

13. Franssen FM, Broekhuizen $R$, Janssen PP, Wouters EF, Schois AM. Ellects of Whale-Body Exercise Training on Body Composition and Functional Capacity in Normal-Weight Patients With COPD. Chest 2004; $125: 2021-8$

14. Bernard $S_{1}$, Whittom $F_{*}$ Leblanc $P_{*}$ et al. Aerobic and strength training in patients with chronic obstructive puimonary disease. Am J Respir Crit care Med 1999;159:896-901.

15. DeVol DL, Rotwein P, Sadow JL, Novakofski J, Bechtel PJ. Activation of insulin-like growth factor gene expression during work-induced skeletal muscle growth. Am J Physiol 1990:259:E89-95.

16. Ferreira IM, Brooks D, Lacasse Y, Goldstein RS, White J. Nutritional supplementation for stable chronic abstructive puimonary disease. Cochrame Database Syst Rev 2002:CD000998. 
17. Creutzberg EC, Wouters EF, Mostert R, Weling-Scheepers CA, Schols AM. Efficacy of nutritional supplementation therapy in depleted patients with chronic obstructive pulmonary disease. Nutrition 2003:19:120-7.

18. Lewis MI, Beiman MJ, Dorr-Uyemura L. Nuiritional supplementation in ambulatory patients with chronic obstructive pulmanary disease. Am Rev Respir Dis 1987;135:1062-8.

19. Knowles JB, Fairbarn MS, Wiggs BJ, Chan-Yan C, Pardy RL. Dietary supplementation and respiratory muscle performance in patients with COPD. Chest 1988;93:977-83.

20. Schols AM, Soeters PB, Mostert R, Phymers RJ, Wouters EF. Physiologic effects of nutritional support and anabolic steroids in patients with chronic obstructive pulmonary disease. A placebocontrolled randomized trial. Am J Respir Crit Care Med 1995;152:1268-74.

21. Borsheim $E_{x}$ Tipton $\mathrm{KD}$, Wolf $\mathrm{SE}$, Wolfe RR. Essential amino acids and muscle protein recovery from resistance exercise. Am J Physial Endocrinol Metab 2002;283:E648-57.

22. Anthony JC, Anthony $T G, K$ Kimball $S R$, Jefferson LS. Signaling pathways involved in translational control of protein synthesis in skeletal muscle by leucine. J Nutr 2001:131:856S-860S.

23. Giovannucci E, Pollak M, Liu $Y$, et al. Nutritional predictors of insulin-like growth factor I and their relationships to cancer in men. Cancer Epidemiol Biomarkers Prev 2003:12:84-9.

24. Steiner MC, Barton RL, Singh SJ, Morgan MD. Nutritional enhancement of exercise performance in chronic abstructive pulmonary disease: a randomised controlled trial. Thorax 2003;58:745-51.

25. Creutzberg EC, Schols AM, Weling-Scheepers CA, Buturman WA, Wouters EF. Characterization of nonresponse to high caloric oral nutritional therapy in depleted patients with chronic obstructive pulmonary disease. Am J Respir Crit Care Med 2000;161:745-52.

26. Ferreira $I M$, Verreschi $I T$, Nery $L E$, et al. The influence of 6 months of oral anabolic steroids on body mass and respiratory muscles in undernourished COPD patients. Chest 1998;114:19-28.

27. Creutzberg EC, Wouters EF, Mostert R, Pluymers RJ, Schols AM. A Role for Anabolic Steroids in the Riehabilitation of Patients With COPD?: A Double-Blind, Placebo-Controlled, Randomized Trial. Chest 2003:124:1733-42.

28. Casaburi $R$, Bhasin $S$, Cosentino $L$, et al. Effects of Testosterone and Resistance Training in Men with Chronic Obstructive Pulonary Disease. Am J Respir Crit Care Med 2004.

29. Yeh SS, DeGuzman B, Kramer T. Reversal of COPD-associated weight loss using the anabolic agent oxandrolone. Chest 2002:122:421-8.

30. Ferrando $A A$, Sheffield-Moore $M$, Yeckel $C W$, et al. Testosterone administration to older men improves muscle function: molecular and physiological mechanisms. Am J Physiol Endocrinol Metab 2002:282:E601-7.

31. Van Balkom RH, Dekhuijzen PN, Folgering $H T$, et al. Anabolic steroids in part reverse glucocorticoid-induced alterations in rat diaphragm. J App| Physio 1998;84:1492-9.

32. van Balkom RH, Dekhuijzen PN, van der Heijden HF, Folgering HT, Fransen JA, van Herwaarden CL. Effects of anabolic steroids on diaphragm impairment induced by methylprednisolone in emphysemalous hamsters. Eur Respir J 1999;13:1062-9.

33. Creutzberg EC, Schols AM. Anabolic steroids. Curr Opin Clin Nutr Metab Care 1999;2:243 53.

34. Burdet $L$, de Muralt $B$, Schutz $Y$, Pichard $C$, Fitting JW. Administration of growth hormone to underweight patients with chronic obstructive pulmonary disease. A prospective, randomized, controlled study. Am J Respir Crit Gare Med 1997;156:1800-6. 
35. Vernooy $\mathrm{JH}$, Kucukaycan $\mathrm{M}$, Jacobs JA, et al. Local and systemic inflammation in patients with chronic obstructive puimonary disease: soluble tumor necrosis factor receptors are increased in sputum. Am J Respir Crit Care Med 2002;166:1218-24.

36. Frohlich $M$, Sund $M$, Lowel $H_{1}$ Imhof $A$, Hoffmeister $A$, Koenig $W$. Independent association of various smoking characteristics with markers of systemic inflammation in men. Results from a representative sample of the general population (MONICA Augsiburg Survey 1994/95). Eur Heart $J$ 2003:24:1365-72.

37. Takabatake $N$, Nakamura $H$, Abe $S$, et al. The relationship between chronic hypoxemia and activatiom of the tumor necrosis factor-alpha system in patients with chronic obstructive pulmonary disease. Am J Respir Crit Care Med 2000;161:1179-84.

38. Pitsiou $G$, Kyriazis $G$, Hatzizisi O, Argyropoulou P, Mavrofridis $E$, Patakas D. Tumor mecrosis factoralpha serum levels, weight loss and tissue oxygenation in chronic obstructive pulmonary disease. Respir Med 2002;96:594-8.

39. van den Biggelaar AH, Huizinga TW, de Craen AJ, et al. Impaired innate immunity predicts frailty in old age. The Leiden 85-plus study. Exp Gerontol 2004;39:1407-14.

40. Wouters EF, Creutzberg EC, Schols AM. Systemic Effects in COPD(*). Chest 2002;121:127S-30S.

41. Pedersen BK, Hoffman-Goetz L. Exercise and the immune system: regulation, integration, and adaptation. Physiol Rev 2000;80:1055-81.

42. Rabinovich RA, Figueras M, Ardite $E$, et al. Increased tumour necrosis factor-alpha plasma levels during moderate-intensity exercise in COFD patients. Eur Respir J 2003;21:789-94.

43. Barber MD, Ross JA, Preston T, Shenkin A, Fearon KC. Fish oil-enriched nutritional supplement attenuates progression of the acute-phase response in weight-losing patients with advanced pancreatic cancer. II Nutr 1999;129:1120-5.

44. Barber MD, Ross JA, Voss AC, Tisdale MU, Fearon KC. The effect of an oral nutritional supplement enriched with fish oil on weight-loss in patients with pancreatic cancer. Br J Cancer 1999:81:80-6.

45. Wigmore SJ, Fearon KC, Maingay JP, Ross JA. Down-regulation of the acute-phase response in patients with pancreatic cancer cachexia receiving oral eicosapentaenoic acid is mediated via suppression of interleukin-6. Clin Sci (Colch) 1997;92:215-21.

46. Wigmore SJ, Ross JA, Falconer JS, et al. The effect of polyunsaturated fatty acids on the progress of cachexia in patients with pancreatic cancer. Nutrition 1996;12:S27-30.

47. Babcock T, Helton WS, Espat NJ. Eicosapentaenoic acid (EPA): an antinflammalory omega-3 fat with potential clinical applications. Nutrition 2000;16:1116-8.

48. Furst $P$, Kuhn KS. Fish oll emulsions: what benefits can they bring? Clin Nutr 2000;19:7-14.

49. Tisdale MJ, Dhesi JK. Inhibition of weight loss by omega-3 fatly acids in an experimental cachexia model. Cancer Res 1990:50:5022-6.

50. Beck $S A_{y}$ Smith KL, Tisdale MJ. Anticachectic and antitumor effect of eicosapentaenoic acid and its effect on protein turnover. Cancer Res 1991;51:6089-93.

51. Beck SA, Mulligan HD, Tisdale MJ. Lipolytic factors associated with murine and human cancer cachexia. J Natl Cancer Inst 1990;82;1922-6.

52. Fearon KC, Von Meyenfeldt MF, Moses AG, el al. Effect of a protein and energy dense N-3 latly acid enriched oral supplement on loss of weight and lean tissue in cancer cachexia: a randomised double blind trial. Gut 2003;52:1479-86.

53. Grimble RF, Howell WM, OReilly $G_{\text {, }}$ et al. The ability of fisth oil to suppress tumor necrosis factor alpha production by peripheral bload mononuciear cells in healthy men is associated with 
polymorphisms in genes that influence tumor necrosis factor alpha production. Am $J$ Clin Nutr $2002,76: 4549$.

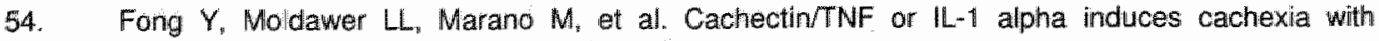
redistribution of body proteins. Am J Physiol 1989;256;R659-65.

55. Michie HR, Sherman ML; Spriggs DR, Rounds J, Christie M, Wilmore DW. Chronic TNF infusion causes anorexia but not accelerated nitrogen loss. Ann Surg 1989;209:19-24.

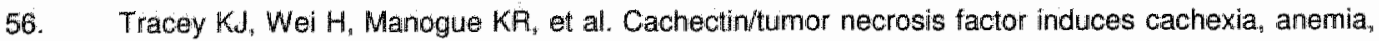
and inflammation. $\$$ Exp Med 1988;167:1211-27.

57. Pomposelli $\mathrm{JU}_{\mathrm{J}}$ Flores EA Bistrian BR. Role of biochemical mediators in clinical nutrition and surgical metabolism. JPEN J Parenter Enteral Nutr 1988;12:212-8.

58. Mahony $S M$, Beck $S A$, Tisdale MJ. Comparison of weight loss induced by recambinant tumour necrosis factor with that produced by a cachexia-inducing tumour. Br J Cancer 1988;57:385 9.

59. Warren RS, Stames HF, Jr, Gabrilove JL, Oettgen HF, Brennan MF. The acute metabolic effects of tumor necrosis factor administration in humans. Arch Surg 1987;122:1396-400.

60. Starnes HF, Jr. Warren RS, Jeevanandam M, et al. Tumor necrosis factor and the acute metabolic response to tissue injury in man. J Clin Invest 1988;82:1321-5.

61. de Godoy I, Donahoe M, Calhoun WJ, Mancino J, Rogers RM. Elevated TNF-alpha production by peripheral blood monocytes of weight- losing COPD patients. Am J Respir Crït Care Med 1996; $153: 633-7$.

62. Di Francia M, Barbier D, Mege JL, Orehek J. Tumor necrosis factor-alpha levels and weight loss in chronic obstructive pulmonary disease. Am J Respir Crit Care Med 1994;150:1453-5.

63. Siegel SA, Shealy DJ, Nakada MT, et al. The mouse/human chimeric monoclonal antibody cA2 neutralizes TNF in vitro and protects transgenic mice from cachexia and TNF lethality in vivo. Cytokine 1995;7:15-25.

64. Steensma DP, Mesa RA, Li CY, Gray L, Tefferi A. Etanercept, a soluble tumor necrosis factor receptor, palliates constitutional symptoms in patients with myelofibrosis with myeioid metaplasia: results of a pilot study. Blood 2002;99:2252-4.

65. Infliximab. http://www.rxlist.com/cgi/generic3/infliximab_ad.htm\#AR, 01-02-2005

66. Cai D, Frantz JD, Tawa NE, Jr, et al. IKKbeta/NF-kappaB activation causes severe muscle wastina in mice. Cell 2004:119:285-98.

67. Moses AW, Slater $C_{4}$ Preston T, Barber MD, Fearon KC. Reduced total energy expenditure and physical activity in cachectic patients with pancreatic cancer can be modulated by an energy and protein dense oral supplement enriched with n-3 fatty acids. Br $\mathbb{J}$ Cancer 2004:90*996-1002.

68. Schoonjans K, Peinado-Onsurbe J Lefebvre AM, et al. PPARalpha and PPARgamma activators direct a distinct tissue-specific transcriptional response via a PPRE in the lipoprotein lipase gene. Embo J 1996" 15:5336-48.

69. Reddy JK, Hashimoto T. Peroxisomal beta-oxidation and peroxisome proliferator-activated receptor alpha: an adaptive metabolic system. Annu Rev Nutr 2001;21:193-230.

70. Kersten S, Desvergne $B$, Wahll W. Roles of PPARs in health and disease. Nature 2000;405:421-4.

71. Debril MB, Renaud JP, Fajas $L$, Aumerx J. The pleiotropic functions of peroxisome proliferatoractivated receptor gamma. J Mol Med 2001;79:30 47.

72. Peters JM, Lee SS, Li W, et al. Growth, adipose, brain, and skin alterations resulting from targeted disruption of the mouse peroxisome proliferator-activated receptor beta(delta). Mol Cell Biol 2000;20:5119-28. 
73. Jakabsson $P$, Jorfeldt $L$. Long-term oxygen therapy may improve skeletal muscle metabolism in advanced chronic obstructive pulmonary disease patients with ohronic hypoxaemia. Respir Med 1995;89:471-6.

74. Engelen MP, Schols AM, Does JD, Gosker HR, Deutz NE, Wouters EF. Exercise-induced lactate increase in relation to muscle substrates in patients with chronic obstructive pulmonary disease. Am J Respir Crit Care Med 2000;162:1697-704.

75. Maltais $F$, LeBlanc $P$, Simard $\mathrm{C}_{x}$ et al. Skeletal muscle adaptation to endurance training in patients with chronic obstructive pulmonary disease. Am J Respir Crit Care Med 1996; $154: 442-7$.

76. Asada $K$, Sasaki $S$, Suda $T$, Chida $K$, Nakamura $H$. Antïnflammatory roles of peroxisome proliferator-activated receptor gamma in human alveolar macrophages. Am J Respir Crit Care Med 2004;169:195-200.

77. Gadek JE, DeMichele SJ, Karlstad MD, et al. Effect of enteral feeding with eicosapentaenoic acid, gamma-linolenic acid, and antioxidants in patients with acute respiratory distress syndrome. Enteral Nutrition in ARDS Study Group. Crit Care Med 1999;27:1409-20.

78. Pacht ER, DeMichele SJ, Nelson JL, Hart J, Wennberg AK, Gadek JE. Enteral nutrition with eicosapentaenoic acid, gamma-linolenic acid, and antioxidants reduces alveolar inflammatory mediators and protein influx in patients with acute respiratory distress syndrome. Crit Care Med 2003;31:491-500.

79. Murray MJ, Kumar M, Gregory TJ, Banks PL, Tazelaar HD, DeMichele SJ. Select dietary fatty acids attenuate cardiopulmonary dysfunction during acute lung injury in pigs. Am J Physiol 1995;269:H2090-9. 


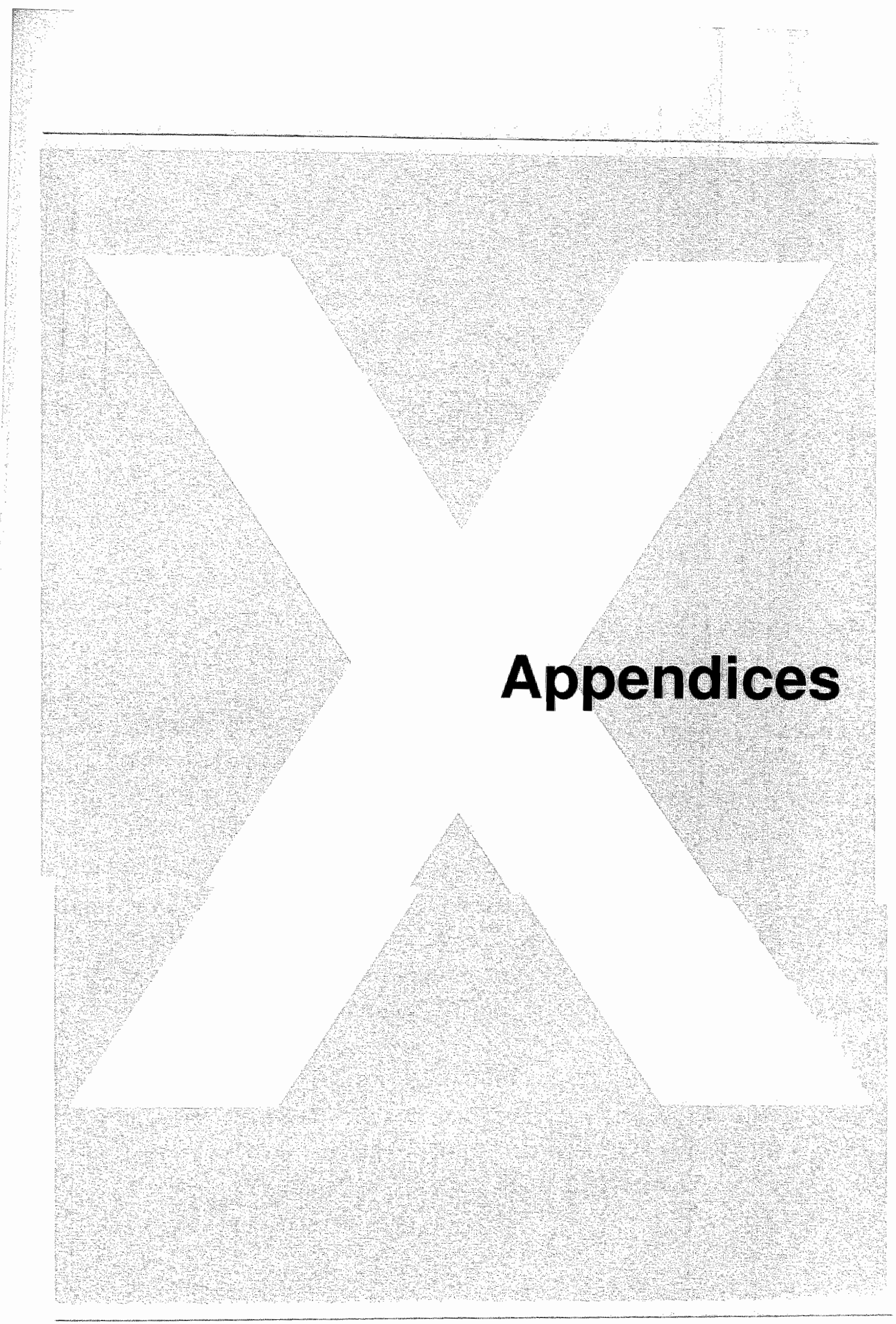




\section{Summary}

Weight loss and muscle wasting frequently occur in patients with chronic obstructive pulmonary disease (COPD), negatively influencing physical performance, health status and mortality. These body compositional changes are often referred to as pulmonary cachexia and can, as opposed to the lung impairment, at least partly be reversed by nutritional therapy as integrated part of pulmonary rehabilitation. Prior research has shown that some cachectic COPD patients do not respond adequately to this therapeutic strategy even when performed in a controlled clinical setting. The aim of this thesis was to investigate means of optimizing nutritional therapy by gaining more insight into the genotypic and phenotypic characterization of patients with pulmonary cachexia and by evaluating the modulating effects of specific nutritional interventions.

Pulmonary cachexia has previously been associated with an elevated systemic inflammatory response but the available studies have shown contradicting results, depending on the definition of cachexia and the studied inflammatory markers. In chapter 2, COPD patients stratified by the presence of cachexia, defined as low fat-free mass index (FFMI), are characterized with regard to inflammatory genotype and phenotype and compared with healthy control subjects. While the total group of COPD patients had higher plasma levels of soluble tumor necrosis factor receptor 75 (STNF-R75), interleukin (IL)-6 and C-reactive protein (CRP) compared to healthy controls, stratification by cachexia showed no differences in these inflammatory markers between the COPD subgroups. The inflammatory gene polymorphisms of TNFa and IL-6 were not related to systemic inflammatory cytokine levels, and were also not different between patients and controls, or between cachectic and non-cachectic subgroups. However, gene polymorphism distribution of IL-1 $\beta-511$ in cachectic patients, differed significantly from healthy 
controls. The functional significance of this difference needs to be further investigated.

Stratification by cachexia also revealed a significant difference in fat mass, leptin and pseudouridine concentrations. These markers are indicative of increased fat catabolism and protein breakdown in cachexia. Non-cachectic COPD patients also had body compositional shifts compared to controls, having decreased fat-free mass (FFM) and increased fat mass (FM). This might indicate accelerated sarcopenia in COPD or an early phase of the cachexia process. The effect of different body compositional profiles on survival is studied in chapter 3. FFM was shown to be an independent predictor of mortality in patients with COPD, irrespective of FM. Since it is also well established that FFM is an important determinant of physical functioning in COPD, independent of disease severity, these results indicate that anabolic and metabolic therapeutic strategies should not be determined by body mass index (BMI), but also include a measure of body composition.

As shown in chapter 2 and in accordance with previous research, COPD is characterized by a mildly elevated acute phase response. The systemic consequences, however, are unknown. Chapter 4 studies differences in body composition and energy metabolism at rest and during exercise in COPD patients with normal and elevated CRP levels as marker of the acute phase response. CRP was increased in $47 \%$ of the COPD patients. These patients were characterized by worse post-bronchodilator forced expiratory volume in one second $\left(F E V_{1}\right)$ and related reversibility. They also had increased plasma levels of IL-6. In addition, compared to patients with normal CRP, patients with elevated CRP had a lower peak workload during the incremental bicycle ergometry test, a lower duration time during the submaximal bicycle ergometry test and a shorter walking distance during the 6-minute walking test. We hypothesized that in COPD patients intrinsic changes in muscle energy metabolism and in exercise-induced oxidative stress 
may disturb the normal exercise-induced IL-6 response as seen in healthy subjects. This may lead to an exacerbated induction of the exercise factor IL-6, which subsequently induces the increase in CRP. The increased demand for specific amino acids needed to generate CRP could be an explanation for the increased resting energy expenditure seen in patients with elevated CRP. In this study, we also showed an association between CRP and BMI that could be attributed to fat mss index (FMI), but not to FFMI. Remarkably, this association has previously also been shown in obese subjects.

The link between local and systemic inflammation in COPD is still unclear. Pulmonary inflammation can be studied by determining the level of inflammatory markers in induced sputum. Chapter 5 studies the concentrations of CRP and TNFa, as inflammatory markers, and the pleiotrophic cytokine leptin in induced sputum of non-cachectic patients with moderate COPD. Previous research has shown that the receptor for leptin (leptin-R) is present in the lung, suggestive of a specific local function of leptin. Our results showed that leptin is indeed present in sputum of COPD patients, and that sputum leptin was strongly correlated to sputum CRP and TNFa. These results indicate that leptin might play a role in the local innate immune system. Sputum leptin was inversely related to plasma leptin, which makes systemic-to-local spill-over unlikely. The origin of sputum leptin is, however, as yet unknown. Furthermore, this inverse relationship raises the question of whether elevated local leptin activity is linked to the presence or severity of pulmonary cachexia, as cachectic patients have disproportionately low leptin levels (chapter 2).

Based on the studies described in the first part of this thesis, targeted therapeutic interventions were studied to optimize the efficacy of nutritional therapy during pulmonary rehabilitation of cachectic and non-cachectic COPD patients. These intervention studies are described in the second part of this thesis. 
Chapter 6 shows that the combination of nutritional therapy and pulmonary rehabilitation is an effective tool to improve body composition despite the presence of low-grade systemic inflammation and increased protein breakdown in COPD patients. Nevertheless, four weeks after cessation of the rehabilitation program, FFM gain was lost and back to pre-rehabilitation values. Pseudouridine, a urinary marker for protein breakdown, and the systemic inflammatory markers $\mathbb{L}-6$ and TNFa did not change during the course of rehabilitation, or four weeks thereafter. These results imply that, while the anabolic effect of pulmonary rehabilitation improved FFM by offsetting the background catabolic state, it did not reverse protein breakdown or systemic inflammation. Consequently, after cessation of the rehabilitation program, the pro-anabolic effects were lost, resulting in a return to predominantly catabolic intermediary metabolism. Rehabilitation should therefore not be restricted to a defined period, but incorporated in daily activities of these patients.

Another way to optimize weight response is by modifying dietary intake. During pulmonary rehabilitation, all cachectic patients receive nutritional supplement drinks to maintain or induce a positive energy balance and to provide sufficient protein intake. Chapter 7 shows that simple therapeutic solutions like providing smaller portions of supplement drinks, $125 \mathrm{ml}$ instead of the regular 200 $m l$ cartons, can further enhance weight gain and FFM during rehabilitation, despite the fact that overall the patients receive fewer calories by means of the supplement drinks. The most likely explanation for the difference in weight response between the different portion sizes is a load-related drop in habitual dietary intake, but it is very difficult to measure this precisely. This study also showed that the gain in FFM was most pronounced in the first four weeks of rehabilitation. This indicates that timing and harmonization of training to nutritional intervention, for example by switching the intensity or type of exercise, may be of importance to further optimize the efficacy of nutritional support in COPD. 
Despite an optimal fine tuning of nutritional support, there is still a number of patients who do not respond adequately. These so-called non-responders are characterized by increased systemic inflammation. Previous research has shown that polyunsaturated fatty acids (PUFA) have anti-inflammatory effects. in patients with cancer cachexia, studies suggested that supplementation with PUFA reverses weight loss and decreases the acute-phase response. It has also been shown that PUFA supplementation in cachectic patients with pancreatic cancer increase physical activity level. We questioned whether these results could be translated to COPD patients. Chapter 8 shows the results of a large randomized placebocontrolled clinical trial carried out to study the potential anti-inflammatory effects of PUFA on systemic inflammation, body composition and outcome of pulmonary rehabilitation. One hundred and two patients with COPD received 9 grams of either PUFA or placebo daily during eight weeks of rehabilitation. The standardized inpatient rehabilitation program consisted of a combination of endurance and strength exercise training. COPD patients who were cachectic also received nutritional supplement drinks. Eighty patients completed the study. After eight weeks, no additional beneficial effect of PUFA was found on weight or FFM gain during rehabilitation. In addition, neither PUFA nor rehabilitation modified the systemic inflammatory markers CRP, IL-6 or TNFa. It was remarkable that the patients receiving PUFA had a significantly enhanced improvement in exercise capacity, as determined by peak workload during the incremental bicycle ergometry test, and duration time during the submaximal bicycle ergometry test.

The present thesis shows that nutritional supplementation is an elegant, feasible and effective strategy to prevent or treat cachexia in patients with COPD, producing relatively few side effects. The findings described in this thesis further identify a new angle for nutritional therapy to improve physical performance in these patients. 


\section{Samenvatting voor niet-ingewijgen}

Chronische obstructieve longziekten (COPD) is een verzamelnaam voor longemfyseem en chronische bronchitis. Patiënten met COPD krijgen eerst te maken met kortademigheid tijdens inspanning, maar later ook tijdens rust. Bovendien hebben deze patiënten een steeds slechtere lichamelijke conditie. Dit wordt onder andere veroorzaakt door het verlies van gewicht en met name spiermassa, wat ook well cachexie wordt genoemd. Cachexie komt relatief veel voor bij patiënten met COPD en heeft een negatief effect op de ademhalingspieren en skeletspieren, de kwaliteit van leven en de overleving. De oorzaak van cachexie bij COPD-patiënten is nog niet helemaal duidelijk. Factoren die meespelen, zijn onder andere een verhoogd energieverbruik en een verminderde voedselinname. Ook inactiviteit en een verhoogde hoeveelheid ontstekingseiwitten in het bloed spelen een rol. In tegenstelling tot de afwijkingen in de longen, die karakteristiek zijn voor COPDpatiënten, kan bij een deel van de patiënten de cachexie worden behandeld door een combinatie van revalidatie en extra voeding. In dit proefschrift is onderzocht hoe voedingstherapie bij COPD kan worden geoptimaliseerd door kenmerken van COPD-patiënten met cachexie te bestuderen en door specifieke voedingstherapieën te testen.

Het onderzoek toonde aan dat COPD-patiënten met cachexie niet alleen een lagere spiermassa, maar ook een lagere vetmassa blijken te hebben vergeleken met niet-cachectische patiënten. Ook is gebleken dat niet-cachectische patiënten vergeleken met gezonde mensen een lagere spiermassa hebben, wat door een hogere vetmassa wordt gemaskeerd. Als artsen en diëtisten alleen de 'body mass index' (dit is het gewicht gecorrigeerd voor de lengte, afgekort als BMI) bepalen, is thet mogelijk dat de lage spiermassa niet opvalt. Lit ons onderzoek bleek dat de spiermassa een belangrijke component is voor de overleving: de overlevingskans bleek bij patiënten met een lage spiermassa (onafhankelijk van de vetmassa) kleiner te zijn dan bij patiënten met een normale spiermassa. Het is 
daarom belangrijk dat, naast de BMI, ook de spiermassa wordt vastgesteld bil COPD-patiënten en regelmatig wordt gecontroleerd om op tijd in te kunnen grijpen bij spiernassaverlies. In eerder onderzoek is namelijk aangetoond dat de spiermassa weer kan worden opgebouwd door middel van lichamelijk training en genoeg voeding. Cachectische patiënten moeten weer aankomen en krijgen daarom bijvoeding in de vorm van pakjes drinkvoeding voor extra energie-inname. In dit proetschrift, tonen wij aan dat COPD-patiënten inderdaad kunnen aankomen in gewicht en spiermassa tijdens longrevalidatie, maar dat deze patiënten dit weer verliezen als de lichamelijke inspanning met revalidatie is opgehouden. Dit laat zien hoe belangrijk lichamelijke inspanning is voor dit proces. Daarnaast laten we zien dat cachectische patiënten tijdens revalidatie beter kunnen aankomen in gewicht en spiermassa als er porties van $125 \mathrm{ml}$ worden gebruikt in plaats van evenveel porties van $200 \mathrm{ml}$, terwijl de energiedichtheid hetzelfde is. De reden hiervan is waarschijnlijk dat patiënten naast de porties van $200 \mathrm{ml}$ minder van hun gewone maaltijden gaan eten omdat ze minder honger hebben. Dit onderzoek toonde ook aan dat COPD-patiënten vooral tijdens de eerste vier weken van de revalidatie aankwamen in spiermassa. Dit kan betekenen dat de timing en afstemming van de training op de voedingstherapie, bijvoorbeeld door het veranderen van de soort en intensiteit van de training, belangrijk is in het verder optimaliseren van de voedingstherapie.

Naast lichaamssamenstelling zijn er ook andere verschilien tussen COPDpatiënten en gezonde mensen onderzocht. De COPD-patiënten bleken een verhoogde hoeveelheid ontstekingseiwitten in het bloed te hebben. Dit leek niet te verschillen tussen cachectische en niet-cachectische COPD-patiënten. Tussen deze twee COPD-groepen bieek wel een verschil te bestaan in een gen dat codeert voor één van de ontstekingseiwitten. De betekenis hiervan is nog niet opgehelderd, maar het is mogelijk dat sommige mensen meer kans hebben cachexie te krijgen dan anderen door hun genetische opmaak. Bovendien zijn de gevolgen van die verhoogde ontstekingseiwitten nog niet bekend. Wij hebben 
daarom ook gekeken naar patiënten met en zonder verhoging in het ontstekingseiwit 'C-reactive protein' ofwel CRP. Uit dit onderzoek bleek dat patiënten met een verhoogd CRP een slechtere longfunctie hadden, een hoger energieverbruik tijdens rust, een slechtere kwaliteit van leven en minder vetmassa. We toonden ook aan dat de patiënten met verhoogd CRP zich minder goed konden inspannen. Hieruit blijkt dat de verhoging in ontstekingseiwitten ver strekkende lichamelijke gevolgen heeft. Bovendien heeft eerder onderzoek aangetoond dat de verhoging in ontstekingseiwitten samenhangt met het niet goed kunnen aankomen, andanks de combinatie van revalidatie en voedingstherapie. Een verdere optimalisatie van de voedings-therapie zou kunnen liggen in het beïnvloeden van de ontsteking in het bloed. Eerder onderzoek heeft aangetoond dat meorvoudig onverzadigde vetzuren $(\mathrm{MOM})_{8}$ zoals in visolie, een ontstekingsremmende werking hebben. We hebben daarom onderzoek gedaan naar het effect van MOV ten opzichte van placebo bij COPD-patiënten die opgenomen waren voor acht weken revalidatie op het astmacentrum Hornerheide. Uit dit onderzoek bleek dat MOV geen effect had op de lichaamssamenstelling of op de ontstekingseiwitten. Wel bleek dat patiënten die MOV kregen meer in lichamelijke conditie vooruit gingen tijdens de revalidatie dan patiënten die placebo kregen. Een verklaring hiervoor zou kunnen zijn dat MOV de omzetting van voedingsstoffen naar energie verbeteren in de spieren. Dit moet nog verder onderzocht worden.

Het onderzoek beschreven in dit proefschrift heeft aangetoond dat er nog verschillende mogelijkheden zijn om de behandeling van cachectische COPDpatiënten verder te verbeteren met behulp van voedingstherapie. Voedingstherapie kan een goede optie zijn bij het verbeteren van gewicht en spiermassa, maar ook bij het verbeteren van de lichamelijke conditie. Het nauwkeurig in kaart brengen van de kenmerken van de cachectische patiënten kan handvatten bieden voor verdere ontwikkelingen in de behandeling van cachectische COPD-patiënten. 


\section{Abbreviations}

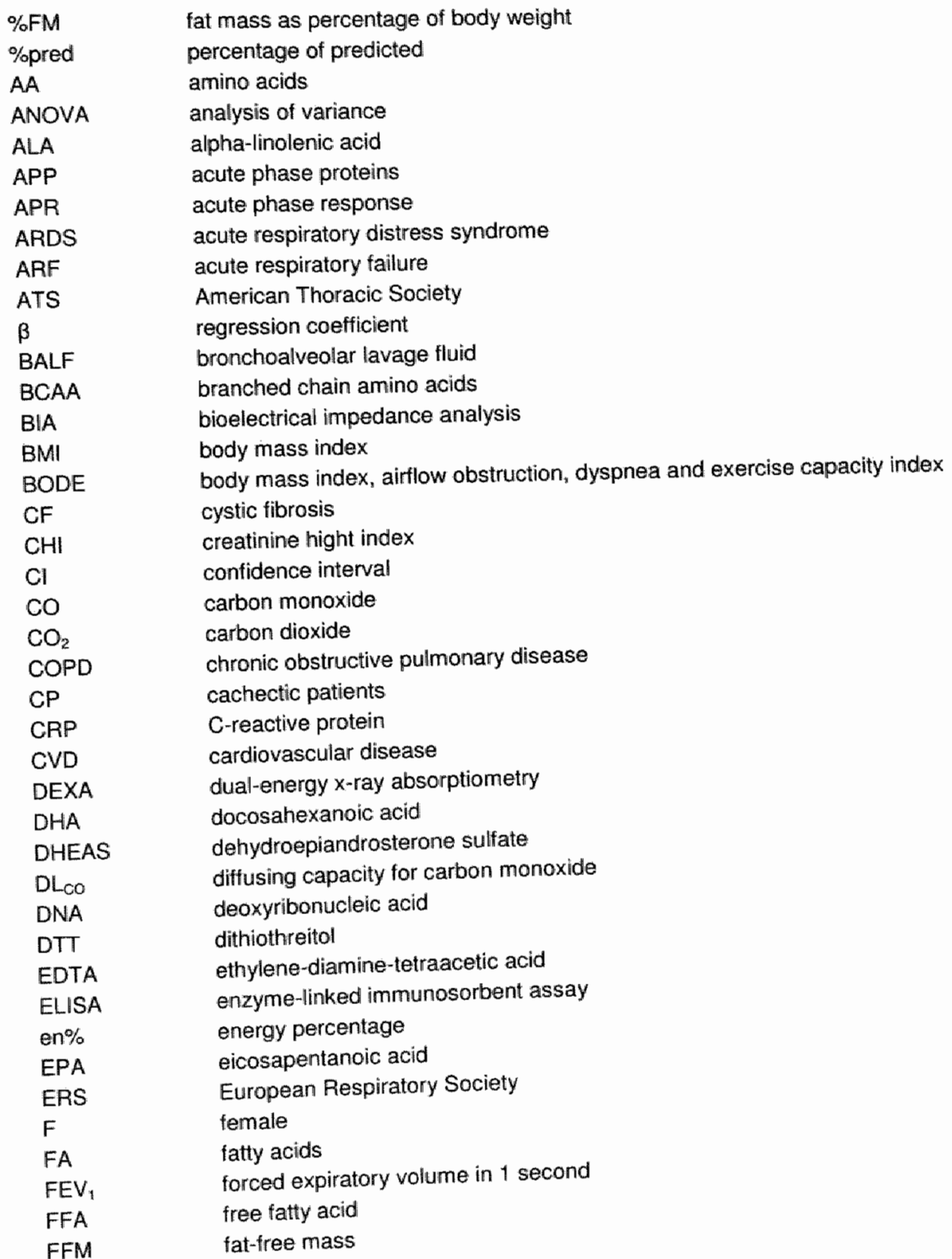




\begin{tabular}{|c|c|}
\hline FFMII & fat-free mass index \\
\hline FM & fat mass \\
\hline FMI & fat mass index \\
\hline FVC & forced vital capacity \\
\hline GLA & gammaulinoleinic acid \\
\hline GLUT: & glucose transporter \\
\hline GOLD & Global Iniliative for Chronic Obstructive Lung Disease \\
\hline HB-equations & Harris \& Benedict-equations \\
\hline $\mathrm{HC}$ & Healthy controls \\
\hline HRCT & high-resolution computed tomography \\
\hline HS-CRP & high sensitivity C-reactive protein \\
\hline$\| G F-1$ & insulin-like growth factor-1 \\
\hline llL & interleukin \\
\hline ITGV & intrathoracic gas volume \\
\hline IVG & inspiratory vital capacity \\
\hline LA & linoleic acid \\
\hline LBP & LPS binding protein \\
\hline leptin $R$ & receptor for leptin \\
\hline LPS & lipopolysaccharide \\
\hline LT & leukotriene \\
\hline LTOT & long-lerm oxygen therapy \\
\hline M & male \\
\hline MOV & meervoudig onverzadigde vetzuren \\
\hline MRNA & messenger ribonucleic acid \\
\hline MVV & maximal voluntary ventilation \\
\hline NA & not available \\
\hline NAC & N-acetylcystein \\
\hline NCP & Non-cachectic patients \\
\hline ND & not detectable \\
\hline$N F=K B$ & nuclear factor kappa B \\
\hline NHANES & National Health and Nutrition Examination Survey \\
\hline NMR & nuclear magnetic resonance \\
\hline n.s. & not significant \\
\hline $\mathrm{O}_{\mathrm{z}}$ & oxygen \\
\hline $\mathrm{PaCO}_{2}$ & arterial carbon dioxide tension \\
\hline PAL & physical activity level \\
\hline $\mathrm{PaO}_{22}$ & arterial oxygen tension \\
\hline PBMC & peripheral blood mononuclear cells \\
\hline $\mathrm{PGE}_{2}$ & prostaglandin $\mathbb{E} 2$ \\
\hline Pi-max & maximal inspiratory mouth pressure \\
\hline PPAR & peroxisome proliferators activated receptor \\
\hline PSU & pseudouridine \\
\hline PUFA & polyunsaturated fatty acids \\
\hline PY & pack-years \\
\hline
\end{tabular}


r

RBMD

REE

RER

RNA.

RR

RV

$\mathrm{SaO}_{2}$

$\mathrm{SD}$

SEM

SGRQ

$\mathrm{SM}$

SMII

SNP

SPSS

STA

STNF-R

TDEE

TNFa

$\mathrm{VCO}_{2}$

VE

$\mathrm{VO}_{2}$

WD

WHO

Wmax correlation coefficient

renal and bone marrow donors

resting energy expenditure

respiratory exchange ratio

ribonucleic acid

relative risk

residual volume

arterial oxygen saturation

standard deviation

standard error of the mean

Saint Johns' Respiratory Questionnaire

submaximal

skeletal muscle index

single nucleotide polymorphisms

Statistical Package for the Social Sciences

stearidonic acid

soluble TNF-receptor

total daily energy expenditure

tumor necrosis factor-alpha

carbon dioxide production

ventilation

oxygen consumption

walking distance

World Health Organisation

maximal workload 


\section{Publications}

\section{Published manuscripts}

R Broekhuizen, EFM Wouters, EC Creutzberg, CAPM Weling-Scheepers, AMWJ Schols. Modulation with polyunsaturated fatty acids enhances the response to pulmonary rehabilitation in patients with COPD. A randomized placebo controlled clinical trial. Thorax $2005 ; 60: 376-382$

Ri Broekhuizen, EC Creutzberg, CAPM Weling-Scheepers, EFM Wouters, AMWJ Schols. Optimizing oral nutritional supplementation in patients with chronic obstructive pulmonary disease. Br J Nutr 2005; 93:965-971

AMW Schols, R Broekhuizen, CAPM Weling-Scheepers, EFM Wouters. Body composition and mortality in chronic obstructive pulmonary disease. Am J Clin Nutr 2005; 82:53-9.

R Broekhuizen, JHJ Vernooy, AMWJ Schols, MA Dentener, EFM Wouters. Leptin as local inflammatory marker in COPD. Resp Med 2005; 99:70-74

FME Franssen, R Broekhuizen, PP Janssen, EFM Wouters, AMWJ Schols. Limb muscle dysfunction in COPD patients: effects of muscle wasting and exercise training. Med Sci Sports Exerc 2005;37:2-9

FME Franssen, R Broekhuizen, PP Janssen, EFM Wouters, AMWJ Schols. The effects of whole body exercise training on body composition and functional capacity in normal weight patients with chronic obstructive pulmonary disease. Chest 2004;125:2021-8

MJAL Grubben, CCM van den Braak, $R$ Broekhuizen, $R$ de Jong, $L$ van Rijt, E de Ruijter, WHM Peters, MB Katan, FM Nagengast. The effect of unfiltered coffee on potential biomarkers for colonic cancer risk in healthy valunteers: a randomized trial. Alimentary Pharmacology and Therapeutics $2000 ; 14: 1181-1190$

M.JAL Grubben, GH Boers, HJ Blom, R Broekhuizen, $R$ de Jong, $L$ van Fijt, E de Ruilter, DW Swinkels, FM Nagengast, MB Katan. Unfiltered colfee increases plasma homocysteine concentrations in healthy volunteers: a randomized trial. Am J Clin Nutr 2000; 71:480-484.

\section{Accepted manuscripls}

R Broekhuizen, EFM Wouters, EC Creutzberg, AMWJ Schols. Elevated CRP levels mark metabolic and functional impairment in advanced COPD. Accepted by Thorax 


\section{Submitted manuscripts}

R Broekhuizen, RF Grimble, WM Howell, DJ Shale, EC Creutzberg, EF Wouters, AM Schols. Pulmonary cachexia, systemic inflammatory profile and the $\mid L-1 \beta-511$ single nucleotide polymorphism. In revision for Am J Clin Nutr

CE Bolton, F Broekhuizen, AA lonescu, LS Nixon, EFM Wouters, DU Shale, AMWJ Schols. Increased cellular protein breakdown is not reduced by pulmonary rehabilitation in COPD.

Gosker HR, Schrauwen P. Broekhuizen R, Hesselink MKC, Moonen-Kornips E, Ward KA, Franssen $F M$, Wouters FM, Schols AMWJ. Exercise training restores uncoupling protein-3 content in limb muscles of patients with chronic obstructive pulmonary disease.

\section{Book contribution}

R Broekhuizen, EC Creutzberg, AMWJ Schols. Metabolism and Nutrition in Acute Exacerbations of Chronic Obstructive Pulmonary Disease. In: Siafakas NM, Anthonisen NR, Georgopoulos D, eds. Lung Biology in Health and Disease: Acute Exacerbations of Chronic Obstructive Pulmonary Disease. 1 ed. New York, USA: Marcel Dekker, Inc., 2004:281-304.

\section{Abstracts}

R Broekhuizen, CE Bolton, AA lonescu, LS Nixon, EFM Wouters, DJ Shale and AMWJ Schols. increased cellular protein breakdown is not reduced by pulmonary rehabilitation in COPD. ESPEN Brussels 2005, Belgium

A Broekhuizen, AF Grimble, EC Creutzberg, EFM Wouters and AMWJ Schols. Interaction between Cachexia, Systemic Inflammatory Profile and Inflammatory Gere Polymorphism in COPD. Am d Respir Crit Care Med 2004, 171 (suppl.) A134

CE Bolton, R Broekhuizen, AA lonescu, LS Nixom, EFM Wouters, DJ Shale and AMWJ Schols. Skeletal Muscle Function and Urinary Markers of Cellular Protein Breakdown in Patients with COPD. Am J Respir Crit Care Med 2004, 171 (suppl.) A317

R Broekhuizen, EFM Wouters, EC Creutzberg, MA Akkermans and AMWJ Schols. High sensitivity CRP discriminates in COPD for altered metabolic response at rest and during exercise. Clin Nutr 2004: 23 (4): 774 
R Broekhuizen, EFM Wouters, CAPM Weling. MA Akkermans, EC Creutzberg and AMWJ Schols. Polyunsaturated fatty acids modulation enhances the response to pulmonary rehabilitation in patients with COPD: a randomized placebo controlled clinical trial Clin Nutr 2004: 23 (6):1497

R Broekhuizen, RF Grimble, EFM Wouters, EC Creutzberg, AMWJ Schols. Interaction between body composition, systemic inflammatory profile and inflammatory gene polymorphism in COPD Clin Nutr 2004: $23(4): 836$

R Broekhuizen, EFM Wouters, CAPM Weling. MA Akkermans, EC Creutzberg and AMWJ Schals. Polyunsaturated fatty acids modulation enhances the response to pulmonary rehabilitation in patients with COPD: a randomized placebo controlled clinical trial. Am J Respir Crit Care Med 2004, 169 (suppl.), A893.

R Broekhuizen, EC Creutzberg, CAPM Weling, EFM Wouters and AMWJ Schols. Weight and fatfree mass response of cachectic COPD patients during pulmonary rehabilitation is not enthanced by anti-inflammatory modulation. Am \& Respir Crit Care Med 2004, 169 (suppl.), A891.

R Broekhuizen, EFM Wouters, EC Creutzberg. MA Akkermans and AMWJ Schols. High sensitwity CRP discriminates in COPD for altered metabolic response at rest and during exercise. Eur Resp J 2004: 24 (suppl. 48), 214s-215s.

A Broekhuizen, HR Gosker, FME Franssen, KA Ward, EFM Wouters and AMWJ Schols. The effect of pulmonary rehabilitation on peripheral muscle metabolic profile and fiber atrophy. Eur Resp $J$ 2004: 24 (suppl. 48). 255 s

EC Creutzberg, A Schilstra, R Broekhuizen, EFM Wouters. The prevalence of low hemoglobin levels in patients with COPD stratified for disease stage. Eur Resp J 2004: 24 (suppl. 48),63s

HR Gosker, R Broekhuizen, P Schrauwen, MKC Hesselink, FME Franssen, EFM Wouters and AMWJ Schols. Exercise training restores peripheral muscular uncoupling protein 3 levels in COPD. Am J Respir Crit Care Med 2004, 169 (supplement), A901.

R Broekhuizen, EC Creutzberg, JEMG Derks, EFM Wouters, AMWJ Schols. Inflammatory markers in relation to cachexia in patients with COPD. Eur Respir J 2003:22 (suppl. 45): 2085

R Broekhuizen, EC Creutzberg, CAPM Weling-Scheepers, EFM Wouters, AMWJ Schols. Portion size rather than energy content of nutritional supplements enhances weight gain in depleted COPD patients. Eur Respir J 2003;22 (suppt. 45):551s-552s.

CAPM Weling-Scheepers, R Broekhuizen, EC Creutzberg, EFM Wouters, AMWJ Schois. The effect of enteral tube feeding in underweight COPD patients. Poster presentatie CAPM WelingScheepers. Eur Respir J 2003:22 (suppl. 45): $551 \mathrm{~s}$ 
FME Franssen, R Broekhuzen, EFM Wouters, AMWJ Schols. Lower and upper limb muscle function in normal weight COPD patients relative to controls and the effect of whole body exercise training. Am J Respir Crit Care Med 2003, 167(suppl.) A669

FME Franssen it Broektuizen; R Mostert, EFM Wouters, AMWJ Schols. The effects of exercise training on body composition in normal weight COPD patients. Am $J$ Respir Crit Care Med 2003, 167 (suppl.) A432

R Broekhuizen, JHJ Vernooy, AMWJ Schols, MA Dentener, EFM Wouters. The interaction between leptin and inflammatory markers in induced sputum in patients with moderate COPD. Eur Respir $J$ 2002: 20: Suppl. 38, 404/s

R Broekhuizen, EC Creutzberg, EFM Wouters, R Mostert, AMWJ Schols. Relationship between nutritional depietion and incidence of disease exacerbations in patients with COPD. Am J Respir Crit Care Med 2001, 163 (suppl) 5:A503.

\section{Awards}

2004 ESPEN: Travel tellowship for highest scoring abstract

2003 EAS: Young scientist sponsorship 


\section{Naschrift}

Bijna... bijna is het proefschrift klaar en kan ik me gaan voorbereiden op de verdediging. Het geeft enorme voldoening om een proefschritt vorm te zien krijgen na jaren hard werken aan de inhoud. Ik had dit niet kunnen doen zonder de steun en hulp van anderen. Al die mensen wil ik hier heel erg bedanken voor hun geduld, goede raad en praktische inzet.

Allereerst wil ik Prof. Annemie Schols, mijn eerste promotor en al die jaren mijn directe begeleidster, bedanken. Annemie: jiil hebt mij de kans gegeven dit onderzoek te doen en hebt mij opgeleid tot de wetenschapper die ik nu ben. Je beviogenheid voor het onderzoek is aanstekelijk! Prof. Wouters: u wil ik ook graag bedanken voor de feedback, met name tijdens het schrijven. Ik bewonder uw overkoepelende visie, uitgebreide kennis en inzichten. Beiden bedankt voor alles!

Ik wil mijn beoordelingcommissie, bestaande uit Prof. Mensink, Prof. Seidell, Prof. Buurman en Prof. Stockbrügger, hartelijk bedanken voor het kritisch beoordelen van mijn proefschrift. Prof. Vestbo, thank you for your critical evaluation of this thesis.

Het onderzoek heb ik uitgevoerd op Astmacentrum Hornerheide. Allereerst wil ik alle patiënten bedanken, die mee hebben gewerkt. Zij zijn degenen die 8 weken lang elke dag 9 capsules hebben geslikt en al die testen en extra keren bloedafname hebben ondergaan. Met eigen ogen heb ik kunnen zien hoe moeilijk het voor velen was om te fietsen en adem te kunnen krijgen. Ik heb daarvoor grote bewondering en dank jullie dat jullie mee hebben willen doen.

Het onderzoek op Hornerheide heb ik natuurlijk niet alleen gedaan. Graag wil ik de (long)artsen Rob Mostert, Herman-Jan Pennings, Jean Simons en Joan Does bedanken voor hun hulp bij het includeren van de patiënten, het nemen van 
spierbiopten en het superviseren bij de fietstesten. De verpleging en fysiotherapeuten will ik ook bedanken voor hun inzet bij het onderzoek. Alle inspanningsonderzoeken en trainingen zijn uitgevoerd door het team van bewegingsagogen (Marco, Tom, Anne, Jerome, Leon) en Gerda. Heel erg bedankt voor al jullie inspanningen. De woedingsconsulentes (Alda, Truus, Marjanka, Gonny, Karien, Cilly en Lies) wil ik bedanken voor het uitdelen van de pakjes drinkvoeding en de vetzuurcapsules. De afdeling diëtetiek (Clarie en Sandra) wil ik bedanken voor de vele extra metingen die voor mijn onderzoek moesten worden gedaan. Leedies from the lab (Annelies, Peggy, Monique en Gonny): jullie wil ik in het bijzonder bedanken voor de gastvrijheid en gezelligheid op het lab. Het is niet niks dat elke keer die 'vreemde' AlO's weer ongevraagd op het lab komen werken. Daarnaast wil ik jullie ook bedanken voor alle essays die jullie zo precies hebben uitgevoerd. Kitty en Marianne: bedankt voor alle longfunctietesten en assistentie bij de spierbiopten. Annemiek, Gerry en Marianne wil ik ook bedanken voor de medewerking. Vele handen maken zwaar werk lichter.

Daarnaast will ik de collegae in Maastricht bedanken. Allereerst mijn kamergenootjes van de afgelopen tijd: Evi en Erica. Ik vond het fijn bij jullie op de 'Belgen'kamer te zitten. Bedankt voor het gezellige sfeertje en goede feedback. Keep in touch! Frits: bedankt voor het nemen van zovele spierbiopten. Harry: bedankt voor het helpen bij alle computercrises en flaters. Wat zouden we zonder je moeten beginnen! Ramon, Jos, Juanita, Mieke, Astrid, Roy, Kim, Marco, Mariëlle, Alex, Kirsten, Petra, Marja en Chris: bedankt voor alle huip, samenwerking en gezelligheid. Ook de longartsen (in opleiding) en het secretariaat van de afdeling Longziekten: bedankt voor de prettige samenwerking! Diederik: zonder jou was ik misschien wel helemaal niet in Maastricht terecht gekomen. Nu jij nog! Eva, bij jou kon ik altijd terecht met vragen en problemen. Heel erg bedankt dat je altijd wel even tijd voor me vijmaakte, ik heb er erg veel aan gehad en heb het zeer gewaardeerd. 
Een groot deel van het onderzoek was gesponsord door Numico Research BV, waarvoor veel dankzegging. I would also like to thank all the co-authors for their contributions to the articles in this thesis.

Er is ook leven naast het werk. Ik wil me graag verontschuldigen bij veel van mijn vrienden en familie omdat ik de afgelopen tijd weinig tijd voor ze heb kunnen vrijmaken. Bedankt voor jullie geduld en vriendschap. Een paar mensen wil ik in het bijzonder bedanken. Sandra en Margreet: Het leven is een feestl Bedankt voor het helpen ophangen van de Maastrichtse slingers. Barbara en Frank van Reijsen: jullie peptalks en goede raad hebben me altijd erg goed gedaan, super bedankt! Bar: we gaan snel weer LvdB!

Karen, bedankt dat je de kaft en de lay-out van dit proefschrift hebt ontworpen ondanks je drukke leven tussen je mannen. Ik ben er erg blij mee en vind het geweldig dat je het hebt gedaan! Alieke, Ed, Chris en Saskia: bedankt voor de steun de afgelopen jaren!

Clarie: jou wil ik in het bijzonder bedanken voor het feit dat je me onder de vleugeis hebt genomen. Ik bewonder je open houding en positieve instelling. Bedankt dat je mijn paranimf wilt zijn!

Mijn andere paranimt, mijn vader Hendrik: bij jou is het, letterlijk en figuurlijk, allemaal begonnen. Jij hebt mij aangespoord, raad gegeven, geholpen op elke manier waarop je kon, hart onder de riem gestoken, schop onder de kont gegeven en niet over de bok laten dromen. Voor mij was het vanzelfsprekend dat jij mijn paranimf zou zijn. Mam, Henny: voor jou geldt dit ook allemaal. Samen staan jullie altijd klaar voor ons. Allebei enorm bedankt voor alles! Ik had niet van een liefdevoller gezin deel uit kunnen maken. 